\title{
Sulfur Tolerant Solid Oxide Fuel Cell for Coal Syngas Application: Experimental Study on Diverse Impurity Effects and Fundamental Modeling of Electrode Kinetics
}

\author{
Mingyang Gong \\ West Virginia University
}

Follow this and additional works at: https://researchrepository.wvu.edu/etd

\footnotetext{
Recommended Citation

Gong, Mingyang, "Sulfur Tolerant Solid Oxide Fuel Cell for Coal Syngas Application: Experimental Study on Diverse Impurity Effects and Fundamental Modeling of Electrode Kinetics" (2010). Graduate Theses, Dissertations, and Problem Reports. 4599.

https://researchrepository.wvu.edu/etd/4599

This Dissertation is protected by copyright and/or related rights. It has been brought to you by the The Research Repository @ WVU with permission from the rights-holder(s). You are free to use this Dissertation in any way that is permitted by the copyright and related rights legislation that applies to your use. For other uses you must obtain permission from the rights-holder(s) directly, unless additional rights are indicated by a Creative Commons license in the record and/ or on the work itself. This Dissertation has been accepted for inclusion in WVU Graduate Theses, Dissertations, and Problem Reports collection by an authorized administrator of The Research Repository @ WVU. For more information, please contact researchrepository@mail.wvu.edu.
} 


\title{
Sulfur Tolerant Solid Oxide Fuel Cell for Coal Syngas Application: Experimental Study on Diverse Impurity Effects and Fundamental Modeling of Electrode Kinetics
}

\author{
By \\ Mingyang Gong \\ Dissertation submitted to the College of Engineering and Mineral Resources \\ at West Virginia University \\ in partial fulfillment of the requirements \\ for the degree of \\ Doctor of Philosophy \\ in \\ Mechanical Engineering
}

\author{
Xingbo Liu, Ph. D., Committee Chair \\ Darran R. Cairns, Ph.D. \\ Edward M. Sabolsky, Ph.D. \\ Harry O. Finklea, Ph.D. \\ John W. Zondlo, Ph.D. \\ Randall S. Gemmen, Ph.D. \\ Department of Mechanical and Aerospace Engineering
}

Morgantown, West Virginia

2010

Keywords: SOFC anode, Impurity, Degradation, Sulfur tolerant, Impregnation, Phosphine, Perovskite anode, SOFC cathode, Electrochemical Model Copyright 2010 Mingyang Gong 


\section{ABSTRACT \\ Sulfur Tolerant Solid Oxide Fuel Cell for Coal Syngas \\ Application: Experimental Study on Diverse Impurity Effects and Fundamental Modeling of Electrode Kinetics}

\section{By Mingyang Gong}

With demand over green energy economy, fuel cells have been developed as a promising energy conversion technology with higher efficiency and less emission. Solid oxide fuel cells (SOFC) can utilize various fuels in addition to hydrogen including coal derived sygas, and thus are favored for future power generation due to dependence on coal in electrical industry. However impurities such as sulfur and phosphorous present in coal syngas in parts per million (p.p.m.) levels can severely poison SOFC anode typically made of Ni/yttria-stabilized-zirconia (Ni-YSZ) and limit SOFC applicability in economically derivable fuels. The focus of the research is to develop strategy for application of high performance SOFC in coal syngas with tolerance against trace impurities such as $\mathrm{H}_{2} \mathrm{~S}$ and $\mathrm{PH}_{3}$. To realize the research goal, the experimental study on sulfur tolerant anode materials and examination of various fuel impurity effects on SOFC anode are combined with electrochemical modeling of SOFC cathode kinetics in order to benefit design of direct-coal-syngas SOFC.

Tolerant strategy for SOFC anode against sulfur is studied by using alternative materials which can both mitigate sulfur poisoning and function as active anode components. The Ni-YSZ anode was modified by incorporation of lanthanum doped ceria (LDC) nanocoatings via impregnation. Cell test in coal syngas containing $20 \mathrm{ppm} \mathrm{H}_{2} \mathrm{~S}$ indicated the impregnated LDC coatings inhibited on-set of sulfur poisoning by over 10hrs. Cell analysis via X-ray photon spectroscopy (XPS), X-ray diffraction (XRD) and electrochemistry revealed LDC coatings reacted with $\mathrm{H}_{2} \mathrm{~S}$ via chemisorptions, resulting in less sulfur blocking triple--phase-boundary and minimized performance loss. Meanwhile the effects of $\mathrm{PH}_{3}$ impurity on SOFC anode is examined by using Ni-YSZ anode supported SOFC. Degradation of cell is found to be irreversible due to adsorption of $\mathrm{PH}_{3}$ on TPB and further reaction with Ni to form secondary phases with low melting point. The feasibility of mixed ionic and electronic conductive (MIEC) metal oxides with perovskite structure $\left(\mathrm{ABO}_{3}\right)$ as alternative ceramic SOFC anodes in coal syngas has been examined by $\mathrm{PH}_{3}$ exposure test. The study found although perovskite anodes can be generally more tolerant against $\mathrm{H}_{2} \mathrm{~S}$, further examination on $\mathrm{PH}_{3}$ tolerance is indispensable before their extensive application in coal syngas.

On the theoretical end it is this research's initiative that oxygen reduction reaction at mixed ionic and electronic conductive (MIEC) cathode is a key factor controlling SOFC performance at intermediate temperature $\left(700 \sim 850^{\circ} \mathrm{C}\right)$. It is generally recognized that the overall charge-transfer process could occur through both surface pathway at triple-phase boundary (3PB) and bulk pathway at electrolyte/cathode interface (2PB). A modified 
one-dimensional model is thus developed to predict defect evolution of MIEC cathode under overpotential by incorporating multi-step charge-transfer into the bi-pathway continuum model. Finite volume control method is applied to obtain solutions for the model. The simulation predicted kinetics transition from 3PB control to 2PB control as cathodic overpotential stepping from $-0.2 \mathrm{~V}$ to $-0.4 \mathrm{~V}$, depending on the material properties parameters. Meanwhile significant activation behavior of the MIEC electrode was also observed as indicated by extension of reaction region towards gas-exposed oxide surface. This model addressed contribution from electrochemical-controlled ratelimiting steps (RLSs) on the reduction kinetics, and identified the role played by multiple material property parameters such as surface oxygen ion concentration and bulk vacancy concentration on the kinetics transition.

Combined academic knowledge gained through experimental investigation and theoretical simulation in this research would benefit the future design, development and application strategy of high-performance SOFC in coal syngas fuels. 


\section{DEDICATION}

To my wife, Huanling Liu, whose love, support, and understand always accompany me and lighten up everyday in my life.

To my parents, who nourished me and educated me with all they have. 


\section{ACKNOWLEDGMENTS}

The author wishes to greatly thank my advisor, Dr. Xingbo Liu, during the Ph.D study of these years for his extensive support and instruction on performing experimental and theoretical research tasks and education on attitude towards scientific pursuit and life fulfillment.

The author also expresses gratitude to Dr. John Zondlo and Dr. Chunchuan Xu in Department of Chemical Engineering for their long-time cooperation and help during cell testing. Dr. Scott A. Barnett and Dr. David Bierschenk from Department of Material Science and Engineering, Northwestern University are specially thanked for their cooperation and instructive guidance on alternative anode material study.

It is the author's pleasure to have opportunity to work with Dr. Edward Sabolsky, Dr. Ismail Celik and Dr. Harry Finklea from West Virginia University on the EPSCoR project during recent year study and learn from them invaluable academic skills and knowledge.

The author is in debt to Dr. Ranall S.Gemmen, Dr. Kirk Gerdes, Dr. Christopher Johnson and Dr. Jason Trembly together with Mr. Richard Pineault from National Energy and Technology Lab for their guidance, instruction and tutoring during years of study at NETL and WVU.

Finally the author thanks current and former group members Dr. Dong Ding, Dr. Yinglu Jiang, Mr. Mark Dodson and Mr. Jared Nutter for share of their contribution and even friendship during laboratory research life. 


\section{Table of Contents}

ABSTRACT

2.1 Sulfur-poisoning Effects and recent development of sulfur-tolerant anode materials

2.1.1 General Requirement of SOFC anode .............................................. 5

2.1.2 Degradation of SOFC anodes by sulfur poisoning ................................ 6

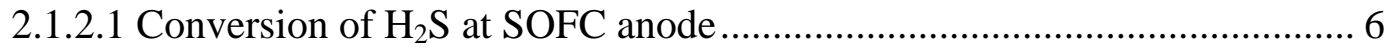

2.1.2.2 Sulfur-poisoning degradation mechanism of Ni-based SOFC anode ......... 8

2.1.2.3 Degradation of Ni-cermet anode at low $\mathrm{H}_{2} \mathrm{~S}$ concentration level.............. 9

2.1.2.4 Degradation of SOFC anode at high $\mathrm{H}_{2} \mathrm{~S}$ concentration level ................. 12

2.1.3 Sulfur tolerant anode materials for SOFC application ............................ 13

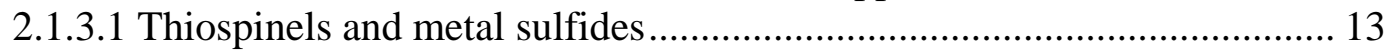

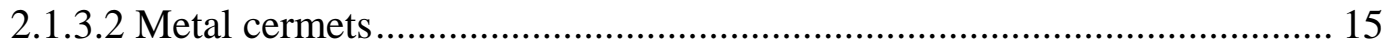

2.1.3.3 Mixed ionic and electronic conductor (MIEC) ................................. 20

2.1.4 Concluding remarks on sulfur poisoning and future work overlook ............... 30

2.2 Poisoning effects from other impurities............................................................ 31

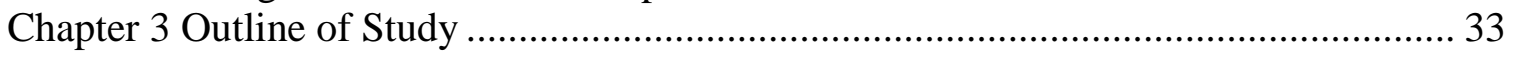

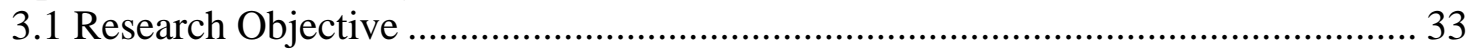

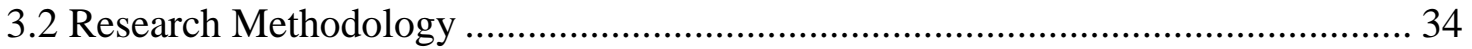

Chapter 4 Experimental Study on Sulfur Impurity Effects and Sulfur-Tolerant Materials

for SOFC Anodes in Coal Syngas ........................................................................... 35

4.1 Investigation with impregnated La-doped Ceria as effective sulfur tolerant anode materials - Test with anode supported cell.......................................................... 35

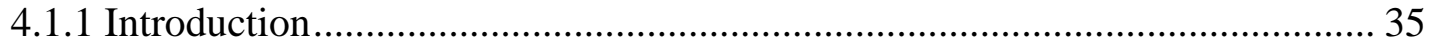

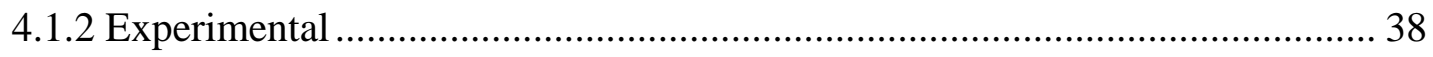

4.1.2.1 Impregnation of Ni-YSZ anode supported cell by doped ceria ............... 38

4.1.2.2 Cell testing and electrochemical measurement ....................................... 39

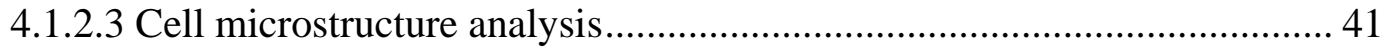

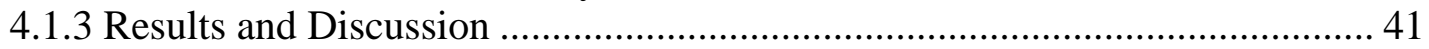

4.1.3.1 Impregnated MSRI cell by $\mathrm{La}_{0.3} \mathrm{Ce}_{0.7} \mathrm{O}_{1.85}$ (LDC) ............................... 41

4.1.3.2 Sulfur tolerance test in simulated coal syngas .................................... 43

4.1.3.3 AC impedance investigation of sulfur poisoning................................ 46

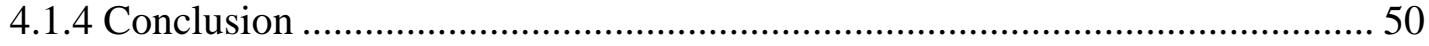


4.2 Investigation with impregnated La-doped Ceria as effective sulfur tolerant anode materials - Test with electrolyte supported cell .......................................................... 52

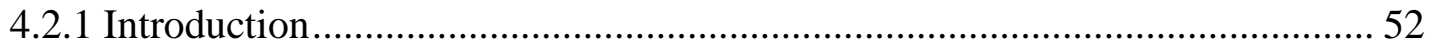

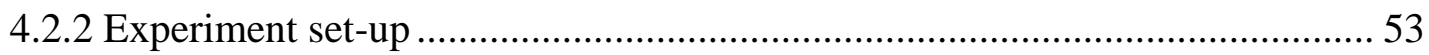

4.2.3 Results and discussion .............................................................................. 54

4.2.3.1 Cell performance comparison between baseline and impregnated electrolyte supported cells................................................................................. 54

4.2.3.2 Electrochemical test on sulfur tolerance of LDC-impregnated anode...... 56 4.2.3.3 Post-test cell characterization on interaction between LDC-impregnated

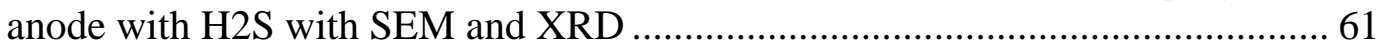

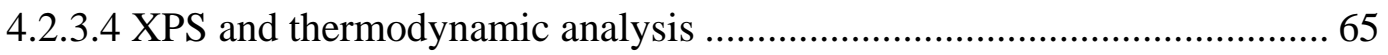

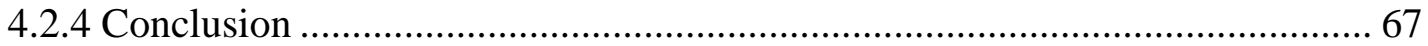

Chapter 5 Experimental Investigation of Impurity Effects from Phosphine on SOFC

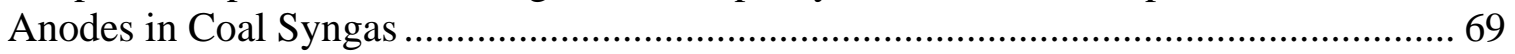

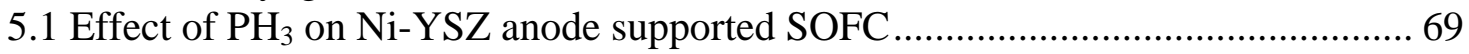

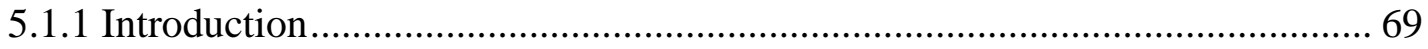

5.1.2. Experimental Methods ........................................................................... 70

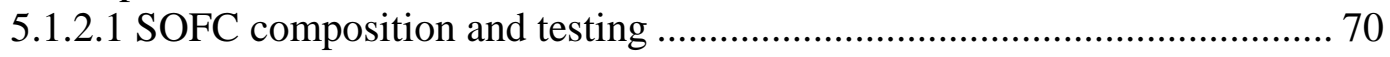

5.1.2.2 Electrochemical testing of SOFC.......................................................... 72

5.1.2.3 Morphology and structural analysis..................................................... 73

5.1.3. Experimental Results and Discussion ............................................................. 73

5.1.3.1. Polarization Curves and Impedance Spectra............................................. 73

5.1.3.2 SEM Micrograph and EDS Spectra ....................................................... 76

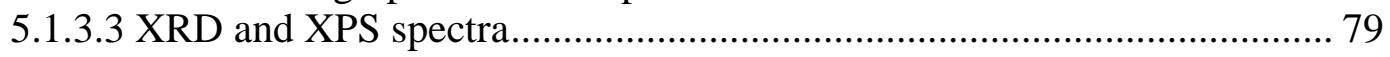

5.1.4 Thermodynamic and Phase Transition analysis.............................................. 81

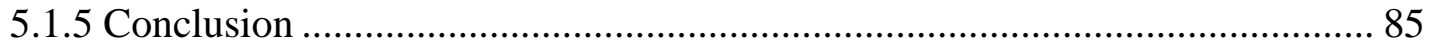

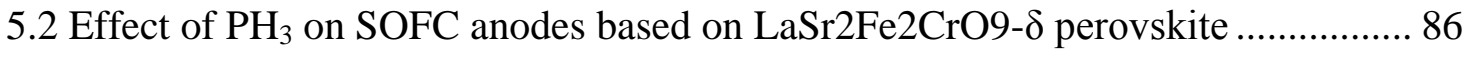

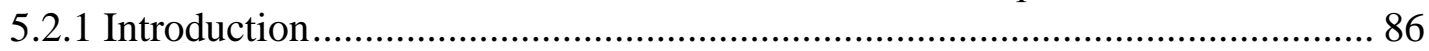

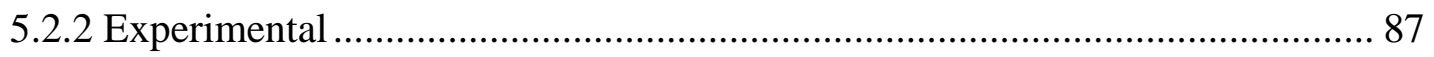

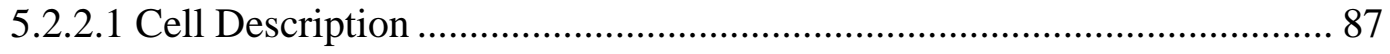

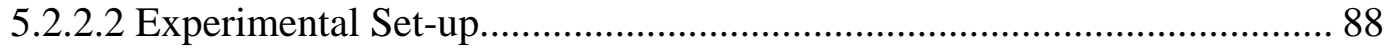

5.2.2.3 $\mathrm{PH}_{3}$ Testing Procedure ....................................................................... 90

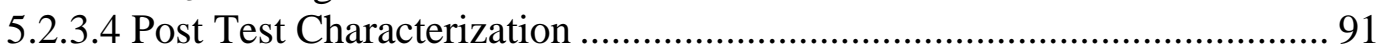

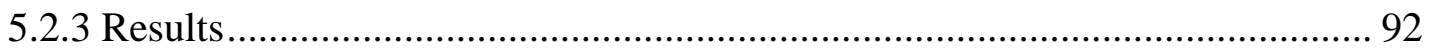

5.2.3.1 SOFC Performance in pure fuels ............................................................ 92

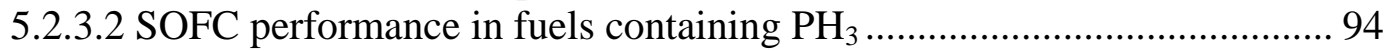

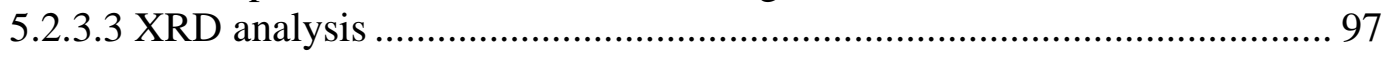

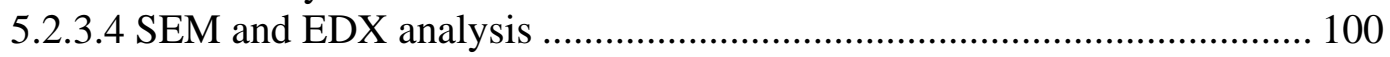

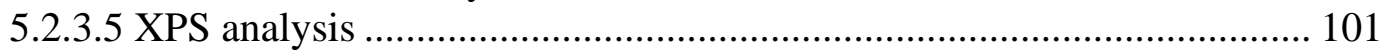

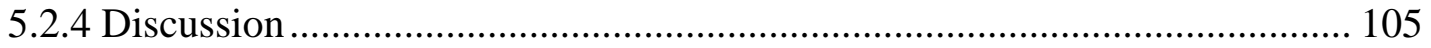

5.2.4.1 Thermodynamic Calculations ................................................................. 106

5.2.4.2 Anode Reaction and Degradation Mechanisms ........................................ 111

5.2.4.3 Comparison with Ni-YSZ Anodes .......................................................... 113

5.2.5 Summary and Conclusions .......................................................................... 114

Chapter 6 Fundamental Modeling of SOFC Cathode Kinetics ....................................... 116

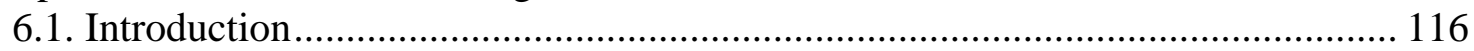


6.2 Physical model ............................................................................................ 120

6.2.1 General schemes for oxygen reduction..................................................... 120

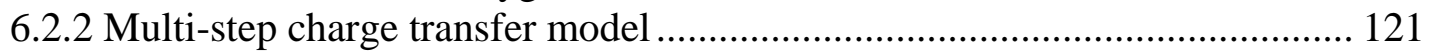

6.2.3 Thermal equilibrium and electrode activation ............................................ 123

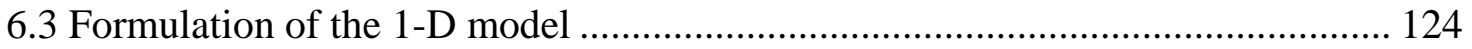

6.3.1 Governing equations and boundary conditions............................................. 124

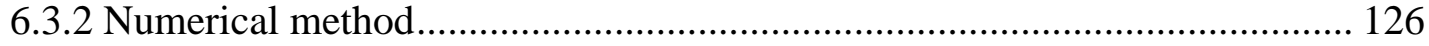

6.4. Model Validation with oxygen partial pressure dependence .............................. 128

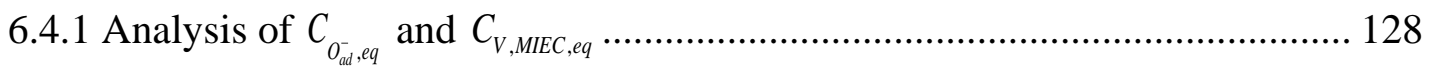

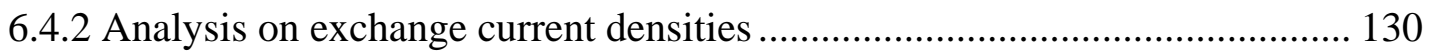

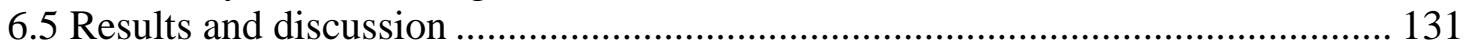

6.5.1 Transient distribution of the active electrode species .................................... 131

6.5.2 Transition of the dominant pathway for cathode kinetics............................... 135

6.5.2.1 Overpotential effects and the mechanism of pathway transition ............. 137

6.5.2.2 Effect of material property on pathway transition and electrode

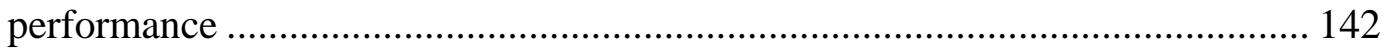

6.5.3 Dependence of active reaction zone and surface reaction rates on overpotential

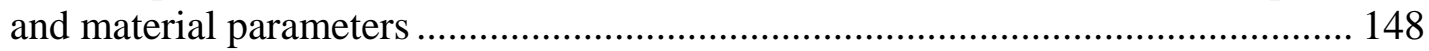

6.5.3.1 Effects of overpotential and material property on active reaction zone . 149

6.5.3.2 Change of surface reaction rates $r_{S 2}$ and $r_{B 3}$ as functions of electrode position, overpotential and material property ……………………………......... 153

6.5.4 Assumption of oxygen reduction scenario................................................... 160

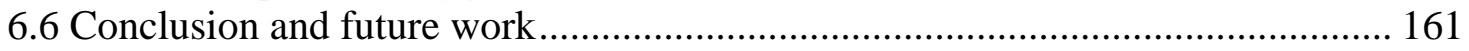

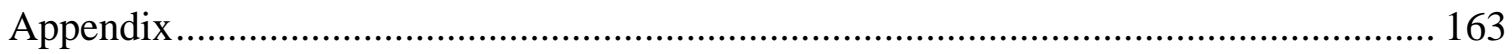

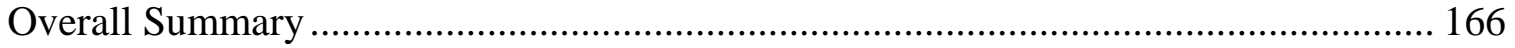

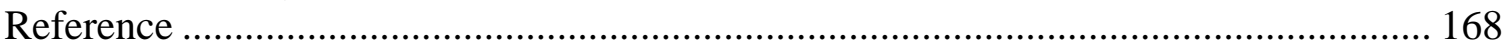

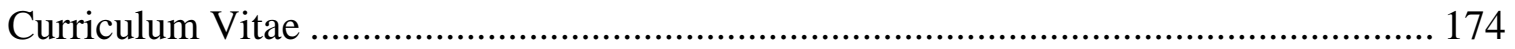

\section{List of Tables}

Table 2.1 Typical composition and $\mathrm{H}_{2} \mathrm{~S}$ concentration of some fuel sources ................... 4 Table 4.1.1 EDXS results of $\mathrm{La}$ and Ce distribution inside the anode after LDC impregnation ( the point numbers correspond to detection points labeled in Fig.4.1.2 (b))

Table 5.2.1 Summary of testing conditions for CG-Fe cells .......................................... 90 Table 5.2.2: P 2p, Sr 3d and Fe 2p XPS peaks of anodes after exposure to 5 and $20 \mathrm{ppm}$

$\mathrm{PH}_{3}$ 103

Table 6.1 Electrode processes assigned to each elementary steps in surface and bulk

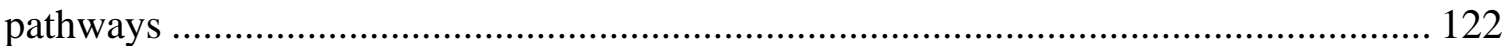

Table 6.2 Values of Type I and II parameters used in the simulation cases................... 128

Table 6.3 Summary of V-I curve simulaiton and tafel analysis results for case 1 to 3. 136 


\section{List of Figures}

Figure 2.1. Equilibrium partial pressure of $\mathrm{H}_{2} \mathrm{~S}$ vs. reciprocal temperature (open symbols $\theta=0.5-0.6$; closed symbols, $\theta=0.8-0.9)[19](\theta$, coverage rate).................................... 10 Figure 2.2. Cell voltage drop with various additives impregnated in porous anode at 200 $\mathrm{mA} / \mathrm{cm}^{2}\left(800^{\circ} \mathrm{C}, \mathrm{H} 2 \mathrm{~S}\right.$ conc. $=20 \mathrm{ppm}, \mathrm{H}_{2} / \mathrm{CO} 100: 0$, electrolyte/ SSZ, anode/Ni-YSZ + impregnated additives.)[4] ............................................................................... 16 Figure 2.3 Performance of a $\mathrm{Cu} / \mathrm{CeO}_{2} / \mathrm{YSZ}$ SOFC as a function of time. $(800 \mathrm{C}$, cell

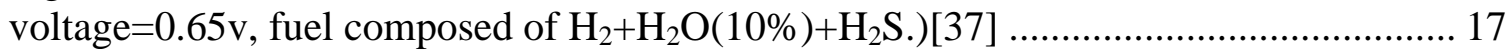
Figure 2.4. Schematic illustration of anode microstructure coated with SDC sol [42] ... 19 Figure 2.5.XRD patterns of LSCMs after being exposed to humidified $\mathrm{H}_{2}$ containing $10 \%$ $\mathrm{H} 2 \mathrm{~S}$ at $950^{\circ} \mathrm{C}$ for 5 days [24]. 23

Figure 2.6 Performance of sulfur tolerance anodes for different $\mathrm{H} 2 \mathrm{~S}$ concentration under various conditions. (*:the initial performance was recovered after $700 \mathrm{~h}$; open symbols for output change; closed symbols for power density)..................................................... 25 Figure 4.1.1 Cell testing assembly set-up ..................................................................... 39 Figure 4.1.2 Morphology and compositional analysis of MSRI cell with lanthanum doped ceria(a Before LDC impregnation b After LDC impregnation c Mapping of La inside anode )

Figure 4.1.3 XRD spectrum of MSRI cell after 6 impregnation cycles with La and Ce nitrates.

Figure 4.1.4 Performance of MSRI cells in coal syngas with 20ppm $\mathrm{H}_{2} \mathrm{~S}$. (a without LDC impregnation; b with 1 impregnation of LDC; $c$ with 6 cycles of LDC; d On-set duration vs Loading of LDC)

Figure 4.1.5 AC impedance of MSRI cell with LDC impregnation measured at OCP for various atmospheres

Figure 4.1.6 AC impedance of MSRI cell with LDC impregnation measured at $-0.3 \mathrm{v}$ overpotential for various atmospheres

Figure 4.2.1 Performances of baseline and LDC-impregnated cells at $800^{\circ} \mathrm{C}$ in dry $\mathrm{H}_{2} . .54$ Figure 4.2.2 AC impedance of baseline and LDC-impregnated electrolyte supported cells at $800 \mathrm{Cin}$ dry $\mathrm{H} 2$.

Figure 4.2.3 Change of cell voltage over time during syngas gas test with $20 \mathrm{ppm} \mathrm{H} 2 \mathrm{~S}$ for (a) SSZ baseline cell with impregnation (b) LDC impregnated SSZ cell........................57 Figure 4.2.4 Change of AC impedance at OCV over time during test with $20 \mathrm{ppm}_{2} \mathrm{~S}$ for (a) baseline cell (b) LDC impregnated cell.

Figure 4.2.5 SEM pictures of the baseline and-LDC impregnated cells after $\mathrm{H} 2 \mathrm{~S}$ testing

(a) Baseline cell (b) LDC impregnated cell 61

Figure 4.2.6 EDS of LDC-impregnated electrolyte supported andoe after $\mathrm{H} 2 \mathrm{~S}$ testing... 62 Figure 4.2.7 XRD patterns of SOFC anode after syngas gas test with $20 \mathrm{ppm} \mathrm{H2S} \mathrm{for} \mathrm{(a)}$ baseline cell (b) LDC impregnated cell . 
Figure 4.2.8 XPS spectrum of SOFC anode after syngas gas test with 20 ppm H2S for (a)

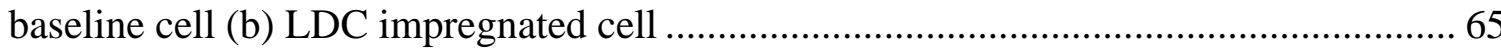

Figure 4.2.9 Thermodynamic calculated Ni-S-H-O with Factsage software at $800^{\circ} \mathrm{C} \ldots . .67$ Figure 4.2.10 Thermodynamic estimation of Gibbs free energy for reaction between reduced ceira oxide and $20 \mathrm{ppm}_{2} \mathrm{~S}$ to form cerium oxy-sulfide (estimated with $26 \%$

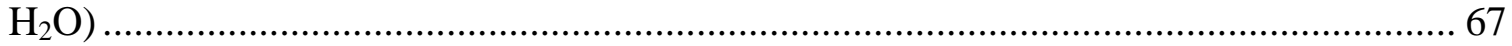

Figure 5.1.1 Button cell contact configuration ..................................................... 71 Figure 5.1.2 MSRI Cell No.12 Exposure to Syngas Before/After Adding 10 ppm PH3 at $\mathrm{T}=800 \mathrm{oC}$, Load $\mathrm{J}=0.5 \mathrm{~A} / \mathrm{cm}^{2}$.

Figure 5.1.3 The polarization curves of Ni-YSZ anode supported button cell exposure to

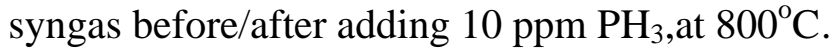

Figure 5.1.4 The normalized impedance spectrum of Ni-YSZ anode supported button

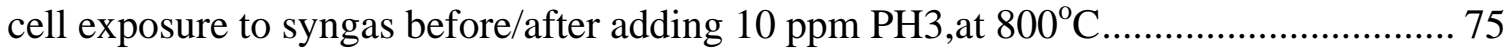

Figure 5.1.5 The cell ohmic resistance $R s$ and Polarization $R p$ versus time after adding 10

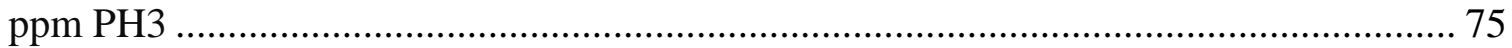

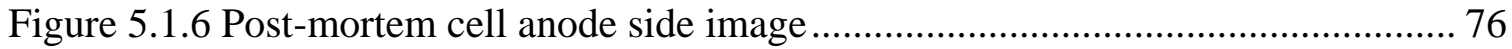
Figure 5.1.7 (a) The cell anode surface SEM micrograph after exposure to syngas with

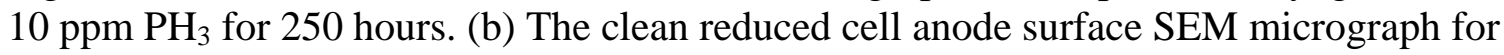
comparison..... 76

Figure 5.1.8 (a) The top $50 \mu \mathrm{m}$ cell anode cross-section SEM micrograph after exposure

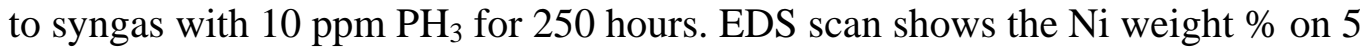
different spots. (b) The top $50 \mu \mathrm{m}$ clean reduced cell anode cross-section SEM micrograph for comparison.

Figure 5.1.9 The EDS spectra of the clean reduced Ni-YSZ anode surface (dash line) and

the Ni-YSZ anode surface after exposure to $\mathrm{PH}_{3}$ for 250 hours (solid line). .................. 78

Figure 5.1.10 XRD spectra of Ni-YSZ anode supported cell surfaces. $\mathrm{Ni}_{5} \mathrm{P}_{2}$ was confirmed to be present on the anode surface of cell after exposure to syngas with 10

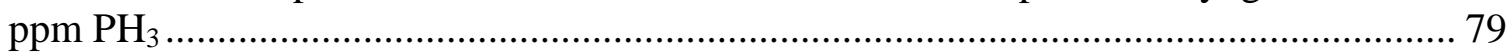

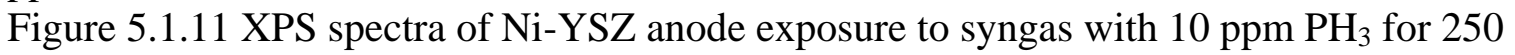

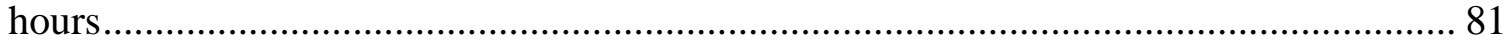

Figure 5.1.12 The thermodynamic phase diagram shows that $10 \mathrm{ppm}\left(10^{-5} / \mathrm{cm}^{-3}\right) \mathrm{PH}_{3}$ impurity is potentially capable of reacting with $\mathrm{Ni}$ in the reducing environment. ........... 82 Figure 5.1.13 P-Ni phase diagram. The cell working condition could fall well within the

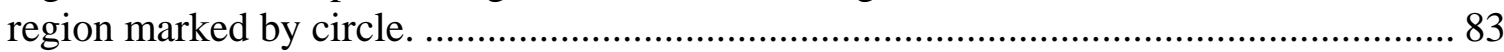

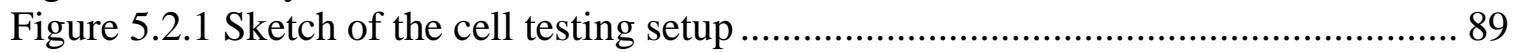

Figure 5.2.2 Cell performances as a function of feed fuel composition (CG-P20).........93 Figure 5.2.3 AC impedance spectra at OCV of CG-P20 tested in $97 \% \mathrm{H}_{2} / 3 \% \mathrm{H}_{2} \mathrm{O}$ and simulative coal syngas before/after $\mathrm{PH}_{3}$ addition .................................................. 94 Figure 5.2.4 Cell voltage change in syngas for a baseline cell (CG-P0) and cell poisoned

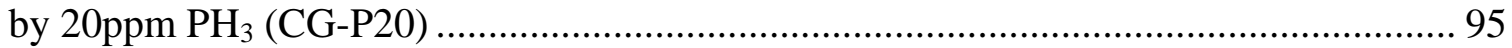
Figure 5.2.5 Cell voltage change in $97 \% \mathrm{H}_{2} / 3 \% \mathrm{H}_{2} \mathrm{O}$ for cells poisoned by $20 \mathrm{ppm} \mathrm{PH}_{3}$

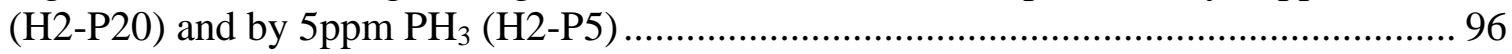

Figure 5.2.6 AC impedance change at $\mathrm{OCV}$ of $\mathrm{H} 2-\mathrm{P} 5$ cell tested in $97 \% \mathrm{H}_{2} / 3 \% \mathrm{H}_{2} \mathrm{O}$ before/after 5ppm $\mathrm{PH}_{3}$ addition ........................................................................ 97 Figure 5.2.7 XRD spectra of cells tested with $97 \% \mathrm{H}_{2} / 3 \% \mathrm{H}_{2} \mathrm{O}$ and different levels of $\mathrm{PH}_{3}$ 
Figure 5.2.8 XRD spectra of cells tested in syngas with and without $\mathrm{PH}_{3}$ impurity ....... 99 Figure 5.2.9 Cross-sectional SEM pictures of a cell (a) anode operated in wet $\mathrm{H}_{2}$ with 5 ppm $\mathrm{PH}_{3}$, (b) anode operated in wet $\mathrm{H}_{2}$ with $20 \mathrm{ppm} \mathrm{PH}_{3}$, (c) anode operated in syngas with 20ppm $\mathrm{PH}_{3}$.

Figure 5.2.10 Cross-section EDS spectra of H2-P5 cell after 5ppm PH3 poisoning in $97 \% \mathrm{H}_{2} / 3 \% \mathrm{H}_{2} \mathrm{O}$ recorded at (a) the LSFeCr-GDC anode and (c) near the LDC layer. The inset (b) is a close-up of the $\mathrm{P}(\mathrm{K} \alpha)$ and $\mathrm{Au}(\mathrm{M} \alpha)$ line position.

Figure 5.2.11 XPS spectra of a survey scan of the H2-P5 cell anode surface after 5ppm $\mathrm{PH}_{3}$ testing in $97 \% \mathrm{H}_{2} / 3 \% \mathrm{H}_{2} \mathrm{O}$

Figure 5.2.12 Original (raw) and deconvoluted Sr3d and P2p XPS spectra for an (a.) anode after exposure to 20ppm $\mathrm{PH}_{3}$ in simulated syngas (CG-P20) and (b) anode after exposure to $5 \mathrm{ppm}^{\mathrm{PH}_{3}}$ testing in $97 \% \mathrm{H}_{2} / 3 \% \mathrm{H}_{2} \mathrm{O}(\mathrm{H} 2-\mathrm{P} 5)$

Figure 5.2.13 Comparison of Fe2p XPS spectra of the H2-P5 cell anode andCG-P20 cell anode after $\mathrm{PH} 3$ testing in $97 \% \mathrm{H}_{2} / 3 \% \mathrm{H}_{2} \mathrm{O}$

Figure 5.2.14 Predominant phase diagrams of Fe-P-O-H system at $800^{\circ} \mathrm{C}$ and $850^{\circ} \mathrm{C}$, assuming $\mathrm{PH}_{3}$ as reactant and $\mathrm{pH}_{2}=0.97$ bar.

Figure 5.2.15 Predominant phase diagrams of Fe-P-O-H system at $800^{\circ} \mathrm{C}$ and $850^{\circ} \mathrm{C}$, assuming $\mathrm{PH}_{3}$ as reactant and $\mathrm{pH}_{2}=0.31$ bar.

Figure 6.1 Three mechanisms for oxygen reduction on SOFC cathode

Figure 6.2 Schematic description of the bi-pathway dominated oxygen reduction on MIEC cathode (LSM)

Figure 6.3 Transient diffusion profiles of surface oxygen ion and bulk vacancy calculated with $\mathrm{C}_{\mathrm{v}, \mathrm{eq}}=1 \times 10^{-7} \mathrm{~mol} \mathrm{\textrm {cm } ^ { - 3 }}$ and $\mathrm{C}_{\mathrm{o}-\mathrm{eq}}=1 \times 10^{-10} \mathrm{~mol} \mathrm{~cm}^{-2}$ at $-0.2 \mathrm{~V}$ overpotential (open

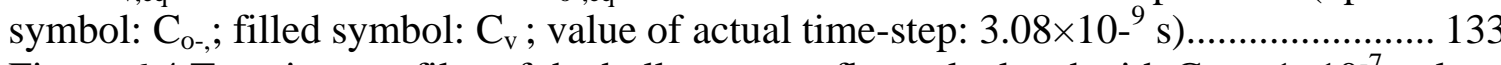
Figure 6.4 Transient profiles of the bulk vacancy flux calculated with $\mathrm{C}_{\mathrm{v}, \mathrm{eq}}=1 \times 10^{-7} \mathrm{~mol}$ $\mathrm{cm}^{-3}$ and $\mathrm{C}_{\mathrm{o}-\mathrm{eq}}=1 \times 10^{-10} \mathrm{~mol} \mathrm{\textrm {cm } ^ { - 2 }}$ at $-0.2 \mathrm{~V}$ overpotential

Figure 6.5 Logarithmic current versus overpotential profiles for bi-pathway constituted overall electrode kinetics with the parameters in Case 1 as $\mathrm{C}_{\mathrm{o}-\mathrm{eq}}=1 \times 10^{-11} \mathrm{~mol} \mathrm{~cm}^{-2}$ and $\mathrm{C}_{\mathrm{v}, \mathrm{eq}}=1 \times 10^{-8} \mathrm{~mol} \mathrm{~cm}^{-3}$

Figure 6.6 Evolution of the local reaction current $\left(i_{\text {loc }}\right)$ in the total 3PB current $\left(i_{\text {tot }}\right)$ as function of overpotential in Case 1 with $\mathrm{C}_{\mathrm{o}-\mathrm{eq}}=1 \times 10^{-11} \mathrm{~mol} \mathrm{~cm}^{-2}$ and $\mathrm{C}_{\mathrm{v}, \mathrm{eq}}=1 \times 10^{-8} \mathrm{~mol}$ $\mathrm{cm}^{-3}$

Figure 6.7 Logarithmic current versus overpotential profiles with parameters in Case 2 as $\mathrm{C}_{\mathrm{o}-\mathrm{eq}}=1 \times 10^{-10} \mathrm{~mol} \mathrm{~cm}^{-2}$ and $\mathrm{C}_{\mathrm{v}, \mathrm{eq}}=1 \times 10^{-8} \mathrm{~mol} \mathrm{~cm}^{-3}$.

Figure 6.8 Logarithmic current versus overpotential profiles with parameters in Case 3 as $\mathrm{C}_{\mathrm{o}-\mathrm{eq}}=1 \times 10^{-10} \mathrm{~mol} \mathrm{~cm}^{-2}$ and $\mathrm{C}_{\mathrm{v}, \mathrm{eq}}=1 \times 10^{-7} \mathrm{~mol} \mathrm{~cm}^{-3}$

Figure 6.9 Comparison of the relationship between local reaction currents and total 3PB currents in Case 2 and Case 3 (Case 2: $\mathrm{C}_{\mathrm{o}-\text {,eq }}=1 \times 10^{-10} \mathrm{~mol} \mathrm{~cm}^{-2}$ and $\mathrm{C}_{\mathrm{v}, \mathrm{eq}}=1 \times 10^{-8} \mathrm{~mol} \mathrm{~cm}^{-}$ ${ }^{3}$; Case 3: $\mathrm{C}_{\mathrm{o}-\mathrm{eq}}=1 \times 10^{-10} \mathrm{~mol} \mathrm{~cm}{ }^{-2}$ and $\mathrm{C}_{\mathrm{v}, \mathrm{eq}}=1 \times 10^{-7} \mathrm{~mol} \mathrm{~cm}^{-3}$ ).

Figure 6.10 Distribution profiles of oxygen vacancy concentrations under different overpotential in Case 1 as $\mathrm{C}_{\mathrm{o}-\mathrm{eq}}=1 \times 10^{-11} \mathrm{~mol} \mathrm{~cm}^{-2}$ and $\mathrm{C}_{\mathrm{v}, \mathrm{eq}}=1 \times 10^{-8} \mathrm{~mol} \mathrm{~cm}^{-3}$......

Figure 6.11 Distribution profiles of oxygen vacancy concentrations under different overpotential in Case 2 as $\mathrm{C}_{\mathrm{o}-\mathrm{eq}}=1 \times 10^{-10} \mathrm{~mol} \mathrm{~cm}^{-2}$ and $\mathrm{C}_{\mathrm{v}, \mathrm{eq}}=1 \times 10^{-8} \mathrm{~mol} \mathrm{~cm}^{-3}$..... Figure 6.12 Distribution profiles of surface oxygen concentrations and step-B3 reaction

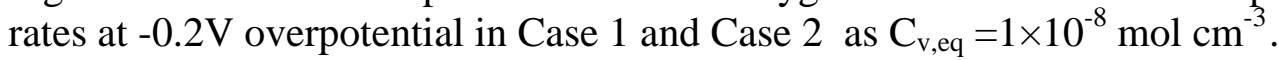
151 
Figure 6.13 Dependence of rates of step $\mathrm{S} 2$ and $\mathrm{B} 3$ reactions at $3 \mathrm{~PB}(\mathrm{x}=0)$ on overpotential in Case 1 and 2 as $\mathrm{C}_{\mathrm{v}, \mathrm{eq}}=1 \times 10^{-8} \mathrm{~mol} \mathrm{~cm}^{-3}$ 154 Figure 6.14 Dependence of rates of step S2 and B3 reactions at $0.5 \mu \mathrm{m}$ away from $3 \mathrm{~PB}$ on overpotential in case 1 (open symbol) and case 2 (filled symbol) as $C_{\mathrm{v}, \mathrm{eq}}=1 \times 10^{-8} \mathrm{~mol} \mathrm{~cm}^{-3}$

Figure 6.15 Dependence of backward reaction rates and forward reaction rates of step B3 reactions at $0.5 \mu \mathrm{m}$ away from $3 \mathrm{~PB}$ on overpotential in Case 1 and Case 2 as $\mathrm{C}_{\mathrm{v}, \mathrm{eq}}=1 \times 10^{-8}$ $\mathrm{mol} \mathrm{cm} \mathrm{cm}^{-3}$.... 158 


\section{Chapter 1: Background and Significance of Study}

To date coal is still the dominating source for electrical power generation in the energy industry. However with the forthcoming of green energy economy era, cleaner and more $\mathrm{CO}_{2}$-neutral methods of utilizing coal are required in order to make use of abundant world-wide coal reserves. Solid oxide fuel cell (SOFC) is a leading fuel cell technology that utilizes chemical energy for clean and direct electricity conversion. Compared with other types of fuel cells, SOFC provides advantages in terms of higher theoretical energy conversion efficiency, fuel flexibility, heat recovery and control over carbon emission. Thus SOFCs are of particular interest for coal-based generation since they oxidize coal-derived syngas with pure oxygen, producing a $\mathrm{CO}_{2}$-rich product that allows for easier and lower-cost sequestration compared to $\mathrm{N}_{2}$-rich air-combustion products. An additional advantage of SOFCs is their ability to utilize fuels containing various species in addition to hydrogen, such as $\mathrm{CO}$, hydrocarbons, and impurities. Thus, SOFC-based power plants can be designed with reduced fuel processing and cleanup requirements compared to other fuel cells, reducing power plant cost. On the other hand for commercialization of SOFC in the near future, it is crucial to reduce the cell operation temperature to an intermediate temperature (IT) range between 650 to $850^{\circ} \mathrm{C}$, which favors system cost-reduction by replacement of ceramic interconnects by inexpensive metallic counterparts, and improves stack stability due to reduction of the reactions between electrodes and other cell components as well as CTE mismatch.

Direct utilization of coal syngas in IT-SOFCs, however, is greatly challenged by the common presence of various trace impurities in the fuel such as sulfur, phosphor and 
chlorine, which can degrade cell performance by poisoning the SOFC anode. Additionally at lower temperature the interfacial polarization resistance between cathode material and electrolyte becomes the most rate-limiting factor for cell performance due to the sluggish oxygen reduction kinetics. Therefore it is rather demanding to develop high performance SOFC with improved anode tolerance against impurity for practical operation with coal syngas. Out from this point of view, my doctorate study is committed to two aspects. For the experimental part tolerant anode materials are developed through investigation on the poisoning mechanisms of various impurities on anode performance. Meanwhile a theoretical model is designed to simulate the SOFC cathode kinetics with the purpose of identifying rate-determining step and potential route of performance enhancement. With the combined knowledge from both experimental and theoretical work, it is in a hope that more insights can be gained on the design, identification and improvement of advanced energy materials for application in clean and efficient power generation with coal syngas. 


\section{Chapter 2: Literature Review}

Solid oxide fuel cell (SOFC) is promising candidate for future energy conversion systems because they have higher energy conversion efficiency than conventional heat engine systems and other types of fuel cells. Capability of SOFC to use conventional fossil fuels with multiple compositions is found essential for commercialization of SOFCs $[1,2]$. Fuel flexibility decreases operation costs of SOFC system by eliminating need of high-grade purifying apparatus and directly utilizing economically derived fuels, and also facilitates SOFC's application in the conversion and treatment processes with special importance for industrial and environmental businesses [2,3,4]. However, one of the major challenges for extended fuel application in SOFC is anode poisoning caused by unfavorable reactions of catalytic anode materials with impurities species such as sulfur and phosphorus present in readily available hydrocarbon fuels (Tab.2.1), resulting in performance loss and degradation of the anode. In particular, sulfur poisoning of SOFC systems operating at intermediate temperatures (typically $700-850^{\circ} \mathrm{C}$ ) [1] which are

known as IT-SOFC systems can be irreversible, whereas the performance degradation in HT-SOFC $\left(>900^{\circ} \mathrm{C}\right)$ can be reversible $[4,5]$. The IT-SOFC however, have the advantage of using more economical component materials, such as low cost metallic interconnects, and thus material economics favor the IT-SOFC. 
Table 2.1 Typical composition and $\mathrm{H}_{2} \mathrm{~S}$ concentration of some fuel sources

\begin{tabular}{ccc}
\hline Fuel type & Typical composition & $\mathrm{H}_{2} \mathrm{~S}$ concentration \\
\hline Coal syngas & $\mathrm{H}_{2}, \mathrm{CO}, \mathrm{CO}_{2}, \mathrm{H}_{2} \mathrm{O}, \mathrm{N}_{2}$ & $100-300 \mathrm{ppm}$ \\
Biogas & $\mathrm{H}_{2}, \mathrm{CO}, \mathrm{CO}_{2}, \mathrm{CH}_{4}, \mathrm{H}_{2} \mathrm{O}, \mathrm{N}_{2}$ & $50-200 \mathrm{ppm}$ \\
Sour (natural) gas & $\mathrm{H}_{2}, \mathrm{CO}_{2}, \mathrm{~N}_{2}, \mathrm{C}_{2} \mathrm{H}_{6}, \mathrm{CH}_{4}$ & $>1 \%$ \\
\hline
\end{tabular}

\subsection{Sulfur-poisoning Effects and recent development of sulfur-tolerant anode materials}

Since sulfur species such as hydrogen sulfide are widely present as impurity or additive in many economically available fuel sources, and their concentration can reach high level in some fuels such as coal syngas and diesel, Sulfur tolerance capability of SOFC anode now become a critical standard for advance of SOFC toward commercialization. Although desulphurization pretreatment of fuel is usually available for SOFC, development of anode materials with required sulfur tolerance is indispensable to achieve overall system cost competence, and ensure cell integrity in case of desulphurization system fault $[2,6]$.Early efforts in studying sulfur poisoning and sulfur tolerant materials were initiated on $\mathrm{H}_{2} \mathrm{~S} /$ air fuel cell and MCFC systems [7,8,9]. Recently research interest was focused more on SOFC system feed with $\mathrm{H}_{2} \mathrm{~S}$-containing fuels. Successful results on anode deactivation and anode materials application have been reported by various researchers and summarized in a recent paper [10]. However, prior results tend to vary with each other due to different cell structures, anode features and testing conditions. And there are few reports on the tolerant mechanism and selection criteria of sulfur tolerant materials in this field. In this chapter, a summarization on degradation of SOFC anode and sulfur tolerant anode materials will be presented to promote in-depth understand of predecessor works. The material screening criteria and 
tolerance function of anode materials, which till now have received little attention, are also discussed to facilitate future experimental investigations.

\subsubsection{General Requirement of SOFC anode}

The SOFC anode acts as a reaction site where anion oxidation of fuel catalyzed by anode materials occurs at or near the triple phase boundary (TPB) area. Electricity is generated through transfer of resulting electrons to interconnect materials. The electricity output voltage is given by [1]:

$$
\begin{aligned}
& \mathrm{V}_{\mathrm{c}}=\Delta \mathrm{E}_{\mathrm{e}}-\left|\eta_{\mathrm{c}}\right|-\left|\eta_{\mathrm{a}}\right|-\mathrm{IR}_{\mathrm{c}} \\
& \eta_{\mathrm{e}}=\eta_{\text {act }}+\eta_{\mathrm{conc}}
\end{aligned}
$$

In Eq.2.1, $\mathrm{V}_{\mathrm{c}}$ is the output voltage of the cell, $\Delta \mathrm{E}_{\mathrm{e}}$ the Nernst potential of the cell, $\eta_{\mathrm{c}}$ is the polarization loss of the cathode and $\eta_{\mathrm{a}}$ is the equivalent loss for the anode, and $\mathrm{IR}_{\mathrm{c}}$ is the ohmic polarization loss of the cell. In Eq.2.2, $\eta_{\mathrm{e}}$ is electrode polarization overpotential, consisting of activation and concentration overpotentials $\eta_{\text {act }}$ and $\eta_{\text {conc }}$. To complete the charge transfer required for reaction and electricity generation with low ohmic loss, the anode should be both ionically and electronically conductive. Also, the anode should be catalytically active to minimize polarization loss and promote electrooxidation $[2,11]$. This combination of needs can be satisfied by either using a metalceramic composite material (Metal Cermet) or a single phase mixed ionic-electronic conductor (MIEC). MIECs are receiving more attention in recent research since larger TPB area and better fuel sulfur tolerance can be achieved through tailorable electronic properties.[12,13].In particular, the n-type MIEC materials are electronically more 
suitable for the reducing anode environment. However, p-type MIECs could also serve as anode materials if the initial conductivity of materials is high enough [2]. To reduce the mass transfer overpotential, a porous structure is necessary for the anode. The anode material itself should be thermally and chemically stable in an impurity-containing fuel atmosphere for long term service, and at the same time it should be also chemically and mechanically compatible with electrolyte, cathode and other components in SOFC system.

\subsubsection{Degradation of SOFC anodes by sulfur poisoning}

Mechanistic investigation on sulfur poisoning of SOFC anode has received increasing research interests recently since clear understand of this issue is crucial for identifying specific mitigation solutions against degradation, including development of sulfurtolerant anodes. The performance loss of SOFC anodes in sulfur containing fuels can be attributed to: (1) Physical adsorption/ chemisorption of $\mathrm{H}_{2} \mathrm{~S}$ at surface active sites that lead to reduction of surface area for electrochemical reactions; (2) sulfidation of anode material due to reaction between sulfur and anode materials resulting in loss of catalytic activity, conductivity and stability However till now the reported mechanism and extent of degradation for different anodes vary with different operation atmosphere and concentration level of $\mathrm{H}_{2} \mathrm{~S}$.

\subsubsection{Conversion of $\mathrm{H}_{2} \mathrm{~S}$ at SOFC anode}

Conversion of $\mathrm{H}_{2} \mathrm{~S}$ during anodic process dominates its adverse effects on anode materials, as the sulfur poisoning of SOFC anode greatly depends upon the form and 
reactivity of sulfur species as product of conversion reactions. The reactions and their reversible potentials ${ }^{1}$ at $1000 \mathrm{~K}$ were given by literature [14] as:

$$
\begin{gathered}
\mathrm{H}_{2} \mathrm{~S}+3 \mathrm{O}^{2-} \leftrightarrow \mathrm{H}_{2} \mathrm{O}+\mathrm{SO}_{2}+6 \mathrm{e}^{-}\left(\mathrm{E}^{0}=+0.785 \mathrm{~V}\right) \\
\mathrm{H}_{2} \mathrm{~S}+\mathrm{O}^{2-} \leftrightarrow \mathrm{H}_{2} \mathrm{O}+\mathrm{S}+2 \mathrm{e}^{-}\left(\mathrm{E}^{0}=+0.761 \mathrm{~V}\right) \\
\mathrm{H}_{2} \mathrm{~S} \leftrightarrow \mathrm{H}_{2}+\mathrm{S} \\
\mathrm{S}+2 \mathrm{O}^{2-} \leftrightarrow \mathrm{SO}_{2}+4 \mathrm{e}^{-}\left(\mathrm{E}^{0}=+0.748 \mathrm{~V}\right) \\
\mathrm{H}_{2}+\mathrm{O}^{2-} \leftrightarrow \mathrm{H}_{2} \mathrm{O}+2 \mathrm{e}^{-}\left(\mathrm{E}^{0}=+0.998 \mathrm{~V}\right)
\end{gathered}
$$

At $1100 \mathrm{~K}, 8.6 \%$ of $\mathrm{H}_{2} \mathrm{~S}$ decomposed through reaction Eq.2.5 [14], and sulfur dioxide formed by Eq.2.3 and 2.6 may further react with excess $\mathrm{H}_{2} \mathrm{~S}$ to produce sulfur. Reaction Eq.2.3 and 2.6 are favorable for the purposes of sulfur tolerance of anodes since sulfur dioxide is considered less adverse for SOFC operation $\left(\mathrm{SO}_{2}\right.$ is more thermodynamically stable than $\mathrm{H}_{2} \mathrm{~S}$ and $\mathrm{S}$ ). Sulfur poisoning of anode can be mitigated by either control with electrochemical methods or application of materials inert to $\mathrm{H}_{2} \mathrm{~S}$ promoting the oxidation of $\mathrm{H}_{2} \mathrm{~S}$ into $\mathrm{SO}_{2}$. High utilization rate of fuel and/or excess $\mathrm{O}^{2-}$ at TPB sites increases the prominence of Eq.2.3 and 2.6 [8,9,14]. It was reported that when ratio $\mathrm{M}$ of $\mathrm{O}^{2-}$ surface flux and $\mathrm{H}_{2} \mathrm{~S}$ concentration reached unity, conversion of $\mathrm{H}_{2} \mathrm{~S}$ to $\mathrm{SO}_{2}$ was above 99\%[8]. $M$ was defined by Eq.2.8, where $I$ is the current, $F$ is Faraday's constant, $G$ is the total gaseous molar flow rate fed to the anode, and $y_{H 2 S}^{0}$ is the feed $\mathrm{H}_{2} \mathrm{~S}$ mole fraction.

$$
M=\frac{I}{6 F G y_{H_{2} S}^{0}}
$$

\footnotetext{
${ }^{1}$ The reversible potential at temperature $\mathrm{T}, \mathrm{E}^{\circ}$, is calculated from $\Delta \mathrm{G}^{\circ}$ for the reaction at that temperature [1].
} 
Hence sulfur tolerance of anode can be obtained by electrochemically introducing sufficient $\mathrm{O}^{2-}$ on anode site. This strategy is also borrowed in previous research on recovering poisoned fuel cell anodes by sulfur or coke $[15,16]$, during which an out electro-field was applied onto cell to electrochemically oxidize anode surface contaminates at different pulse rate according to poisoning level. However electrochemical control over oxidation of $\mathrm{H}_{2} \mathrm{~S}$ requires the SOFC system to run at low efficiency or even electrolytically [14], hence it may serve as an auxiliary solution for sulfur poisoning of SOFC anode. In the long run material modification and design is a more practical remedy for the above issues.

\subsubsection{Sulfur-poisoning degradation mechanism of Ni-based SOFC anode}

Ni-based cermet is the most popular anode in most SOFC systems due to its low cost, ease of fabrication and relative high electrochemical efficiency. However, the Ni-cermet consisting of $\mathrm{Ni}$ and yttria stabilized zirconia ceramic (Ni-YSZ) experience severe degradation in fuels containing only a few ppm of $\mathrm{H}_{2} \mathrm{~S}$ due to the high vulnerability of $\mathrm{Ni}$ to sulfur poisoning. The possible reactions of $\mathrm{Ni}$ with $\mathrm{H}_{2} \mathrm{~S}$ include physical adsorption (adsorption of molecular $\mathrm{H}_{2} \mathrm{~S}$ on Ni surface), chemisorption (dissociative adsorption of sulfur atom from $\mathrm{H}_{2} \mathrm{~S}$ ) and sulfidation according to different $\mathrm{H}_{2} \mathrm{~S}$ concentrations. The latter two can be summarized as $[4,9,17]$ :

$$
\begin{aligned}
\mathrm{H}_{2} \mathrm{~S}(\mathrm{~g}) \leftrightarrow & \mathrm{HS}_{\mathrm{ads}}+\mathrm{H}(\mathrm{g} / \mathrm{ads}) \leftrightarrow \mathrm{S}_{\mathrm{ads}}+\mathrm{H}_{2}(\mathrm{~g} / \mathrm{ads}) \\
& \mathrm{Ni}+\mathrm{H}_{2} \mathrm{~S} \leftrightarrow \mathrm{NiS}+\mathrm{H}_{2} \\
& 3 \mathrm{Ni}+\mathrm{xH}_{2} \mathrm{~S} \leftrightarrow \mathrm{Ni}_{3} \mathrm{~S}_{\mathrm{x}}+\mathrm{xH}_{2}
\end{aligned}
$$


Degradation mechanism of $\mathrm{Ni}$ anode based upon above reactions is determined by $\mathrm{H}_{2} \mathrm{~S}$ level in the fuel, operation temperature as well as cell current. The reported results of experimental and theoretical research on specific degradation mechanisms of $\mathrm{Ni}$-cermet anode throughout different operation conditions tend to vary with each other and do not yield a thorough understand of this issue till now.

\subsubsection{Degradation of Ni-cermet anode at low $\mathrm{H}_{2} \mathrm{~S}$ concentration level}

At low $\mathrm{H}_{2} \mathrm{~S}$ concentration in the fuel( typically below 20ppm), performance loss of SOFC happened under energetically unfavorable conditions for reactions Eq.2.10 and 2.11 at intermediate temperature [4,5], as reported $\mathrm{H}_{2} \mathrm{~S}$ concentration (a few ppm) leading to additional polarization was much lower than required level (1\%) for sulfide formation at $800^{\circ} \mathrm{C}$ [4]. Hence, sulfur adsorption is generally considered as the major cause for anode degradation in this case. However the prior research has not yet clarified the specific poisoning mechanism of SOFC anode under adsorbed sulfur. Studies conducted first by Matsuzaki and coworkers and later by researchers from the same group indicated that, as operation temperature decreased, the critical $\mathrm{H}_{2} \mathrm{~S}$ concentration for Ni-YSZ degradation decreased, while performance loss increased in the intermediate temperature range $\left(<850^{\circ} \mathrm{C}\right)$ for $\mathrm{H}_{2} \mathrm{~S}$ concentrations ranging from 0.2 to $20 \mathrm{ppm}[4,5]$. The poisoning effects became irreversible at low temperature due to a more stable adsorption state of sulfur on the Ni surface. This conclusion was confirmed in a more recent study of sulfur poisoning mechanism completed by Dr. Meilin Liu's group using 2 to $50 \mathrm{ppm}_{2} \mathrm{~S}$ at 700 to $900^{\circ} \mathrm{C}[18]$. Although similar cell test settings were used for above research, the observed power density drop of cells followed divergent kinetic routes during incipient 
and evolution stage of test, indicating further investigation is needed on anode structural evolution during sulfur poisoning process. The adsorption and poisoning effect of sulfur on Ni were further studied by Bartholomew and coworkers [19, 20]. Figure 2.1 shows the influence of $\mathrm{H}_{2} \mathrm{~S}$ 's partial pressure in hydrogen on coverage of nickel surface by $\mathrm{H}_{2} \mathrm{~S}$ $(\theta)[19]$. Plot with lower slope corresponds to a lower enthalpy according to the equation $R T \ln \left(P_{\mathrm{H} 2 \mathrm{~S}} / P_{\mathrm{H} 2}\right)=\Delta H-T \Delta S$ where $\Delta H$ is calculated based on $1 \mathrm{~mol} \mathrm{H}_{2} \mathrm{~S}$. Hence it is indicated that adsorbed sulfur was more stable than bulk sulfide at intermediate temperatures and $90 \%$ surface coverage may occur at $1000 \mathrm{~K}$ for a low $\mathrm{H}_{2} \mathrm{~S}$ concentration (10ppm).

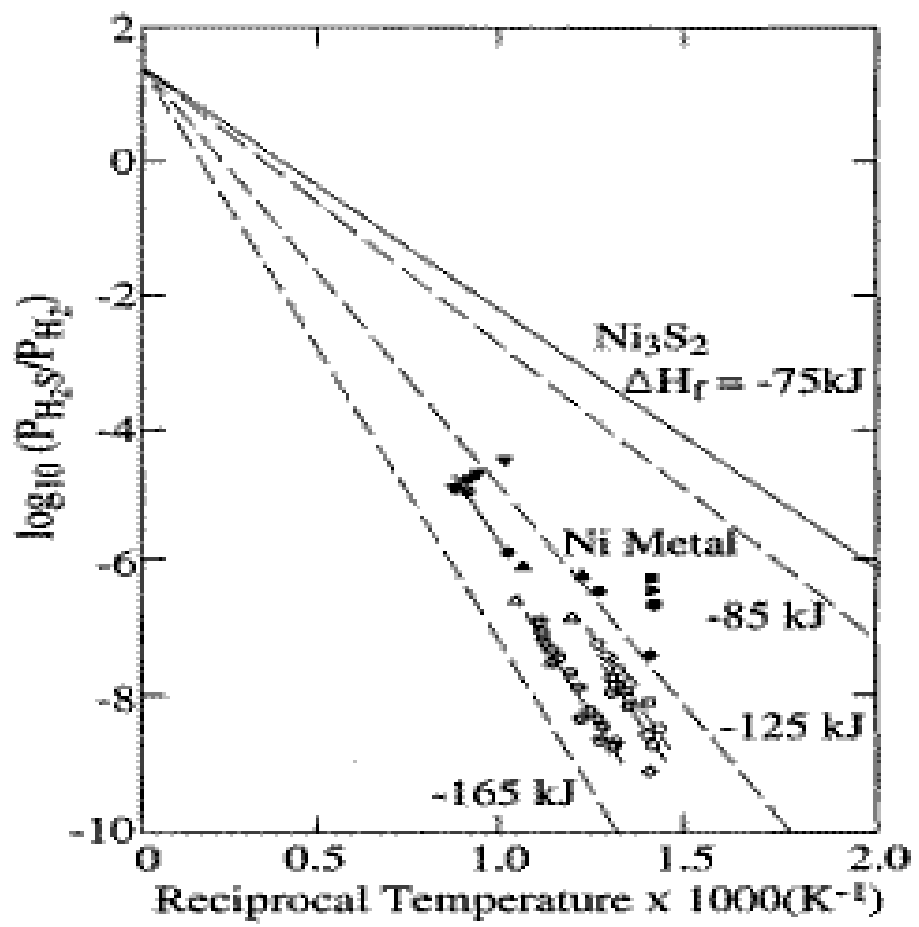

Figure 2.1. Equilibrium partial pressure of $\mathrm{H}_{2} \mathrm{~S}$ vs. reciprocal temperature (open symbols $\theta=0.5-0.6$; closed symbols, $\theta=0.8-0.9)[19](\theta$, coverage rate $)$

According to the research described above, a wide range of sulfur adsorption is energetically favorable during typical SOFC operation conditions and is thought to account for cell performance losses since sulfur-induced degradation becomes more 
remarkable at low temperature as adsorbed sulfur is more stable[4,5]. However, Barnett and coworkers reported that, when the Ni-YSZ anode was used with hydrogen containing $10 \mathrm{ppm} \mathrm{H}_{2} \mathrm{~S}$, cell performance was worse at $800^{\circ} \mathrm{C}$ as compared with $700^{\circ} \mathrm{C}$, which is contradictory to previous results[21]. Deviation of previous experimental study results on sulfur poisoning mechanisms indicates detailed investigation on $\mathrm{H}_{2} \mathrm{~S}$ 's reaction with $\mathrm{Ni}$ cermet is needed to gain a better understand of the issue. Recently computational molecular modeling methods including quantum chemistry and molecular dynamics have emerged as valuable tool to simulate interaction between $\mathrm{H}_{2} \mathrm{~S}$ and $\mathrm{Ni}$ at molecular level and determine material performance regarding sulfur tolerance [17,22]. Choi and coworkers implemented periodic density functional theory (DFT) calculation to study the adsorption of $\mathrm{H}_{2} \mathrm{~S}$ on $\mathrm{Ni}$ and $\mathrm{Cu}$ surface [17]. Dissociative adsorption of $\mathrm{H}_{2} \mathrm{~S}$ On $\mathrm{Ni}$ surface was found as the dominant adsorption mechanism with a adsorption energy of $1.75 \mathrm{ev}$ much lower than that of molecular adsorption $(-0.48 \mathrm{ev})$ Also copper is found much sulfur-tolerant than nickel due to a low adsorption energy of $\mathrm{H}_{2} \mathrm{~S}$ on $\mathrm{Cu}$ surface ( 0.0ev). The same method and molecular dynamics (MD) have been borrowed by Marquez and coworkers in a more targeted study on reaction betweens Ni-YSZ anode and gas-phase $\mathrm{H}_{2}$ and $\mathrm{H}_{2} \mathrm{~S}[22]$. Although presence of $\mathrm{H}_{2} \mathrm{~S}$ slows down oxidation of $\mathrm{H}_{2}$, the simulated adsorption and oxidation of $\mathrm{H}_{2}$ on Ni-YSZ are still more thermodynamically favorable than $\mathrm{H}_{2} \mathrm{~S}$. However only molecular adsorption was considered as adsorption pathway during the computation model. The current simulation of sulfur poisoning mechanism with DFT and MD methods provide alternative implementation of experimental results and guide for further material and test design, however for in-depth research refining of the computation model would need to take 
various operational factors into account and incorporate more data obtained from practical studies, and this may greatly complicate the simulating process.

\subsubsection{Degradation of $\mathrm{SOFC}$ anode at high $\mathrm{H}_{2} \mathrm{~S}$ concentration level}

For SOFCs operating with higher concentrations of $\mathrm{H}_{2} \mathrm{~S}$, formation of nickel sulfide on the anode surface appeared to account for the performance loss. J. Dong and coworkers detected $\mathrm{Ni}_{3} \mathrm{~S}_{2}$ by Raman spectroscopy on $\mathrm{Ni}-\mathrm{YSZ}$ anode exposed to $100 \mathrm{ppm}$ $\mathrm{H}_{2} \mathrm{~S}$ for 5 days [23]. Formation of sulfide was also found to account for a $10 \%$ power loss of Ni-GDC-YSZ anode running with $240 \mathrm{ppm}_{2} \mathrm{~S}$ at $850^{\circ} \mathrm{C}$ [10]. However even for such concentrations, the level of $\mathrm{H}_{2} \mathrm{~S}$ is not high enough for formation of stable sulfide according to thermodynamic calculations [23]. The contradiction between prediction and experimental results suggests that reactions between the anode and $\mathrm{H}_{2} \mathrm{~S}$ may be greatly influenced by surface-featured factors like morphology, particle size and exchange processes under the influence of the local electric field during actual SOFC operation. Therefore, the calculation of bulk materials under equilibrium conditions cannot accurately predict the surface reactions. However, degradation caused by sulfur adsorption at high concentrations should not be excluded since chemisorbed sulfur is still quite stable [20]. For other SOFC systems tested with very high concentration of $\mathrm{H}_{2} \mathrm{~S}$ (>1000ppm), degradation of the anode is mainly caused by chemical reactions between the anode material and sulfur, which often cause phase transformations of the anode structure and/or delamination of anode layers [24,25]. However, anode composition can be tailored to produce a sulfide with considerable conductivity and stability to prevent any further degradation [26]. 


\subsubsection{Sulfur tolerant anode materials for SOFC application}

The screening criteria and testing parameters for sulfur-tolerant materials tend to vary from cell to cell based on the fuel composition and anode reactions. Thiospinel and metal sulfides of good conductivity were first examined as sulfur tolerant anodes $[7,27]$. These materials show both catalytic activity toward $\mathrm{H}_{2} \mathrm{~S}$ oxidation and stability in a $\mathrm{H}_{2} \mathrm{~S}$-rich fuel environment. However, potential stability and catalytic activity issues limit composite sulfides applications in SOFC systems with conventional fuels. Hence, further efforts have been made to improve the sulfur tolerance of traditional metal-cermet anodes and develop new oxide anodes with sufficient catalytic activity for $\mathrm{H}_{2}$ oxidation, redox stability and resistance towards sulfur impurities.

\subsubsection{Thiospinels and metal sulfides}

Thiospinel sulfides were first applied as electrocatalytic anodes for $\mathrm{H}_{2} \mathrm{~S}$ oxidation by Pujare and coworkers on a $\mathrm{H}_{2} \mathrm{~S} /$ air fuel cell [7]. The observed initial OCP of $1.04 \mathrm{~V}$ at $900^{\circ} \mathrm{C}$ for the cell using $\mathrm{CuFe}_{2} \mathrm{~S}_{4}$ as the anode material was much higher than the theoretical OCPs for reactions of Eq. 2.3 and 2.4. Hence, decomposition of $\mathrm{H}_{2} \mathrm{~S}$ into $\mathrm{H}_{2}$ and a subsequent oxidation of $\mathrm{H}_{2}$ were concluded as the possible reaction pathways on the anode. The authors also proposed that a sulfur tolerance of thiospinel oxide could be obtained by reaching equilibrium in the following reaction at the anode [7]:

$$
\mathrm{A}_{2} \mathrm{BO}_{4}+4 \mathrm{H}_{2} \mathrm{~S} \leftrightarrow \mathrm{A}_{2} \mathrm{BS}_{4}+4 \mathrm{H}_{2} \mathrm{O}
$$


Such strategy was also borrowed in the development of other sulfur tolerant materials [26]. During another detailed investigation performed later by the same group [27],. $\mathrm{NiFe}_{2} \mathrm{~S}_{4}, \mathrm{WS}_{2}$, and $\mathrm{CuCo}_{2} \mathrm{~S}_{4}$ were identified as the most active anode electrocatalysts. The exchange current density $\left(\mathrm{i}_{0}\right.$ ) reached a peak value for a fuel containing $50 \% \mathrm{H}_{2} \mathrm{~S}$ at $900^{\circ} \mathrm{C}$, and increased as the $\mathrm{H}_{2}$ composition ascended from $0.5 \%$ to $2 \%$. Hence, the researchers identified oxidation of hydrogen from the reaction of Eq.2.5 as the dominant reaction on the thiospinel anode, while direct $\mathrm{H}_{2} \mathrm{~S}$ oxidation was the second most favorable reaction. These reports show the potential utility of thiospinel materials as the anode in fuel cells with $\mathrm{H}_{2} \mathrm{~S}$-rich fuels. Since both material analysis and performance versus time tests were absent in the study, electrocatalytic features and stability of thiospinel materials needs further examination for SOFC with higher $\mathrm{H}_{2} / \mathrm{H}_{2} \mathrm{~S}$ ratio in fuels.

Metal sulfides $\mathrm{WS}_{2}, \mathrm{CoS}_{2}$ and lithium cobalt oxide $\mathrm{LiCoO}_{2}$ were also chosen as anode materials in $\mathrm{H}_{2} \mathrm{~S}$ oxidation fuel cells to improve performance [3,28]. Degradation of $\mathrm{CoS}_{2}$ into $\mathrm{CoS}_{1.035}$ was found responsible for anode degradation after only 1 hour of operation. $\mathrm{WS}_{2}$ and $\mathrm{Li} / \mathrm{Co}$ oxide anodes were more stable and active, yet the testing time was rather short ( $36 \mathrm{~h}$ ) and $\mathrm{Li}_{2} \mathrm{~S} / \mathrm{CoS}_{1.035}$ was found on the anode after testing. The power density of the $\mathrm{Li} / \mathrm{Co}$ based cell with a thin film electrolyte reached $400 \mathrm{~mW} / \mathrm{cm}^{2}$, which is the highest for $\mathrm{H}_{2} \mathrm{~S} /$ air fuel cells to date. The results did not clarify whether process of Eq.2.3 or 2.4 was the major anode reaction. A time-dependent performance decrease was also observed possibly due to oxygen leakage or anode delamination. Liu and coworkers examined several composite sulfides as $\mathrm{H}_{2} \mathrm{~S}$ oxidation anode materials [28]. They found that the addition of $\mathrm{Fe}, \mathrm{Co}$, or $\mathrm{Ni}$ into $\mathrm{MoS}_{2}$ reduced the sulfide volatility at high 
temperature and maintained high activity comparable to the activity of Pt anodes, which was attributed to the additives being promoter atoms for anode reactions. Further study indicated addition of $\mathrm{Ag}$ instead of Pt into the anode layer resulted in higher performance and longer service life due to an improved contact of Ag with M-Mo-S [29]. The electrocatalytic reaction on anode and stability in hydrogen-rich fuels still needs to be clarified for sulfur-tolerant application of metal sulfides in SOFC. And control of reactions between other fuel components and anode materials to achieve the desired long term stability also remains an unclear issue.

\subsubsection{Metal cermets}

Direct modification of traditional Ni-YSZ cermet by composition tailoring offers a comparatively simple and effective method for achieving sulfidation resistance up to a few hundred or even thousand of ppm of $\mathrm{H}_{2} \mathrm{~S}$. This policy can be completed by a partial or total substitution of Nickel with more sulfur tolerant alloy constituent like copper, and/or a replacement of YSZ by electrolyte materials with higher ionic conductivity and stability during $\mathrm{H}_{2} \mathrm{~S}$-containing fuels. A balance between electrochemical performance and stability could be achieved during anode modification by material selection.

SSZ as the anode component--Scandia-doped zirconia oxide (SSZ) was reported to possess the highest conductivity among zirconia based electrolytes [30]. Substitution of YSZ with SSZ as electrolyte resulted in a remarkable output voltage rise of Ni-YSZ anode in $5 \mathrm{ppm} \mathrm{H}_{2} \mathrm{~S}$ at $800^{\circ} \mathrm{C}$ [4]. Sulfur tolerance of anode in $100 \mathrm{ppm}_{2} \mathrm{~S}$ with low output voltage loss was obtained by simultaneously substituting YSZ with SSZ as both electrolyte and anode component. Therefore increase of ionic conductivity tended to 
improve sulfur tolerance of Ni-cermet anode. In the same research, partial replacement of Ni by impregnating selected elements or oxides into Ni-YSZ anode was also found to suppress sulfur poisoning effects (Fig.2.2). However, both anode performance after impregnation and the sulfur tolerant mechanism were not experimentally investigated. Another problem with this material is the high cost of SSZ that limits its wide application as a sulfur-tolerant component.

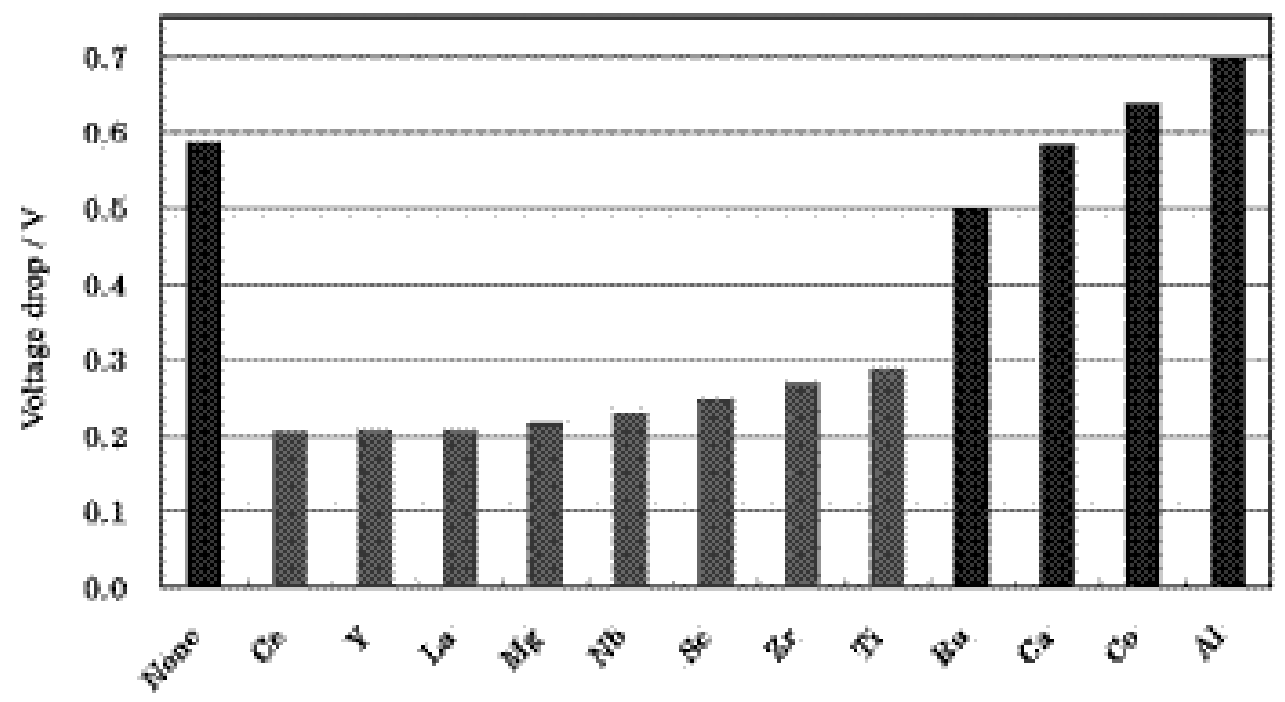

Figure 2.2. Cell voltage drop with various additives impregnated in porous anode at 200 $\mathrm{mA} / \mathrm{cm}^{2}\left(800^{\circ} \mathrm{C}, \mathrm{H} 2 \mathrm{~S}\right.$ conc. $=20 \mathrm{ppm}, \mathrm{H}_{2} / \mathrm{CO} 100: 0$, electrolyte/ SSZ, anode/Ni-YSZ + impregnated additives.)[4]

Ceria and doped ceria oxides--Doped or undoped ceria oxides are commonly applied as sulfur-tolerant components in metal cermet anodes due to good performance and lower cost relative to available alternatives. $\mathrm{CeO}_{2}$ is widely used in sulfur removal processes and adds coking resistance in catalytic processes [31,32], Copper $(\mathrm{Cu})$ also resists coking formation and sulfur adsorption better than $\mathrm{Ni}[33,34]$. Combined application of $\mathrm{Cu}$ and $\mathrm{CeO}_{2}$ in the $\mathrm{Cu} / \mathrm{CeO}_{2} / \mathrm{YSZ}$ anode introduces both high sulfur tolerance (as shown in Fig.2.3) and good electro-catalytic performance [33,35,36,37]. 


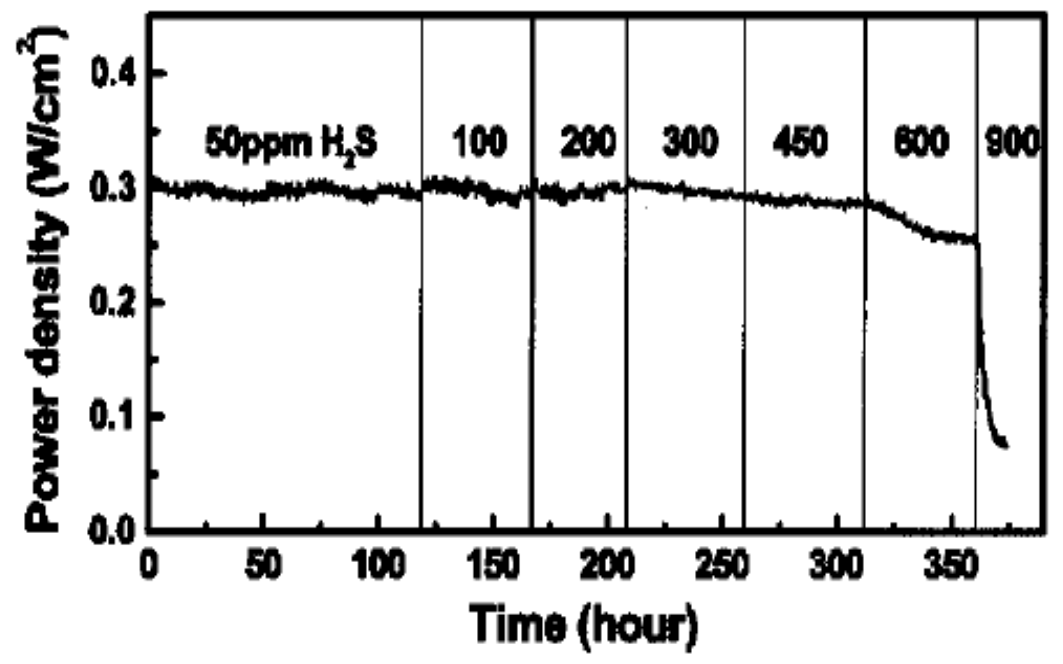

Figure 2.3 Performance of a $\mathrm{Cu} / \mathrm{CeO}_{2} / \mathrm{YSZ}$ SOFC as a function of time. (800C, cell voltage $=0.65 \mathrm{v}$, fuel composed of $\mathrm{H}_{2}+\mathrm{H}_{2} \mathrm{O}(10 \%)+\mathrm{H}_{2} \mathrm{~S}$. $)[37]$

In addition to aiding in electrochemical functions, $\mathrm{CeO}_{2}$ also directly acts as an oxidation catalyst for $\mathrm{CH}_{4}$ in anode reforming applications [30]. When used together with $\mathrm{Ni}$ to form a cermet anode, $\mathrm{CeO}_{2}$ also clearly suppresses the sulfur poisoning of the $\mathrm{Ni}$, which indicates that $\mathrm{CeO}_{2}$ effectively acts as a $\mathrm{H}_{2} \mathrm{~S}$ absorbent in fuel cells [31]. Degradation of a $\mathrm{CeO}_{2}$ anode is linked with the formation of ceria oxysulfide $\left(\mathrm{Ce}_{2} \mathrm{O}_{2} \mathrm{~S}\right)$ $[30,31,32]$. Although the thermodynamic diagram for Ce-O-S indicates that the critical $\mathrm{H}_{2} \mathrm{~S}$ level for formation of $\mathrm{CeO}_{2} \mathrm{~S}_{2}$ is approximately $450 \mathrm{ppm}$ at $800^{\circ} \mathrm{C}[37]$, the ceria oxide anode maintains sulfur tolerance up to $900-5000 \mathrm{ppm}_{2} \mathrm{~S}[35,36,37]$, while $\mathrm{Ce}_{2} \mathrm{O}_{2} \mathrm{~S}$ is observed on a $\mathrm{Ni}-\mathrm{CeO}_{2}$ anode in a molten carbonate fuel cell running at $650^{\circ} \mathrm{C}[31]$. One explanation of the inconsistent results is a partial reduction of $\mathrm{CeO}_{2}$ to $\mathrm{CeO}_{2-\mathrm{n}}$ occurring during operational conditions. The product $\mathrm{CeO}_{2-\mathrm{n}}$ is highly reactive with $\mathrm{H}_{2} \mathrm{~S}$, resulting in formation of $\mathrm{Ce}_{2} \mathrm{O}_{2} \mathrm{~S}$ [31]:

$$
2 \mathrm{CeO}_{2-\mathrm{x}}(\mathrm{s})+\mathrm{H}_{2} \mathrm{~S}(\mathrm{~g})+(1-2 \mathrm{x}) \mathrm{H}_{2}(\mathrm{~g}) \leftrightarrow \mathrm{Ce}_{2} \mathrm{O}_{2} \mathrm{~S}(\mathrm{~s})+2(1-\mathrm{x}) \mathrm{H}_{2} \mathrm{O}(\mathrm{g})(\mathrm{x}<0.5)
$$


It can be assumed that a full range transformation of $\mathrm{CeO}_{2}$ occurring at high level of $\mathrm{H}_{2} \mathrm{~S}$ may account for a catastrophic degradation of the anode. However, random electrochemical modification of surface composition of ceria oxide may also compromise the prediction based on thermo-equilibrium data. The successful strategy of $\mathrm{Cu}$-Ceria anode is difficult to apply in other SOFC systems operating at higher temperatures and with hydrogen rich fuels, because the operation temperature for $\mathrm{Cu}$ anode should be kept relatively low $(<700 \mathrm{C})$ to prevent agglomeration of $\mathrm{Cu}$ particles. And both $\mathrm{Cu}$ and $\mathrm{CeO}_{2}$ have poor catalytic activity for hydrogen oxidation.

Ceria oxides with lanthanum series dopants have been used in the Ni-based anode. Compared with ceria oxide, doped ceria oxide exhibits approximately two orders-ofmagnitude higher ionic conductivity due to extra oxygen vacancies introduced by doping with low valent ions[38], and maintains good stability against $\mathrm{H}_{2} \mathrm{~S}$ plus considerable catalytic activity for oxidizing $\mathrm{H}_{2}$. Gadolinium-doped ceria (GDC) and samarium-doped ceria (SDC) were chosen in cermet anodes due to higher conductivity arising from similarity of $\mathrm{Gd}^{3+}, \mathrm{Sm}^{3+}$ and $\mathrm{Ce}^{4+}$ on ion radius [38]. The Ni-doped ceria anodes with different Ni contents exhibit both higher performance with practical fuels and remarkable sulfur tolerance compared to the Ni-YSZ anodes. The enhanced performance is attributed to enlargement of reactive sites [10,39]. $\mathrm{A} \mathrm{H}_{2} \mathrm{~S}$ concentration of $9 \mathrm{ppm}$ in fuel was found to have no effect on performance of $\mathrm{Ni}-\mathrm{Gd}_{0.1} \mathrm{Ce}_{0.9} \mathrm{O}_{2.95}$ anode after $1.5 \mathrm{~h}$ operation [39]. A similar anode suffered $10 \%$ performance loss after operating with 200$240 \mathrm{ppm} \mathrm{H}_{2} \mathrm{~S}$ for $650 \mathrm{~h}[10]$. Material surface analysis by XPS indicated both loss of $\mathrm{Ni}$ and gain of sulfur after operation, while the concentration of $\mathrm{Ce}$ and $\mathrm{Gd}$ remained constant. This result showed degradation caused by formation of nickel sulfide and the 
promising stability of GDC. However, doped ceria may not be effective sulfur absorbent as ceria oxide. The presence of more $\mathrm{O}^{2-}$ in the anode layer rather than reactivity with $\mathrm{H}_{2} \mathrm{~S}$ seems to contribute more to doped ceria's sulfur tolerance, since $\mathrm{Ni}$ in Ni-SDC was

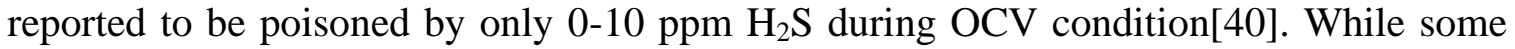
active sites of nickel were blocked, doped ceria can still electro-oxidize $\mathrm{H}_{2}$ with covered $\mathrm{Ni}$ as current collector [39].

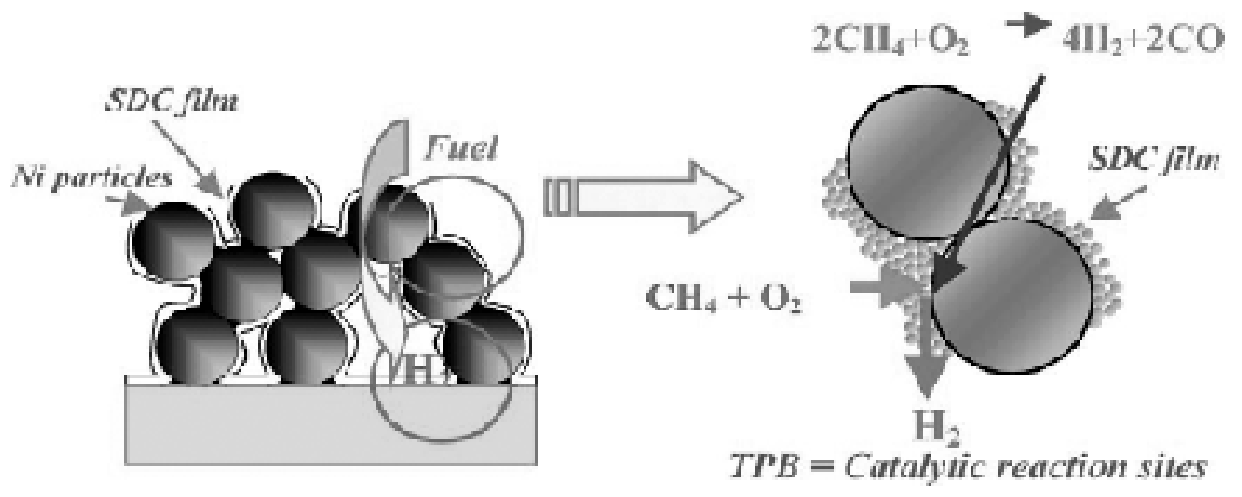

Figure 2.4. Schematic illustration of anode microstructure coated with SDC sol [42]

Although the presence of a large amount of doped ceria in the anode may result in further improvement of electrochemical kinetics and sulfur tolerance, a balance between output performance and stability needs to be kept. Excess content of ionic conductor with low electronic conductivity in the anode compromises the electron transfer capability of the anode by increasing the polarization overpotential and activation energy for $\mathrm{H}_{2}$ oxidation $[41,42]$. The reported upper limit of YSZ content is typically $30 \%-40 \%$ for the nickel cermet, while $10 \%$ content of GDC in the cermet was found optimal for electrochemical performance [41]. With respect to sulfur tolerance, replacing more $\mathrm{Ni}$ with ionic conductive ceramics in the anode without incurring remarkable polarization resistance can be achieved by the following methods: preparing an anode microstructure with well dispersed different phases[42,43,44]; and using electronically conducting 
ceramics as the conductive phase at the same time[45]. Suitable anode microstructures are fabricated by impregnation or surface modification with oxide agents (Figure 2.4) $[42,43]$. This method provides a larger TPB area with the same or smaller amount of doped ionic oxide, and it results in reduced polarization resistance through improving anode morphology and contact between different phases. The second method usually introduces a perovskite ceramic as electronic conductive phase to reduce interfacial polarization resistance between different anode components, while a small amount of $\mathrm{Ni}$ can be kept as the catalyst in the anode [45]. There are few reports until now about the influences of content and distribution of ionic oxides in the anode on sulfur tolerance and consequent performance of the anode. This area still requires research to provide insight towards the sulfur poisoning and sulfur-tolerant mechanisms taking place in these anode materials. However, it can be assumed that the presence of an ionic phase with a consequent large amount of $\mathrm{O}^{2-}$ may help in removing sulfur in the form of $\mathrm{SO}_{2}$, as suggested by earlier research [8], and/or limiting sulfur content's adverse interaction with oxidation catalyst inside the anode.

\subsubsection{Mixed ionic and electronic conductor (MIEC)}

Ceramics with both ionic and electronic conductivity at high temperature and in a reducing environment have received increasing interest in recent years on their application as SOFC anodes or anode components due to a combination of the following points[2]: (1) reduced interfacial polarization resistance by expanding reaction sites to the whole anode; (2) relatively good compatibility with high-quality electrolytes; mechanical stability during long term service without expansion of metal components; and (3) higher 
sulfur tolerance compared to metal components. Therefore, considerable effort has been devoted to developing various MIEC anode materials for the application on fuel-flexible SOFC with sulfur tolerance.

Perovskite materials for sulfur tolerance----MIEC oxides with perovskite structures have drawn significant interest during the development of high performance sulfur tolerant anode materials. The $\mathrm{ABO}_{3}$ structure of perovskite has been found to be less reactive with $\mathrm{H}_{2} \mathrm{~S}$ than the Ni-based anode [46]. The capacity of the perovskite structure to accommodate vacancy and stoichiometric deviation allows doping of various ions with different oxidation states to either enhance conductivity and catalytic activity of sulfur tolerant ceramics or to augment stability in a ceramic with promising electrochemical performance. Doping of small valent cations on the A-site results in an ionic conductivity increase in a reducing environment. Selected $4 d$ or $5 d$ transition ions with multiple valences are preferable components for the B-site, since additional conductivity can be introduced by releasing electrons which either hop between mixed valent cations or which occupy the conduction band. To date, several perovskite materials have been examined for application as sulfur-tolerant anodes $[6,24,26,40,46,47,48,49,50,51]$. However, few reported perovskite anodes simultaneously display both good sulfur tolerance and catalytic activity for $\mathrm{H}_{2}$ oxidation equivalent to the catalytic activity of $\mathrm{Ni}$ doped ceria or Ni-YSZ anodes. In addition, there is limited research on the sulfur tolerance mechanism of such materials.

Cr-based perovskite anodes----Originally used as an interconnect material, the strontium doped lanthanum chromate (LSC) recently has been modified to be used as methane oxidation anodes due to their better stability than the Ni anode. During 
preparation of LSC, a 20\%-25\% doping of $\mathrm{Sr}$ on the A-site is found necessary for keeping TEC close to the electrolyte and for maintaining a low activation energy required for ionic conductivity[52]. A 3\% doping of $\mathrm{V}$ on the B-site does improve the sinterability of LSC $[53,54]$. However, the conductivity of LSC is rather low in a reducing environment. Transition metal cations have been doped on the B-site to improve conductivity and catalytic activity. Since $\mathrm{Cr}$ has strong hexagonal coordination with oxygen deficiency[55], introducing cations with lower coordination number, like $\mathrm{Mn}, \mathrm{Co}, \mathrm{Fe}, \mathrm{Ni}$, to the material has been shown to improve catalytic activity by improving ionic conductivity[50, 56 ]. $\left(\operatorname{La}_{0.75} \mathrm{Sr}_{0.25}\right)_{0.9} \mathrm{Cr}_{0.5} \mathrm{Mn}_{0.5}$ (LSCM) with the Mn dopant exceeding percolation level (33\%) was reported to have comparable performance as the Ni-YSZ anode with $\mathrm{H}_{2}$ and methane as fuel [50]. Both LSC and LSCM have been tested for sulfur-tolerant applications[24,46].The results, however, indicated that sulfur tolerance of materials decreases as Mn content increased, while the opposite trend is found for anode performance. A $20 \%$ Mn doping doubled the voltage loss of a LSCM anode in $\mathrm{H}_{2}$ with 1000 ppm $\mathrm{H}_{2} \mathrm{~S}$. In humidified $\mathrm{H}_{2}$ with $10 \% \mathrm{H}_{2} \mathrm{~S}$, performance of $\mathrm{La}_{0.75} \mathrm{Sr}_{0.25} \mathrm{Cr}_{0.5} \mathrm{Mn}_{0.5}$ was reported to degrade rapidly after exposure under open circuit for $16 \mathrm{~h}[18]$. This behavior was attributed to enhancement of poisoning effects by $\mathrm{MnS}$ and $\mathrm{La}_{2} \mathrm{O}_{2} \mathrm{~S}$ impurity phases present during exposure, which were also shown in Fig.2.5 where XRD results of LSCM anodes exposed in similar atmosphere for 5 days indicated that higher Mn content in LSCM anodes could enhance formation of such phases. Although the test was under quite severe conditions, earlier research conducted with 100 ppm $\mathrm{H}_{2} \mathrm{~S}$ still indicated a comparatively low sulfur tolerance of the material with even low levels of Mn doping [46]. The low sulfur tolerance may be due to the lack of stability 
of strontium doped lanthanum manganese (LSM) in a reducing environment. Therefore, composition optimization is required for such materials to be an effective sulfur tolerant anode with high electrochemical performance at the same time.

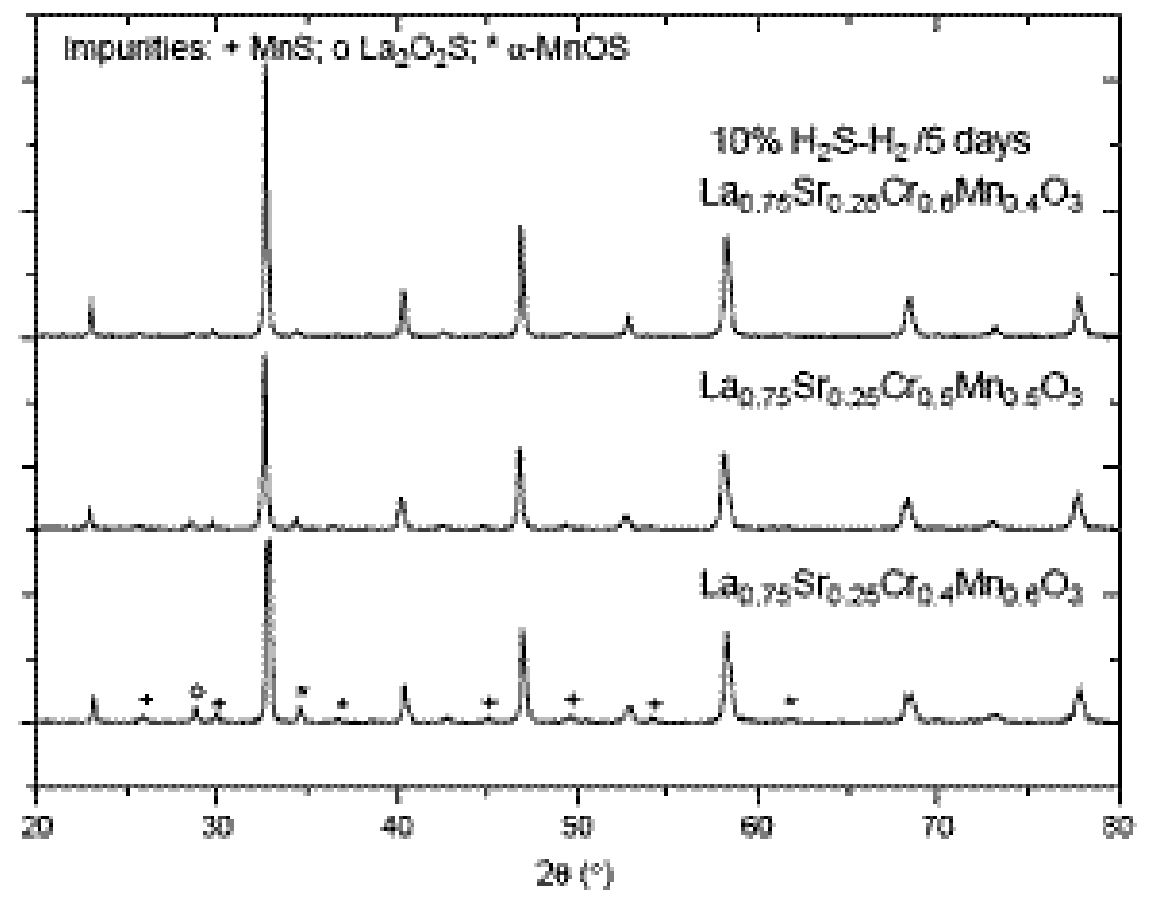

Figure 2.5.XRD patterns of LSCMs after being exposed to humidified $\mathrm{H}_{2}$ containing $10 \%$ $\mathrm{H} 2 \mathrm{~S}$ at $950^{\circ} \mathrm{C}$ for 5 days [24].

Ti-based perovskite anode ---- Lanthanum-doped strontium titanate (LST) has received concentrated research interests for the SOFC anode due to its stability in reducing environments and comparatively high electric conductivity among available perovskite materials. LST also has less volume change during redox cycling compared with chromites and other perovskites [57]. Replacement of $\mathrm{Sr}$ with $\mathrm{La}$ in $\mathrm{SrTiO}_{3}$ introduces partial transformation of $\mathrm{Ti}^{3+}$ to $\mathrm{Ti}^{4+}$ through charge compensation and n-type conductivity during reducing atmosphere. The defect equilibrium is given as [2]:

$$
2 \mathrm{Oo}^{\mathrm{x}}+4 \mathrm{Ti}_{\mathrm{Ti}_{\mathrm{i}}^{\mathrm{x}}}^{\mathrm{x}}----2 \mathrm{Vo}^{*}+4 \mathrm{Ti}_{\mathrm{Ti}}{ }^{\prime}+\mathrm{O}_{2}
$$


Conductivity of doped titanate reaches a peak value of $360 \mathrm{~S} / \mathrm{cm}$ at $1000^{\circ} \mathrm{C}$ when the occupancy of lanthanum approaches 0.4 in the A-site [57]. Despite the high electric conductivity and nominal oxygen over-stoichiometry, LST does not show comparable electro-catalytic performance for hydrogen oxidation as Ni-cermet anodes and LSCM. Improvement of electro-catalytic activity of LST has been studied in terms of: doping with various transition ions onto the B-site [13,58]; low-level doping on B-site to modify defect chemistry [59]; and using the ionic conductive phase to form a composite layer [60].

Performances and sulfur tolerances of different pervoskite anodes have been compared in fig.2.6 in terms of output power change and power density. Undoped $\mathrm{La}_{0.4} \mathrm{Sr}_{0.6} \mathrm{TiO}_{3}$ has proven to be much more resistant to sulfur poisoning than chromites perovskites [46]. However, the effects of $\mathrm{H}_{2} \mathrm{~S}$ on anode performance vary for different levels of $\mathrm{H}_{2} \mathrm{~S}$ at different temperatures. For LST anodes, Mukundan and coworkers' reported that at $1000^{\circ} \mathrm{C}$, the anode overpotential first degraded slightly by $6 \%$ as $\mathrm{H}_{2} \mathrm{~S}$ content increased from $10 \mathrm{ppm}$ to $100 \mathrm{ppm}$ [46]. As $\mathrm{H}_{2} \mathrm{~S}$ increased to $5000 \mathrm{ppm}$, anode performance was recovered and further improved by $20 \%$ during $24 \mathrm{hrs}$ as indicated in fig 2.6. 


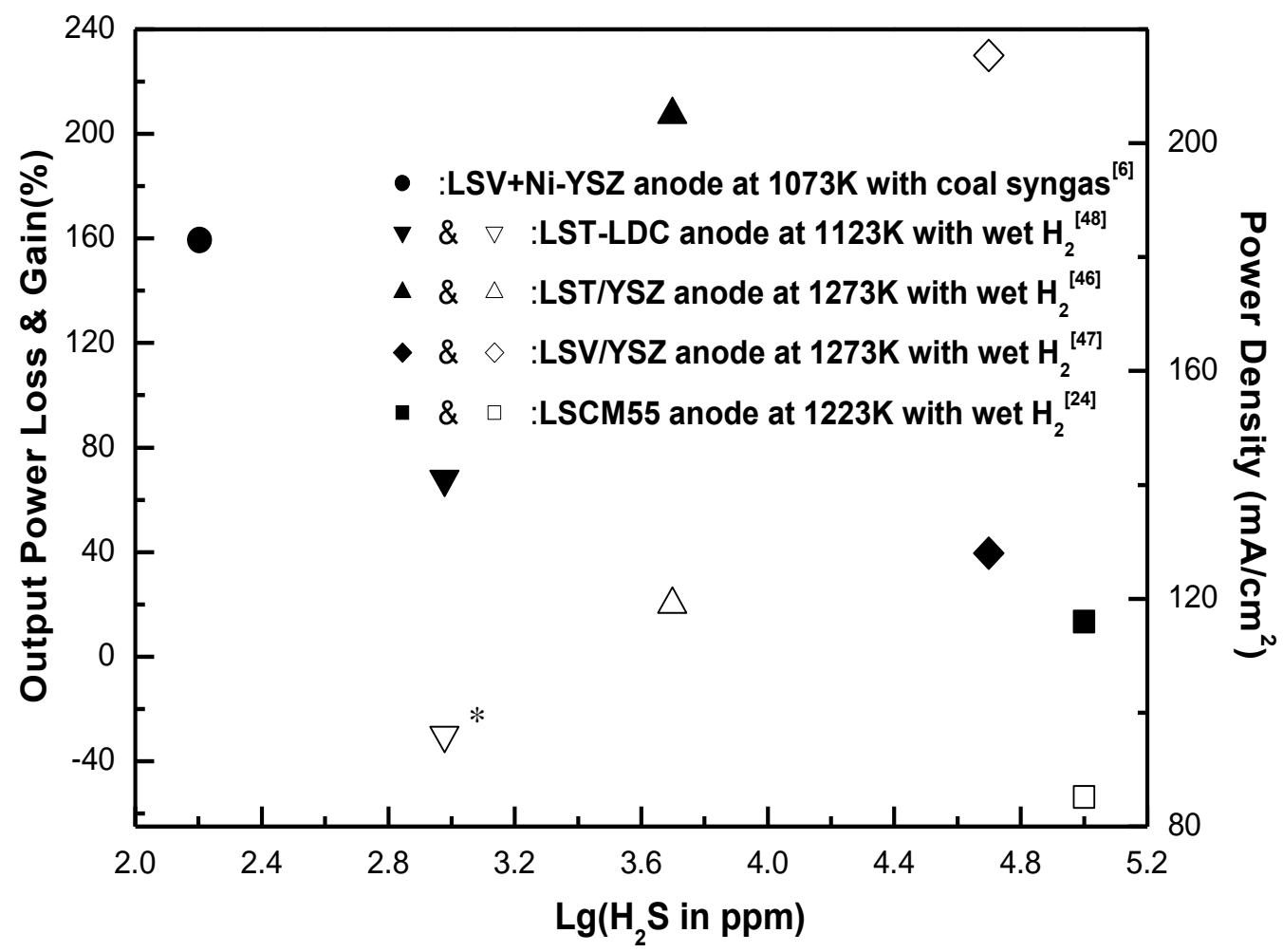

Figure 2.6 Performance of sulfur tolerance anodes for different H2S concentration under various conditions. ( $^{*}$ the initial performance was recovered after $700 \mathrm{~h}$; open symbols for output change; closed symbols for power density).

Examination of the anode exhaust gas indicated an increase of $\mathrm{H}_{2} \mathrm{O}$ content without trace $\mathrm{SO}_{2}$, which may be consumed by excess $\mathrm{H}_{2} \mathrm{~S}$ to produce elemental sulfur. During a different test, an anode of a two-phase structure consisting of $(\mathrm{La}) \mathrm{SrTiO}_{3}$ and $(\mathrm{La}) \mathrm{CeO}_{2}$ mixed oxides suffered instant performance losses [60], which increased as $\mathrm{H}_{2} \mathrm{~S}$ content rose from $280 \mathrm{ppm}$ to $950 \mathrm{ppm}$ at $850^{\circ} \mathrm{C}$, and maintained a stable performance afterward for a long period $\left(500 \mathrm{~h}\right.$ ) before being recovered by removing the $\mathrm{H}_{2} \mathrm{~S}$ from the fuel. An irreversible performance drop of $18 \%$ occurred at $850^{\circ} \mathrm{C}$ for fuels with $50 \% \mathrm{H}_{2}$ and 1000 ppm $\mathrm{H}_{2} \mathrm{~S}$. Accordingly, a linear increase of overpotential resistance with $\mathrm{H}_{2} \mathrm{~S}$ content was found in contrast to the previous test on an LST/YSZ anode. Sulfates were found on the anode after testing, which was a sign of apparent transformation of surface sulfides into 
sulfates during operation. No analysis and explanation has been made regarding the different results in terms of effects of test set-up and phase influences. The superior performance of the LST anode may be ascribed to the high test temperature $\left(950^{\circ} \mathrm{C}\right)$, under which a significant amount of $\mathrm{H}_{2} \mathrm{~S}$ may decompose to $\mathrm{H}_{2}$ and $\mathrm{S}$ (8.6\% for decomposition rate at $850^{\circ} \mathrm{C}$ [14] and compensate the adverse effect of $\mathrm{H}_{2} \mathrm{~S}$ on the anode due to a higher $\mathrm{H}_{2} / \mathrm{H}_{2} \mathrm{~S}$ ratio. The anode performance was thus improved during higher level of $\mathrm{H}_{2} \mathrm{~S}$. However, for the second study conducted at lower temperature $\left(800^{\circ} \mathrm{C}\right)$ [48], decomposition of $\mathrm{H}_{2} \mathrm{~S}$ in a low amount may be not enough to compensate for the poisoning effect under a lower $\mathrm{H}_{2} / \mathrm{H}_{2} \mathrm{~S}$ ratio, which was confirmed by the research result. Since an earlier study by researchers from the same group found that an improvement of electrochemical performance of the LST-LDC anode was mainly due to the ceria phase[60], it may be assumed that an enhancement of surface $\mathrm{O}^{2-}$ concentration caused by ceria will help the oxidation of surface sulfides and enhance the sulfur tolerance of LST. Hence, further work is needed to investigate sulfur tolerance mechanisms of the LST anode.

Two recent studies have been successful on promoting the catalytic performance of LST through low-level doping of Mn and Ga and over-percolation doping of Mn on the B-site [58,59]. Inflexible octahedral coordination of the Ti cation greatly limits the concentration of mobile oxygen defects inside the material [59]. Addition of a small amount of transition cations $(<8 \%)$ with lower oxygen coordination numbers (e.g., Mn and $\mathrm{Ga}$ ) was found to significantly enhance ionic conductivity and performance of the anode. Another strategy is to use $\mathrm{Mn}$ as the normal dopant of $\mathrm{B}$-site for $\mathrm{La}_{0.4} \mathrm{Sr}_{0.6} \mathrm{TiO}_{3}[58]$. Substituting $\mathrm{Ti}^{4+}$ with $\mathrm{Mn}^{3+}$ introduces both extra oxygen vacancies and $\mathrm{Mn}^{4+}$ through a 
compensation shift. The reducibility of $\mathrm{Mn}^{4+}$ helps to increase the ionic conductivity. Ptype conductivity is also introduced by doping Mn beyond the 20 atom \% level. The presence of Mn proved to be favorable for promoting the electro-catalytic activity of LST. However, considering Mn's tendency to react with $\mathrm{H}_{2} \mathrm{~S}$ in a reducing environment, element tailoring may need to be applied to maintain LST's sulfur resistance while obtaining an improved performance of LSTM.

Lanthanum Vanadate----Sulfur tolerant anode materials based on strontium doped lanthanum vanadate $\left(\mathrm{La}_{1-\mathrm{x}} \mathrm{Sr}_{\mathrm{x}} \mathrm{VO}_{3}\right)$ were recently developed by researchers at Georgia Tech. Substituting La with Sr beyond 20\% was found to endow LSV with a high n-type conductivity(60-800 S/cm) due to a metal-insulator(M-I) transition occurring between 196 and $527^{\circ} \mathrm{C}[61]$. LSV also has an improved oxygen partial pressure stable range $\left(10^{-}\right.$ ${ }^{14}-10^{-20}$ atm) compared with that of $\mathrm{SrVO}_{3}$ due to stabilization of $\mathrm{V}^{3+}$ inside perovskite structure [49]. However, redox stability is still a potential problem for LSV. Formation of $\mathrm{V}^{5+}$ valence usually occurs during the oxidation process of vandanates, which may lead to collapse of perovskite structure and formation of insulator phases such as $\mathrm{Sr}_{3} \mathrm{~V}_{2} \mathrm{O}_{8}[49,61]$. Hence, careful control of oxidation and operation is needed for LSV to function as a stable anode. LSV has good stability in the $48 \mathrm{~h}$ testing period and superior performance with high $\mathrm{H}_{2} \mathrm{~S}$ concentration in fuels (5\%-10\%), while performance with pure $\mathrm{H}_{2}$ or hydrocarbons as fuel is relatively low [47,62]. No further report is presented on the selective catalytic characteristics of LSV towards $\mathrm{H}_{2} \mathrm{~S}$ oxidation rather than $\mathrm{H}_{2}$ oxidation. One proposed explanation, based on thermodynamic prediction without experimental confirmation, was that $\mathrm{SrVO}_{3}$ as one member in LSV tends to catalyze $\mathrm{H}_{2} \mathrm{~S}$ oxidation while the other member $\mathrm{LaVO}_{3}$ maintains structural integrity of the anode. 
However, it has been reported that thermodynamic predictions of doped perovskite using simple oxide solutions as a model may be questionable due to the fluctuation of different cations' distribution inside the structure[63]. A solution for compensating for the insufficient activity of LSV was recently developed by JP Trembly and coworkers by applying LSV as a current collector outside the Ni-YSZ anode layer [10]. The preferential oxidation of $\mathrm{H}_{2} \mathrm{~S}$ and high conductivity of LSV yields the twin advantages of forming a sulfur tolerant layer for purifying fuels by oxidizing excess $\mathrm{H}_{2} \mathrm{~S}$ while adequately conducting electrons to the Ni/YSZ interface. As shown in Fig 6, the composite anode was found to improve the anode performance by 100 percent using coal

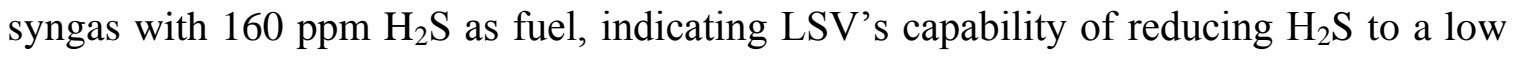
level. To develop LSV into a promising anode material, import issues such as oxygen ionic conductivity and selection of oxidizing dopant require in-depth investigation. The successful policies applied for improving chromites and titanates indicated proper doping of low valent cations on B-site may be needed to create oxygen vacancy while stabilizing the vanadate perovskite.

Other perovskite and Pyrochlore MIECs ----Double perovskite generally refers to a perovskite with an $\mathrm{A}^{\prime} \mathrm{A}^{\prime} \mathrm{B}^{\prime} \mathrm{B}{ }^{\prime \prime} \mathrm{O}_{6}$ structure, during which $\mathrm{A}^{\prime}$ and $\mathrm{A}$ " can be rare earth or alkaline elements, and B' and B" are two different transition cations in ordered form [64]. The newly developed $\mathrm{Sr}_{2} \mathrm{MgMoO}_{6}$ double perovskite by $\mathrm{YH}$ Huang and coworkers is a break-through in the development of perovskites anode materials [50,51]. The anode shows comparable or superior performances in fuels containing $\mathrm{H}_{2}$ and dry $\mathrm{CH}_{4}$ as the state-of-art anodes. The anode's high performance is maintained without change during introduction of $5 \mathrm{ppm} \mathrm{H}_{2} \mathrm{~S} / \mathrm{H}_{2}$, while slightly degrading $(<5 \%)$ after operating with 50 
ppm $\mathrm{H}_{2} \mathrm{~S} / \mathrm{H}_{2}$ for $200 \mathrm{hrs}$. The high power density achieved by reduction of Mo cations near maximum power output tended to contribute to the sulfur tolerance of the anode, since a high exchange current density is considered favorable for $\mathrm{H}_{2} \mathrm{~S}$ oxidation. $\mathrm{Mg}^{2+}$ in the material, which is used with $\mathrm{Mo}^{6+} / \mathrm{Mo}^{5+}$ couple to stabilize perovskite structure due to its ability to accept less than six-fold oxygen coordination [51], also resulted in a better sulfur-poisoning resistance compared with the materials with substitution of $\mathrm{Mg}$ by $\mathrm{Mn}$ and $\mathrm{Cr}$ cations. Although the sulfur tolerance mechanism or long-term stability has not been studied, the novel double-perovskite-structure material actually shows promise as an ideal anode material with not only high catalytic activity for various practical fuels but also sufficient sulfur tolerance.

Cerate-based perovskite $\mathrm{BaCe}_{0.8} \mathrm{Y}_{0.2} \mathrm{O}_{3}$ is usually a solid electrolyte but can obtain electronic conductivity as $\mathrm{Ce}^{4+}$ reduced to trivalent ceria [38]. A new method has been developed by Atsuko Tomita and coworkers to produce an anode-free structure by deriving $\mathrm{Y}_{0.2} \mathrm{Ce}_{0.8} \mathrm{O}_{3}$ anode phase directly from barium cerate electrolyte via surface heat treatment [40]. The perovskite-doped ceria structure not only possesses stability against carbon deposition and resistance for $10 \mathrm{ppm}$ levels of $\mathrm{H}_{2} \mathrm{~S}$, but also lowers the interfacial resistance between electrolyte and anode layer. The material shows relatively low catalytic activity for hydrogen oxidation but good redox stability after 20 trials, indicating a potential to serve as a sulfur-tolerant anode layer.

$\mathrm{Gd}_{2} \mathrm{Ti}_{1.4} \mathrm{Mo}_{0.6} \mathrm{O}_{7}$ with pyrochlore structure showed promise as a sulfur-tolerant anode recently [65]. The anode was found to be stable during 6-day test with $10 \% \mathrm{H}_{2} \mathrm{~S}$ $90 \% \mathrm{H}_{2}$ fuels and showed an improved performance compared with LSV under similar conditions. Mo-doped $\mathrm{Gd}_{2} \mathrm{Ti}_{2} \mathrm{O}_{7}$ derives its ionic conductivity of about $10^{-2} \mathrm{~S} / \mathrm{cm}$ from the 
intrinsic oxygen ion defects and valence change brought by Mo [66]. Such relatively high ionic conductivity of perovskites should help achieve a high electro-catalytic activity for the material. However, no specific material and electrochemical analysis study was reported. The material also has limited existence range of oxygen partial pressure with high Mo content, which imposes similar redox stability problem for GTM as a sulfurtolerant anode.

\subsubsection{Concluding remarks on sulfur poisoning and future work overlook}

The degradation mechanisms of SOFC anodes by sulfur and recent development of sulfur-tolerant anode are reviewed and summarized. Several concluding remarks and future work recommendations are presented below:

1) The difference between experimental results on sulfur poisoning and theoretical prediction indicated that it is necessary to investigate the role of adsorbed sulfur or formed sulfide on the electrochemical reactions on the anode. Particular attention should be paid to the surface and to the influence of the local electric field on sulfur poisoning.

2) Among various sulfur tolerant anode materials, thiospinel and metal sulfides are favorable for $\mathrm{H}_{2} \mathrm{~S}$ oxidation fuel cell while stability and catalytic activity for $\mathrm{H}_{2}$-rich fuels with low concentrations of $\mathrm{H}_{2} \mathrm{~S}$ need verification. Addition of more ionic conductive and sulfur-reactive phases into $\mathrm{Ni}$-cermet tends to be an easy and effective way to promote sulfur tolerance, but due to activity limitations of ionic phases, composition and contact of different phases need to be adjusted to ensure both adequate sulfur tolerance and fueloxidation performance. For the strategy of developing materials with mixed oxygen ion/electron conductivity, comparatively low catalytic activity towards hydrogen 
oxidation is the common challenge for the most sulfur-tolerant MIEC anodes for practical fuels, while the ones with promising oxidation performance need composition optimization to achieve sufficient stability for $\mathrm{H}_{2} \mathrm{~S}$. One exception is the recently developed double perovskite anode, which indicates that a connection between high catalytic activity and sulfur tolerance can be acquired simultaneously via a proper material match.

3) The lack of investigation on sulfur tolerance mechanisms and catalytic behaviors of different materials obscures clear criteria for design and evaluation of sulfur-tolerant materials. Based on the advantages and disadvantages of current sulfur-tolerant materials, the combined application of available materials as different functional components in anodes through proper design may be effective to achieve a balance between stability and performance. As previously suggested [12], the effects of ionic conductivity as well as interfacial resistance on anode performance in terms of catalytic activity and impurity tolerance need to be investigated during experimental trials.

\subsection{Poisoning effects from other impurities}

Besides sulfur, thermodynamic calculations suggest the presence of volatile impurities containing $\mathrm{P}, \mathrm{As}, \mathrm{Sb}, \mathrm{Se}, \mathrm{Cd}, \mathrm{Pb}$, and $\mathrm{Hg}$ in warm syngas [67]. It was also predicted that vapor species of $\mathrm{PH}_{3}, \mathrm{AsH}_{3}$, and $\mathrm{As}_{3} \mathrm{Sb}$ under warm gas cleanup conditions could potential react with Ni-YSZ anode and form secondary phases with Ni [67]. Several researchers have already experimentally studied the effects of these impurities in syngas mixtures on $\mathrm{Ni}-\mathrm{YSZ}$ anodes. $\mathrm{Ni}_{5} \mathrm{P}_{2}$ was produced on the Ni-YSZ anode surface in the $\mathrm{PH}_{3}$ testing reported by Trembly [67]. Pederson et al. observed a delay in 


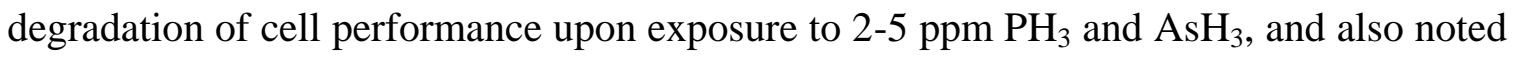
the formation of $\mathrm{NiAs}_{\mathrm{x}}$ and $\mathrm{NiP}_{\mathrm{x}}$ compounds on the nickel metal current collector and in the Ni/YSZ composite anode. Degradation was assigned to changes in the current collector. [68]. Zhi et al. exposed Ni/YSZ half cells to a high concentration of $\mathrm{PH}_{3}(20$ ppm). Post-mortem analyses by $x$-ray diffraction indicated the presence of nickel phosphate and zirconium phosphate phases. [69]. More recently Marina and co-workers further studied interactions between Sb and Se with Ni-YSZ anode in coal syngas [70]. They confirmed $\mathrm{Sb}$ attached both active anode interface and supporting layer, and eventually caused anode conductivity loss by forming secondary phase with Ni. While for Se the main degradation effects arose from surface adsorption of Se on TPB and potential formation of $\mathrm{Ni}_{\mathrm{x}} \mathrm{Se}_{\mathrm{y}}$ compounds depending on cell operation conditions. Unlike sulfur for which the poisoning mechanism is well established, more works need to done to further clarify the underlying degradation kinetics of SOFC anode caused by these impurities in the foregoing research. 


\section{Chapter 3 Outline of Study}

\subsection{Research Objective}

(1) Fabrication of electrolyte-supported and anode-supported solid oxide fuel cells with high performance for coal-derived syngas operation. The specific goal is to optimize the output and stability of baseline SOFC cells typically composed of yttria-stabilized zirconia (YSZ) electrolyte and Ni-YSZ anode through fabrication process control to serve the studies on understanding reaction mechanism between various syngas impurities and Ni-cermet anode and improvement of anode tolerance against impurity poisoning effects

(2) Improve stability of SOFC anode in sulfur and phosphorus-containing coal syngas by development and incorporation of ceramic coating materials with mixed ionic and electronic conductivity (MIEC) into anode structure through cost-efficient methods.

(3) Fundamentally study the SOFC cathode kinetics with specific electrochemical ratelimiting steps (RLSs) and activation characteristics under typical SOFC operation condition for commonly used cathode materials 


\subsection{Research Methodology}

(1) Design and deposit MIEC materials with preferential reactivity with sulfur and compatibility with SOFC anode into the electrode architecture

(2) Electrochemically characterizer SOFC stability and performance with the presence of impurities in coal syngas to assess remedy efficiency.

(3) Utilize advanced surface and structural characterization techniques to study interaction of anode materials with impurity to establish degradation mechanism

(4) Numerically quantify the contribution from different reaction pathway to the SOFC cathode kinetics via continuum modeling to identify the relationship between RLSs for oxygen reduction and operation condition as well as material property parameters

(5) Promote applicability of SOFC in coal syngas with understand on improvement of SOFC stability and electrochemical performance from both experimental and theoretical aspects 


\section{Chapter 4 Experimental Study on Sulfur Impurity Effects and Sulfur- Tolerant Materials for SOFC Anodes in Coal Syngas}

\subsection{Investigation with impregnated La-doped Ceria as effective sulfur tolerant anode materials-Test with anode supported cell}

\subsubsection{Introduction}

With the contemporary nickel and yttria-stabilized-zirconia (Ni-YSZ) as the most applied anode materials, sulfur mostly present in various fuels in the form of hydrogen sulfide $\left(\mathrm{H}_{2} \mathrm{~S}\right)$, has been clarified to pose the most threaten to SOFC cell performance at intermediate temperature of $700-800^{\circ} \mathrm{C}$, in which even a few parts per million (ppm) level of sulfur could cause significant performance drop by increasing cell polarization resistance up to $200 \%$ of the original extent. Considering the cost of high-level fuel clean-up systems as well as potential damage to cell by system fault, there is a call for developing advanced SOFC anode materials that can withstand sulfur poisoning to desired level and duration for operation in coal syngas as well as other fuels containing sulfur contaminant.

Previously research attempts have been made for improving sulfur resistance of SOFC anode by various means including usage of metal -sulfide-based anode[3,28] replacement of $\mathrm{Ni}$ in $\mathrm{Ni}$-cermet anode with less sulfur-sensitive metals such as $\mathrm{Cu}$ [37], addition of alloying elements into $\mathrm{Ni}$ to form bimetallic anode[4], developing mixedionic-and-electronic conductive (MIEC) ceramic like perovskite oxide as anode component[46] as well as substituting YSZ by electrolyte component with higher ionic conductivity like scandia stabilized zirconia (SSZ) [4].and gadolinium doped ceria (GDC) [10,39]. Above research policies have been successful in different extents with $\mathrm{H}_{2} \mathrm{~S}$ 
content varying from trace element level (1 to $600 \mathrm{ppm}$ ) to fuel component level (tens of percentage), however there is generally lack of ideal anode materials that can achieves both high cell performance and desired sulfur tolerance using practical fuels.

Recently surface modification of SOFC anode by ceramic coating have shown promising results in improving anode resistance to carbon deposition and sulfur poisoning with methane and coal syngas as fuels while maintaining baseline cell performance without additional require for anode composition change[6,34]. Typically protective ceramic oxides made from rare earth elements were applied into the porous anode through wet impregnation [34], dip coating [32] or screen printing [6]. By this way the impurity can be adsorbed and/or reacted by the incorporated ceramic components before it reached the anode/electrolyte interlayer. Ceria $\left(\mathrm{CeO}_{2}\right)$ has been chosen in both SOFC and molten carbon fuel cell (MCFC) as the protective coating components in anode due to its high adsorption capacity and reactivity with carbon and sulfur impurities[32,37], which is given by through following reaction under reducing environment:

$$
2 \mathrm{CeO}_{2-\mathrm{x}}(\mathrm{s})+\mathrm{H}_{2} \mathrm{~S}(\mathrm{~g})+(1-2 \mathrm{x}) \mathrm{H}_{2}(\mathrm{~g})--\mathrm{Ce}_{2} \mathrm{O}_{2} \mathrm{~S}(\mathrm{~s})+2{ }_{(1-x)} \mathrm{H}_{2} \mathrm{O}(\mathrm{g})(\mathrm{x}<0.5)
$$

In contrast ceria doped with rare earth elements generally had high stability and limited capacity for capture of carbon and sulfur impurities [2], and therefore is conventionally more chosen to improve electrode kinetics through its superior ionic conductivity [42]. In some recent work gadolinium doped ceria has been explored as sulfur tolerant anode component [71,72], and generally the sulfur poisoning effects of anode could be mitigated by usage of GDC in terms of less cell voltage drop and 
resistance increase compared to $\mathrm{Ni}$-YSZ anode. However the reported duration for $\mathrm{Ni}$ GDC anode to operate without degradation in wet $\mathrm{H}_{2}$ is relatively short (around one hour)after introduction of a few ppm of $\mathrm{H}_{2} \mathrm{~S}[71]$, and in fuels containing more water degradation of Ni-GDC anode was even observed after a couple hours for $\mathrm{H}_{2} \mathrm{~S}$ level as low as $0.5 \mathrm{ppm}[72]$, indicating limited sulfur tolerance of GDC in this case Nevertheless the direct use of Ni-GDC as sulfur-tolerant SOFC anode is so far mostly limited to electrolyte supported cells [71,72], while for application wise it would be more desirable to improve sulfur tolerance of the powerful anode-supported cells. Though, the relatively large TEC (thermal-expansion-coefficient) and volume change upon reduction for GDC phase can make it problematic for direct application of Ni-GDC as sulfur-tolerant anode in anode-supported-cells especially with the mostly-used zirconia as electrolyte [42,73]. On the other hand lanthanum doped ceria has been successfully developed as adsorbent material for high-temperature gas desulfurization prior to the SOFC system [31], which can effectively reduce sulfur content down to ppm level. So it would be encouraging to investigate the feasibility of incorporating lanthanum-doped ceria into the SOFC anode for sulfur tolerance enhancement, knowing that generally rare-earth-element-doped ceria has ionic conductivity needed for use as SOFC electrode. This study differs from other practice with gadolinium doped ceria directly used as sulfur tolerant anode. For one aspect lanthanum doped ceria with capacity for sulfur adsorption is examined for the first time as a sulfur tolerant anode material, and alternatively a cost-effective impregnation method is used to incorporate doped ceria into Ni-YSZ anode network to enhance anodesupported SOFC stability in coal syngas. Preliminary results showed impregnation of doped ceria coating improved sulfur tolerance of cell anode against 20ppm of $\mathrm{H}_{2} \mathrm{~S}$ by 
delaying degradation and reducing poisoning extent. And the sulfur-poisoning degradation of doped-ceria-infiltrated anode was further investigated through Galvanostatic cell potential measurement and AC impedance test.

\subsubsection{Experimental}

\subsubsection{Impregnation of Ni-YSZ anode supported cell by doped ceria}

Anode supported cell from Materials and Systems Research, Inc. (MSRI, UT) was used in current research for impregnation of doped ceria. The button cells are composed of a $0.75 \mathrm{~mm}$ thick anode supporter with diameter of $2.7 \mathrm{~cm}$, a $10 \mu \mathrm{m}$ thick electrolyte layer and a $40 \mu \mathrm{m}$ thick cathode layer with an area of about $2 \mathrm{~cm}^{2}$. The anode consists of a $20 \mu \mathrm{m}$ thick anode interlayer (Ni-YSZ) and anode current collection layer. The cathode is

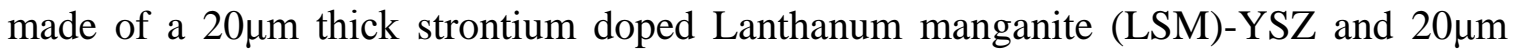
thick LSM current collection layer.

Wet impregnation method, which has been previously adopted in application of GDC in SOFC anode for performance improvement, is employed for current deposition of lanthanum doped ceria into $\mathrm{Ni}$-YSZ anode layer. First cerium nitrate $\left(\mathrm{Ce}\left(\mathrm{NO}_{3}\right)_{3} \cdot 6 \mathrm{H}_{2} \mathrm{O}\right)$ and lanthanum nitrate $\left(\mathrm{La}\left(\mathrm{NO}_{3}\right)_{3} \cdot 6 \mathrm{H}_{2} \mathrm{O}\right)$ from Aldrich Co.(U.S) in a mole ratio of 7:3 are evenly dissolved into de-ionized water to form a precursor with a total metal concentration of $0.6 \mathrm{M}$. Urea $\left(\mathrm{CO}\left(\mathrm{NH}_{2}\right)_{2}\right.$, Alfa Aesar $\left.\mathrm{Co}\right)$ of the same concentration is also added into the solution for even distribution of the metal ions. The ion solution is drop-coated onto the top of the MSRI anode supported cell, and then the cell is placed on a vacuum chuck, which provides vacuum to hold the cell and allow impregnation of nitrate solution inside the anode body. After hold on the vacuum chuck for $1 \mathrm{~h}$, the impregnated cell was calcinated at $900^{\circ} \mathrm{C}$ for $1 \mathrm{~h}$ to convert the nitrates into $\mathrm{La}_{0.3} \mathrm{Ce}_{0.7} \mathrm{O}_{1.85}$ 
(LDC) oxide. After each impregnation the cell is weighed to measure the overall loading of LDC oxide.

\subsubsection{Cell testing and electrochemical measurement}

For a cell testing assembly, first Pt meshes were attached to the anode and cathode side by hand-brushing of Ni paste and Pt paste respectively. Then silver current wires and voltage leads were welded onto both of the Pt meshes with load supply from load box. The cell assembly was then mounted into an alumina tube furnace using ceramic flanges with Mecca gaskets as seals to separate meshes, electrodes and ceramic parts from each other. The cell set-up structure is as shown in Figure 4.1.1.

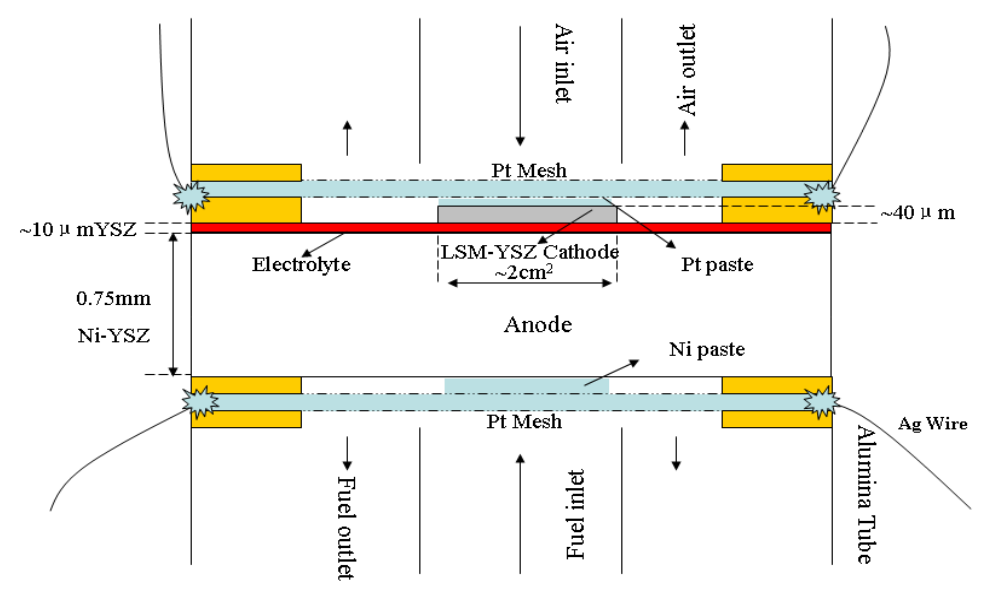

Figure 4.1.1 Cell testing assembly set-up

All Cell tests are operated at $800^{\circ} \mathrm{C}$ using air as oxidant with a controlled flow rate of 500sccm, and wet hydrogen $\left(3 \% \mathrm{H}_{2} \mathrm{O}\right)$.or simulated coal syngas as fuel with flow rate between approximately $200 \mathrm{sccm}$. Mass Flow Controllers from Alicat Co. (AZ, U.S) were used to control the flow rates of the different gas composition in the fuel and air. The water content in the fuel is controlled by adjusting the temperature of water bubbler prior to the anode inlet. The nominal composition of simulated coal syngas by volume 
consists of $30 \% \mathrm{H}_{2}, 26 \% \mathrm{H}_{2} \mathrm{O}, 23 \% \mathrm{CO}$, and $21 \% \mathrm{CO}_{2}$. The water gas shift reaction $\left(\mathrm{CO}+\mathrm{H}_{2} \mathrm{O} \rightarrow \mathrm{CO}_{2}+\mathrm{H}_{2} \mathrm{O}\right)$ for simulated syngas of above composition was calculated to be at thermodynamic equilibrium at $1073 \mathrm{~K}$ with thermodynamic software FactSage v5.4. The steam/carbon $(\mathrm{S} / \mathrm{C})$ ratio of the syngas is kept at 0.62 to prevent carbon deposition.

The cells with or without doped ceria impregnation are first operated in wet $\mathrm{H}_{2}$ with a constant current load of $250 \mathrm{~mA} / \mathrm{cm}^{2}$. The cell performance is recorded with source meter under galvanostatic mode. After cell potential reaching stable level the fuel is switched to simulated syngas with introduction of $20 \mathrm{ppm}_{2} \mathrm{~S}$ into the system at the mean time, and the temperature of water bubbler is raised to supply additional steam. The cell operation under $\mathrm{H}_{2} \mathrm{~S}$ ranged from about 10 to $90 \mathrm{hrs}$, and after test all cells were regenerated with wet hydrogen for performance recovery expect for the one operating in $\mathrm{H}_{2} \mathrm{~S}$ for around 90 hrs was taken out without $\mathrm{H}_{2}$ recovery for microstructure analysis.

Electrochemical measurement was carried out with an electrochemical interface SI1287 and impedance analyzer SI-1260 (Solartron Instruments, Hampshire, UK). AC impedance tests were performed during frequency range of $0.1 \mathrm{~Hz}$ to $10^{5} \mathrm{~Hz}$ with $\mathrm{AC}$ signal amplitude of $10 \mathrm{mV}$ under open circuit potential (OCP) and polarization conditions with anode as working electrode and cathode as counter electrode. The electrode ohmic serial resistance (Rs) was measured from the high-frequency intercepts of impedance curves with the real axis of the Nyquist Diagram, and electrode polarization resistance $\left(R_{p}\right)$ was taken as the difference between the low-frequency and high frequency intercepts of the impedance curves with real axis. 


\subsubsection{Cell microstructure analysis}

Scanning electron microscopy (SEM) and Energy dispersive x-ray spectroscopy (EDXS) analyses were performed on MSRI cells after doped ceria impregnation and $\mathrm{H}_{2} \mathrm{~S}$ exposure for microstructure characterization using a JEOL JSM 6300FV SEM and Thermo Electron Noran System Six EDS. X-ray Diffraction (XRD) analysis was completed to examine the doped ceria phase inside anode with an X-pert Pro PANlytical XRD.

\subsubsection{Results and Discussion}

\subsubsection{Impregnated MSRI cell by $\mathrm{La}_{0.3} \mathrm{Ce}_{0.7} \mathrm{O}_{1.85}(\mathrm{LDC})$}

Figure 4.1.2 show the morphology and composition distribution of LDC-impregnated MSRI cell. From (a) and (b) it can be seen that the lanthanum and cerium nitrates solution mainly penetrated into the anode structure through the pore channels.

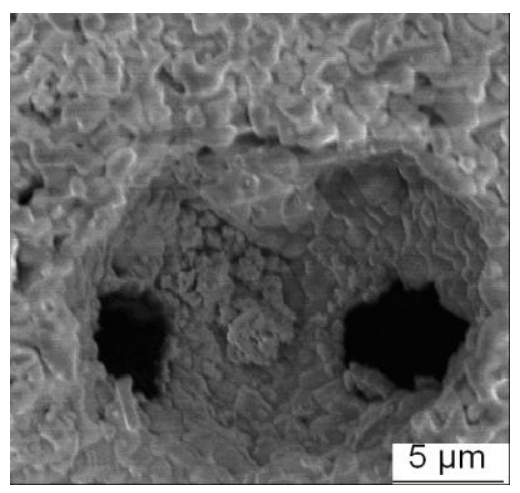

a

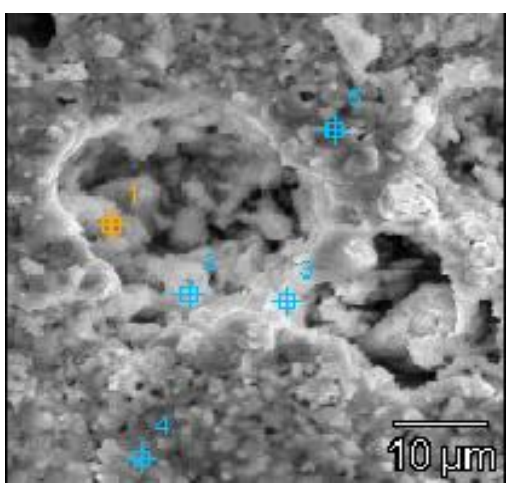

b

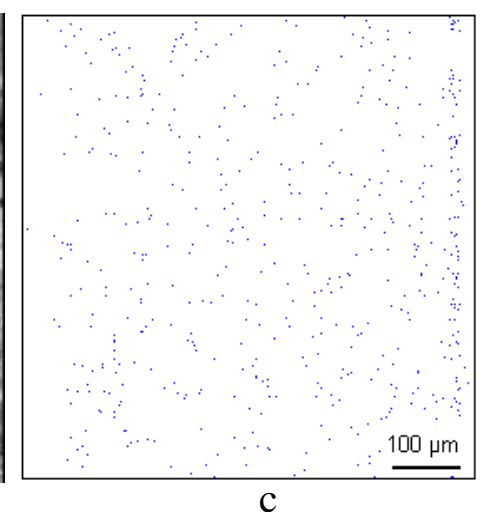

C

Figure 4.1.2 Morphology and compositional analysis of MSRI cell with lanthanum doped ceria(a Before LDC impregnation b After LDC impregnation c Mapping of La inside anode ) 
Table 4.1.1 EDXS results of $\mathrm{La}$ and Ce distribution inside the anode after LDC impregnation ( the point numbers correspond to detection points labeled in Fig.4.1.2 (b))

\begin{tabular}{|c|c|c|c|c|c|c|c|}
\hline Pom (\%) & 1 & 2 & 3 & Average & 4 & 5 & Average \\
\hline La & 6.61 & 45 & 459 & 5.23 & 0.53 & 0.79 & 0.66 \\
\hline Ce & 14.46 & 1253 & 12.08 & 13.023 & 1.75 & 1.36 & 156 \\
\hline
\end{tabular}

Relatively large clusters of LDC oxides formed inside the pores after sintering at $900^{\circ} \mathrm{C}$ with $\mathrm{La}$ and $\mathrm{Ce}$ composition close to the initial designed value as confirmed by EDXS results in Table 4.1.1, while EDXS also showed the LDC content in the parts beyond the pores was fairly low. This may indicate the outside-pore anode structure is not very permeable for nitrates solution penetration. Hence the solution would be infiltrated into the anode preferentially through macro-pores by the vacuum suction force, resulting in uneven loading of doped ceria oxide across the pore channels. After one impregnation the doped ceria oxide loading in the $\mathrm{Ni}-\mathrm{YSZ}$ anode is $0.14 \mathrm{mg} / \mathrm{cm}^{2}$, and the value increased to $0.97 \mathrm{mg} / \mathrm{cm}^{2}$ after 6 impregnation cycles. X-ray mapping results in Fig.4.1.2 c) after 6 impregnation cycles demonstrated doped ceria scattered over the entire anode structure distributing along the pore channel network, with some of the oxides reaching the anode/electrolyte interface.

The phase of doped ceria impregnated into the Ni-YSZ anode was checked with XRD, and the result in Fig.4.1.3 showed single-phased lanthanum doped ceria (LDC) inside the anode structure. The LDC was reported to have higher ionic conductivity than YSZ at the SOFC operation condition due to the enhanced reducibility of Ce cations by the low- 
valent dopant[74], however given the small loading of doped ceria in this study the anode conductivity may not be influenced appreciably. Although the light impregnation of LDC inside Ni-YSZ may be not enough to significantly improve anode electrochemical performance via promoting ionic conductivity and enlarging TPB area, as shown in the cell testing results this receipt was quite helpful to protect anode against the poisoning effects from $\mathrm{H}_{2} \mathrm{~S}$.

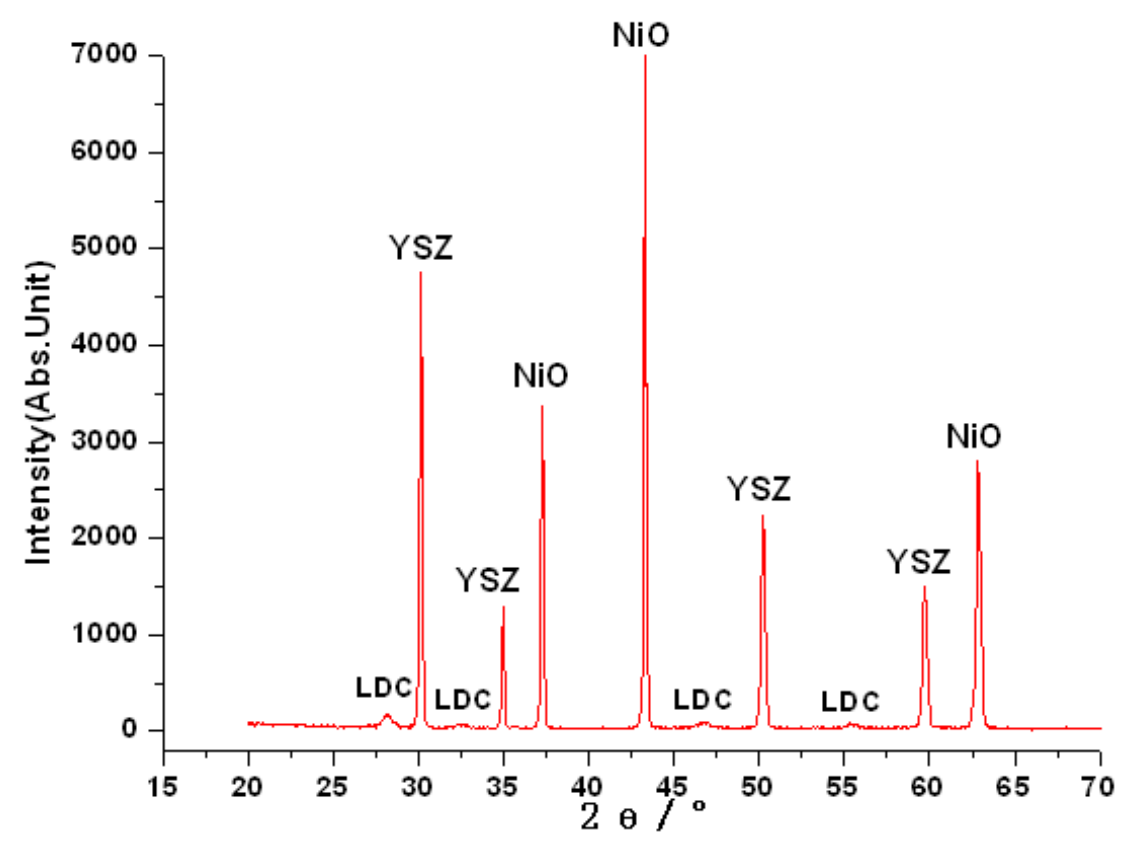

Figure 4.1.3 XRD spectrum of MSRI cell after 6 impregnation cycles with La and Ce nitrates.

\subsubsection{Sulfur tolerance test in simulated coal syngas}

Figure 4.1.4 showed effects of doped LDC on sulfur tolerance of anode-supported MSRI cell in coal syngas with the composition of $30 \% \mathrm{H}_{2}, 26 \% \mathrm{H}_{2} \mathrm{O}, 23 \% \mathrm{CO}$, and $21 \%$ $\mathrm{CO}_{2}$. All the cells were first operated in $\mathrm{H}_{2}$ with a constant current density of $250 \mathrm{~mA} / \mathrm{cm}^{2}$. Then the fuel was switched to syngas, and then $20 \mathrm{ppm}$ of $\mathrm{H}_{2} \mathrm{~S}$ was introduced once a 
stable potential was achieved. The results in the figure indicated that the sulfur poisoning of the anode supported cell consisted of 2-stage mechanism similar to that previously reported for electrolyte-supported cell: first stage of rapid loss of cell potential followed by second stage of slow and continue potential drop.
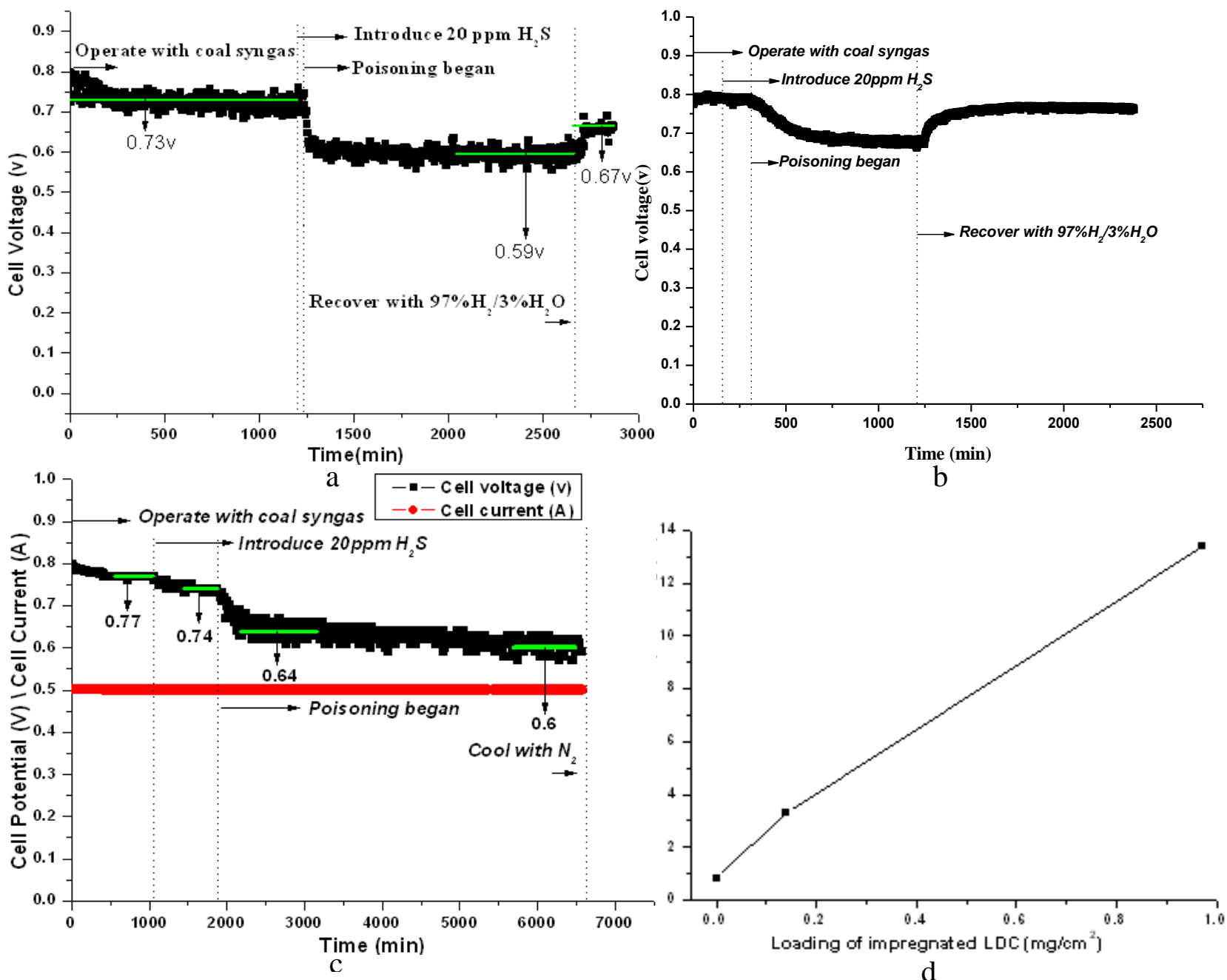

Figure 4.1.4 Performance of MSRI cells in coal syngas with 20ppm $\mathrm{H}_{2} \mathrm{~S}$.(a without LDC impregnation; b with 1 impregnation of LDC; $c$ with 6 cycles of LDC; d On-set duration vs Loading of LDC)

Different from electrolyte-supported cell for which the cell immediately depredated upon introduction of even a few ppm of $\mathrm{H}_{2} \mathrm{~S}$, there was a lag-behind period before on-set of sulfur poisoning for the anode-supported cells tested in $\mathrm{H}_{2} \mathrm{~S}$. The existence of such onset period is regarded due to adsorption of sulfur by thick anode support layer, which 
could delay the time for sulfur to transfer into active anode reaction layer and poison the active reaction sites.

Impregnation of lanthanum doped ceria was found to improve the sulfur tolerance of the cell by elongating the duration of the on-set period and mitigating the voltage drop during sulfur poisoning. For the Ni-YSZ anode supported cell without impregnation, the on-set duration for sulfur poisoning is about $50 \mathrm{mins}(0.8 \mathrm{hr})$, and the value increased to $3.3 \mathrm{hrs}$ after 1 impregnation cycle of $\mathrm{La}_{0.3} \mathrm{Ce}_{0.7} \mathrm{O}_{1.85}$ and further increased to $13.5 \mathrm{hrs}$ after 6 impregnation cycles. Comparatively at $750-850^{\circ} \mathrm{C}$ the Ni-GDC anode is reported to be exempt from degradation by $9 \mathrm{ppm} \mathrm{H}_{2} \mathrm{~S}$ for up to $1.5 \mathrm{hrs}$ in wet $\mathrm{H}_{2}$ [39], while poisoned by $0.5 \mathrm{ppm}_{2} \mathrm{~S}$ in other more oxidizing fuel [72]. The observed time duration before onset of sulfur poisoning for LDC impregnated Ni-YSZ anodes in $20 \mathrm{ppm}$ of $\mathrm{H}_{2} \mathrm{~S}$ is comparable or much longer than that reported for Ni-GDC anode in even lower concentration of $\mathrm{H}_{2} \mathrm{~S}$, after taking the anode support effect into account. This improved tolerance against sulfur could be attributed to the large adsorption capacity and/or the high reactivity of the lanthanum doped ceria with $\mathrm{H}_{2} \mathrm{~S}$. As adsorbent for high temperature removal of $\mathrm{H}_{2} \mathrm{~S}$, mixed lanthanum and cerium oxides were reported to have long breakthrough time for $\mathrm{H}_{2} \mathrm{~S}$ adsorption and short recovery time for activity regain [31]. Also lanthanum oxide was regarded to can actively react with $\mathrm{H}_{2} \mathrm{~S}$ in SOFC anode [49]. Thus the incorporation of LDC inside Ni-YSZ anode may contribute to protect the anode/electrolyte interface by preferentially adsorb/react with $\mathrm{H}_{2} \mathrm{~S}$ inside the anode network. Meanwhile the current strategy of impregnating high-performance anode with small content of sulfur tolerant materials (well below $1 \mathrm{wt} \%$ ) avoid the potential cost and 
stability issues associated with direct construction of sulfur tolerant anode from doped ceria materials as been discussed.

The initial electrochemical performance of impregnated cell was not found to differ appreciably with that of the cell without impregnation due to the small loading of LDC oxide. As for the performance loss during the first $20 \mathrm{hrs}$ of $\mathrm{H}_{2} \mathrm{~S}$ exposure, the voltage drop for the cell without impregnation was $19.2 \%$, while the voltage drops for the cell impregnated with LDC in 1 cycle and 6 cycles were $12.8 \%$ and $15.6 \%$ respectively. In the second stage till $90 \mathrm{hrs}$ exposure of $\mathrm{H}_{2} \mathrm{~S}$, the cell degradation for all the cells displayed similar feature of approximately $15 \mathrm{mv}$ drop per $24 \mathrm{hrs}$. Therefore the impregnated LDC did help to reduce sulfur poisoning effect and improve cell performance upon $\mathrm{H}_{2} \mathrm{~S}$ exposure.

\subsubsection{AC impedance investigation of sulfur poisoning}

AC impedance of the MSRI impregnated with LDC was obtained in different atmospheres and polarization conditions. The results are shown in Fig.4.1.5 and Fig.4.1.6.

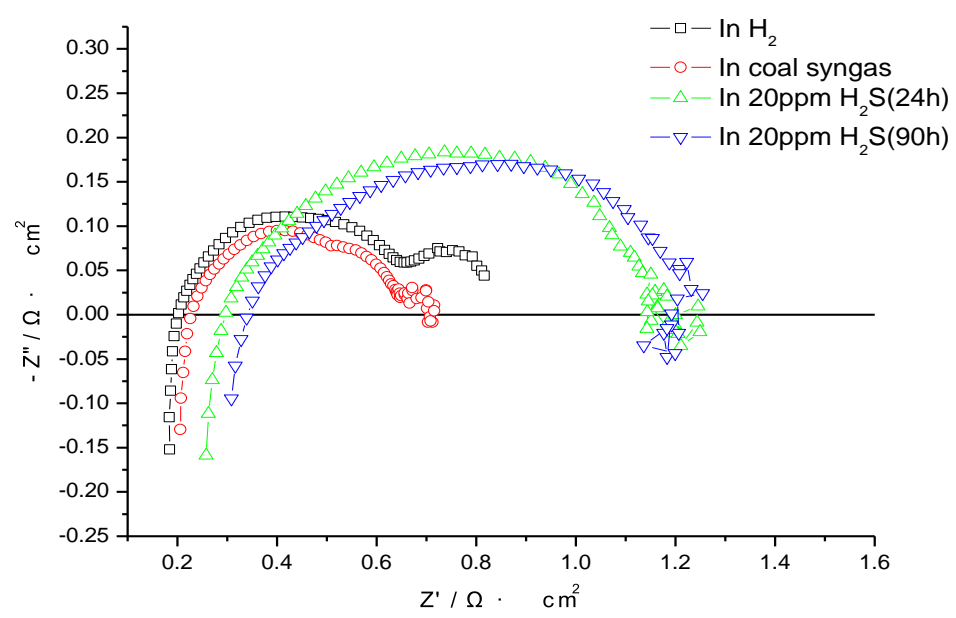

Figure 4.1.5 AC impedance of MSRI cell with LDC impregnation measured at OCP for various atmospheres 


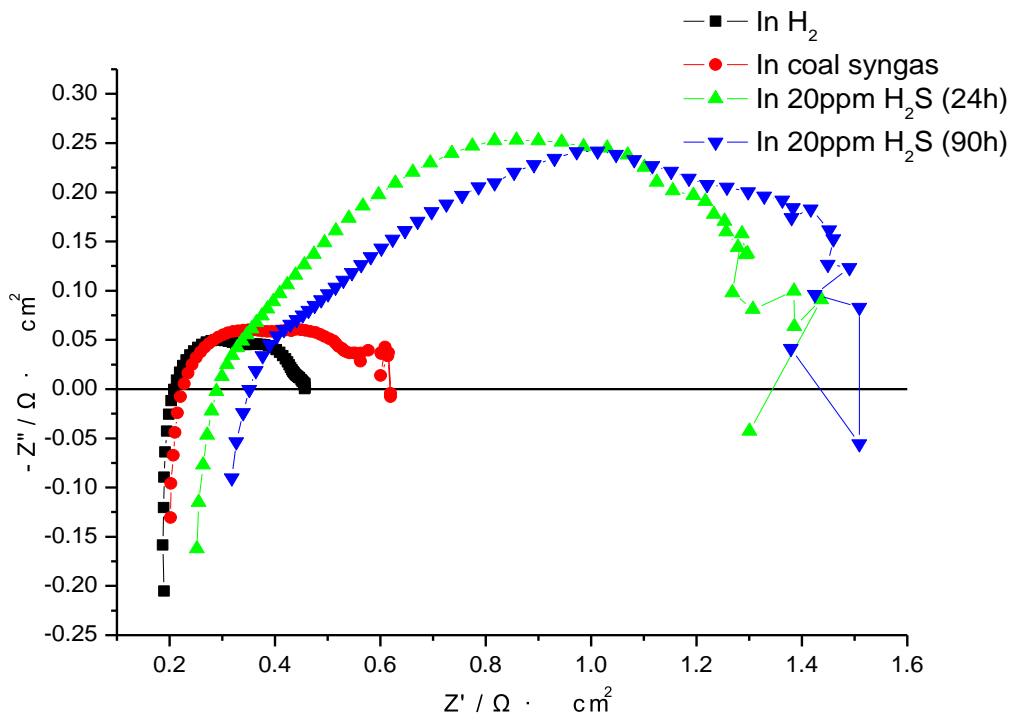

Figure 4.1.6 AC impedance of MSRI cell with LDC impregnation measured at $-0.3 \mathrm{v}$ overpotential for various atmospheres

A small variation of serial resistance Rs has been observed for the cell when the fuel was changed to coal syngas. This is assumed to come from the change of ambipolar conductivity of the anode as a function of the different oxygen partial pressures under $\mathrm{H}_{2}$ and syngas. Fig. 4.1.5 and 4.1.6 indicated by applying a potential loading of $-0.3 \mathrm{v}$ on the cell, the electrode kinetics can be greatly improved with a reduction of polarization resistance $\mathrm{Rp}$ by $44.1 \%$ in $\mathrm{H}_{2}$ and $12.4 \%$ in syngas respectively, which was mainly associated with activation of cathode electrochemical processes under current passage according to previous reports. The cathodic kinetic improvement was also though to account for the impedance difference observed in Fig 4.1.5 for cell in $\mathrm{H}_{2}$ and syngas, since measurement of the cell impedance in syngas was made long after operation in $\mathrm{H}_{2}$, just prior to $\mathrm{H}_{2} \mathrm{~S}$ introduction. The smaller decrease and larger value of $\mathrm{Rp}$ obtained in syngas compared with $\mathrm{H}_{2}$ implied slower electrode kinetics in syngas. With the 
introduction of 20ppm contaminate $\mathrm{H}_{2} \mathrm{~S}$, both Rs and Rp increased significantly, accounting for cell degradation.

Externally applied voltage also displayed significant effect on cell kinetic change caused by sulfur poisoning. After $90 \mathrm{hrs} \mathrm{H}_{2} \mathrm{~S}$ exposure, the increase of Rs was about $50.4 \%$ of initial value measured at OCP condition and $59.2 \%$ under a $0.3 \mathrm{v}$ DC bias., while the increase of $\mathrm{Rp}$ were $181 \%$ and $273 \%$ respectively under OCP and $-0.3 \mathrm{v}$ load. The observed different evolution of $\mathrm{Rs}$ and $\mathrm{Rp}$ in $\mathrm{H}_{2} \mathrm{~S}$ due to external load deserves further analysis to unveil the sulfur degradation mechanism for the anode supported cell.

Firstly it is necessary to understand the specific physical processes associated with change of Rs and Rp during sulfur poisoning. Considering the level of $\mathrm{H}_{2} \mathrm{~S}$ used in this study, the sulfur poisoning predominantly occurred by rapid chemisorption of sulfur on Ni surface through following reaction [18]:

$$
\mathrm{Ni}(\mathrm{s})+\mathrm{H}_{2} \mathrm{~S}(\mathrm{~g}) \leftrightarrow \mathrm{Ni} \bullet \mathrm{S}(\mathrm{s})+\mathrm{H}_{2}(\mathrm{~g})
$$

Formation of bulk Ni sulfide is not thermodynamically favorable at $800^{\circ} \mathrm{C}$ under low concentration level of $\mathrm{H}_{2} \mathrm{~S}$, hence the sulfur species mainly presented as superficial elemental sulfur, which may contribute to the increase of Rs due to lower electrical conductivity compared with Ni. This influence will be further discussed below. However as the impedance measurement was performed from time to time during the sulfur exposure test and for each time wire connection between Solartron machine and fuel cell system had to be remade, it is also possible that change of connection could affect the stability of Rs measurement considering the much smaller ohmic resistance of anodesupported-cell compared to electrolyte-supported cell. Thus the poisoning effect from sulfur on cell ohmic resistance needs to be further studied in subsequent research 
preferably with electrolyte supported cell. On the other hand the increase of Rp after sulfur exposure should come from inhibition of hydrogen adsorption/desorption on $\mathrm{Ni}$ and subsequent electrochemical oxidation due to coverage of active sites on Ni by sulfur. Careful analysis on impedance diagrams in Fig. 4.1.5 and 4.1.6 indicated proportion of polarization resistance at low frequency $(\sim 10 \mathrm{~Hz})$ range seemed to be mostly affected by sulfur exposure with overpotential load, which can be related to surface diffusion of adsorbed hydrogen on Ni towards TPB site [72].

Secondly the observed load effect on cell impedance can be explained with interaction between adsorbed sulfur and Ni-YSZ anode during electrochemical reaction. It was reported previously that current/voltage load might have two primary effects on the degradation of Ni-based anode caused by $\mathrm{H}_{2} \mathrm{~S}$. Zha and Cheng have suggested that adsorbed sulfur on Ni can be electrochemically oxidized at TPB by local oxygen ion flux from electrolyte component as [18,75]:

$$
\mathrm{S}(\mathrm{ads})+2 \mathrm{O}^{2-} \leftrightarrow \mathrm{SO}_{2}(\mathrm{~g})+4 \mathrm{e}^{-}
$$

Hence operating cell at larger current density or lower potential can introduce higher ion flux, and facilitate desorption of S through reaction Eq.4.1.3 and reduce the extent of sulfur poisoning. In contrast Sasaki proposed that electrochemical reaction at TPB inside anode could decrease local $\mathrm{H}_{2}$ concentration, and shifted the equilibrium of reaction Eq. 4.1.2 to right side [4]. Consequently current/voltage load was predicted to aggravate sulfur poisoning, and sulfur might preferentially adsorb on active reaction sites.

The impedance results in Fig. 4.1.5 and 4.1.6 appeared to be more consistent with the poisoning mechanism proposed by Sasaki; however, other reports also supported Zha and Cheng's conclusion [72]. Contradiction of the impedance data trend obtained here with 
the first mentioned mechanism of load effects may result from the different cell dimension employed in this study. Since relatively thick anode $(0.75 \mathrm{~mm})$ layer was used for sulfur poisoning in this test, external current/voltage load may introduce larger variation of $\mathrm{H}_{2}$ concentration at active anode interlayer due to transportation effect compared with thin electrolyte-supported anode used in other research. More sulfur can deposit on Ni surface when local partial pressure of $\mathrm{H}_{2}$ drops as overpotential or current denisty increases according to reaction (2), and as a result larger increase of Rs and Rp would occur as observed in Fig. 4.1.5 and 4.1.6. However, the mechanism through Eq. 4.1.3 cannot be totally excluded at this point, rather long-term test with different current load is recommended to further clarify the load effects on sulfur poisoning for Ni-YSZ anode.

Above discussion on the AC impedance results has shown that the sulfur adsorption on $\mathrm{Ni}$ could block the active reaction site for $\mathrm{H}_{2}$ oxidation and increase both ohmic resistance and polarization resistance for the cell. Higher value of Rs and Rp measured under $-0.3 \mathrm{~V}$ than $\mathrm{OCV}$ indicated sulfur poisoning reaction could be accelerated by external load through reaction Eq.4.1.2

\subsubsection{Conclusion}

The effect of lanthanum loped ceria applied onto the Ni-YSZ anode by wet impregnation on sulfur tolerance of SOFC anode supported cell was studied. Microstructural analysis on anode after impregnation through SEM, EDXS and XRD indicated the ceria nitrates mainly permeated into the anode through the network of macro-pores, and formed large oxide clusters after sintering. Testing results of anode supported MSRI cell in simulated coal syngas with 20ppm of $\mathrm{H}_{2} \mathrm{~S}$ showed there was 
typical duration for which cell poisoning lagging behind sulfur introduction due to the thick anode layer used. Application of lanthanum doped ceria (LDC) could greatly improve sulfur tolerance of the cell by extending the cell stability against $\mathrm{H}_{2} \mathrm{~S}$ exposure from about $1 \mathrm{hr}$ to more than $13 \mathrm{hrs}$. The extent of sulfur poisoning in terms of voltage drop is also much lower for the impregnated cell compared with the cell without doped ceria. The enhanced sulfur resistance of anode was mainly attributed to the high capacity for sulfur adsorption and reactivity with sulfur of lanthanum doped ceria, which slows down poisoning kinetics and suppress degradation loss. AC impedance tests reflected the sulfur poisoning of anode supported cell began with rapid increase of polarization resistance and serial ohmic resistance. Applying external load resulted in larger polarization resistance during extended $\mathrm{H}_{2} \mathrm{~S}$ exposure, and the effects of transport limit of anode dimension was found most likely to account for the negative effect of load on cell sulfur tolerance. However since only preliminary results were obtained in the research, further work are required to clarify the sulfur poisoning mechanism of anode supported cell and investigate the specific effects of impregnated doped ceria on cell performance via improved experimental procedure and careful past-test cell characterization. 


\subsection{Investigation with impregnated La-doped Ceria as effective sulfur tolerant anode materials-Test with electrolyte supported cell}

\subsubsection{Introduction}

Previous sulfur tolerance tests with anode supported cells have shown impregnation with La-doped $\mathrm{CeO}_{2}$ oxides (LDC) can effectively improve sulfur tolerance of SOFC anode by delaying the poisoning reaction of $\mathrm{Ni}$ with $\mathrm{H}_{2} \mathrm{~S}$ by over $10 \mathrm{hrs}$ due to the preadsorption effects of LDC. However there are some disadvantages involved for anode supported cell testing which may complex analysis of interaction between impregnated material and sulfur impurity. Firstly the configuration of thick anode supporting layer would extensively react with $\mathrm{H}_{2} \mathrm{~S}$ [70] and cause additional effects on assessment of sulfur tolerance truly introduced by the impregnated materials by delaying the time for the impurity to reach electrochemical active interface between anode and electrolyte. Secondly as is found in the other study with MSRI cells [76], the anode architecture for the commercial cells are well developed with fixed porosity, which is difficult for the infiltration with large amount of sulfur tolerant materials and leads to confined distribution of sulfur tolerant coatings near anode top surface. The effort to introduce additional porosity by pre-reduction of anode before impregnation failed due to repeat crack of YSZ electrolyte during afterward thermal treatment of the impregnated coatings. At last the relatively small resistance of anode supported cell can make cell impedance data more sensitive to connection change and thus enlarge measurement error involved.

In this study the main focus is to further clarify the sulfur tolerance of LDCimpregnated anode and investigate interaction between LDC and $\mathrm{H}_{2} \mathrm{~S}$ with fewer effects form cell configuration mentioned above on fabrication and testing. For this objective electrolyte supported SOFC with porous anode is developed to facilitate impregnation 
with LDC particles. The sulfur tolerance of LDC-impregnated anode is then tested in simulative coal syngas with $20 \mathrm{ppm} \mathrm{H}_{2} \mathrm{~S}$ by means of DC polarization and $\mathrm{AC}$ impedance measurement. Post-test characterization through SEM, XRD and XPS is used to examine the interaction between LDC coating and $\mathrm{H}_{2} \mathrm{~S}$ during the anode degradation process.

\subsubsection{Experiment set-up}

The electrolyte supported SOFC (ESC) is fabricated from a screen-printing process followed by sintering of electrodes. Commercially-available electrolyte disk made of scandium-stabilized-zirconia (SSZ)/8YSZ bi-layer composite (Nextech,OH) is utilized as substrate for electrode deposition with an average thickness of $280 \mu \mathrm{m}$. Sub-micron sized $\mathrm{NiO}$ and $\mathrm{SSZ}$ powders (Nextech, $\mathrm{OH}$ ) with a weight ratio of 50:50 are mixed thoroughly with ink vehicle (Nextech, $\mathrm{OH}$ ) on a 3-roll mill to form anode interlayer ink. Similarly anode outlayer ink is prepared from $\mathrm{NiO}$ and YSZ powders with a weight ratio of 60:40, containing additional graphite powder amount to $10 \%$ of total powder weight to create porosity for impregnation. The anode interlayer ink and outlayer ink are coated subsequently on the electrolyte substrate with an Aremco 3260 screeen printer and sintered at $1350 \mathrm{C}$ for $2 \mathrm{hrs}$ to generate Ni-SSZ/Ni-YSZ composite anode with a thickness of about $30 \mu \mathrm{m}$. The cathode is made of a $20 \mu \mathrm{m}$ thick LSM-GDC interlayer and $20 \mu \mathrm{m}$ thick LSM current collection layer produced from screen printing of corresponding commercial inks and sintering at $1200 \mathrm{C}$ for $2 \mathrm{hrs}$. After cell fabrication, impregnation of LDC coating is following the same material receipt and procedure as in section 4.1.2.1. The sulfur poisoning test is performed at $800 \mathrm{C}$ in simulative coal syngas atmosphere with $20 \mathrm{ppm} \mathrm{H} 2 \mathrm{~S}$. During test cell voltage is continuously monitored under load of $0.15 \mathrm{~A} / \mathrm{cm}^{2}$ 
generated by a Solartron 1287/1260 electrochemical testing system. AC impedance is measured from time to time during the different degradation period for the SOFC anode. Details about set-up of sulfur poisoning and electrochemical experiments can be found in section 4.1.2.2. The microstructure, phase evolution and material constitution of the posttest cell anodes are examined further with SEM, XRD and XPS to characterize effects of LDC impregnation on anode reactivity with sulfur.

\subsubsection{Results and discussion}

\subsubsection{Cell performance comparison between baseline and impregnated electrolyte supported cells}

Fig.4.2.1 shows the V-I curves and power densities of the baseline YSZ/SSZ electrolyte supported cells with Ni-SSZ/Ni-YSZ anode and LDC impregnated ESC measured in dry $\mathrm{H}_{2}$ at $800^{\circ} \mathrm{C}$. As the loading of LDC impregnated materials changed from $2 \mathrm{mg} / \mathrm{cm}^{2}$ to $6 \mathrm{mg} / \mathrm{cm}^{2}$, the maximum powder density increased by $50 \%$ and $250 \%$ from the original level of baseline ESC respectively.

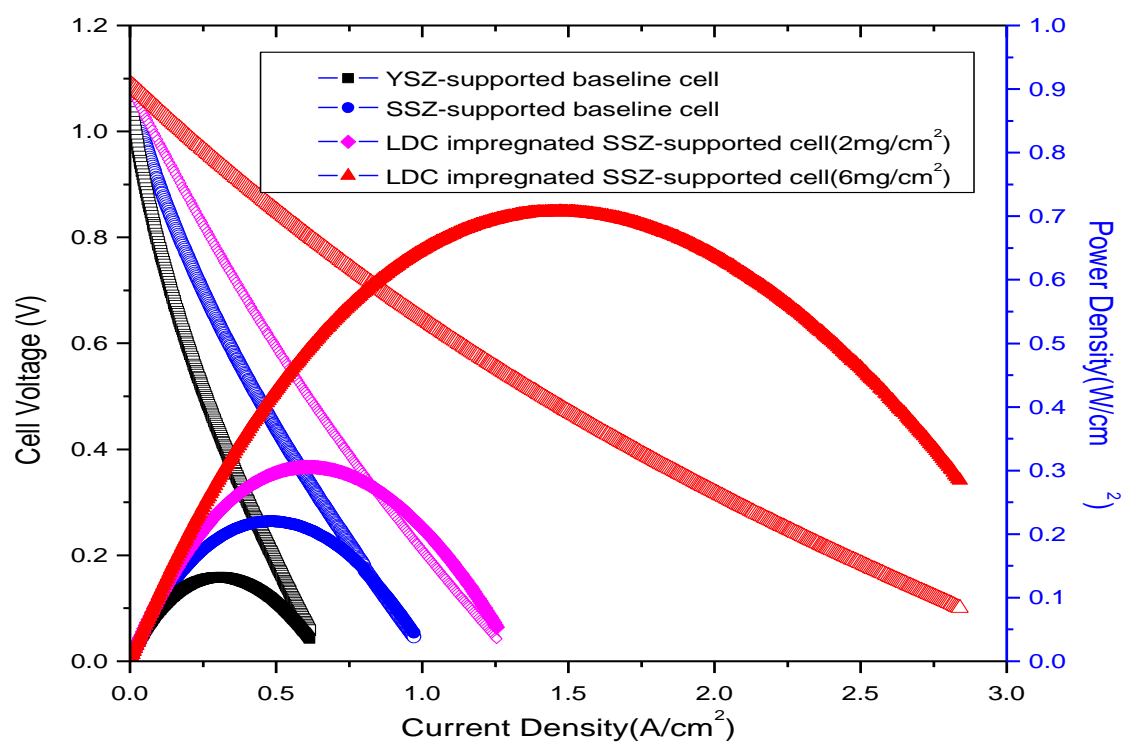

Figure 4.2.1 Performances of baseline and LDC-impregnated cells at $800^{\circ} \mathrm{C}$ in dry $\mathrm{H}_{2}$ 
AC impedance diagrams in Fig.4.2.2 displayed cell polarization resistance (Rp) was reduced greatly after LDC impregnation, while the series resistance (Rs) increased slightly. This indicates the impregnated LDC can improve TPB kinetics inside Ni-SSZ anode functional layer. The ionic conductivity of LDC is reported to be twice of YSZ at temperature around $800^{\circ} \mathrm{C}$ [77], hence impregnated LDC particle at TPB can effectively extend TPB area. It should be noticed that ceria and doped ceria type catalysts have good capability for bulk oxidation/reduction [37,39], and this would also benefit transport of oxygen out from electrolyte network to TPB, resulting in reduced Rp.

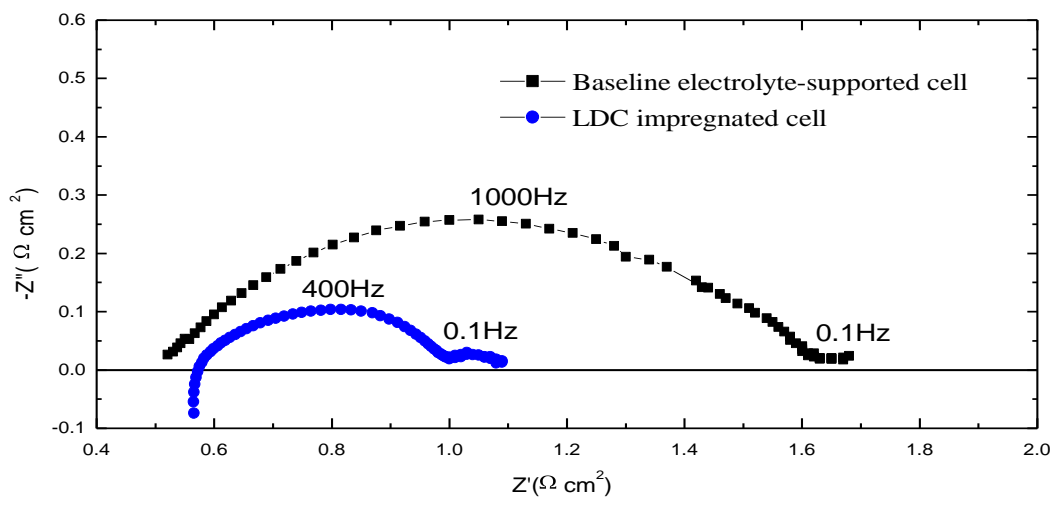

Figure 4.2.2 AC impedance of baseline and LDC-impregnated electrolyte supported cells at $800 \mathrm{Cin}$ dry $\mathrm{H} 2$

Fig. 4.2.5 (see Sect.4.2.3.3) shows that the LDC particles are rather scattered inside the Ni-YSZ/SSZ anode at low impregnated loading of $2 \mathrm{mg} / \mathrm{cm}^{2}$.Such loose distribution may fail to form an effective ionic conduction path between LDC particles, causing ohmic resistance increase due to poor electronic conductivity of the LDC particles unattached to main electrolyte network. The above performance improvement effects, however, cannot be observed with anode supported cell due to prevention of infiltrated particles to reach electrochemical active interfaces by the commercial anode porosity. 


\subsubsection{Electrochemical test on sulfur tolerance of LDC-impregnated anode}

The sulfur tolerance of baseline and LDC-impregnated ESCs are tested in coal syngas $\left(26 \% \mathrm{H}_{2} \mathrm{O}, 30 \% \mathrm{H}_{2}, 23 \% \mathrm{CO}\right.$ and $\left.21 \% \mathrm{CO}_{2}\right)$ containing $20 \mathrm{ppm} \mathrm{H}_{2} \mathrm{~S}$ under load of $0.15 \mathrm{~A} / \mathrm{cm}^{2}$ at $800^{\circ} \mathrm{C}$. In Fig.4.2.3 (a) it can be seen that degradation of baseline cell began within 10 mins after introduction of $20 \mathrm{ppm}_{2} \mathrm{~S}$, while for anode supported baseline cell the on-set time of sulfur poisoning is around $1 \mathrm{hr}$, indicating without thick anode supporting layer the sulfur can easily penetrate into the electrochemically active layer and adsorb on $\mathrm{Ni}$ anode surface. The cell performance continued to degrade by over $20 \%$ before reaching a relatively stable level after another $60 \mathrm{hrs}$. As a comparison in testing of anode supported cell within $20 \mathrm{ppm}_{2} \mathrm{~S}$ as reported in section 4.1.3, the cell voltage dropped much faster than did the electrolyte-supported one and stabilized within $1 \mathrm{hr}$. Such kinetic difference needs to be examined from the anode material and phase divergence existing for the two types of cells. SSZ-based anode is reported to have superior sulfur tolerance than YSZ-based anode due to its higher ionic conductivity [4]. The usage of SSZ in anode interlayer for the ECS thus could affect adsorption of $\mathrm{H}_{2} \mathrm{~S}$ on Ni surface. However, the same study with SSZ as sulfur tolerant materials in electrolytesupported Ni-SSZ anode showed it could only delay the begin of sulfur poisoning and slowed down the process by several minutes. Thus other reason should account for the prolonged degradation of ECS in sulfur up to tens of hours. It is most possible that a secondary phase formed due to interaction of $\mathrm{Ni}$ with $\mathrm{Pt}$ current collector during experiment, and modified Ni anode surface for sulfur adsorption. This will be analyzed in detail during post-test cell characterization. On the other hand It is noteworthy that higher load $\left(0.25 \mathrm{~A} / \mathrm{cm}^{2}\right)$ used in sect. 4.1. for anode supported cell test could also contribute 
partially to faster degradation of the cell, as TPB becomes more susceptible to sulfur attack at high fuel utilization [4].After cut-off of $\mathrm{H}_{2} \mathrm{~S}$ in syngas, there is no observable recovery of cell voltage. The cell performance restored to $96 \%$ of original level only after switching back of fuel to dry $\mathrm{H}_{2}$.
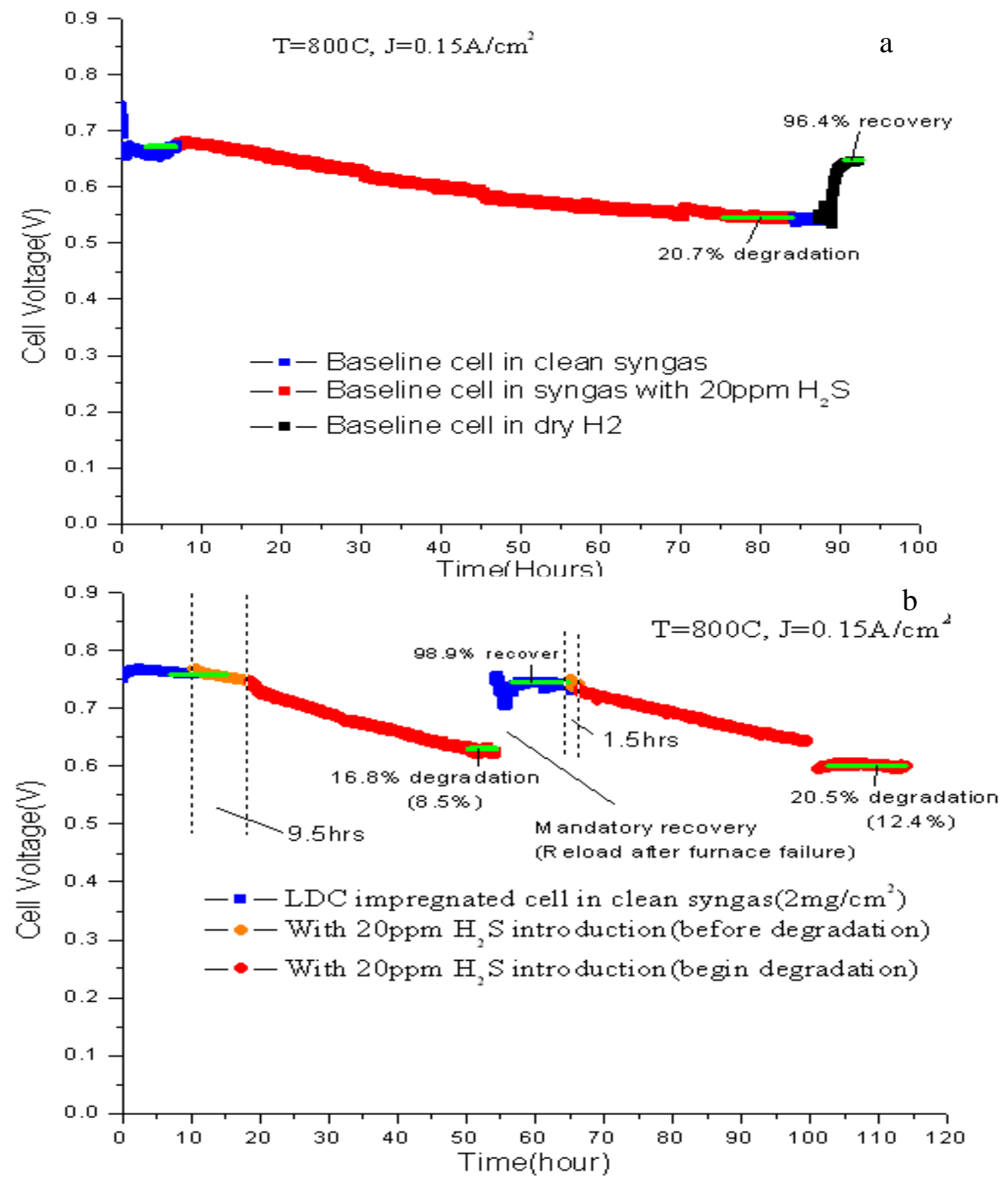

Figure 4.2.3 Change of cell voltage over time during syngas gas test with $20 \mathrm{ppm} \mathrm{H} 2 \mathrm{~S}$ for (a) SSZ baseline cell with impregnation (b) LDC impregnated SSZ cell 
In contrast for LDC-impregnated anode the cell voltage keeps almost stable until over 9hrs after $\mathrm{H}_{2} \mathrm{~S}$ introduction as shown in Fig.4.2.3 (b). In comparison to study in section 4.1, results obtained here clarifies that the capability of LDC impregnated materials to delay on-set of sulfur poisoning is independent of anode configuration, rather depends on its intrinsic microstructure and physical properties. After the first $10 \mathrm{hrs}$, the cell voltage dropped much faster and becomes stable after another $35 \mathrm{hrs}$. The cell was then recovered in dry $\mathrm{H}_{2}$ after furnace power was accidentally shut-off (temperature drops for a couple of hours). The cell performance can be almost totally recovered after switching fuel to coal syngas again. It takes only 1 hour before the cell degradation starts upon $2^{\text {nd }}$ time of 20ppm $\mathrm{H}_{2} \mathrm{~S}$ introduction, indicating the destruction of doped ceria coating during the sulfur adsorption process.

The AC impedances of baseline and LDC-impregnated ESCs are compared in Fig. 4.2.4. For the baseline cell, only polarization resistance of cell anode increased at the beginning of degradation. This implies the mechanism of sulfur poisoning for this stage is adsorption of sulfur on Ni blocking the TPB for electrochemical reaction. During the extensive exposure to $\mathrm{H}_{2} \mathrm{~S}$, there is significant increase of polarization resistance accompanied by slightly increase of series resistance of the cell. This may be associated with partially transform of $\mathrm{Ni}$ by sulfur to produce secondary phase [10] and/or Ni surface reconstruction as reported [20]. Due to such irreversible interaction between $\mathrm{Ni}$ and sulfur during extended exposure part of the cell polarization resistance and series resistance cannot be recovered after fuel switching back to dry $\mathrm{H}_{2}$. On the other hand, in Fig.4.2.4 (b) introduction of LDC into the Ni-SSZ/YSZ anode has dramatic effects on cell degradation kinetics. It can be seen that both cell series resistance and polarization 
resistance increased only after $1 \mathrm{hrs}$ of $\mathrm{H}_{2} \mathrm{~S}$ introduction, and both of them increased significantly after $18 \mathrm{hrs}$ of $\mathrm{H}_{2} \mathrm{~S}$ exposure. Rs can be totally recovered after reload with syngas while $\mathrm{Rp}$ is only recoverable to the level after $1 \mathrm{hr}$ of sulfur poisoning. For such sulfur concentration level (20 ppm) and exposure time (within 20 hours), significant change of ohmic resistance has barely been reported for Ni-YSZ anodes. This signals LDC-impregnated Ni-YSZ anode may have different reaction mechanism with $\mathrm{H}_{2} \mathrm{~S}$ from conventional Ni-cermet anodes.
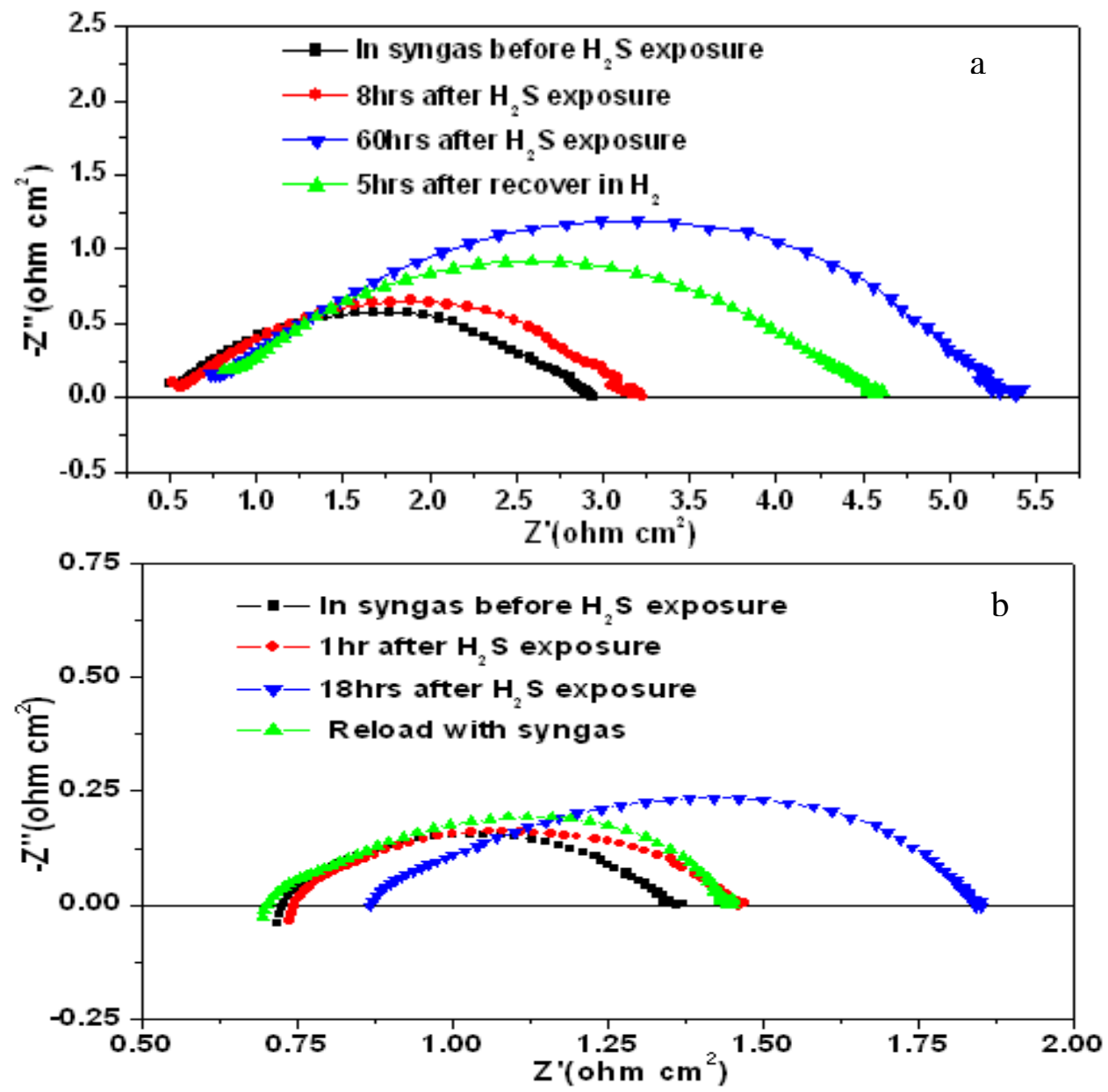

Figure 4.2.4 Change of $\mathrm{AC}$ impedance at $\mathrm{OCV}$ over time during test with $20 \mathrm{ppm}_{2} \mathrm{~S}$ for (a) baseline cell (b) LDC impregnated cell

Recently Bright reported increase of Rs for Ni-GDC anode shortly after introduction of 0.5-3 ppm $\mathrm{H}_{2} \mathrm{~S}$ at $750^{\circ} \mathrm{C}$, and it was ascribed to modified reactivity of Ni with $\mathrm{H}_{2} \mathrm{~S}$ by 
GDC electrolyte [72]. The same phenomenon was also observed in Lohsoontorn's work on Ni-GDC anode at lower temperature of $600^{\circ} \mathrm{C}$, rather reaction of GDC phase with $\mathrm{H}_{2} \mathrm{~S}$ was considered to account for anode ohmic resistance change[78]. For both of the papers no direct evidence from in-situ or ex-situ structural characterization of anode can be found to support the proposed poisoning mechanisms. But these works did suggest the sulfur poisoning of Ni-based anode with presence of doped ceria can be more complex than Ni-YSZ anode. As mentioned in the introduction of section 4.1.1 addition of doped ceria (like GDC) to Ni-based anode has been shown to improve sulfur tolerance compared to Ni-YSZ. Thus It seems unclear why doped ceria could meanwhile promote reaction of $\mathrm{Ni}$ with $\mathrm{H}_{2} \mathrm{~S}$, resulting in large conductivity change absent from Ni-YSZ anode which is degraded even more by $\mathrm{H}_{2} \mathrm{~S}$. Following Lohsoontorn's investigation it is considered in this study that the initial change of Rs and Rp may imply there is physic/chemi-sorbtion of $\mathrm{H}_{2} \mathrm{~S}$ on LDC impregnated particle, which may affect the ionic conductivity of the coating material and reduce the improvement of TPB kinetics compared to baseline Ni-YSZ anode. During longer exposure time, LDC can further react with $\mathrm{H}_{2} \mathrm{~S}$ to form certain secondary phases, and as a consequence both Rs and Rp rise. This assumption will be further examined with XRD and XPS analysis on the post-test anodes later. The fact that Rs can be recovered also suggests no irreversible reaction between $\mathrm{Ni}$ and sulfur occurs, showing the improved tolerance due to impregnation of LDC coatings. The unrecoverable proportion of Rp in Fig.4.2.4 (a) after reloading in syngas thus may relate to irreversible microstructure/phase change for the LDC coatings, which accounts for loss of sulfur adsorption capability during $2^{\text {nd }}$ cycle of $\mathrm{H}_{2} \mathrm{~S}$ test 


\subsubsection{Post-test cell characterization on interaction between LDC-impregnated anode with H2S with SEM and XRD}

The microstructures of baseline cell and LDC-impregnated cell are compared in Fig.4.2.5. As discussed in section 4.2.3.1, the impregnated LDC particles are scattered and only partially cover the Ni-YSZ anode surface. This can be a reason for relatively short period of delay of sulfur poisoning. However after extensive exposure to sulfur, most of the particles remain small in size (a few hundred $\mathrm{nm}$ ), and this high surface area of LDC particles could contribute to its sulfur adsorption capability.
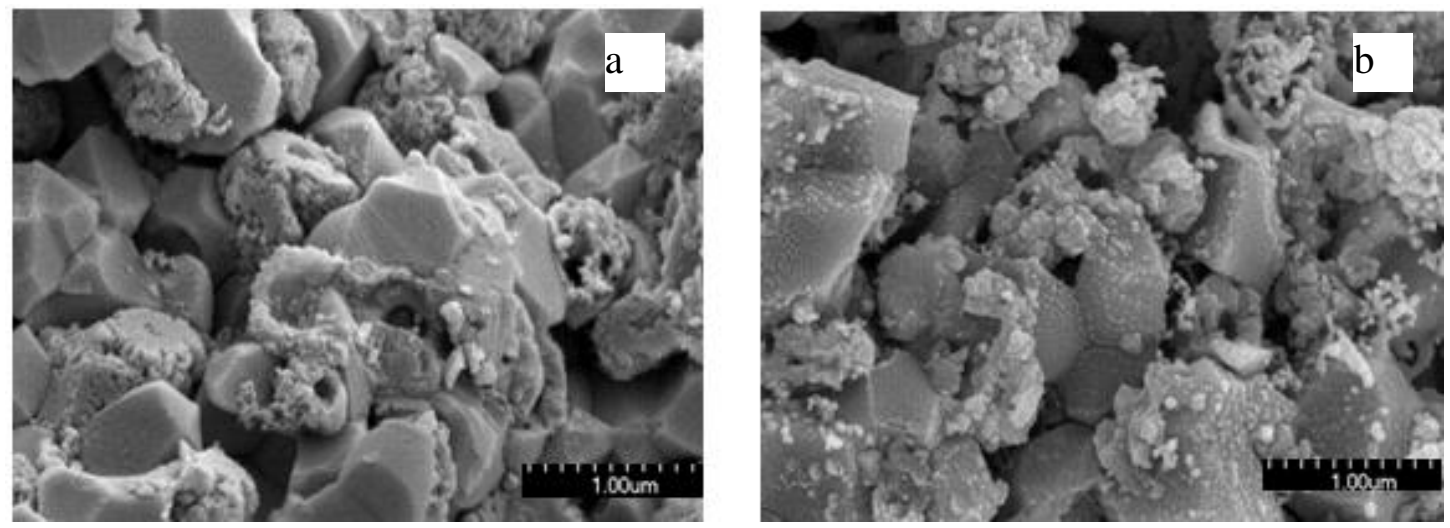

Figure 4.2.5 SEM pictures of the baseline and-LDC impregnated cells after $\mathrm{H} 2 \mathrm{~S}$ testing (a) Baseline cell (b) LDC impregnated cell

Fig.4.2.6 indicates EDS spectrum for the anode surface of LDC-impregnated cell after $2^{\text {nd }}$ test with $\mathrm{H}_{2} \mathrm{~S}$. Main peaks belonging to $\mathrm{Ni}, \mathrm{Sc}$, and $\mathrm{Zr}$ are identified for anode structural constituents, and the minor peaks belonging to $\mathrm{La}$ and $\mathrm{Ce}$ can be identified for the LDC coatings. However no sulfur peak is observable. Dong reported loss of sulfur from Ni-YSZ anode occurred during the cooling down of furnace from high temperature of $700-800^{\circ} \mathrm{C}$, which made remaining sulfur below detection limit for XRD [23]. On the other hand Trembly identified sulfur in EDS spectrum for Ni-GDC anode after exposure 
to $240 \mathrm{ppm} \mathrm{H}_{2} \mathrm{~S}$ for over 600 hours [10]. Hence the relatively low $\mathrm{H}_{2} \mathrm{~S}$ concentration and short-term exposure time used in this study may not leave any detectable sulfur in EDS.

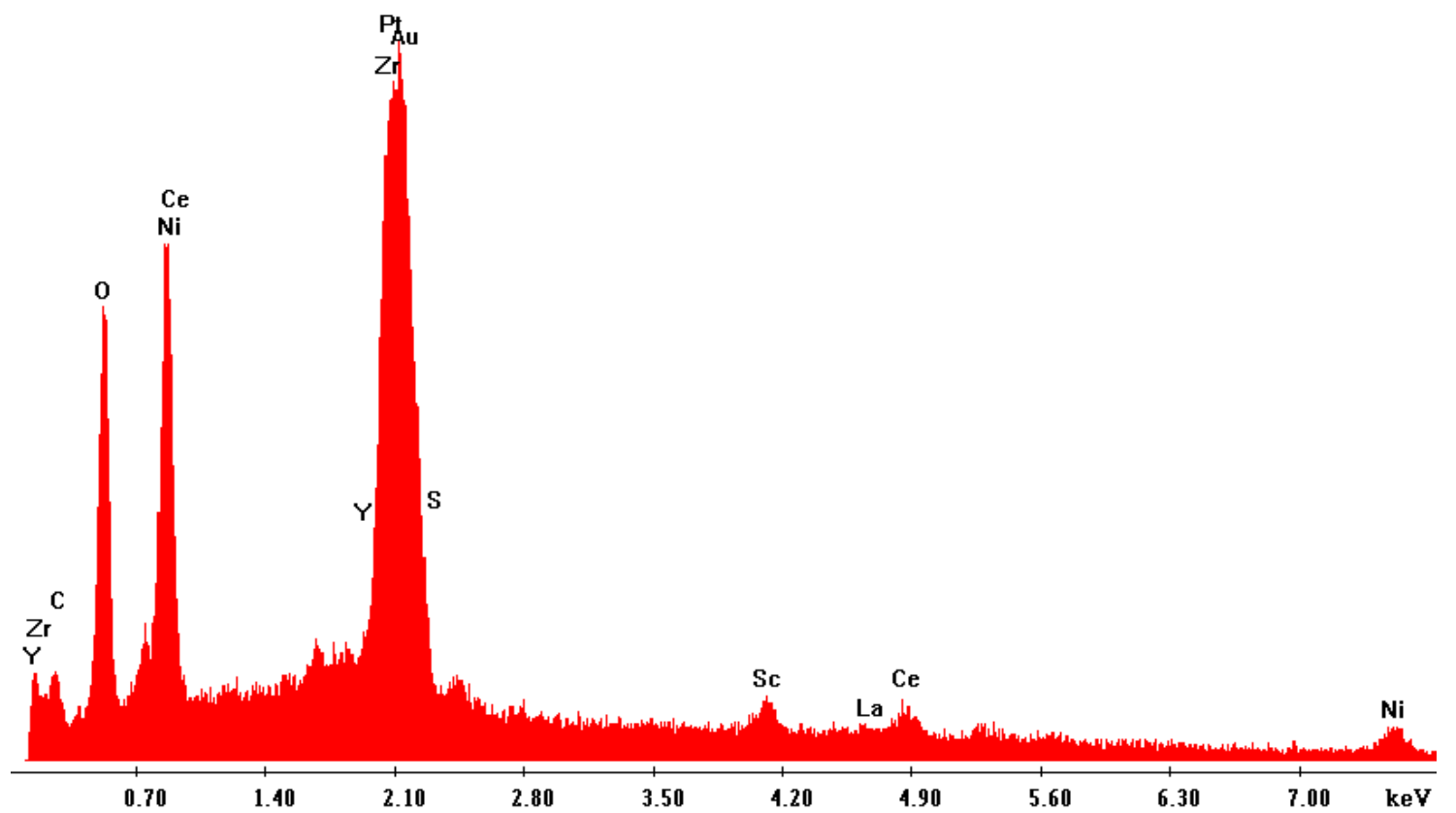

Figure 4.2.6 EDS of LDC-impregnated electrolyte supported andoe after H2S testing

Fig.4.2.7 (a) and (b) shows the XRD patterns for base line cell and LDC-impregnated cell after testing with $20 \mathrm{ppm} \mathrm{H}_{2} \mathrm{~S}$ in syngas. There is no phase transition observable for baseline cell except the structures of basic Ni-SSZ/YSSZ anode and YSZ/SSZ electrolyte. It has been noticed before that even after exposure to $100 \mathrm{ppm}$ of $\mathrm{H}_{2} \mathrm{~S}$ for 5 days, no sulfur can found for Ni-YSZ anode with XRD analysis [23]. The lack of in-situ analysis in this study does not rule out the possibility for formation of secondary Ni-S phases at high temperature. Nevertheless, thermodynamic calculation indicates that bulk Ni sulfide would not form at high temperature until the sulfur level exceeds thousands of ppm as shown in 4.2.3.4. Also in-situ measurement with Raman spectroscopy on Ni-YSZ anode after 50 ppm $\mathrm{H}_{2} \mathrm{~S}$ exposure could not find stable $\mathrm{Ni}$ sulfides above $500^{\circ} \mathrm{C}[79]$. Thus it is considered here that $\mathrm{Ni}$ surface reconstruction due to sulfur coverage rather than $\mathrm{Ni}$ sulfur phase transition accounts for irreversible performance loss of baseline cell [19]. 
The formation of Ni-Pt intermetallic compound is confirmed during the XRD analysis. This is resulted from inter-diffusion of Ni with Pt paste and mesh during the co-sintering of anode with current collector before fuel cell test, which has also been found elsewhere when doing similar test on ESC with Ni-GDC anode[80]. However within the testing period, formation of Ni-Pt does not show apparent effects on cell performance for both baseline and impregnated cells. This may imply the inter-diffusion reaches equilibrium already during the co-sintering of anode with Pt current collector, although further diffusion and secondary phase reaction can be concern for long-term test beyond hundreds of hours. The experimental result showed formation of Ni-Pt intermetallic phase significantly retarded sulfur adsorption on Ni-base anode. As Pt has been successfully used as SOFC anode for electrochemical oxidation of $\mathrm{H}_{2} \mathrm{~S}$ at $650-850{ }^{\circ} \mathrm{C}$ [7,8], the observed dramatic change of sulfur adsorption kinetics for ECS may come directly from superior sulfur resistance of Pt compared to Ni.

The XRD pattern for LDC-impregnated cell in Fig.4.2.7 (b) shows multiple secondary phase formation during the sulfur poisoning test. It is noticeable that $\mathrm{CeO}_{2}$ and $\mathrm{La}_{2} \mathrm{O}_{3} \cdot \mathrm{H}_{2} \mathrm{O}$ formed as a result of LDC decomposition. Hence the XRD result suggests the considerable rise of Rs and $\mathrm{Rp}$ observed in AC impedance for LDC-impregnated cell may be associated with decomposition of LDC to simple oxides as a result of reaction between LDC coating and $\mathrm{H}_{2} \mathrm{~S}$. At sulfur testing condition, these oxides could form secondary phases in-situ with sulfur as will be discussed in section 4.2.3.4. Although sulfur was considered to potentially affect phase stability of doped ceria before $[37,78]$, such structural change observed here has never been reported in the literature, despite in Trembly's study formation of cerium sulfide identified by EDS implied possible 
decomposition of GDC. The reason for detection of LDC phase transition in this study could come from higher reactivity of the small impregnated LDC particles with $\mathrm{H}_{2} \mathrm{~S}$, which are exempt from high-temperature sintering process used in previous works for $\mathrm{Ni}$ GDC bulk anode. On the other hand, further comparative study would be needed to verify whether the sulfur transformation phenomenon is only true for LDC phase or also applicable to other doped ceria materials.

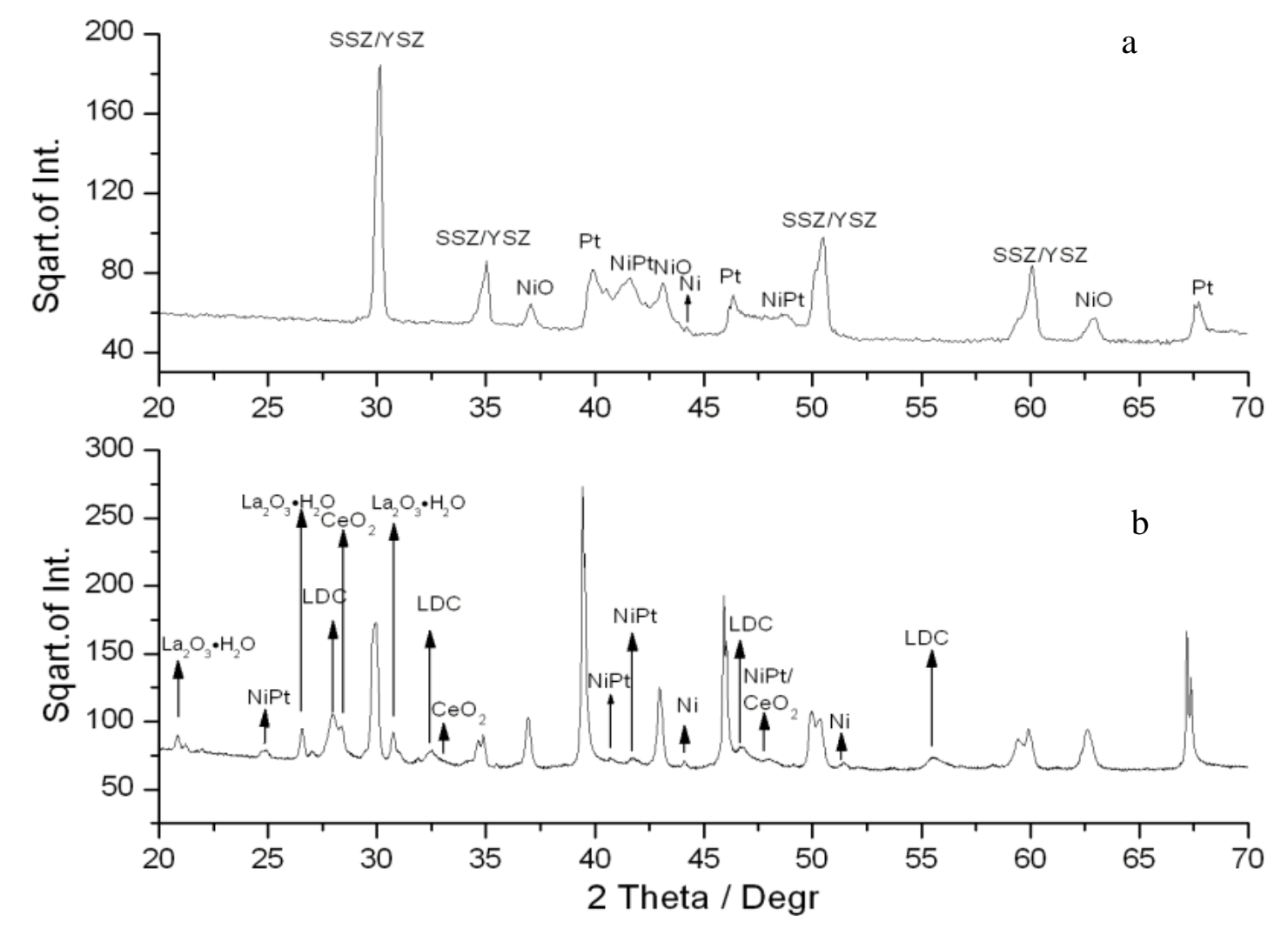

Figure 4.2.7 XRD patterns of SOFC anode after syngas gas test with $20 \mathrm{ppm} \mathrm{H} 2 \mathrm{~S}$ for (a) baseline cell (b) LDC impregnated cell

The decomposition of LDC, as verified by XRD, is at least partially irreversible. This explains the residue polarization resistance unrecoverable during dry $\mathrm{H}_{2}$ exposure. No phases associated with sulfur compounds are detected by XRD test, confirming the EDS result that residue sulfur inside anode after cell cooling down is beyond detection limit. 


\subsubsection{XPS and thermodynamic analysis}

Although the XRD and EDS results at room temperature cannot directly identify existence of sulfur compound in the anode after exposure test, the possibility of sulfurrelated phase transition for LDC-impregnated anode at high temperature should be not ruled out. More sophisticated analysis on anode surface is thus performed by XPS, and thermodynamic calculation is carried out to estimate chemical reaction between sulfur and LDC coatings. Fig. 4.2.8 displays the XPS spectra for baseline and LDC-impregnated cell after sulfur tolerance test. Only one sulfur peak belonging to elemental sulfur $(164.8 \mathrm{eV})$ can be identified for baseline cell, while an additional sulfur peak belonging to sulfide $(160.0 \mathrm{eV})$ is found for LDC-impregnated cell. The overwhelming of elemental sulfur peak in XPS spectra does not necessarily mean sulfur adsorbs on Ni physically, rather if any surface Ni sulfide exists at high temperature as reported previous by in-situ Raman microscopy[23], it could be oxidized to elemental sulfur at room temperature due to exposure to air. However the retention of sulfide peak in XPS spectra for LDC sample has been also found in another study on exposure of $\mathrm{CeO}_{2}$ to sulfur-containing atmosphere[81], which resulted in formation of $\mathrm{Ce}_{2} \mathrm{O}_{2} \mathrm{~S}$.
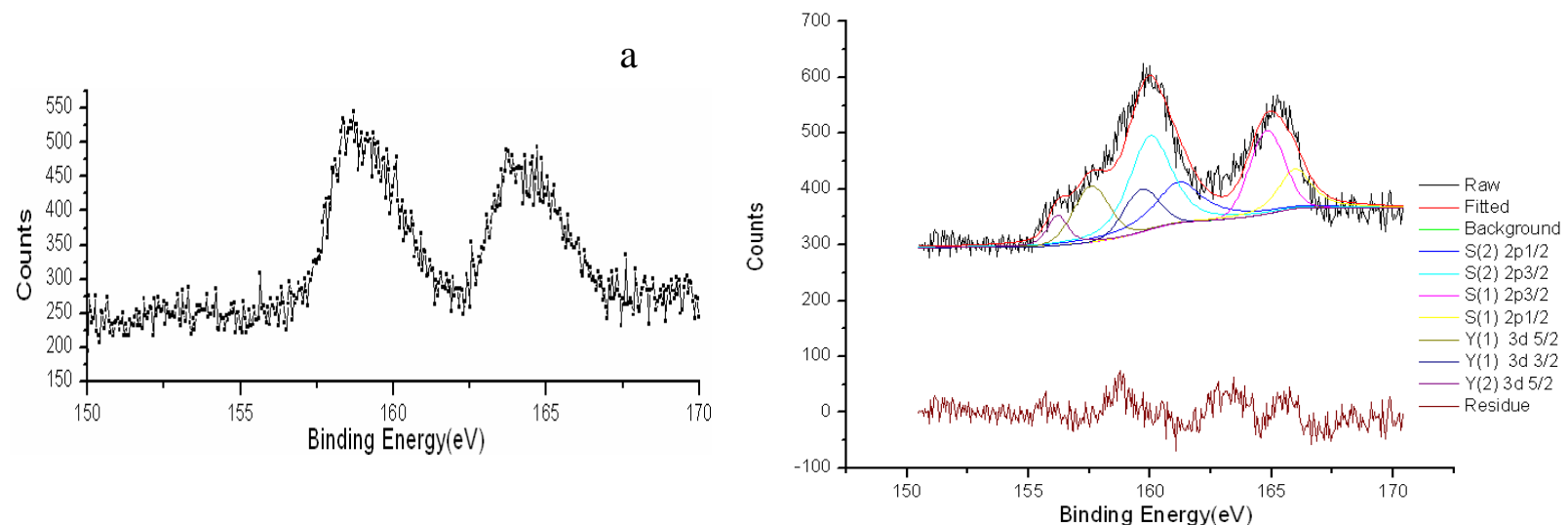

Figure 4.2.8 XPS spectrum of SOFC anode after syngas gas test with $20 \mathrm{ppm}_{2} \mathrm{~S}$ for (a) baseline cell (b) LDC impregnated cell 
Hence the XPS result may reveal reaction of LDC impregnated materials with $\mathrm{H}_{2} \mathrm{~S}$ at high temperature to form oxy-sulfide. Such sulfides may account for decomposition of LDC found in XRD pattern, and experience phase transform at low temperature to generate simple oxides. Without in-situ experimental evidence, thermodynamic calculation result is shown in Fig.4.2.9 and 4.2.10 to analyze the feasibility for reaction between Ni, LDC and $\mathrm{H}_{2} \mathrm{~S}$. Fig.4.2.9 showed that at cell testing condition no stable Ni sulfide phase existed, which is consistent with EDS and XRD results. As thermodynamic data of $\mathrm{La}_{2} \mathrm{O}_{2} \mathrm{~S}$ is lacked from literature survey, Gibbs free energy is estimated from reported thermodynamic values for corresponding ceria compounds in literature and database of Factsage 5.0 software[82]. It is found that at 1073K the Gibbs free energy change for reduced ceria oxide to form $\mathrm{Ce}_{2} \mathrm{O}_{2} \mathrm{~S}$ is slightly positive in Fig.4.2.10. However as the tendency for nanometer-sized Ni particle to reduce system Gibbs free energy was found to facilitate formation of Ni-S compound even with much larger thermodynamic energy barrier in report [23], the small impregnated LDC particles found in fig. 4.2 .5 are expected to favor occurring of such reaction in large magnitude. On the other hand as sulfur accumulates during the exposure test, higher local concentration of sulfur than $20 \mathrm{ppm}$ nominal level would be expected. This would also contribute to the chemical reaction between LDC and $\mathrm{H}_{2} \mathrm{~S}$. Therefore the small energy barrier found for $\mathrm{Ce}_{2} \mathrm{O}_{2} \mathrm{~S}$ formation at high temperature may rather reflect the reaction mechanism between LDC and $\mathrm{H}_{2} \mathrm{~S}$ to form oxy-sulfide. It should be mentioned that Fig.4.2.10 uses $\mathrm{Ce}_{2} \mathrm{O}_{3}$ as starting reactant, while for actual syngas atmosphere the ceria oxide exists as the form of $\mathrm{CeO}_{2-\mathrm{x}}(1.5<\mathrm{x}<2)$ [37]. This suggests total conversion of ceria oxide to oxy-sulfide may not be energetically favorable as only partial decomposition of LDC found in XRD result. 


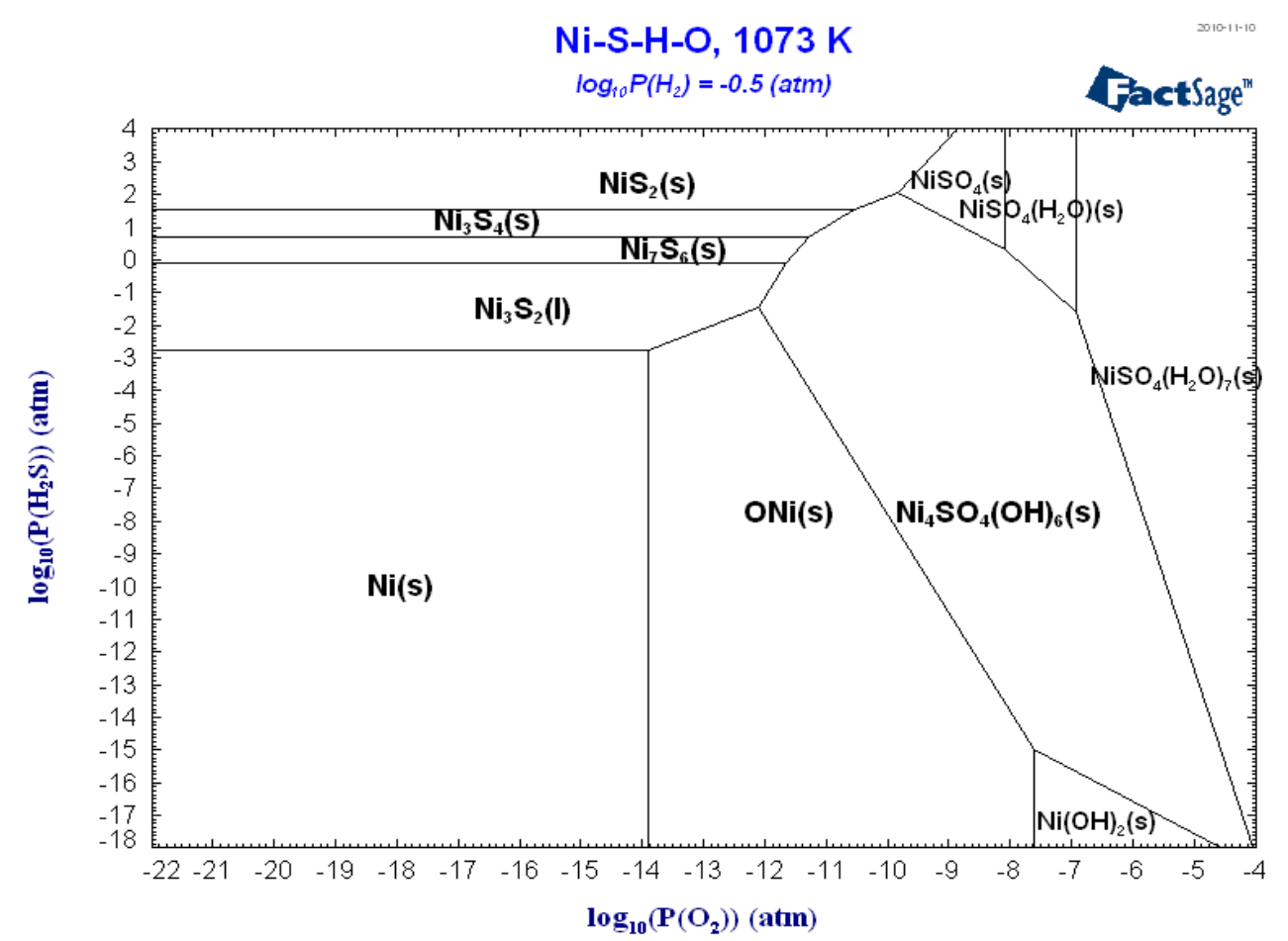

Figure 4.2.9 Thermodynamic calculated Ni-S-H-O with Factsage software at $800^{\circ} \mathrm{C}$

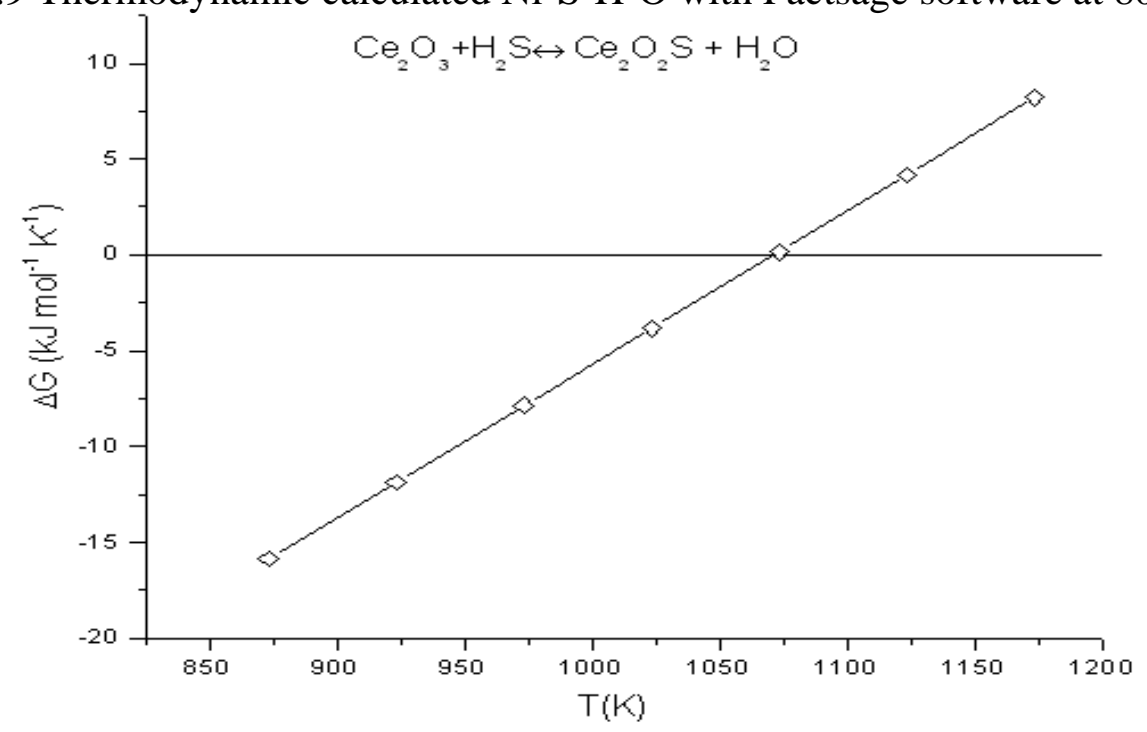

Figure 4.2.10 Thermodynamic estimation of Gibbs free energy for reaction between reduced ceira oxide and $20 \mathrm{ppm}_{2} \mathrm{~S}$ to form cerium oxy-sulfide (estimated with $26 \%$ $\left.\mathrm{H}_{2} \mathrm{O}\right)$

\subsubsection{Conclusion}

Tolerance test of baseline and LDC-impregnated electrolyte supported cell with NiSSZ/YSZ anode in coal syngas with $20 \mathrm{ppm}$ of $\mathrm{H}_{2} \mathrm{~S}$ indicated LDC coating improves sulfur resistance of anode by delaying of sulfur poisoning and preventing of further 
reaction of $\mathrm{Ni}$ with $\mathrm{H}_{2} \mathrm{~S}$, verifying the previous testing results with anode supported cells. Combined analysis with XRD, XPS and thermodynamic calculation suggests the sulfur tolerant mechanism of LDC involves adsorption of sulfur by LDC and subsequent chemical reaction to form oxy-sulfide, resulting in partial decomposition of LDC. The low coverage of impregnated LDC particles on Ni anode surface due to small loading may account for the limited protection effects against $\mathrm{H}_{2} \mathrm{~S}$. Further comparative study is recommended to identify the observed different reaction behavior of LDC with $\mathrm{H}_{2} \mathrm{~S}$ from those reported for GDC and YSZ in the SOFC anode. 


\section{Chapter 5 Experimental Investigation of Impurity Effects from Phosphine on SOFC Anodes in Coal Syngas}

\subsection{Effect of $\mathrm{PH}_{3}$ on Ni-YSZ anode supported SOFC}

\subsubsection{Introduction}

The standard SOFC composition, Ni-YSZ cermet anode plus YSZ electrolyte plus $\mathrm{LaSrMnO}_{3}$ cathode, can directly use coal syngas because of its ability to tolerate the $\mathrm{CO}$ and $\mathrm{CO}_{2}$ in coal-derived syngas. There is substantial interest in the effects of gaseous impurities contained in syngas on the long-term performance of SOFCs [83]. This study focuses on the phosphorus impurities. Volatile forms of phosphorus under warm gas cleanup conditions include $\mathrm{PH}_{3}$ and phosphorus oxides [84]. The effects of phosphine in syngas mixtures on Ni-YSZ anodes have been reported previously [68,69,84], however there is disagreement on the degradation mechanism and reaction products. Trembly found $\mathrm{Ni}_{5} \mathrm{P}_{2}$ formed on the $\mathrm{Ni}$-YSZ anode surface during the $\mathrm{PH}_{3}$ testing in coal syngas [84]. Pederson and co-workers performed degradation test of Ni-YSZ anode supported cell with 2-5 $\mathrm{ppm} \mathrm{PH}_{3}$, and observed delay of the anode poisoning at low concentration of impurity together with formation of $\mathrm{Ni}_{3} \mathrm{P}$ on both nickel current collector and anode supporting layer [68]. The degradation is mainly attributed to Ni migration out from the Ni-YSZ matrix and potential change of anode conductivity and electro-activity. In contrast, Zhi et al. studied YSZ electrolyte-supported Ni/YSZ half-cells under a high concentration of $\mathrm{PH}_{3}(20 \mathrm{ppm})$ [69]. The analysis by x-ray diffraction identified secondary phases of nickel phosphate and zirconyl phosphate on anode after impurity exposure, indicating both $\mathrm{Ni}$ catalyst and ionic-conductive YSZ components actively reacted with $\mathrm{PH}_{3}$ during the degradation process. 
In this study, the extended testing of commercial button cells with Ni/YSZ composite

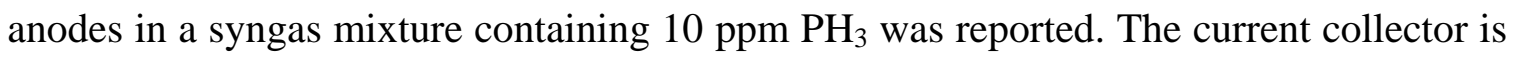
arranged to expose the central part of the anode to the fuel gas mixture without any intervening metal grid or metal paste. Periodic evaluation of impedance is used to follow the ohmic and polarization resistances during the experiment. Extensive post-mortem analyses by SEM, XRD and XPS are used to evaluate chemical and microstructural changes in the anode. These results are compared with the previous reports and thermodynamic predictions in order to understand the degradation mechanism and the basis for potential development of phosphorus tolerant SOFC anode.

\subsubsection{Experimental Methods}

\subsubsection{SOFC composition and testing}

In this study, commercial anode-supported solid oxide button cells manufactured by Materials and Systems Research Inc. (MSRI) were used. The cells consisted of five layers: (1) $\sim 0.8 \mathrm{~mm}$ thick Ni-8YSZ porous anode supporting layer (2) $25-\mu \mathrm{m}$ thick $\mathrm{Ni}-$ 8YSZ anode interlayer. (3) $20-\mu \mathrm{m}$ thick $8 \mathrm{YSZ}$ (YSZ) electrolyte. (4) $25-\mu \mathrm{m}$ thick $\mathrm{La}_{0.8} \mathrm{Sr}_{0.2} \mathrm{MnO}_{3}$ (LSM)-8YSZ cathode interlayer. (5) 50- $\mu \mathrm{m}$ thick current-collection layer made of LSM. The cell effective area (cathode area) is $2 \mathrm{~cm}^{2}$ [85]. A platinum current collection mesh was attached to the cell cathode using platinum paint. A pair of platinum current collection meshes separated by $0.5 \mathrm{~cm}$ was symmetrically attached on the cell anode using nickel paste. The anode center was directly exposed to the injected fuel without any intervening current collector or metal paste so that the impurity effects on the cell anode can be directly observed and identified (Fig.5.1.1). 


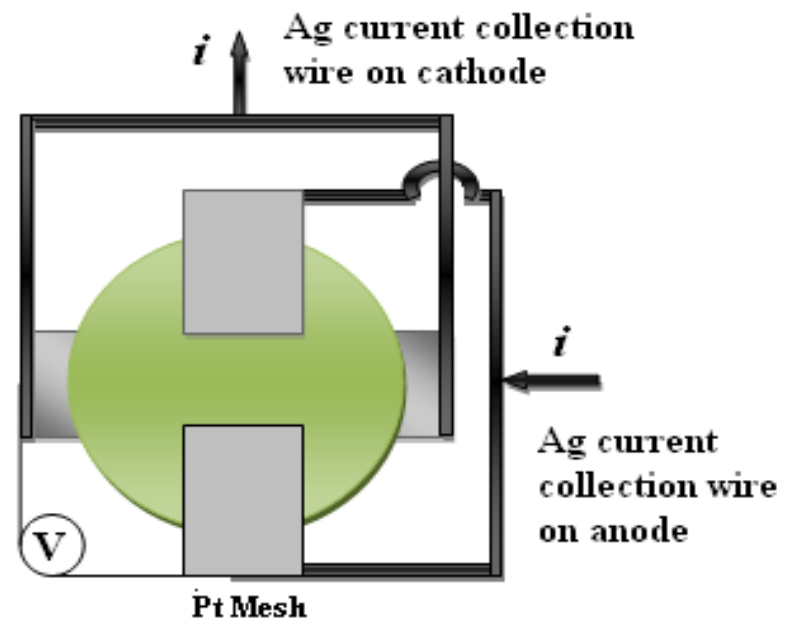

Figure 5.1.1 Button cell contact configuration

The two ends of the cathode and two ends of the anode current collection meshes were connected by thick silver wires; two thin voltage-sensing wires were connected to the cathode and anode current collection meshes. Pure nickel and YSZ coupons were placed on the Pt meshes of the anode to serve as passive reactants for the phosphine. The SOFC was mounted between two alumina flanges using mica washers as the sealing material. For all tests, the button cell assembly was mounted in a furnace operated at $800^{\circ} \mathrm{C}$. Alicat Scientific mass flow controllers (MFCs) were used to control the fuel and air stream flow rates and compositions. MFCs were used to control the flow rates of $\mathrm{H}_{2}$, $\mathrm{H}_{2} \mathrm{O}, \mathrm{CO}, \mathrm{CO}_{2}, \mathrm{~N}_{2} / \mathrm{PH}_{3}$ (1000 ppm $\mathrm{PH}_{3}$ in nitrogen) and air separately. A temperaturecontrolled humidifier was used to adjust the $\mathrm{H}_{2} \mathrm{O}$ concentration of the simulated coal syngas provided to the anode. The total syngas fuel flow rate was kept at approximately $200 \pm 2 \mathrm{sccm}$ (standard cubic centimeters per minute) and the air-flow rate was kept at approximately $300 \pm 2 \mathrm{sccm}$. The anode fuel transfer lines were pre-heated to prevent water condensation between the humidifier and furnace. $\mathrm{CO}, \mathrm{CO}_{2}$ and $\mathrm{PH}_{3}$ were injected 
downstream of the anode humidifier close to furnace to ensure all trace species injected into the stream reached the anode of the SOFC.

\subsubsection{Electrochemical testing of SOFC}

The "as-received" SOFC was heated from room temperature to $800{ }^{\circ} \mathrm{C}$ at a rate of $7^{\circ} \mathrm{C} \min ^{-1}$. Once the SOFC reached $800^{\circ} \mathrm{C}$, the cell was firstly reduced by providing fuel flow containing $10 \% \mathrm{H}_{2}$ and balance $\mathrm{N}_{2}$ for approximately 2 hours. Then the fuel was switched to $50 \% \mathrm{H}_{2}$ and $50 \% \mathrm{~N}_{2}$ and eventually to humidified $\mathrm{H}_{2}\left(3 \% \mathrm{H}_{2} \mathrm{O}\right)$ to complete the reduction. The cell open circuit voltage $(\mathrm{OCV})$ was stable $1.061 \pm 0.001 \mathrm{~V}$ with wet $\mathrm{H}_{2}$ as the fuel. The OCV was less than theoretical value of $1.100 \mathrm{~V}$ with $97 \% \mathrm{H}_{2}, 3 \%$ $\mathrm{H}_{2} \mathrm{O}$ on the anode side and air $\left(21 \% \mathrm{O}_{2}\right)$ on the cathode side presumably because of slight leakage around the cell seals and possibly through the electrolyte. Then, $0.25 \mathrm{~A} \mathrm{~cm}^{-2}$ direct current (DC) was loaded for a current treatment overnight (14 hrs). The constant DC current density load was supplied by a solid-state loaded cell (TDI Transistor Device SD-103). After loading the SOFC at constant current density $0.5 \mathrm{~A} \mathrm{~cm}^{-2}$ for another 24 hours, the cell voltage stabilized at $0.715 \pm 0.001 \mathrm{~V}$. Upon shifting to syngas fuel (nominal concentration $30 \% \mathrm{H}_{2}, 26 \% \mathrm{H}_{2} \mathrm{O}, 23 \% \mathrm{CO}$, and $21 \% \mathrm{CO}_{2}$ ), the cell $\mathrm{OCV}$ decreased to $0.962 \pm 0.002 \mathrm{~V}$. After the cell voltage stabilized at $0.611 \pm 0.003 \mathrm{~V}$ under a loading current density of $0.5 \mathrm{~A} / \mathrm{cm}^{2}$ for 26 hours, $10 \mathrm{ppm}$ PH3 was injected in the fuel stream. The cell polarization curve and impedance spectra were taken at $0 \mathrm{hrs}, 46 \mathrm{hrs}$, $100 \mathrm{hrs}, 160 \mathrm{hrs}$ and $250 \mathrm{hrs}$ after adding $\mathrm{PH}_{3}$. The impedance spectra were collected using a Solartron SI 1260 impedance/gain-phase analyzer with AC amplitude of $20 \mathrm{mV}$ at frequencies ranging from $100 \mathrm{kHz}$ to $0.1 \mathrm{~Hz}$. After exposure to syngas with $10 \mathrm{ppm}$ $\mathrm{PH}_{3}$ for $250 \mathrm{hrs}$, the anode side of cell was purged with $\mathrm{N}_{2}$ and cooled down from $800^{\circ} \mathrm{C}$ 
to room temperature in about 3 hours still under the $\mathrm{N}_{2}$ purge. To check the reversibility of poisoning effects of $\mathrm{PH}_{3}$, one of the $\mathrm{PH}_{3}$-poisoned cells was run under the same conditions except that the fuel was changed to $\mathrm{H}_{2}$ for 12 hours after the prolonged exposure to $\mathrm{PH}_{3}$-contaminated syngas. The loss of performance of cell was not reversed, but the cell did not continually degrade.

\subsubsection{Morphology and structural analysis}

The surface and cross-section microstructure of the cell anode were examined with a Hitachi S-4700 SEM with EDS. To determine the composition of the anode, XRD (Panalytical X'Pert PM-3040 PRO) system, and XPS (PHI 5000 Versa Probe XPS Microprobe) were employed. Thermodynamic analysis is carried out with a FACTSAGE 5.4 software package to predict the predominant phase-diagram under cell operating condition by calculating the minimum Gibbs free energy change of the defined reactions.

\subsubsection{Experimental Results and Discussion}

\subsubsection{Polarization Curves and Impedance Spectra}

After accounting for slight increases in cell performance during burn-in, the SOFC performance (voltage at a constant current density) is stable over 24 hours in coal syngas. The cell performance degrades immediately upon introduction of $\mathrm{PH}_{3}$. (Fig.5.1.2). Performance loss is seen at nearly all current densities (Fig. 5.1.3). At a constant current load of $0.5 \mathrm{~A} \mathrm{~cm}^{-2}$, the cell voltage degradation rate is as constant as $0.46 \mathrm{mV} / \mathrm{hr}$ (Fig. 5.1.2). The cell OCV consistently remains at $0.962 \mathrm{~V}$. The dominant anodic process is assumed to be $\mathrm{H}_{2}$ oxidation, with the $\mathrm{CO}$ consumed by the water-gas shift equilibrium [1]. 


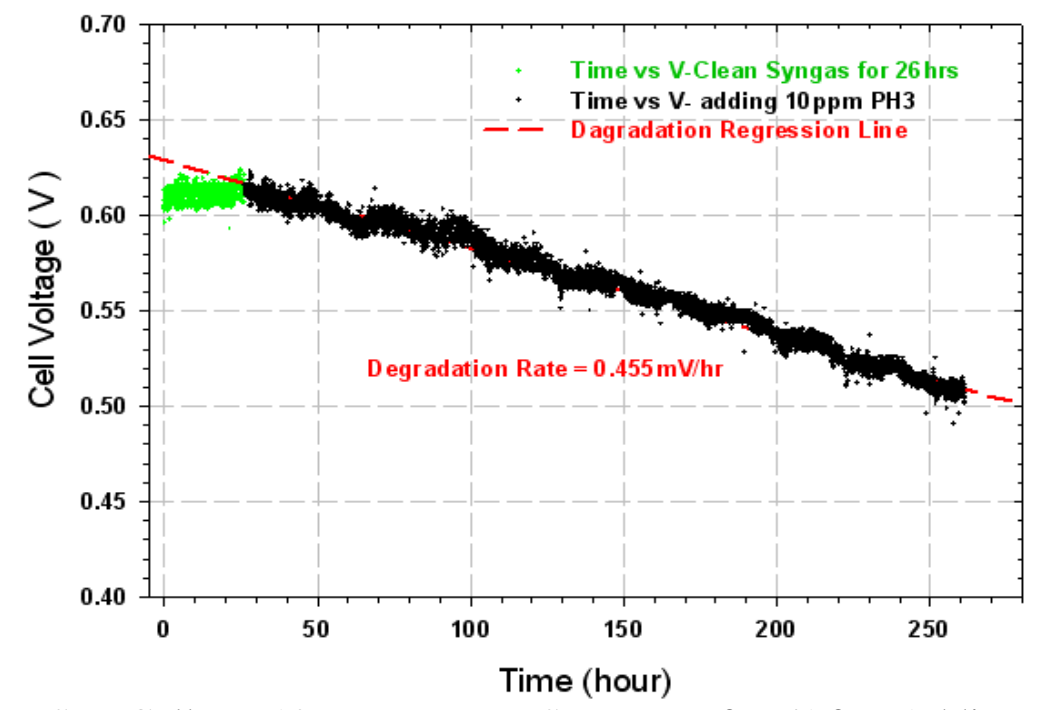

Figure 5.1.2 MSRI Cell No.12 Exposure to Syngas Before/After Adding $10 \mathrm{ppm} \mathrm{PH3} \mathrm{at}$ $\mathrm{T}=800 \mathrm{oC}$, Load $\mathrm{J}=0.5 \mathrm{~A} / \mathrm{cm}^{2}$

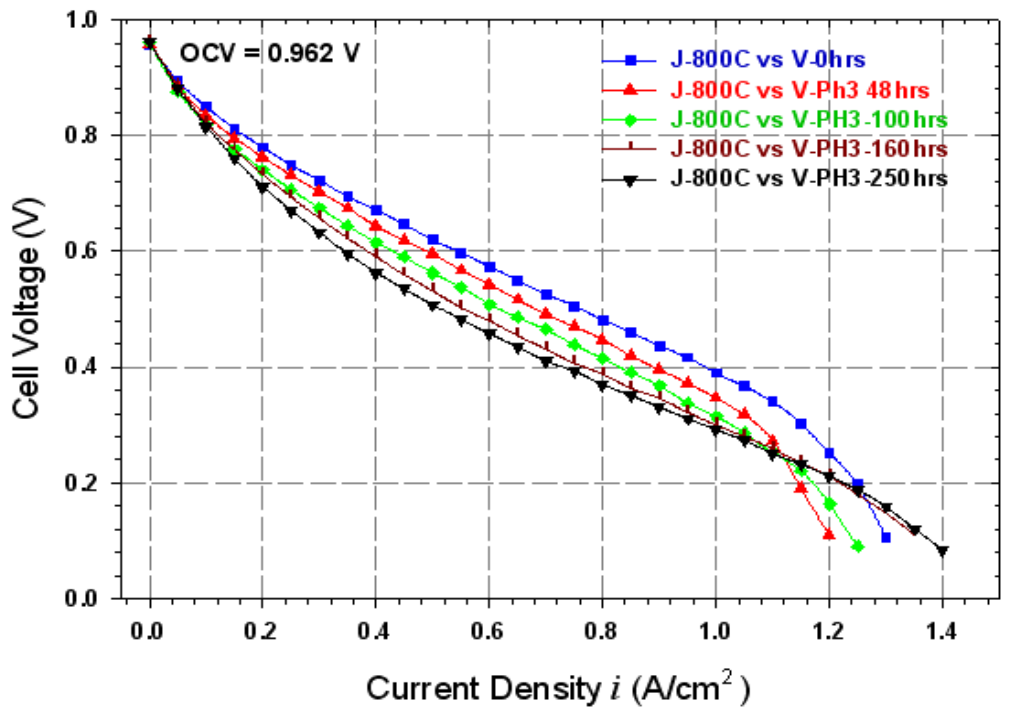

Figure 5.1.3 The polarization curves of Ni-YSZ anode supported button cell exposure to

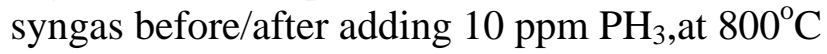

The impedance spectra under a DC bias of $0.662 \mathrm{~V}$ shows that the ohmic polarization resistance $R_{\Omega}$ (high frequency intercept with $Z^{\prime}$ axis) and the total polarization resistance $R_{\text {total }}$ (low frequency intercept with $Z^{\prime \prime}$ axis) increase with increasing time of exposure to $\mathrm{PH}_{3}$ (Fig. 5.1.4). Before adding $\mathrm{PH}_{3}$, the cell series resistance and total polarization resistance (area specific resistance) are about $0.22 \Omega \mathrm{cm}^{2}$ and $0.55 \Omega \mathrm{cm}^{2}$. After adding $\mathrm{PH}_{3}$ for 250 hours, they are $0.325 \Omega \mathrm{cm}^{2}$ and $0.88 \Omega \mathrm{cm}^{2}$ respectively. The difference 
between $R_{\text {total }}$ and $R_{\Omega}$ is the polarization resistance $R_{\rho}$ which is associated with activation and concentration polarization effects. These resistances increase in linearly with time (Fig.5.1.5). The $R_{\text {total }}$ increase rate is $1.29 \mathrm{~m} \Omega \mathrm{cm}^{2} \mathrm{hr}^{-1}$ which is three times the $R_{\Omega}$ increase rate of $0.42 \mathrm{~m} \Omega \cdot \mathrm{cm}^{2} \mathrm{hr}^{-1}$. The polarization resistance $R_{\rho}$ increase rate is about $0.87 \mathrm{~m} \Omega \mathrm{cm}^{2} \mathrm{hr}^{-1}$.

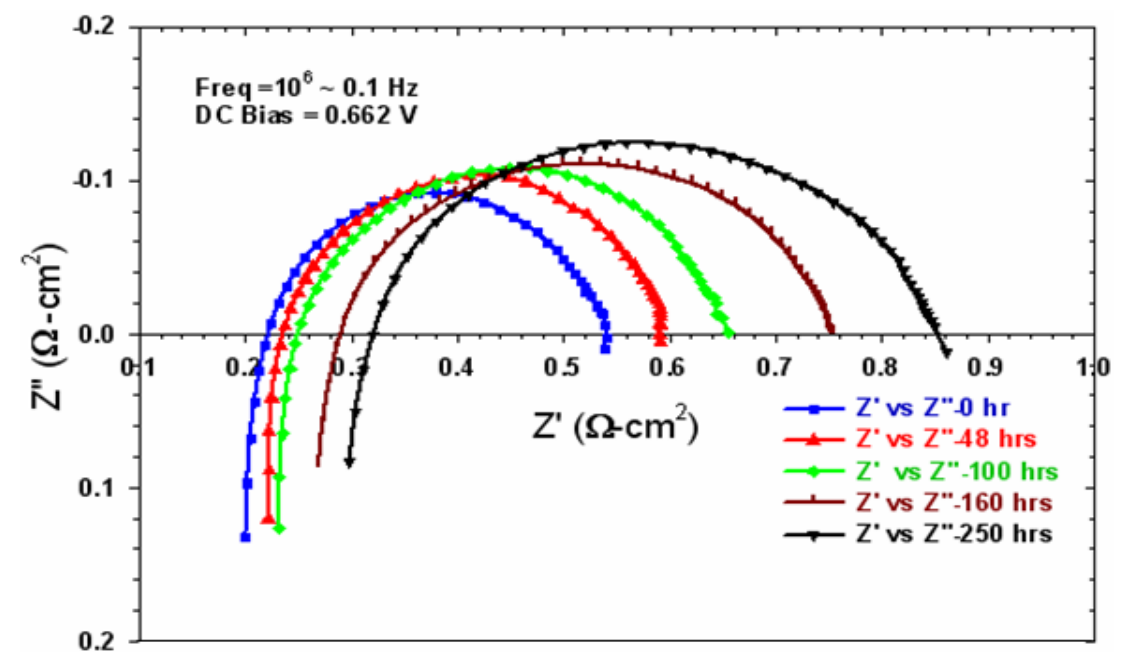

Figure 5.1.4 The normalized impedance spectrum of Ni-YSZ anode supported button cell

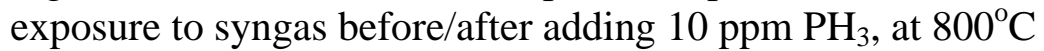

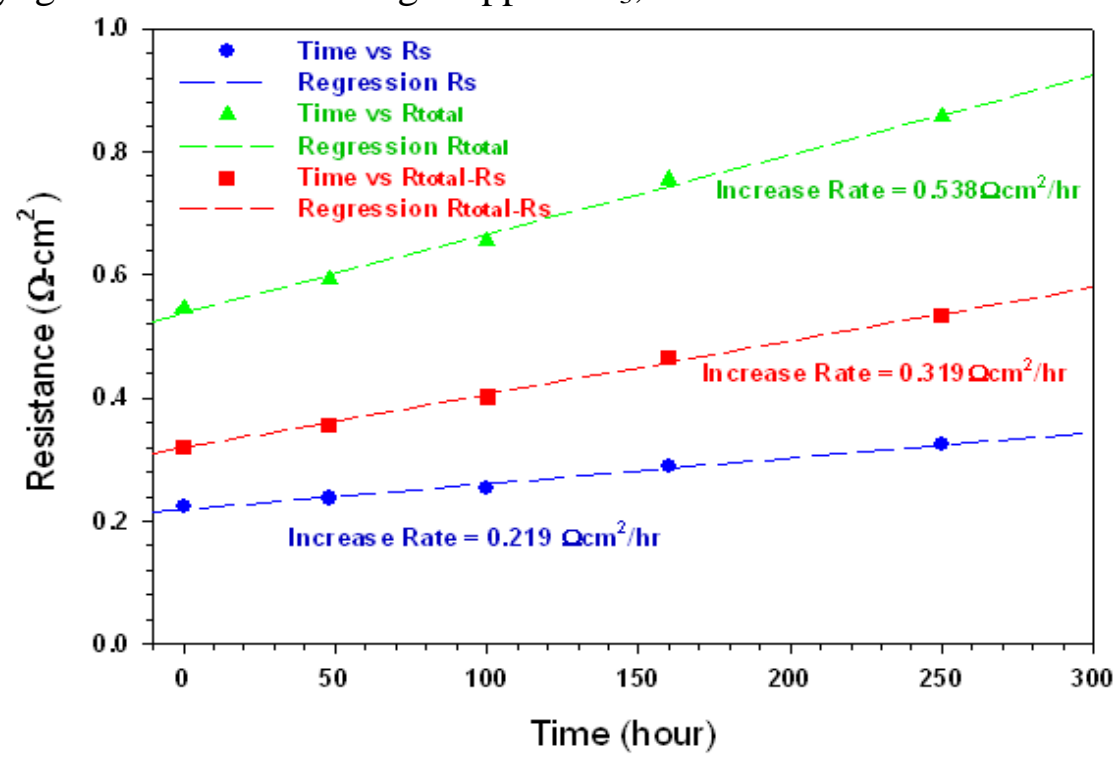

Figure 5.1.5 The cell ohmic resistance $R s$ and Polarization $R p$ versus time after adding 10 ppm $\mathrm{PH}_{3}$ 


\subsubsection{SEM Micrograph and EDS Spectra}

Photograph of a postmortem cell anode is shown in Fig. 5.1.6. In the post-mortem picture, a colored oval pattern at the center of the anode has appeared just under the quarter-inch alumina fuel inlet tubing. The exposed anode surface area is metallic in appearance, which implies a change of Ni-YSZ composition and pore structure.

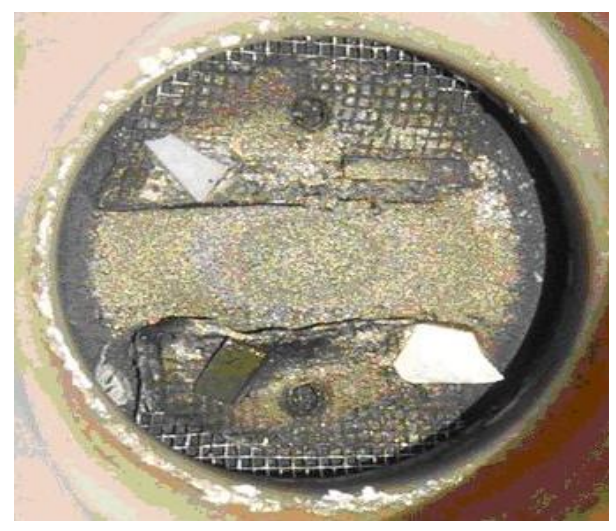

Figure 5.1.6 Post-mortem cell anode side image

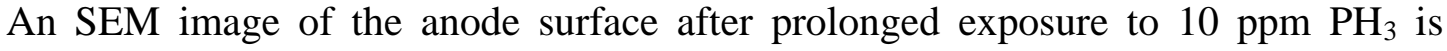
shown in Fig. 5.1.7(a). For comparison, the outer surface of a reduced anode never exposed to $\mathrm{PH}_{3}$ is provided in Fig. 5.1.7(b). The poisoned anode surface shows significant losses of pore structure and agglomeration of material on the open surface area.
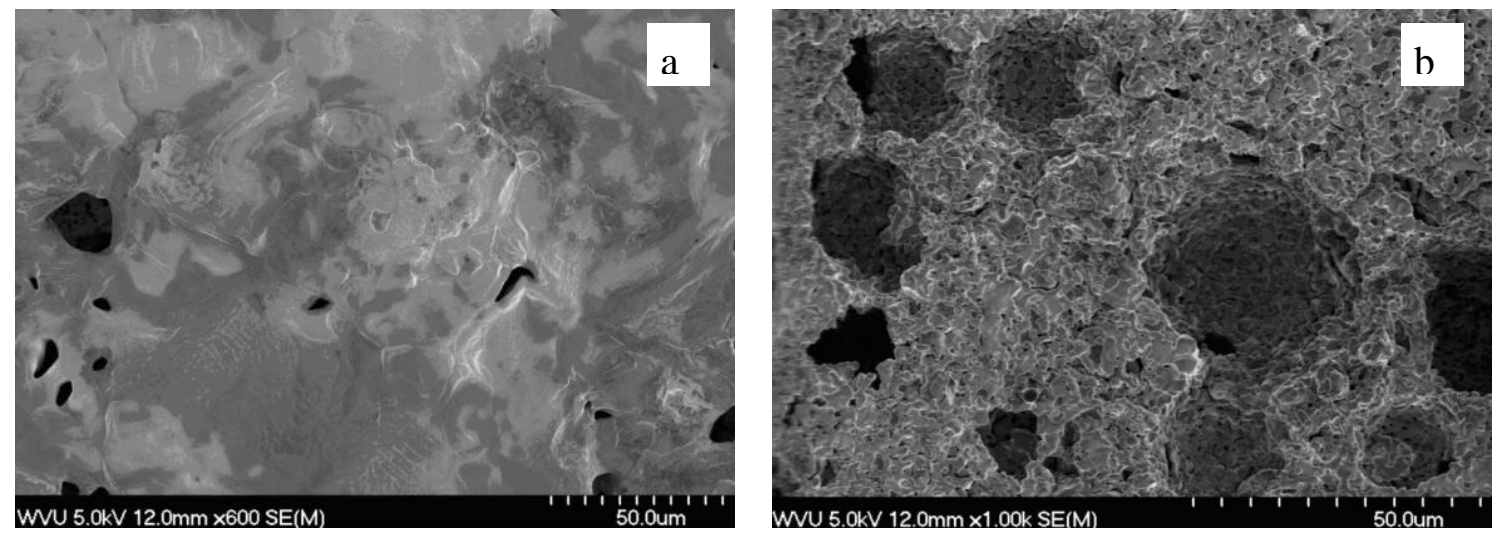

Figure 5.1.7 (a) The cell anode surface SEM micrograph after exposure to syngas with $10 \mathrm{ppm} \mathrm{PH}_{3}$ for 250 hours. (b) The clean reduced cell anode surface SEM micrograph for comparison 
The cross-section image in Fig. 5.1.8(a) shows that the Ni migrated to the top surface to form a layer with $\mathrm{Ni}$ particles fused into big chunks in the pores. $\mathrm{Ni}$ weight concentrations by EDS spectra scan are given at the five spots. Ni weight concentration is $86 \%$ at spot No.1 on the top layer, which is much higher than that of clean reduced anode $(60 \% \sim 63 \%)$. The low Ni weight concentration $18 \%$ at spot No.2 is just under the top layer. No.3 and 5 spots are composed of 59\% and 56\% nickel, respectively, which is consistent with clean anode. Spot No.4 (83\% Ni) appears to be a nickel chunk in a former cavity. Similar morphological changes of Ni-YSZ anode after $\mathrm{PH}_{3}$ exposure have been found in the previous study [ 86]. However, this study uses anode center directly exposed to the contaminant downstream. Consequently, Ni migration inside anode towards surface is clearly independent of the current-collection mesh cover. The cross-section image of the clean reduced anode Fig. 5.1.8(b) displays the same porous Ni-YSZ matrix as the anode surface in Fig.5.1.7 (b), free of any Ni chunk. Overview of the cell crosssection showed anode microstructure reconstruction could occur to anode top layer around the cell center with a thickness up to $200 \sim 300 \mu \mathrm{m}$ by exposure to $\mathrm{PH}_{3}$.
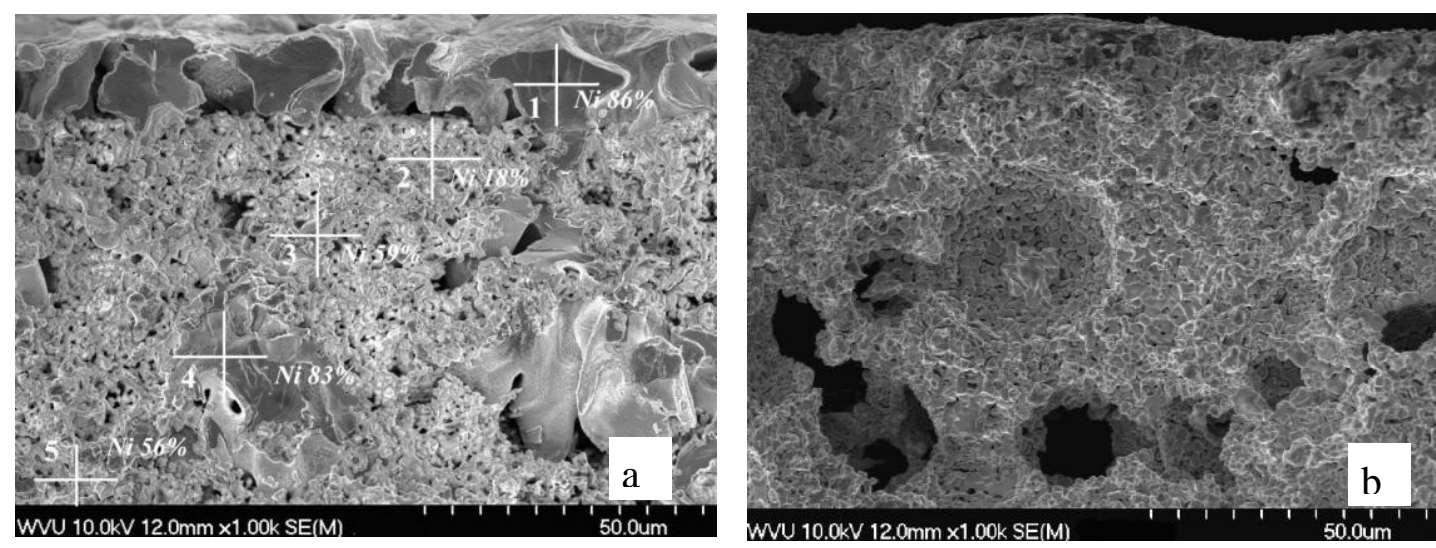

Figure 5.1.8 (a) The top $50 \mu \mathrm{m}$ cell anode cross-section SEM micrograph after exposure to syngas with $10 \mathrm{ppm} \mathrm{PH}_{3}$ for 250 hours. EDS scan shows the $\mathrm{Ni}$ weight \% on 5 different spots. (b) The top $50 \mu \mathrm{m}$ clean reduced cell anode cross-section SEM micrograph for comparison 
The EDS spectra (Fig.5.1.9 (a) and (b)) show the change of the composition on the anode surfaces of a clean reduced anode and the $\mathrm{PH}_{3}$ poisoned anode, respectively. The nickel peak at $0.860 \mathrm{keV}$ becomes much stronger relative to the overlapping $\mathrm{Y}$ and $\mathrm{Zr}$ peaks after the cell anode is exposed to $\mathrm{PH}_{3}$. Deconvolution of the peak at $2.02 \mathrm{keV}$ suggests that phosphorous is present on the surface. The carbon signal is not significant for both of spectra which indicate that the syngas composition used in these experiments does not result in much coke or carbon contamination on the Ni-YSZ anode. These data clearly indicate that nickel migrates to the outer surface of the anode and that nickel particles are redistributed inside the anode upon exposure to $\mathrm{PH}_{3}$. The redistribution of nickel affects multiple parameters important to the anode performance, such as the triple phase boundary (TPB) length, $\mathrm{H}_{2}$ adsorption area, porosity and tortuosity. These microstructural reconstructions appear to be irreversible.

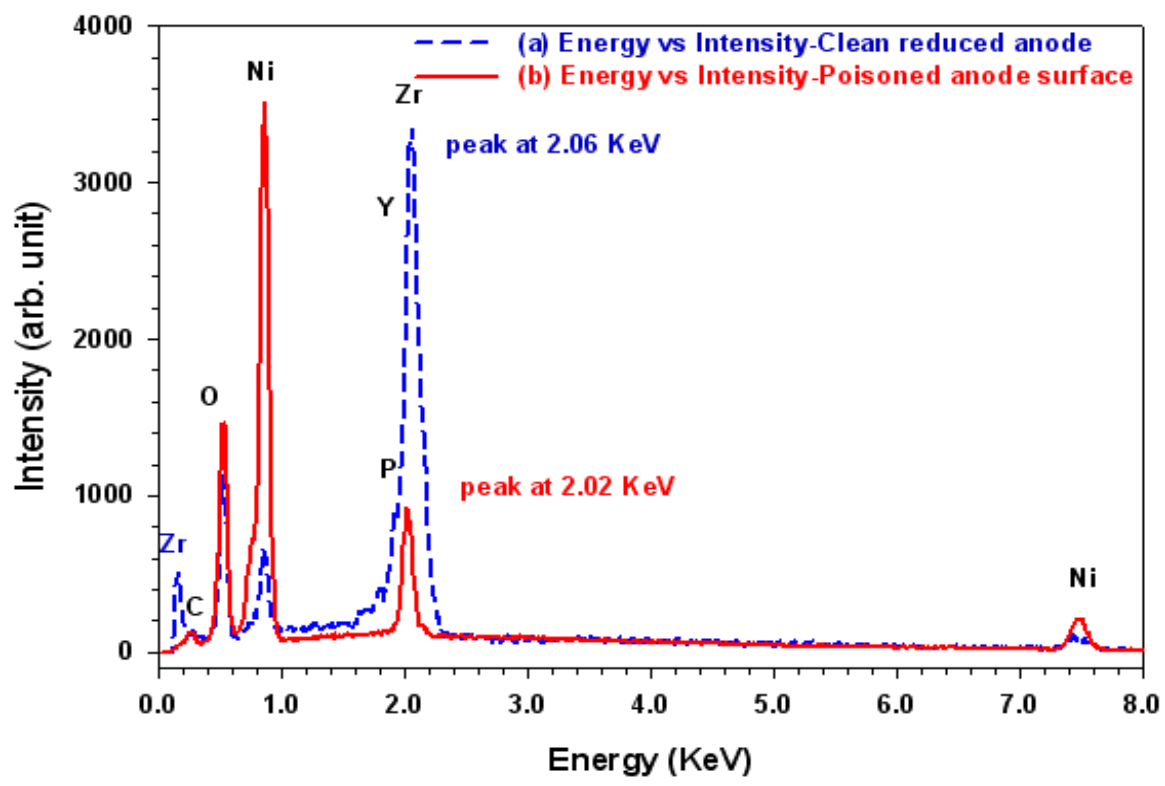

Figure 5.1.9 The EDS spectra of the clean reduced Ni-YSZ anode surface (dash line) and the Ni-YSZ anode surface after exposure to $\mathrm{PH}_{3}$ for 250 hours (solid line). 


\subsubsection{XRD and XPS spectra}

The evidence for nickel phosphide compounds on the $\mathrm{PH}_{3}$ poisoned Ni-YSZ anode center is provided by XRD spectra in Fig. 5.1.10 (a) \& (b). The peak positions of YSZ, $\mathrm{Ni}_{5} \mathrm{P}_{2}, \mathrm{Ni}, \mathrm{NiO}$ and $\mathrm{P}_{2} \mathrm{O}_{5}$ are identified by $2 \theta$ locations according to the $\mathrm{X}$ 'Pert Highscore Plus software database and literature $[87,88,89,90,91]$.

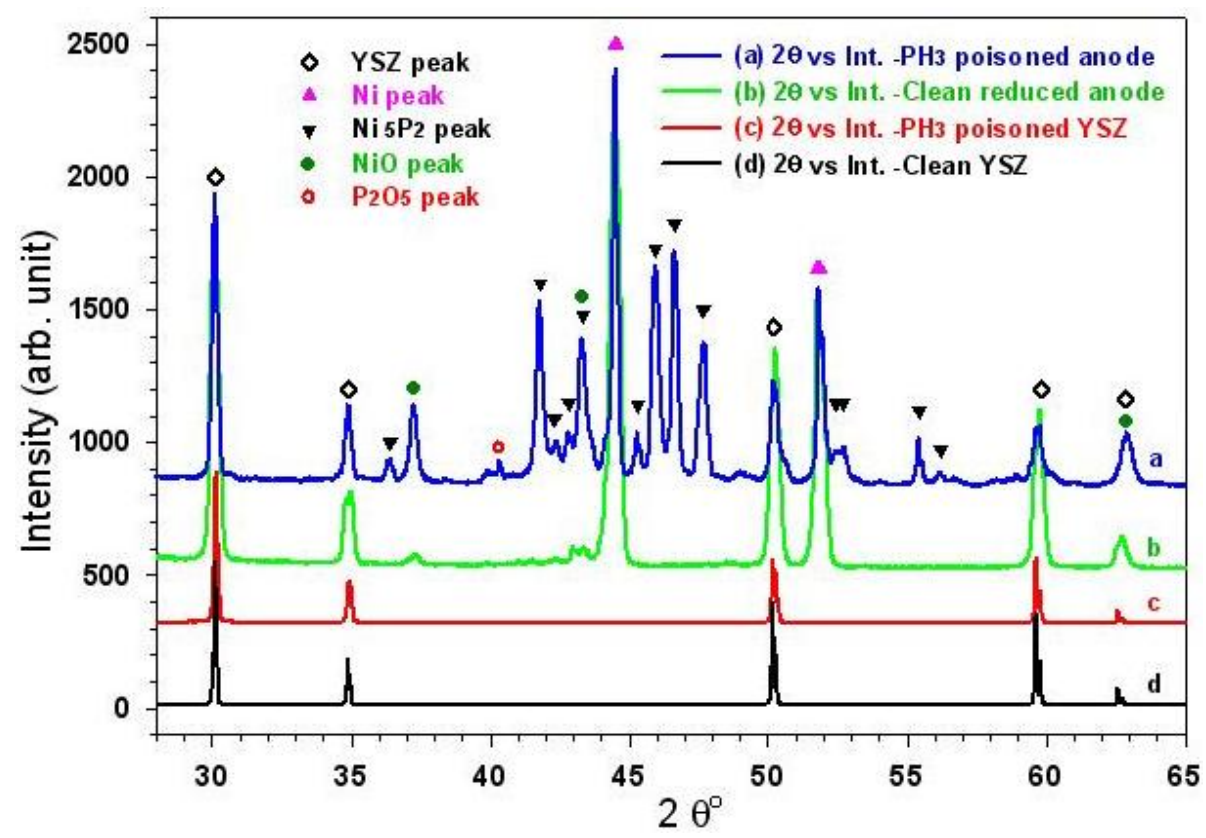

Figure 5.1.10 XRD spectra of $\mathrm{Ni}$-YSZ anode supported cell surfaces. $\mathrm{Ni}_{5} \mathrm{P}_{2}$ was confirmed to be present on the anode surface of cell after exposure to syngas with 10 ppm $\mathrm{PH}_{3}$

Both spectra in Fig. 5.1.10 (a) and (b) of Ni-YSZ anode have YSZ, Ni and NiO peaks. There are a group of $\mathrm{Ni}_{5} \mathrm{P}_{2}$ peaks on the $\mathrm{PH}_{3}$ poisoned Ni-YSZ anode spectrum Fig.5.1.10 (a). The other nickel phosphide peaks, such as $\mathrm{Ni3}, \mathrm{Ni}_{8} \mathrm{P}_{3}$ and $\mathrm{Ni}_{2} \mathrm{P}_{5}$, may overlap with the peaks of $\mathrm{Ni}_{5} \mathrm{P}_{2}$. However, two of the signature peaks of $\mathrm{Ni}_{5} \mathrm{P}_{2}$ at $45.95^{\circ}$ and $47.66^{\circ} \pm$ $0.02^{\circ}$ appear in the spectrum (Fig.5.1.10 (a)) [88], so $\mathrm{Ni}_{5} \mathrm{P}_{2}$ is assumed to be the dominant phase. There is a weak peak at $40.31^{\circ} \pm 0.02^{\circ}$, which could be one of $\mathrm{P}_{2} \mathrm{O}_{5}$ main peaks [91]. The clean, reduced Ni-YSZ anode spectrum (Fig.5.1.10 (b)) only shows the YSZ, $\mathrm{Ni}$ and $\mathrm{NiO}$ peaks, and does not exhibit any nickel phosphide peaks. The five signature 
peaks of YSZ at $2 \theta$ values of $30.10^{\circ}, 34.89^{\circ}, 50.21^{\circ}, 59.79^{\circ}$ and $62.59^{\circ} \pm 0.02^{\circ}$ [87] are displayed on both the YSZ coupon (Fig.5.1.10 (c)) and the clean YSZ sample (Fig.5.1.10 (d)) spectra. Previously published studies have found specific cell operating conditions as well as the experimental set-up greatly influence the reactions of phosphorus species in syngas with the Ni-YSZ anode and the corresponding product phases,. For example it was determined by thermodynamic equilibrium calculation that, for $2 \mathrm{ppm}^{\mathrm{PH}} \mathrm{H}_{3}$ in syngas, $\mathrm{Ni}_{5} \mathrm{P}_{2}$ would most likely form at the inlet of Ni-YSZ anode [67]. Marina et al. conducted a recent experimental study on a Ni-YSZ anode supported cell, and reported formation of $\mathrm{Ni}_{3} \mathrm{P}$ on both anode surface layer and the $\mathrm{Ni}$ grid current collector covering the anode

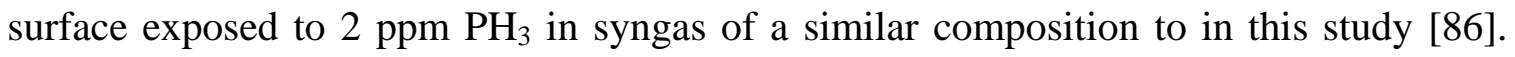
Despite the prior achievements, the degradation mechanism for the SOFC anode by phosphine attack at real operation conditions is still needed to be clarified from both theoretical and experimental ends. Detailed thermodynamic equilibrium calculation is thus performed (see 5.1.4) to further analyze the current XRD results and elucidate the phase-transition history for Ni-YSZ and its effect on the structural failure of the anode.

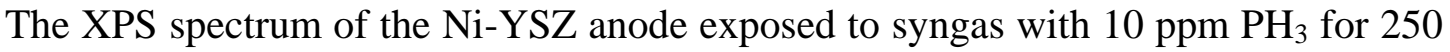
hours is shown in Fig. 5.1.11. The major core level detected peaks are phosphorus 2s, 2p, carbon $1 \mathrm{~s}$, oxygen $1 \mathrm{~s}$, nickel $3 \mathrm{p}$ and LMM. The phosphorus $2 \mathrm{p} 3 / 2$ electron binding energy peak is positioned at $134.30 \pm 0.05 \mathrm{eV}$ which implies that the phosphate phase, $\mathrm{P}_{2} \mathrm{O}_{5}$ or $\mathrm{PO}_{4}{ }^{3-}$, could be present on the sample surface. Ni $2 \mathrm{p} 3 / 2$ electron has two peaks at $854.60 \pm 0.05 \mathrm{eV}$ and $856.80 \pm 0.05 \mathrm{eV}$ which could be assigned to nickel oxide, nickel phosphate or nickel hydroxide $[92,93]$. It should be noted that there are no 
significant YSZ peaks in the spectrum because the nickel and nickel compounds have covered the surface.

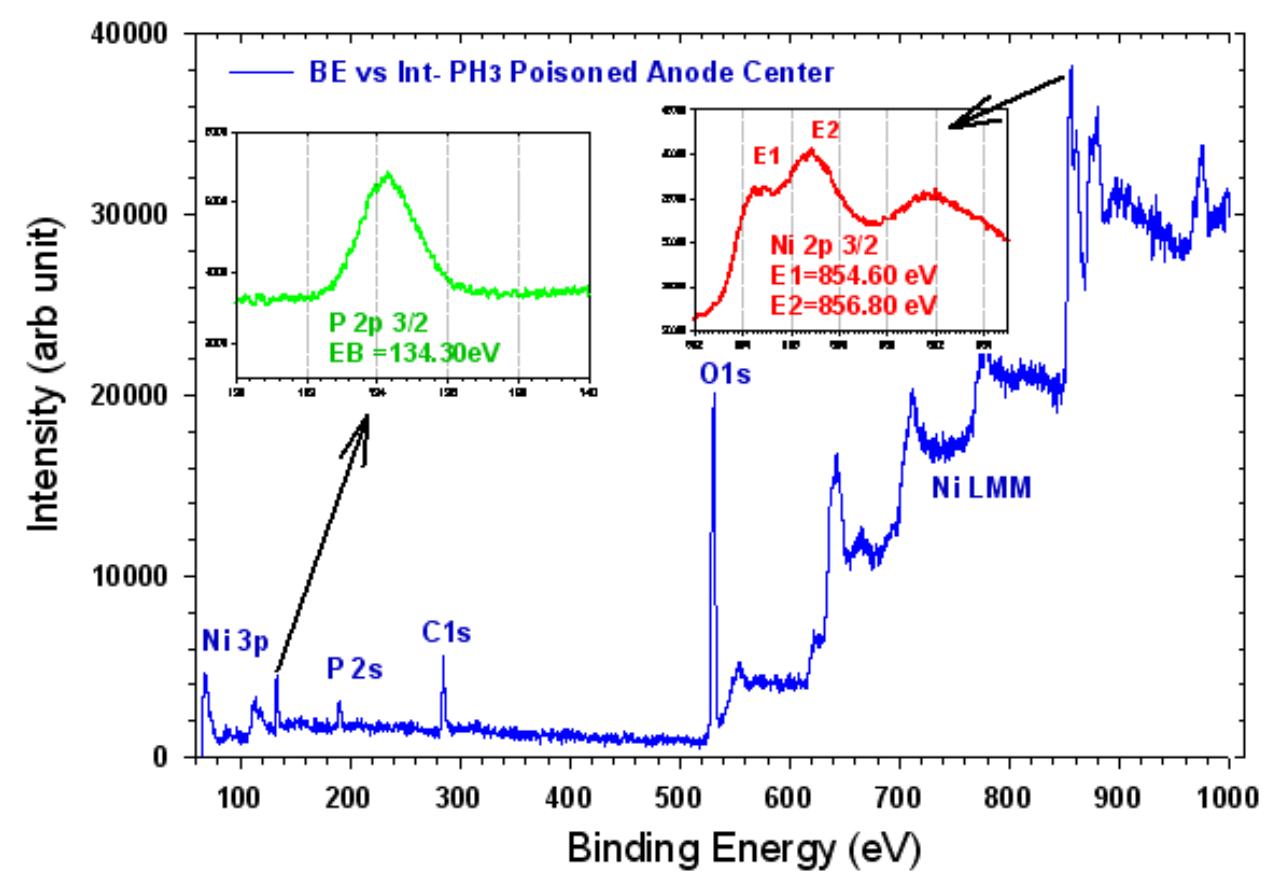

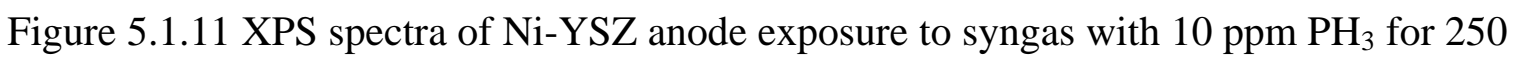
hours

\subsubsection{Thermodynamic and Phase Transition analysis}

At $800^{\circ} \mathrm{C}$, the calculated thermodynamic phase diagram by FACTSAGE software shows that $\mathrm{PH}_{3}$ can potentially react with $\mathrm{Ni}$ (Fig. 5.1.12). Under the cell working conditions, reactions (1), (2) and (3) represent the three possible nickel phosphide products that can form in the cell anode. The changes of Gibbs free energy $(\Delta \mathrm{G})$ are negative values in these reactions at $800^{\circ} \mathrm{C}(1073 \mathrm{~K})$.

$$
\begin{aligned}
2 \mathrm{PH}_{3}(\mathrm{~g})+4 \mathrm{Ni}=2 \mathrm{Ni}_{2} \mathrm{P}(\mathrm{s})+3 \mathrm{H}_{2}(\mathrm{~g}) & \Delta \mathrm{G}(1073 \mathrm{~K})=-431.53 \mathrm{~kJ} \\
10 \mathrm{PH}_{3}(\mathrm{~g})+12 \mathrm{Ni}(\mathrm{s})=2 \mathrm{Ni}_{6} \mathrm{P}_{5}(\mathrm{~s})+15 \mathrm{H}_{2}(\mathrm{~g}) & \Delta \mathrm{G}(1073 \mathrm{~K})=-1845.84 \mathrm{~kJ} \\
2 \mathrm{PH}_{3}(\mathrm{~g})+5 \mathrm{Ni}(\mathrm{s})=\mathrm{Ni}_{5} \mathrm{P}_{2}(\mathrm{~s})+15 \mathrm{H}_{2}(\mathrm{~g}) & \Delta \mathrm{G}(1073 \mathrm{~K})=-495.07 \mathrm{~kJ}
\end{aligned}
$$


The predominant phase diagram calculated by FACTSAGE in Fig.5.1.12 indicates $\mathrm{Ni}_{2} \mathrm{P}$ and $\mathrm{Ni}_{6} \mathrm{P}_{5}$ are the most favorable products at $800{ }^{\circ} \mathrm{C}$ for $10 \mathrm{ppm}$ nominal concentration level of $\mathrm{PH}_{3}$. As the cell operating temperature increases (due to current passage), $\mathrm{Ni}_{5} \mathrm{P}_{2}$ may also occur as a secondary phase. Further analysis revealed these nickel phosphide compounds can be in both solid and liquid states under the cell working conditions.

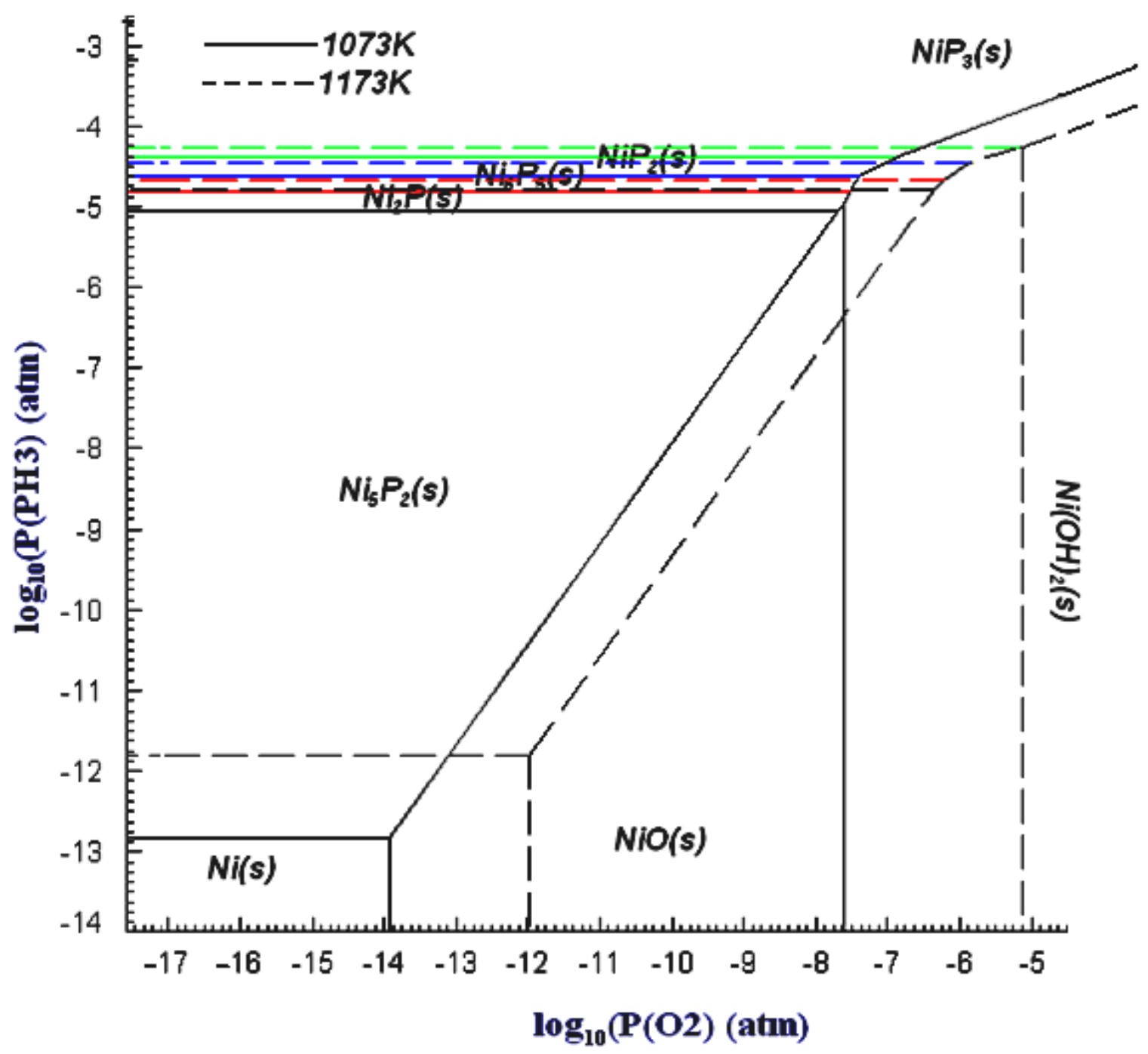

Figure 5.1.12 The thermodynamic phase diagram shows that $10 \mathrm{ppm}\left(10^{-5} / \mathrm{cm}^{-3}\right) \mathrm{PH}_{3}$ impurity is potentially capable of reacting with $\mathrm{Ni}$ in the reducing environment. 
The Ni-P phase diagram (Fig.5.1.13) [94] shows that the solid-liquid phase transition temperature is as low as $800^{\circ} \mathrm{C}$ for nickel phosphide with over $40 \%$ phosphorus atom concentration, which is the eutectic composition between $\mathrm{Ni}_{2} \mathrm{P}$ and the intermediate phase $\mathrm{Ni}_{5} \mathrm{P}_{4}$. Under loading of $0.5 \mathrm{~A} \mathrm{~cm}^{-2}$ current density, the local temperature of cell anode center can be $20^{\circ} \mathrm{C}$ higher than the furnace temperature of $800^{\circ} \mathrm{C}$ [95]. With $10 \mathrm{ppm} \mathrm{PH}_{3}$ added continually to the cell surface over hundreds of hours, the phosphorus atom concentration at the center of anode surface could be high enough to liquefy nickel phosphide compound. The presence of a liquid nickel phosphide phase, most possibly $\mathrm{Ni}_{2} \mathrm{P}$ in this case, explains how the nickel migrates to the cell anode surface and intrudes into the pore space inside the anode structure.

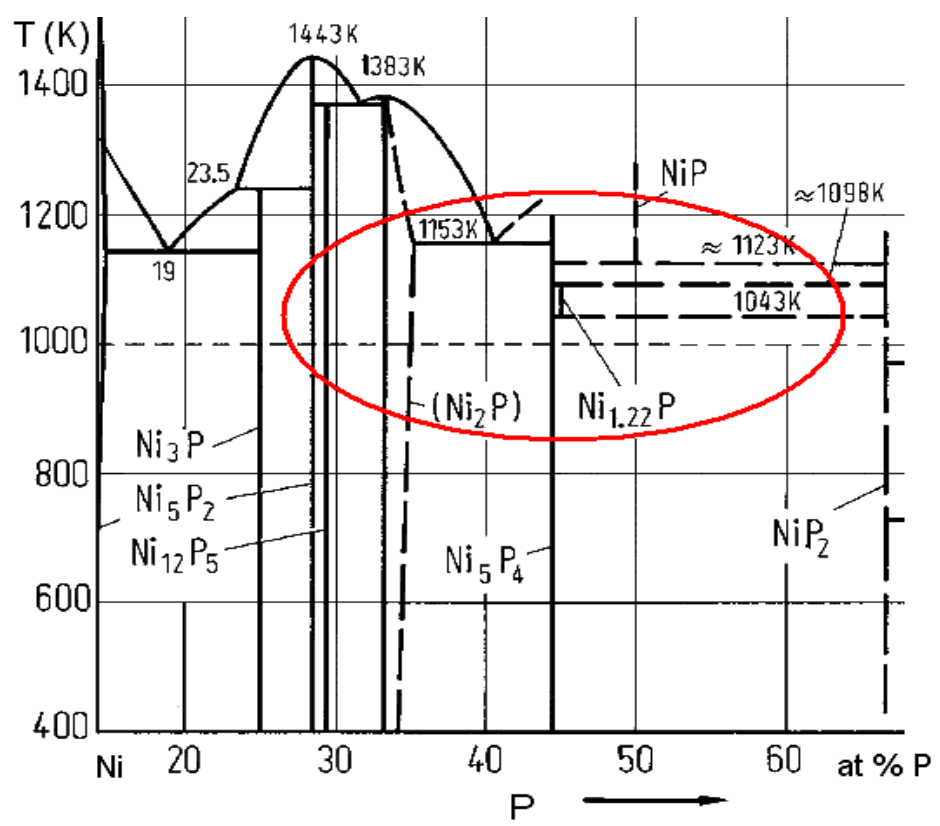

Figure 5.1.13 P-Ni phase diagram. The cell working condition could fall well within the region marked by circle.

When the cell was cooled down from $1073 \mathrm{~K}$ to room temperature with $\mathrm{N}_{2}$ purge, $\mathrm{Ni}_{5} \mathrm{P}_{2}$ was produced as a dominant nickel phosphide in the nickel rich and $\mathrm{PH} 3$-absent environment. 


$$
\begin{array}{ll}
2 \mathrm{Ni}_{2} \mathrm{P}(\mathrm{s})+\mathrm{Ni}(\mathrm{s})=\mathrm{Ni}_{5} \mathrm{P}_{2} & \Delta \mathrm{G}(873 \mathrm{~K})=-64.73 \mathrm{~kJ} \\
2 \mathrm{Ni}_{6} \mathrm{P}_{5}(\mathrm{~s})+13 \mathrm{Ni}(\mathrm{s})=5 \mathrm{Ni}_{5} \mathrm{P}_{2} & \Delta \mathrm{G}(873 \mathrm{~K})=-675.05 \mathrm{~kJ}
\end{array}
$$

This could explain that why $\mathrm{Ni}_{5} \mathrm{P}_{2}$ is detected as a major product on the $\mathrm{PH}_{3}$-poisoned Ni-YSZ anode surface. The condition of the cell cooling may affect the presence of the final dominant nickel phosphide phase. Our finding of the phase $\mathrm{Ni}_{5} \mathrm{P}_{2}$ is distinct from Marina et al.'s report of $\mathrm{Ni}_{3} \mathrm{P}$ as the product on $\mathrm{Ni}$-YSZ anode exposed to syngas with 2ppm $\mathrm{PH}_{3}$ [86]. One possibility that could lead to the different findings is that our study uses an exposed Ni-YSZ anode center. If Ni mesh is placed at the anode center as current collector, the as-formed nickel phosphide liquid phase at cell operating temperature can readily migrate to the anode surface, and be reduced in-situ by the excess $\mathrm{Ni}$ constituent to form $\mathrm{Ni}_{3} \mathrm{P}[96]$.

Thermodynamic calculations at $300 \mathrm{~K}$ indicate that $\mathrm{Ni}(\mathrm{OH})_{2}$ is the sole equilibrium phase for the $\mathrm{Ni}, \mathrm{P}, \mathrm{O}$ and $\mathrm{H}$ system under quite low $\mathrm{H}_{2}$ partial pressure. However this calculation represents the case for complete system phase transition after a thermodynamically long period. At room temperature, such phase transitions may become kinetically very slow. Thus the $\mathrm{N}_{2}$-quenching procedure may prevent most of the nickel phosphide formed at high temperature from transforming to nickel hydroxide. This hypothesis is supported by the XRD finding of $\mathrm{Ni}_{5} \mathrm{P}_{2}$ peaks. Additionally, more than one reaction path may still exist for the nickel phosphide phase transition. When the nickel phosphide at the anode surface is exposed to air and moisture at room temperature, the following reaction becomes thermodynamically quite favorable.

$$
\begin{gathered}
\mathrm{Ni}_{5} \mathrm{P}_{2}(\mathrm{~s})+5 \mathrm{O}_{2}(\mathrm{~g})+2 \mathrm{H}_{2} \mathrm{O}(\mathrm{l})=\mathrm{Ni}_{3}\left(\mathrm{PO}_{4}\right)_{2}(\mathrm{~s})+2 \mathrm{Ni}(\mathrm{OH})_{2}(\mathrm{~s}) \\
\Delta \mathrm{G}(300 \mathrm{~K})=-4104.6 \mathrm{~kJ}
\end{gathered}
$$


The XPS study does show formation of phosphate species on the anode surface, which can result from the transition of nickel phosphide to phosphate (equation 5.1.6) under oxygen-rich condition. Similar XPS results have been reported in literature [84] and [86]. However, this transition should be limited to a very superficial region due to slow kinetics, as it only initiates when the sample is totally cooled down and exposed to air at room temperature.

\subsubsection{Conclusion}

The long term test of a Ni-YSZ anode-supported SOFC cell exposed to syngas with $10 \mathrm{ppm} \mathrm{PH}_{3}$ impurity has been evaluated. Dramatic and irreversible degradation of cell performance (loss of voltage at constant current, increase in both series and polarization resistance) is assigned to the functional deterioration of the Ni-YSZ anode, particularly the active layer near the electrolyte. According to thermodynamic analysis, nickel can react with phosphine under these operating conditions and form liquid nickel phosphide phases. This mechanism is proposed to explain the migration of nickel particles to the exposed anode surface and agglomeration of nickel in the pores of the anode. $\mathrm{Ni}_{5} \mathrm{P}_{2}$ is identified as the major product. Changes of ohmic resistance and the polarization resistance are tentatively assigned to the nickel redistribution, most likely in the active composite layer next to the electrolyte. The polarization resistance increase can also be attributed to the loss of porosity and TBP length. While the investigation presented is based on 10 ppm $\mathrm{PH}_{3}$ which may be more than usual content in coal syngas, the results suggest that lower $\mathrm{PH}_{3}$ concentration (e.g., $\sim 2 \mathrm{ppm}$ ) in the coal syngas may cause significant degradation of a Ni/YSZ anode on a time scale desired by DOE goals. 


\subsection{Effect of $\mathrm{PH}_{3}$ on SOFC anodes based on $\mathrm{LaSr}_{2} \mathrm{Fe}_{2} \mathrm{CrO}_{9-\delta}$ perovskite}

\subsubsection{Introduction}

There is a widespread reliance on coal in the electrical power industry. However, cleaner and more $\mathrm{CO}_{2}$-neutral methods of utilizing coal are required in order to make use of abundant world-wide coal reserves. Solid oxide fuel cells (SOFCs) are being actively developed for clean and fuel-efficient stationary electrical power generation; they are of particular interest for coal-based generation [97,98] since they oxidize coal-derived syngas with pure oxygen, producing a $\mathrm{CO}_{2}$-rich product that allows for easier and lowercost sequestration compared to $\mathrm{N}_{2}$-rich air-combustion products. An additional advantage of SOFCs is their ability to utilize fuels containing various species in addition to hydrogen, such as CO, hydrocarbons, and impurities. Thus, SOFC-based power plants can be designed with reduced fuel processing and cleanup requirements compared to other fuel cells, reducing power plant cost.

Coals contain a large number of different impurities. A recent study examined the coal impurities expected to be present in the syngas after gasification with warm-gas cleanup and found $\mathrm{H}_{2} \mathrm{~S}, \mathrm{PH}_{3}$, and $\mathrm{AsH}_{3}$ to be the most problematic due to their reactivity with typical Ni-based SOFC anodes . Degradation of Ni-cermet anode performance has been shown to occur at ppm levels of $\mathrm{H}_{2} \mathrm{~S}$, and more serious damage at higher levels. Recent studies have shown that Ni-YSZ anodes are rapidly attacked by $\mathrm{AsH}_{3}$ and $\mathrm{PH}_{3}$ at few ppm levels, resulting in the formation of $\mathrm{NiAs}_{\mathrm{x}}$ and $\mathrm{NiP}_{\mathrm{x}}$ compounds $[86,99]$. More extensive syngas clean-up is possible, but not without additional system costs and loss in system efficiency $[67,84]$. Thus, alternative anode materials with improved tolerance to fuel impurities are of interest. Perovskite oxides, some of which are mixed ionic and electronic conductors (MIEC), have been shown to have superior resistance to carbon 
deposition and sulfur poisoning when compared to Ni-cermets $[6,46,47,48]$. Several perovskite and perovskite-related anodes, such as $\mathrm{La}_{0.75} \mathrm{Sr}_{0.25} \mathrm{Cr}_{0.5} \mathrm{Fe}_{0.5} \mathrm{O}_{3}$ [ 100 ], $\mathrm{La}_{0.75} \mathrm{Sr}_{0.25} \mathrm{Cr}_{0.5} \mathrm{Mn}_{0.5} \mathrm{O}_{3}(\mathrm{LSCM})$ [ 101 ], $\mathrm{Sr}_{2} \mathrm{Mg}_{1-\mathrm{x}} \mathrm{Mn}_{\mathrm{x}} \mathrm{MoO}_{6-\delta} \quad$ [50], and $\mathrm{LaSr}_{2} \mathrm{Fe}_{2} \mathrm{CrO}_{9-\delta}(\mathrm{LSFeCr})$ mixed with $\mathrm{Gd}_{0.1} \mathrm{Ce}_{0.9} \mathrm{O}_{2}$ (GDC)[102] have been demonstrated with hydrogen and/or methane fuels, exhibiting electrochemical performance that was good but usually inferior to that of nickel cermets. In some cases, good tolerance to $\mathrm{H}_{2} \mathrm{~S}$ impurities has been demonstrated [51]. However, little is known about the performance and stability of oxide anodes in the presence of ppm levels of $\mathrm{PH}_{3}$, and $\mathrm{AsH}_{3}$.

In the present study, SOFCs with $\mathrm{LaSr}_{2} \mathrm{Fe}_{2} \mathrm{CrO}_{9-\delta}(\mathrm{LSFeCr})-\mathrm{Gd}_{0.1} \mathrm{Ce}_{0.9} \mathrm{O}_{2}$ (GDC) composite anodes were evaluated for operation in simulated coal syngas containing 520ppm $\mathrm{PH}_{3}$, and humidified $\mathrm{H}_{2}$ for comparison. SOFC performance degradation and anode phase transitions caused by $\mathrm{PH}_{3}$-poisoning were investigated.

\subsubsection{Experimental}

\subsubsection{Cell Description}

The SOFCs consisted of $\mathrm{La}_{0.9} \mathrm{Sr}_{0.1} \mathrm{Ga}_{0.8} \mathrm{Mg}_{0.2} \mathrm{O}_{3-\delta}$ (LSGM) electrolyte supports with about 30- $\mu$ m-thick $\mathrm{La}_{0.4} \mathrm{Ce}_{0.6} \mathrm{O}_{2}$ (LDC) layers on the anode side, LSFeCr-GDC composite anode, $\mathrm{La}_{0.6} \mathrm{Sr}_{0.4} \mathrm{Fe}_{0.8} \mathrm{Co}_{0.2} \mathrm{O}_{3-\delta}$ (LSCF)-GDC cathode, and LSCF cathode current collector. The LDC layer was used to prevent any reaction/interdiffusion between the LSGM and LSFeCr during anode firing. The fabrication and performance of these cells was similar to that described in literature [102].

The LSGM was prepared via solid-state reaction. Appropriate quantities of $\mathrm{La}_{2} \mathrm{O}_{3}$, $\mathrm{SrCO}_{3}, \mathrm{Ga}_{2} \mathrm{O}_{3}$, and $\mathrm{MgO}$ were mixed and calcined at $1250^{\circ} \mathrm{C}$ for $12 \mathrm{~h}$. The resulting powder was mixed with poly(vinyl butyral) (PVB), ground, and pressed into $19 \mathrm{~mm}$ 
diameter pellets weighing $0.45 \mathrm{~g}$. The resulting pellets were bisque fired at $1200^{\circ} \mathrm{C}$ for 10 h. The LDC layer was then applied by drop-coating a colloidal solution of LDC to the bisque fired pellets. The resulting structures were sintered at $1450^{\circ} \mathrm{C}$ for $6 \mathrm{~h}$.

LSFeCr was prepared by solid state reaction. Stoichiometric quantities of $\mathrm{La}_{2} \mathrm{O}_{3}$, $\mathrm{SrCO}_{3}, \mathrm{Cr}_{2} \mathrm{O}_{3}$, and $\mathrm{Fe}_{2} \mathrm{O}_{3}$ were mixed and calcined at $1200^{\circ} \mathrm{C}$ for $6 \mathrm{~h}$. The resulting powder was ball milled in ethanol with GDC (1:1 weight ratio) for 24 hours. The resulting slurry was dried, sieved, and mixed with a vehicle (Heraus V-737) using a three roll mill. The LSCF-GDC cathode ink was prepared by mixing commercial LSCF powder (Praxair) and GDC (1:1 weight ratio) and adding a vehicle; whereas the current collector ink was prepared with pure LSCF. The thick-film LSFeCr-GDC anodes were applied with the doctor blade technique and fired at $1200^{\circ} \mathrm{C}$ for $3 \mathrm{~h}$. The cathodes and cathode current collectors were applied in a similar manner and fired at $1000^{\circ} \mathrm{C}$ for $3 \mathrm{~h}$. $\mathrm{Au}$ current collector grids were applied to both electrodes by screen printing Au ink (Heraeus Inc., PA). The resulting fuel cells had a diameter of $\sim 1.5 \mathrm{~cm}$, and electrode thicknesses of $20-30 \mu \mathrm{m}$. The anode and cathode areas were both $0.5 \mathrm{~cm}^{2}$ and defined the cell active area.

\subsubsection{Experimental Set-up}

A schematic of the experimental setup is presented in Figure 5.2.1. Pt meshes were attached to both the anode and cathode surface using Pt paste. Ag wires were then welded to the Pt meshes to provide current supply and voltage measurement leads respectively. The button cell assembly was mounted between two alumina flanges with compressive mica gasket as seals. This cell setup was then placed between two alumina tubes inside a 
vertical furnace. The anode-side tube confined the fuel and the cathode-side tube confined the air. The mica seal was softened/sealed in-situ prior to cell operation at $800^{\circ} \mathrm{C}$. The air flow was maintained at a constant level of 300 standard cubic centimeter per min $\left(s c c-\min ^{-1}\right)$. Humidified hydrogen $\left(3 \% \mathrm{H}_{2} \mathrm{O}\right)$ or surrogate coal syngas was applied as the fuel at $200 \mathrm{scc}-\mathrm{min}^{-1}$. Fuel mixtures were controlled with mass flow controllers from Alicat Co. (AZ, U.S). The surrogate syngas mixture was obtained by blending the wet $\mathrm{H}_{2}$ with $\mathrm{CO}$ and $\mathrm{CO}_{2}$. The resulting coal syngas mixture contained $30 \%$ $\mathrm{H}_{2}, 26 \% \mathrm{H}_{2} \mathrm{O}, 23 \% \mathrm{CO}$, and $21 \% \mathrm{CO}_{2}$. Thermodynamic calculations (FactSage v5.4) for this composition indicated that the water gas shift reaction $\left(\mathrm{CO}+\mathrm{H}_{2} \mathrm{O} \rightarrow \mathrm{CO}_{2}+\mathrm{H}_{2}\right)$ was at equilibrium at 1073K. A similar calculation also predicted the present fuel composition, with a steam/carbon (S/C) ratio of 0.62 , did not favor coke formation [6].

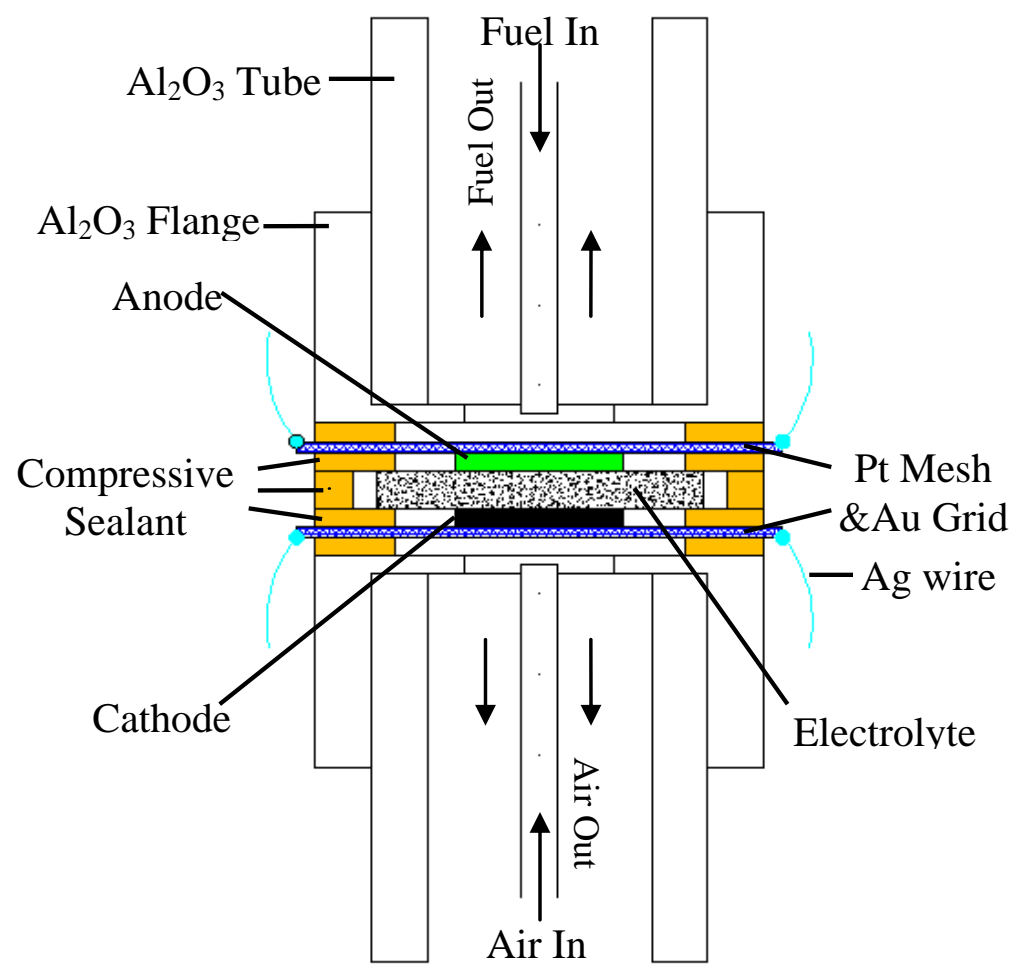

Figure 5.2.1 Sketch of the cell testing setup 


\subsubsection{3 $\mathrm{PH}_{3}$ Testing Procedure}

The stability of $\mathrm{LSFeCr}-\mathrm{GDC}$ in the presence of $\mathrm{PH}_{3}$ was studied as a function of fuel type and impurity concentration. Cells were tested in surrogate syngas and humidified hydrogen containing 5 to $20 \mathrm{ppm}$ of $\mathrm{PH}_{3}$. The specific testing conditions for each sample are summarized in Table 5.2.1.

Table 5.2.1 Summary of testing conditions for CG-Fe cells

\begin{tabular}{|c|c|}
\hline Sample ID & Test Conditions \\
\hline CG-Fe-1 & $\mathrm{T}=800^{\circ} \mathrm{C}, \mathrm{j}=0.25 \mathrm{~A} \mathrm{~cm}^{-2}$, Coal syngas mixture \\
\hline$\underline{\mathrm{CG}-\mathrm{Fe}-2}$ & $\begin{array}{l}\mathrm{T}=800^{\circ} \mathrm{C}, \mathrm{j}=0.25 \mathrm{~A} \mathrm{~cm}^{-2}, \text { Coal syngas mixture with } 20 \mathrm{ppm} \mathrm{PH}_{3} \\
\text { Total exposure time in } \mathrm{PH}_{3}=10 \mathrm{~h}\end{array}$ \\
\hline$\underline{\mathrm{CG}-\mathrm{Fe}-3}$ & $\begin{array}{l}\mathrm{T}=800^{\circ} \mathrm{C}, \mathrm{j}=0.5 \mathrm{~A} \mathrm{~cm}^{-2}, 97 \% \mathrm{H}_{2} / 3 \% \mathrm{H}_{2} \mathrm{O} \text { with } 20 \mathrm{ppm} \mathrm{PH}_{3} ; \\
\text { Total exposure time in } \mathrm{PH}_{3}=15 \mathrm{hrs}\end{array}$ \\
\hline$\underline{\mathrm{CG}-\mathrm{Fe}-4}$ & $\begin{array}{l}\mathrm{T}=800^{\circ} \mathrm{C}, \mathrm{j}=0.25 \mathrm{~A} \mathrm{~cm}^{-2}, 97 \% \mathrm{H}_{2} / 3 \% \mathrm{H}_{2} \mathrm{O} \text { with } 5{\mathrm{ppm} \mathrm{PH}_{3} ;} \\
\text { Total exposure time in } \mathrm{PH}_{3}=22 \mathrm{hrs}\end{array}$ \\
\hline
\end{tabular}

It should be noted that coal syngas, after clean-up, typically contains $\sim 1 \mathrm{ppm} \mathrm{PH}_{3}$ [67]. The present phosphine concentrations are significantly higher and therefore the anode degradation should occur at an accelerated rate. The LSFeCr-GDC cells were heated in air to $800^{\circ} \mathrm{C}$ and then supplied sequentially with $10 \% \mathrm{H}_{2} / 90 \% \mathrm{~N}_{2}, 50 \% \mathrm{H}_{2} / 50 \% \mathrm{~N}_{2}$, and then dry $\mathrm{H}_{2}$. Afterwards, the fuel was switched to $200 \mathrm{scc}^{-\mathrm{min}^{-1}}$ humidified $\mathrm{H}_{2}$ or the surrogate coal syngas and was allowed to stabilize at an operating voltage of $\sim 0.7 \mathrm{~V}$ The $\mathrm{PH}_{3}$ impurity was then introduced into the fuel flow and the cell performance and stability were monitored by measuring the cell voltage, AC impedance and cell 
polarization curve. Electrochemical measurements were carried out with an electrochemical interface SI-1287 and an SI-1260 impedance analyzer (Solartron Instruments, Hampshire, UK). Impedances of the cell at OCV and under DC biases were taken at frequencies ranging from $10^{-1} \mathrm{~Hz}$ to $10^{5} \mathrm{~Hz}$ with $\mathrm{AC}$ signal amplitude of $20 \mathrm{mV}$. The series resistances $\left(R_{s}\right)$ of the cells were obtained from the high-frequency intercept on the Nyquist Diagrams. Cell polarization resistances $\left(R_{p}\right)$ were taken as the difference between the low frequency and the high frequency real axis intercepts of the impedance curves. After testing on $\mathrm{PH}_{3}$-laden fuel, cells were tested again in dry $\mathrm{H}_{2}$. Cells were cooled in $\mathrm{N}_{2}$ after testing.

\subsubsection{Post Test Characterization}

The anode surface and cross-section of the cells were examined using a Hitachi S4700 scanning electron microscope (SEM). Energy dispersive x-ray spectrometry (EDS) attached with the SEM system was used to check for the presence of phosphorous in the anode. X-ray diffraction (XRD) was carried out to determine the phases present in the anode using an X-pert Pro 3040 PANlytical system $(\mathrm{Cu} \mathrm{K \alpha}$ radiation at $45 \mathrm{kV})$. The XRD patterns of an as-processed cell, baseline anode after clean syngas exposure, and anodes tested with $\mathrm{PH}_{3}$-laden fuels were obtained at scanning rates of $0.005 \sim 0.03 \%$ s. Phase identification was completed using the X'Pert Highscore Plus 2.0 software and the PDF2-2004 electronic database.

X-ray photoelectron spectroscopy (XPS) tests were performed using a PHI 5000 Versa Probe system in order to analyze the elemental electron state and chemical composition of the $\mathrm{LSFeCr}$ anode surface after $\mathrm{PH}_{3}$ exposure. A monochromatic $\mathrm{Al} \mathrm{K} \alpha$ 
radiation source $(1486.6 \mathrm{eV})$ at an operating power of $300 \mathrm{~W}$ was used. The Pt mesh was peeled off the anode surfaces prior to XPS measurement. Since there was a peak drift due to surface charging, all of the peaks were identified by shifting the $\mathrm{C} 1 \mathrm{~s}$ peak to $284.8 \mathrm{eV}$, which is the standard peak for hydro-carbon species[103]. Both survey scans and elemental specific scans were completed. Peak identification was aided using the National Institute of Standard and Technology (NIST) XPS database.

To clarify the anode degradation mechanism from reaction with $\mathrm{PH}_{3}$, a thermodynamic analysis was carried out using FACTSAGE 5.4. Possible phases that could form were calculated by minimizing the Gibbs free energy change for reactions involving the anode constituents and $\mathrm{PH}_{3}$. For compounds whose thermodynamic data is not included in the FACTSAGE 5.4 database, calculation of free Gibbs energy change was processed separately by using values collected from the literature.

\subsubsection{Results}

\subsubsection{SOFC Performance in pure fuels}

Figure 5.2.2 shows plots of cell voltage and power density versus current density for a typical LSFeCr-anode SOFC operated at $800^{\circ} \mathrm{C}$ in various fuel compositions and constant air flow of $300 \mathrm{scc}-\mathrm{min}^{-1}$. Open circuit voltages $(\mathrm{OCVs})$ were $\approx 1.08 \mathrm{~V}$ in dry $\mathrm{H}_{2}$ and $1.06 \mathrm{~V}$ in $97 \% \mathrm{H}_{2} / 3 \% \mathrm{H}_{2} \mathrm{O}$. The latter value was slightly lower than the theoretical value of $1.10 \mathrm{~V}$ for wet hydrogen, but slightly higher than measured OCV in wet $\mathrm{H}_{2}$ previously for similar SOFCs [102]. Thus, gas leakage across the compressive Mica sealant was relatively minor. After switching the fuel to the surrogate syngas composition $\left(30 \% \mathrm{H}_{2}\right.$, $26 \% \mathrm{H}_{2} \mathrm{O}, 23 \% \mathrm{CO}$ and $21 \% \mathrm{CO}_{2}$ ), the $\mathrm{OCV}$ dropped to $0.948 \mathrm{~V}$, in good agreement with 
the theoretical $\mathrm{OCV}$ value of $0.949 \mathrm{~V}$ expected at $800^{\circ} \mathrm{C}$. The maximum power density ranged from $355 \mathrm{~mW} \mathrm{~cm}^{-2}$ with $100 \mathrm{scc}-\mathrm{min}^{-1}$ of dry $\mathrm{H}_{2}$, to $341 \mathrm{~mW} \mathrm{~cm}$ with $100 \mathrm{scc}-$

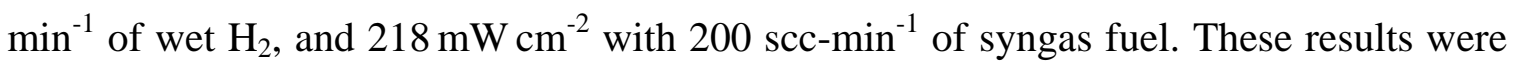
typical of the cells measured in this study, and similar to previously reported results for similar SOFCs [102]. Only one of the cells tested showed inferior performance.

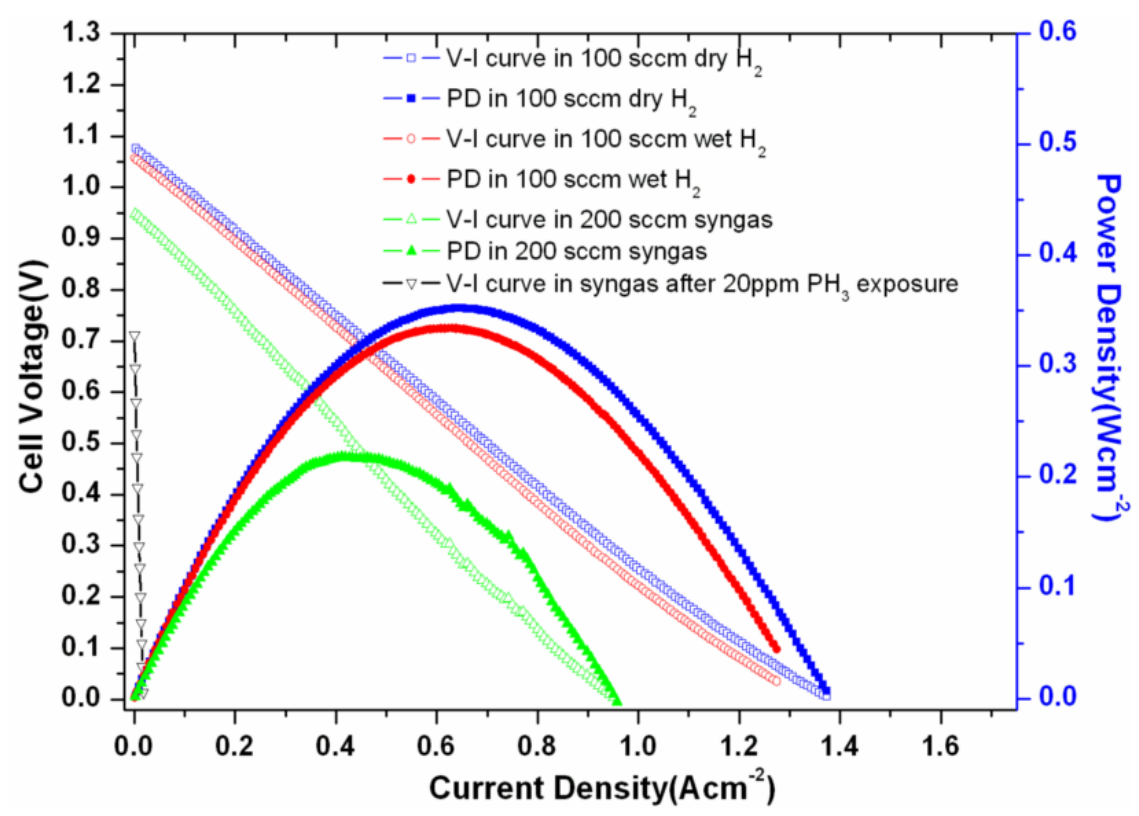

Figure 5.2.2 Cell performances as a function of feed fuel composition (CG-P20).

AC impedance Nyquist plots from a cell measured at OCV with syngas and wet $\mathrm{H}_{2}$ are shown in Fig. 5.2.3. The high-frequency real-axis intercept increased from $0.39 \Omega \mathrm{cm}^{2}$ to $0.47 \Omega \mathrm{cm}^{2}$ when the fuel was switched from $\mathrm{H}_{2}$ to coal syngas; this increase was surprising given that this ohmic resistance $\left(\mathrm{R}_{\mathrm{s}}\right)$ is normally associated with the electrolyte. The impedance spectra showed two characteristic arcs at $\sim 10^{2} \mathrm{~Hz}$ and $\sim 10^{0} \mathrm{~Hz}$ that were attributed to the anode because prior studies on these cells suggested that the cathode resistance was relatively small [102]. The lower frequency electrode arc dominated the impedance spectra, similar to the result reported previously for cells with the $\mathrm{LSFeCr}$ - 
GDC anode. The overall cell polarization resistance $\left(\mathrm{R}_{\mathrm{p}}\right)$ increased from $0.32 \Omega \mathrm{cm}^{2}$ to $0.43 \Omega \mathrm{cm}^{2}$ on switching to coal gas.

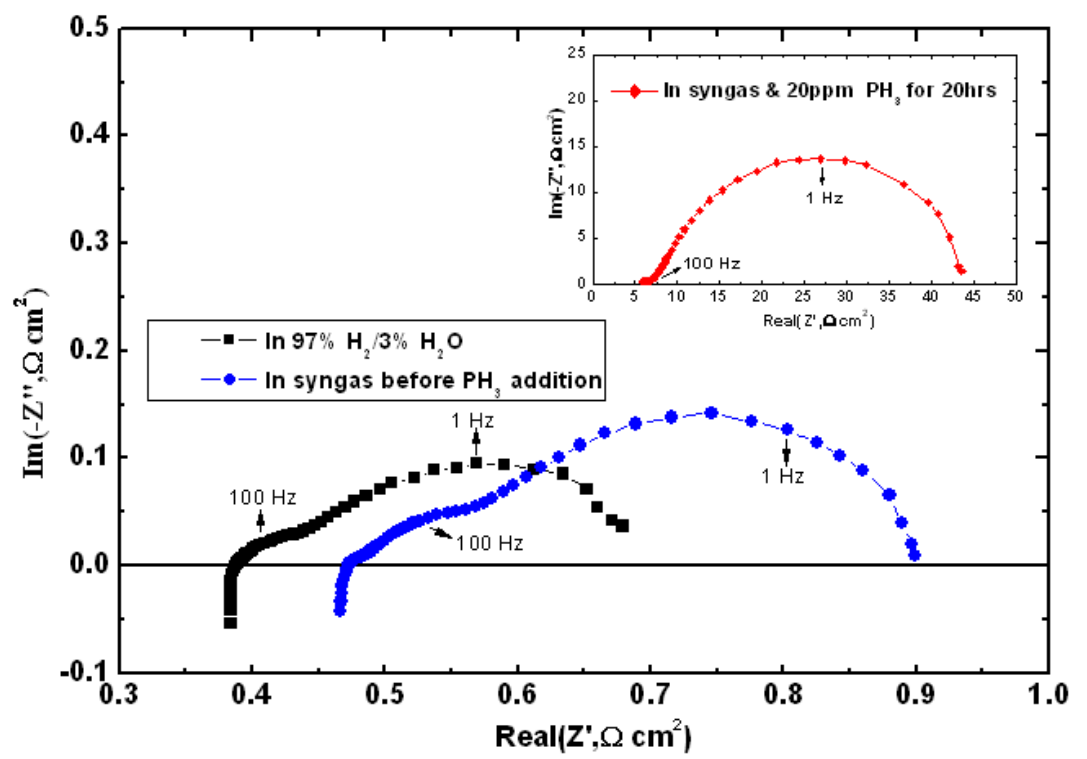

Figure 5.2.3 AC impedance spectra at $\mathrm{OCV}$ of CG-P20 tested in $97 \% \mathrm{H}_{2} / 3 \% \mathrm{H}_{2} \mathrm{O}$ and simulative coal syngas before/after $\mathrm{PH}_{3}$ addition

\subsubsection{SOFC performance in fuels containing $\mathrm{PH}_{3}$}

Figure 5.2.4 shows cell voltage versus time at a fixed current density of $0.25 \mathrm{~A} \mathrm{~cm}^{-2}$ for cells operated in $200 \mathrm{scc}-\mathrm{min}^{-1}$ of simulated coal syngas with and without $20 \mathrm{ppm} \mathrm{PH}_{3}$ impurity. Both cells had been operated in wet $\mathrm{H}_{2}$ with a constant current load of $0.25 \mathrm{~A}$ $\mathrm{cm}^{-2}$ prior to the coal gas testing shown. The cell operated in clean coal syngas showed an initial voltage of $0.68 \mathrm{~V}$ that remained relatively stable, decreasing slightly to stabilize at $\approx 0.64 \mathrm{~V}$. No significant performance/structural degradation was observed in this cell during post-test characterization, indicating that the LSFeCr-GDC composite oxide was generally stable during syngas operation. The other cell was first tested in phosphine-free syngas for $24 \mathrm{~h}$, during which time it displayed good stability. However, $4 \mathrm{~h}$ after the

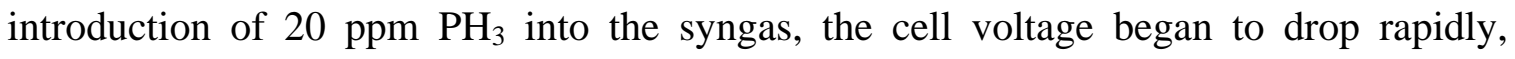


reaching zero in $<5 \mathrm{~h}$. The cell performance did not recover after removing the $\mathrm{PH}_{3}$ from the fuel supply. The inset in Figure 5.2.2 shows the AC impedance spectrum measured after the cell failure. Both $\mathrm{Rs}$ and $\mathrm{Rp}$ increased by orders of magnitude after $\mathrm{PH}_{3}$ exposure, indicating that the perovskite anode had lost both its conductivity and electrocatalytic activity.

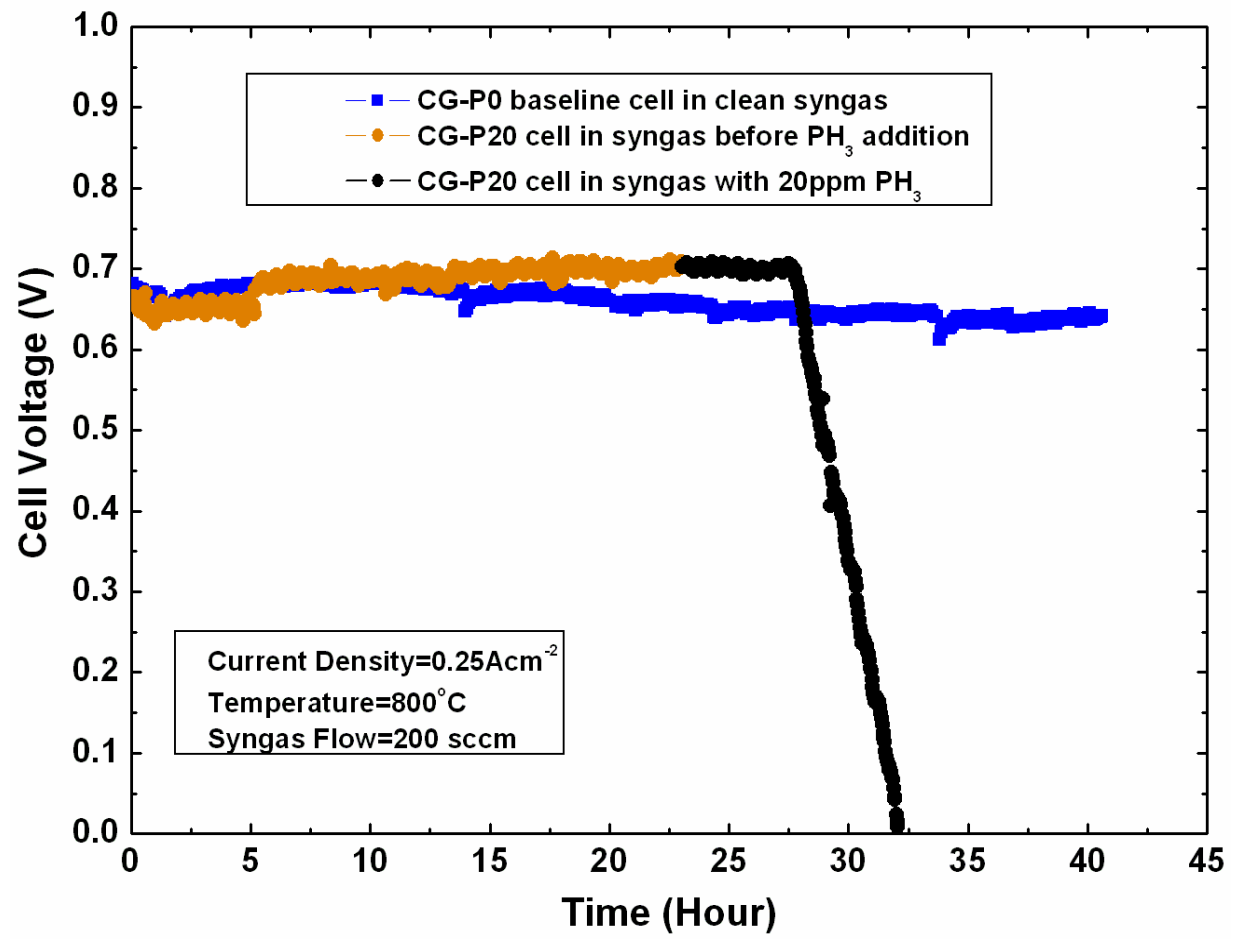

Figure 5.2.4 Cell voltage change in syngas for a baseline cell (CG-P0) and cell poisoned by $20 \mathrm{ppm} \mathrm{PH}_{3}$ (CG-P20)

Additional life tests were carried out with humidified $\mathrm{H}_{2}$ fuel laden with $5 \mathrm{ppm}$ and 20ppm $\mathrm{PH}_{3}$. Figure 5.2.5 shows that both cells operated stably in humidified $\mathrm{H}_{2}$. Similar to Figure 5.2.4, the cells continued to operate stably for several hours after introduction of $\mathrm{PH}_{3}$, but then rapidly degraded For $20 \mathrm{ppm}$, the delay was $\sim 4 \mathrm{~h}$, indicating the fuel composition $\left(\mathrm{H}_{2}\right.$ or coal gas) did not affect the degradation. For $5 \mathrm{ppm}$, the stable cell performance was sustained for a longer period of $7 \mathrm{~h}$ after contaminant introduction, and the subsequent degradation occurred at a slower rate $-96 \mathrm{mV} \mathrm{h}^{-1}$ versus $-65 \mathrm{mV} \mathrm{h}^{-1}$ for 20 
ppm. In both cases, the cell performance did not recover after removing the $\mathrm{PH}_{3}$. Thus, the anode was destroyed by both $\mathrm{PH}_{3}$ concentrations, but the degradation took longer for the lower $\mathrm{PH}_{3}$ level.

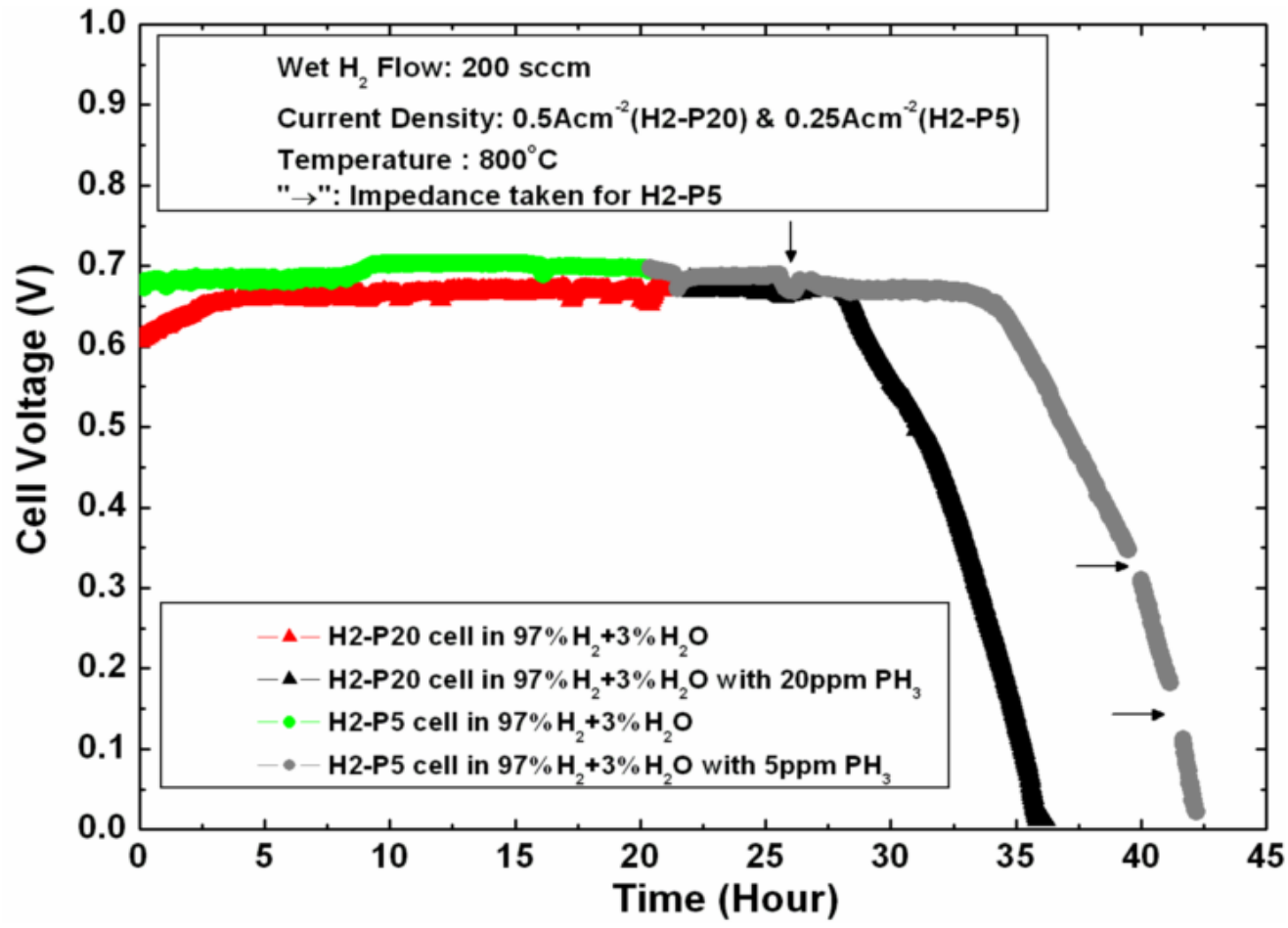

Figure 5.2.5 Cell voltage change in $97 \% \mathrm{H}_{2} / 3 \% \mathrm{H}_{2} \mathrm{O}$ for cells poisoned by $20 \mathrm{ppm} \mathrm{PH}_{3}$ (H2-P20) and by $5 \mathrm{ppm} \mathrm{PH}_{3}(\mathrm{H} 2-\mathrm{P} 5)$

Fig. 5.2.6 presents the AC impedance spectra taken at 5, 6, 18 and $20 \mathrm{~h}$ after the

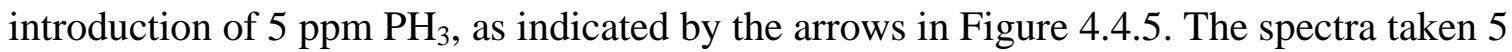
$\mathrm{h}$ and $6 \mathrm{~h}$ after $\mathrm{PH}_{3}$ introduction were only slightly changed from the pre- $\mathrm{PH}_{3}$ spectrum. The primary change was an increase in the high-frequency intercept. In contrast, after serious cell degradation (18 and $20 \mathrm{~h}$ after $\mathrm{PH}_{3}$ introduction), both $\mathrm{R}_{\mathrm{s}}$ and $\mathrm{R}_{\mathrm{p}}$ were substantially larger. 


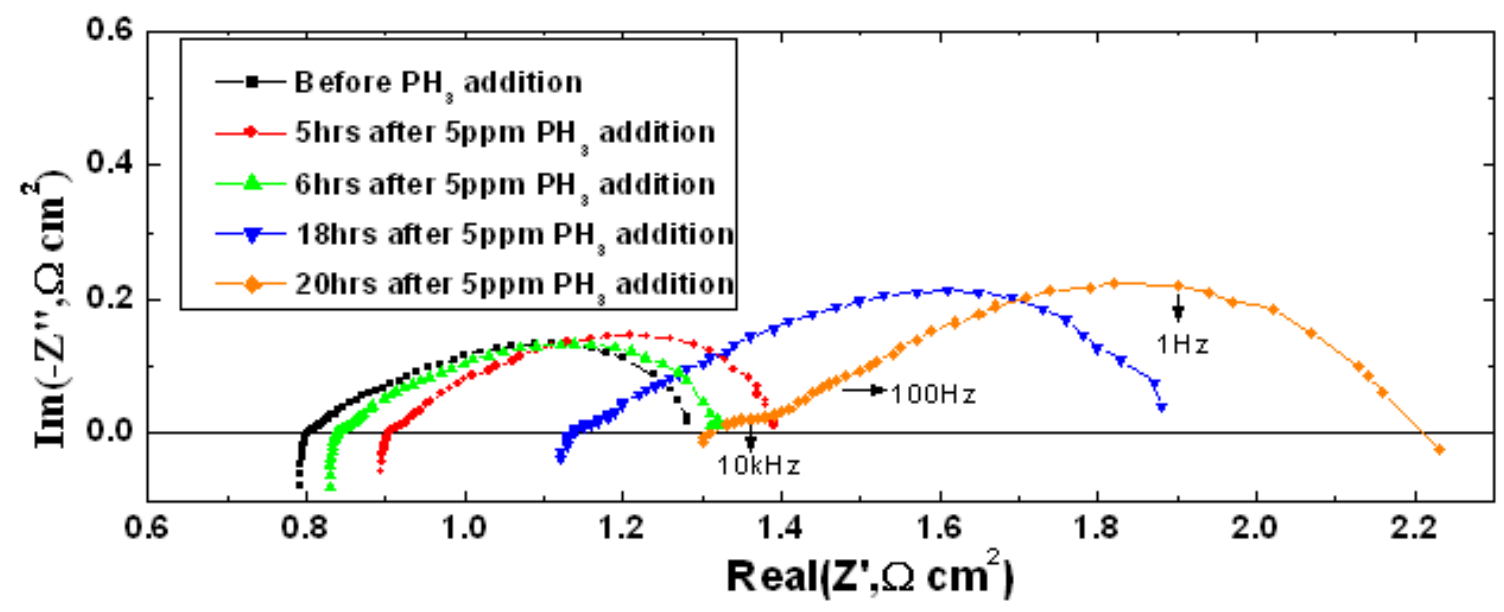

Figure 5.2.6 AC impedance change at OCV of $\mathrm{H} 2-\mathrm{P} 5$ cell tested in $97 \% \mathrm{H}_{2} / 3 \% \mathrm{H}_{2} \mathrm{O}$ before/after $5 \mathrm{ppm} \mathrm{PH}_{3}$ addition

\subsubsection{XRD analysis}

XRD spectra were taken from the anodes after cell testing in order to identify changes in the phases present. In each case with $\mathrm{PH}_{3}$ exposure, the test was continued until the cell voltage went to zero, as illustrated in Figure 5.2.5. Figure 5.2.7 shows the XRD

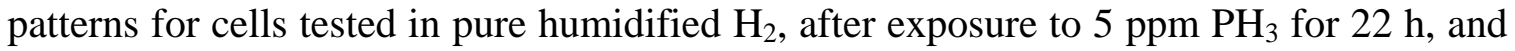
after exposure to $20 \mathrm{ppm} \mathrm{PH}_{3}$ for $15 \mathrm{~h}$. The humidified $\mathrm{H}_{2}$ case showed only the expected phases LSFeCr, GDC, and LSGM along with Au from the anode current collectors. After $\mathrm{PH}_{3}$ exposure, additional XRD reflections were observed and tentatively identified as new oxide $\left(\mathrm{FeO}, \mathrm{Fe}_{2} \mathrm{O}_{3}, \mathrm{Sr}_{2} \mathrm{CrO}_{4}\right.$, and $\left.\mathrm{P}_{2} \mathrm{O}_{5}\right)$, phosphate $\left(\mathrm{LaPO}_{4}\right.$ and $\left.\mathrm{FePO}_{4}\right)$, and phosphide $(\mathrm{FeP})$ phases. The strongest peaks were those identified as $\mathrm{FeP}, \mathrm{FeO}, \mathrm{Fe}_{2} \mathrm{O}_{3}$, $\mathrm{FePO}_{4}, \mathrm{Sr}_{2} \mathrm{CrO}_{4}$ and $\mathrm{P}_{2} \mathrm{O}_{5}$. Note that there was considerable overlap of the various impurity phase reflections, such that these identifications have some uncertainty. Though not shown here for a matter of simplification, the pattern of Pt (peaks appear at around 
$39.7^{\circ}, 46.2^{\circ}$ and $67.4^{\circ}$ ) was observed to only enhance the peak intensity at the corresponding peak positions for the XRD spectra taken after cell testing. The results for the two $\mathrm{PH}_{3}$ concentrations were similar, except that the main peaks belonging to $\mathrm{FeP}$ and $\mathrm{LaPO}_{4}$ were slightly stronger at the higher concentration of $\mathrm{PH}_{3}(20 \mathrm{ppm})$, while the $\mathrm{P}_{2} \mathrm{O}_{5}$ and $\mathrm{FePO}_{4}$ peaks were slightly less prominent. Substantially increased product formation would be expected at higher $\mathrm{PH}_{3}$ concentrations, but was probably mitigated by the 0.5 times shorter $20 \mathrm{ppm}$ exposure compared to the $5 \mathrm{ppm}$ exposure time. No phases were detected that would indicate reactions of $\mathrm{Pt}$ or Au with phosphorus, indicating that the current collector did not degrade in the presence of $\mathrm{PH}_{3}$.

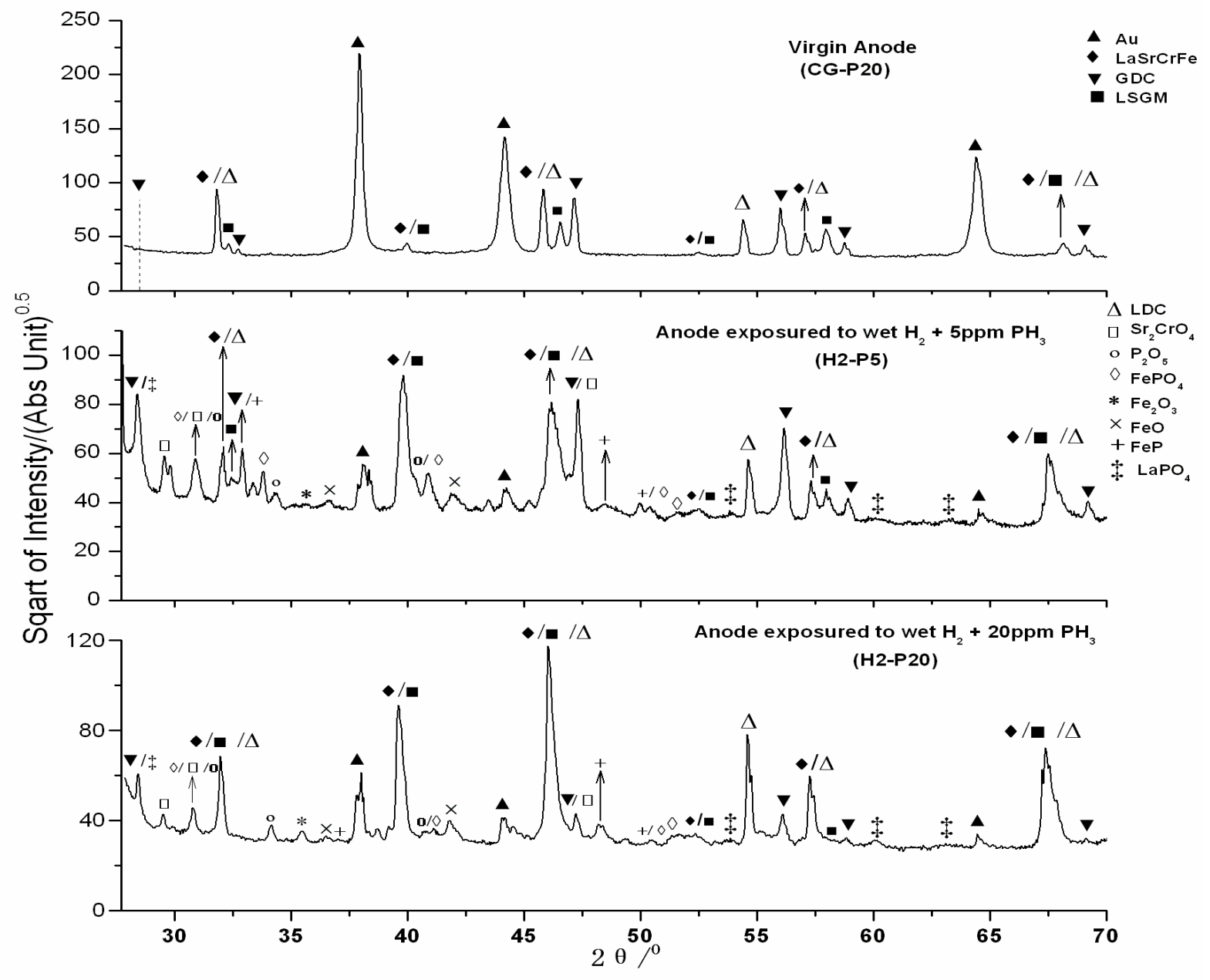

Figure 5.2.7 XRD spectra of cells tested with $97 \% \mathrm{H}_{2} / 3 \% \mathrm{H}_{2} \mathrm{O}$ and different levels of $\mathrm{PH}_{3}$ 
Figure 5.2.8 displays the XRD spectra for cells tested in syngas. After syngas exposure for $40 \mathrm{~h}$, peaks corresponding to $\mathrm{Sr}_{2} \mathrm{CrO}_{4}$ were detected, and weak peaks identified as $\mathrm{FeO}$ were also present. This showed that a slight anode phase evolution occurred during the syngas operation, although there was no apparent effect on anode electrical performance (Figure 5.2.4). For the CG-Fe-2 cell sample after operation in syngas with 20 ppm $\mathrm{PH}_{3}$, all the peaks of impurity phases belonging to phosphides and phosphates previously identified for other samples are present, are sharper and clearer, and the perovskite peaks are weaker. Thus, the anode reaction may have been more complete for $\mathrm{PH}_{3}$ exposure in syngas compared to hydrogen.

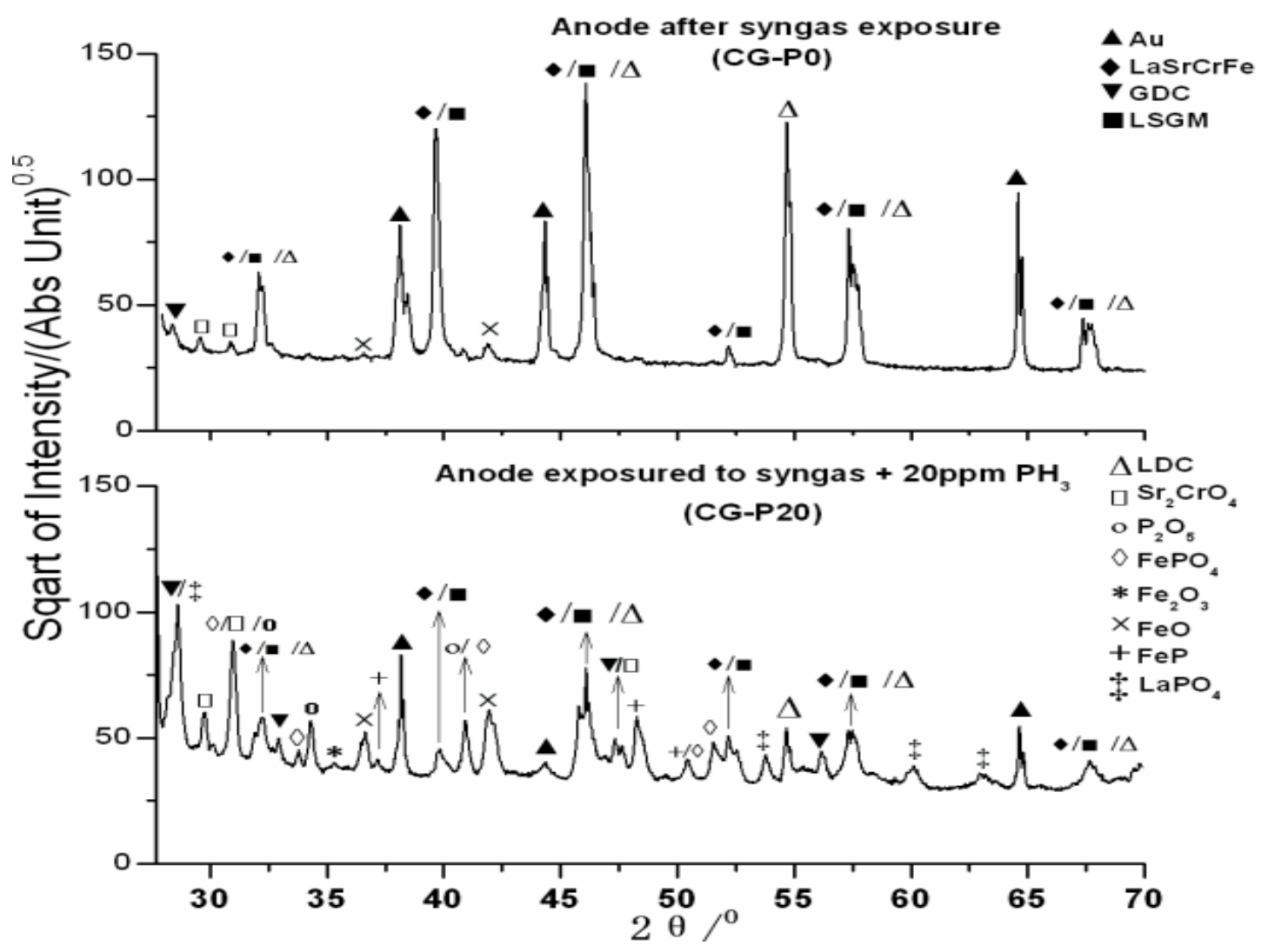

Figure 5.2.8 XRD spectra of cells tested in syngas with and without $\mathrm{PH}_{3}$ impurity 


\subsubsection{SEM and EDX analysis}

Figure 5.2.9 shows cross-sectional SEM images of the anodes described in Figures 5.2.3-8. After exposure to $5 \mathrm{ppm} \mathrm{PH}_{3}$ (5.2.9b), the anode microstructure remained porous with no significant morphological change from the starting anode (5.2.9a). However, anodes exposed to $20 \mathrm{ppm} \mathrm{PH}_{3}$ in syngas (5.2.9c) had become densified, a change presumably associated with the various reactions and new phases shown in Figures 5.2.7 and 5.2.8.
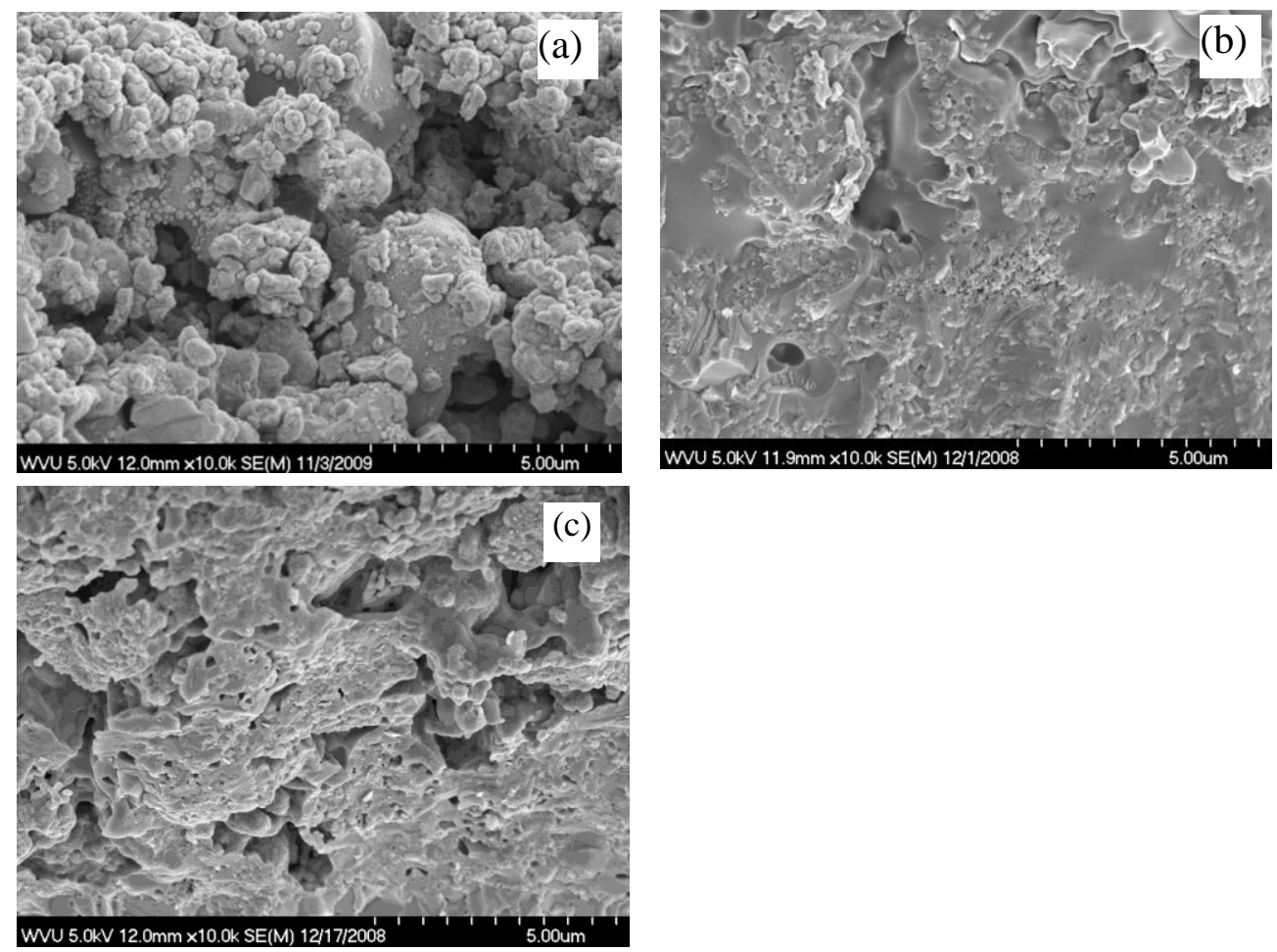

Figure 5.2.9 Cross-sectional SEM pictures of a cell (a) anode operated in wet $\mathrm{H}_{2}$ with $5 \mathrm{ppm} \mathrm{PH}_{3}$, (b) anode operated in wet $\mathrm{H}_{2}$ with $20 \mathrm{ppm} \mathrm{PH}_{3}$, (c) anode operated in syngas with $20 \mathrm{ppm} \mathrm{PH}_{3}$.

Figure 5.2.10 shows EDS spectra obtained from the cross-sectioned surfaces of the anode layer and the LDC interlayer after operation in $5 \mathrm{ppm} \mathrm{PH}_{3}$. The spectra showed all of the expected peaks in each case, with the addition of a strong P peak in the anode layer. The inset shows a magnified view of the region around the $\mathrm{P}$ peak, clarifying that a 
strong $\mathrm{P}$ peak was indeed present. On the other hand, only a trace amount of $\mathrm{P}$ was observed in the LDC interlayer, in agreement with the above XRD results that showed no change of LDC peak before and after $\mathrm{PH}_{3}$ testing.

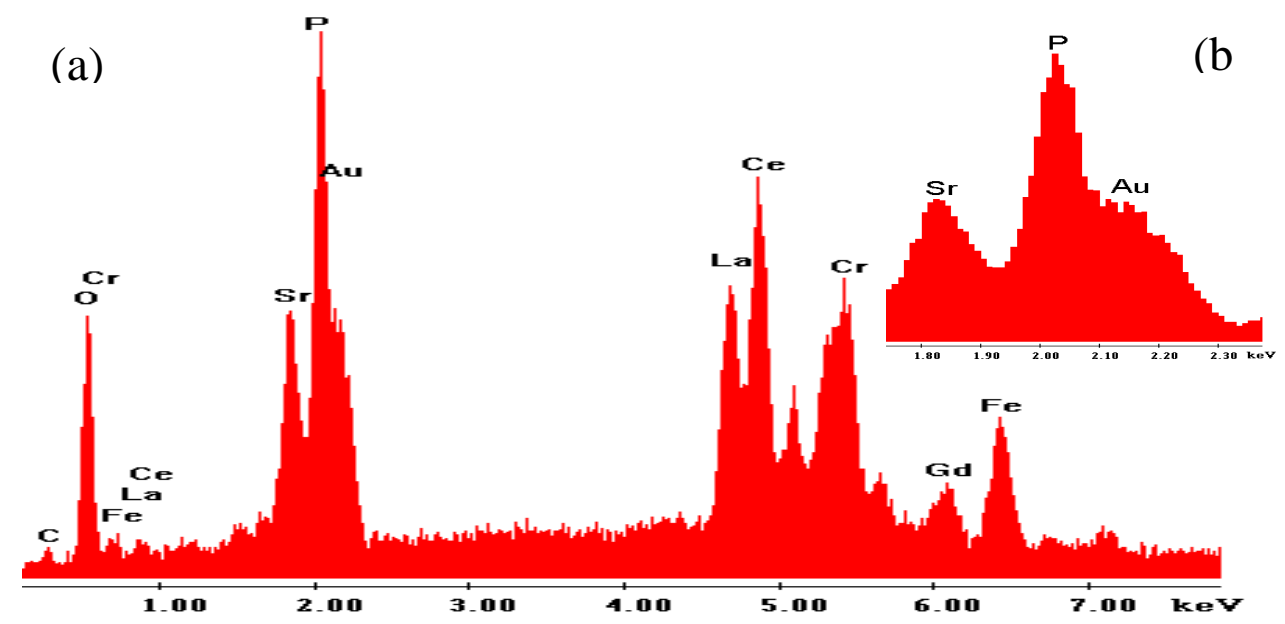

(c)

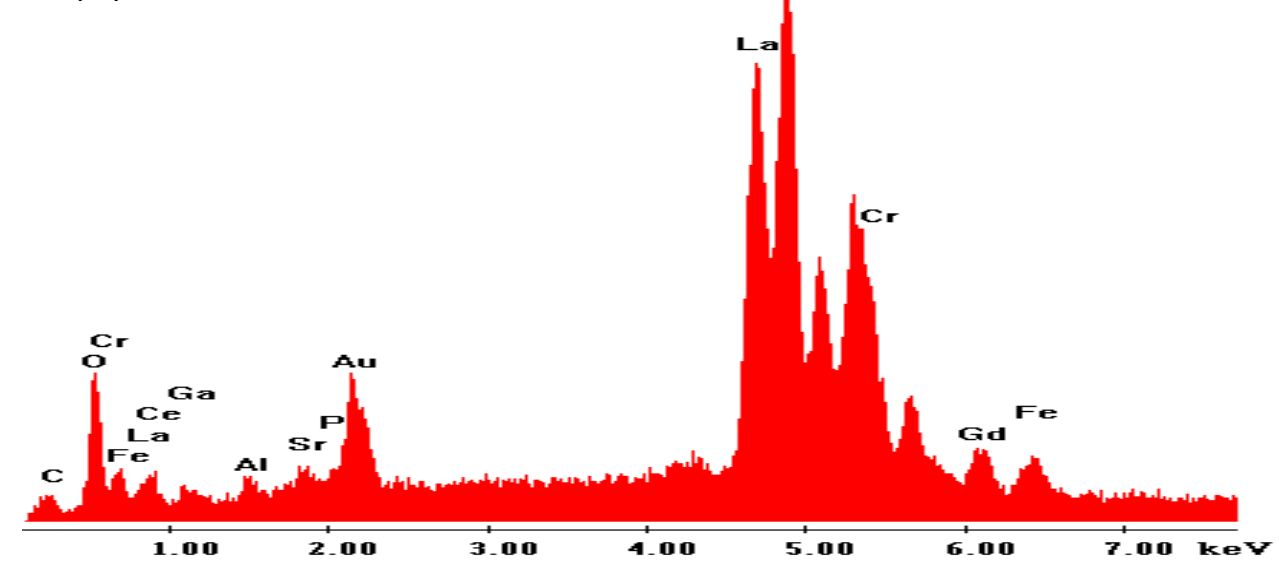

Figure 5.2.10 Cross-section EDS spectra of $\mathrm{H} 2-\mathrm{P} 5$ cell after 5pm $\mathrm{PH}_{3}$ poisoning in $97 \% \mathrm{H}_{2} / 3 \% \mathrm{H}_{2} \mathrm{O}$ recorded at (a) the LSFeCr-GDC anode and (c) near the LDC layer. The inset (b) is a close-up of the $\mathrm{P}(\mathrm{K} \alpha)$ and $\mathrm{Au}(\mathrm{M} \alpha)$ line position.

\subsubsection{XPS analysis}

Figure 5.2.11 shows a survey XPS spectrum from the anode that had been tested in 5 ppm $\mathrm{PH}_{3}$ in $\mathrm{H}_{2}$. Again, peaks are identified from each of the anode constituents, along with $\mathrm{P}$. The $\mathrm{O} 1 \mathrm{~s}, \mathrm{Sr} 3 \mathrm{~d}$ and $\mathrm{P} 2 \mathrm{p}$ peaks were relatively strong compared to the $\mathrm{Fe} 2 \mathrm{p}, \mathrm{Cr}$ 
2p, La 3d and Ce 3d peaks, suggesting that the anode surface was enriched with $\mathrm{Sr}$ and P. The P $2 p$ peaks were overlapped with the Sr $3 d$ peaks at $130-135 \mathrm{eV}$, but the presence of surface $\mathrm{P}$ and $\mathrm{Sr}$ were confirmed separately by the $\mathrm{P} 2 \mathrm{~s}$ and $\mathrm{Sr} 3 p$ peaks.

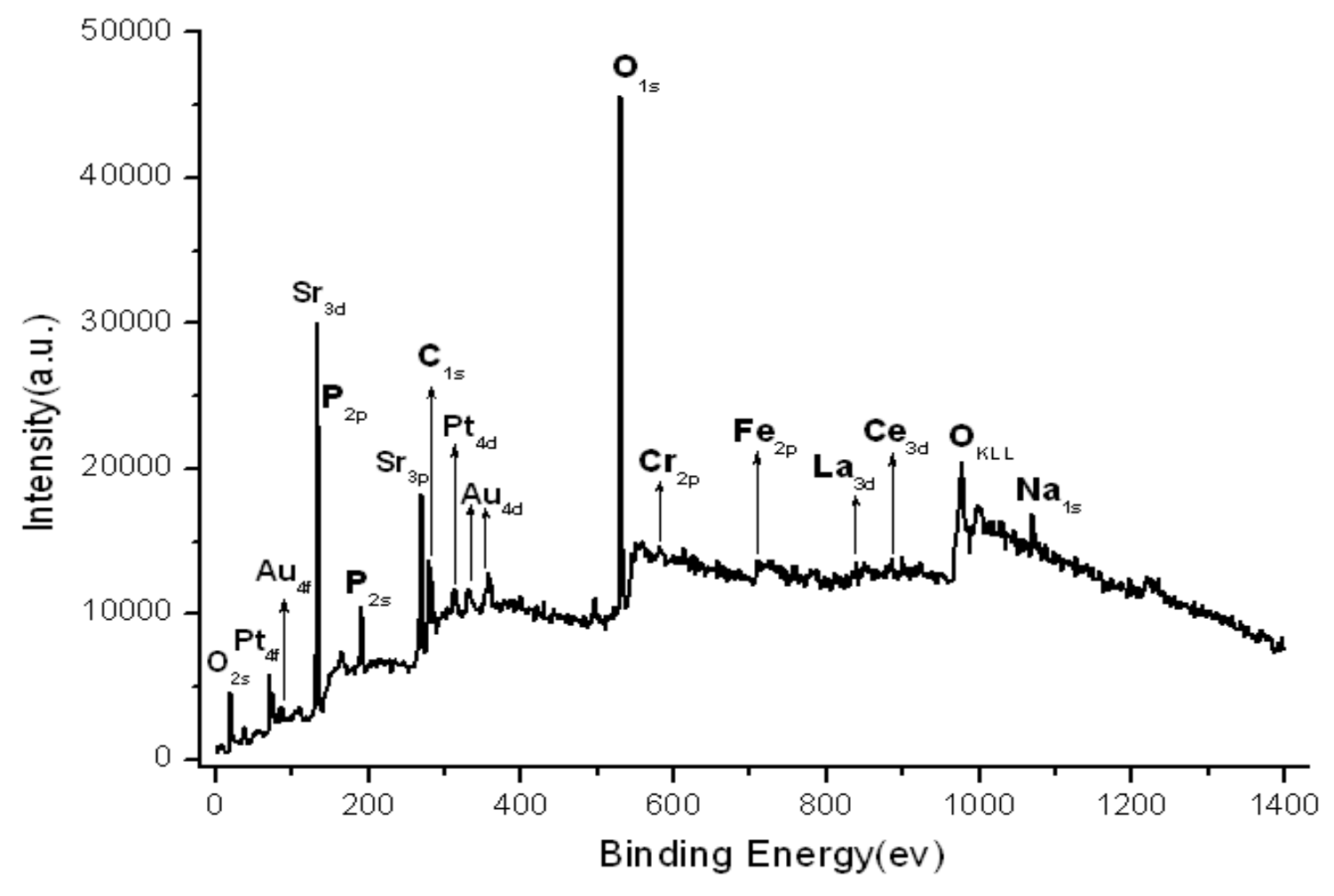

Figure 5.2.11 XPS spectra of a survey scan of the H2-P5 cell anode surface after 5ppm $\mathrm{PH}_{3}$ testing in $97 \% \mathrm{H}_{2} / 3 \% \mathrm{H}_{2} \mathrm{O}$

Figure 5.2.12 shows magnified views of the $130-135 \mathrm{eV}$ region for the anode tested in $20 \mathrm{ppm} \mathrm{PH}_{3}$ in syngas (Fig.5.2.12a) along with the $5 \mathrm{ppm} \mathrm{PH}_{3}$ in $\mathrm{H}_{2}$ case (Fig.5.2.12b). The Sr 3d and P 2p peaks combined to yield an apparent double peak. Figure 5.2.12 also shows that excellent fits to the combined $\mathrm{Sr} / \mathrm{P}$ peaks were obtained in both cases by deconvoluting the spectra into coupled electron peaks, using the Multipack XPS software carried by the Versa Probe testing system. The identified peak positions for P $2 p$ and $\mathrm{Sr}$ 3d high-spin electrons are listed in Table 5.2.2: 


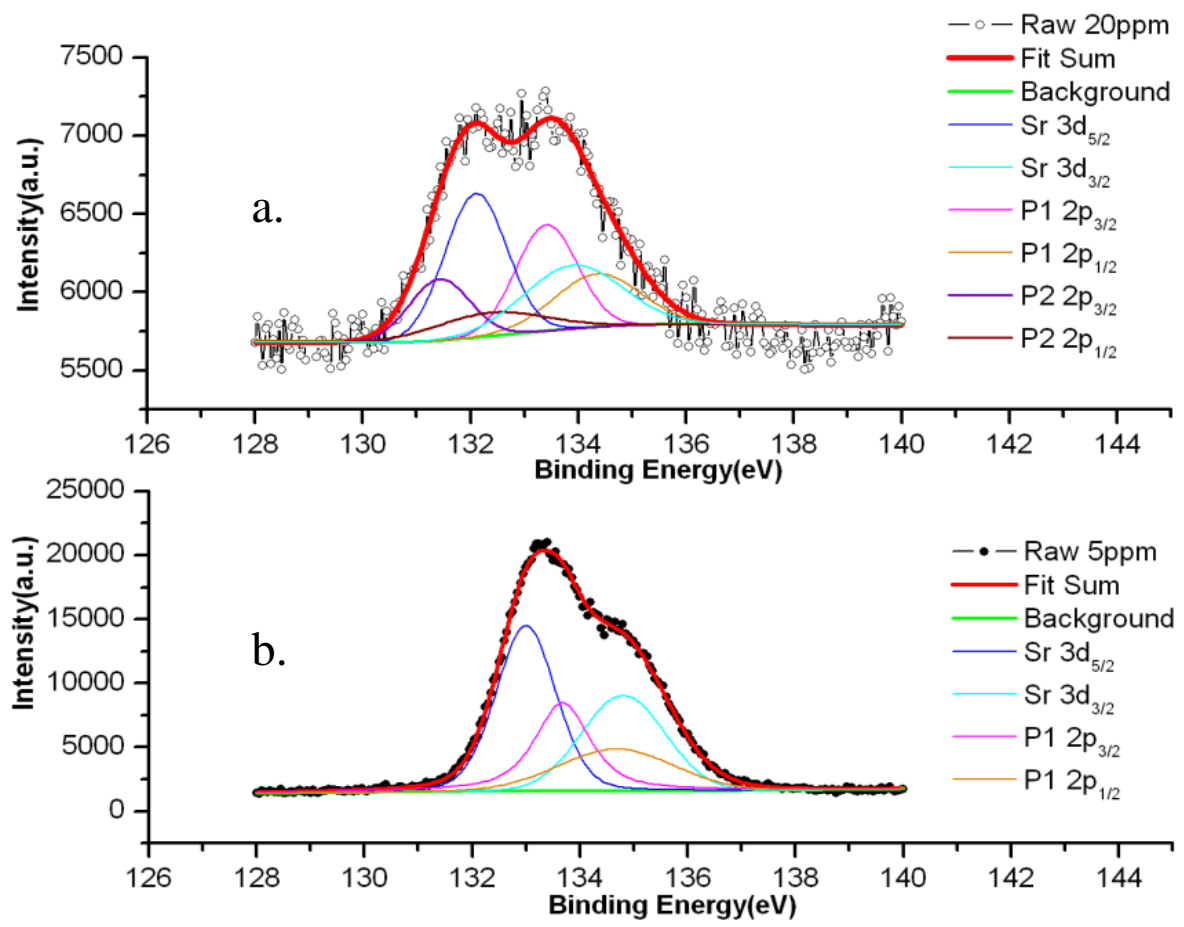

Figure 5.2.12 Original (raw) and deconvoluted Sr3d and P2p XPS spectra for an (a.) anode after exposure to 20ppm $\mathrm{PH}_{3}$ in simulated syngas (CG-P20) and (b) anode after exposure to $5 \mathrm{ppm} \mathrm{PH}_{3}$ testing in $97 \% \mathrm{H}_{2} / 3 \% \mathrm{H}_{2} \mathrm{O}(\mathrm{H} 2-\mathrm{P} 5)$

Table 5.2.2: P 2p, Sr 3d and Fe 2p XPS peaks of anodes after exposure to 5 and 20 ppm $\mathrm{PH}_{3}$.

\begin{tabular}{|c|c|c|c|c|}
\hline SamplelPeak position & $\begin{array}{c}\mathrm{P} 2 \mathrm{p}_{3 / 2} \text { peak 1 } \\
(\mathrm{eV})\end{array}$ & $\begin{array}{c}\mathrm{P} 2 \mathrm{p}_{3 / 2} \text { peak } 2 \\
(\mathrm{eV})\end{array}$ & $\begin{array}{c}\text { Sr 3d } \\
5 / 2 \text { peak } \\
(\mathrm{eV})\end{array}$ & $\begin{array}{c}\text { Fe 2 } \mathrm{p}_{3 / 2} \text { peak } \\
(\mathrm{eV})\end{array}$ \\
\hline $\mathrm{CG}-\mathrm{Fe}-2\left(20 \mathrm{ppm} \mathrm{PH}_{3}\right)$ & 133.4 & 131.4 & 132.1 & 709.5 \\
\hline $\mathrm{CG}-\mathrm{Fe}-4\left(5 \mathrm{ppm} \mathrm{PH}_{3}\right)$ & 133.7 & - & 133.0 & 712.1 \\
\hline
\end{tabular}

The $\mathrm{P} 2 \mathrm{p}_{3 / 2}$ electron in the XPS spectrum for the anode poisoned by $5 \mathrm{ppm} \mathrm{PH}_{3}$ showed binding energies of $133.7 \mathrm{eV}$, which corresponded well to the phosphorous state in phosphate, according to the NIST XPS database[104]. For the 20ppm $\mathrm{PH}_{3}$ case two valence states were identified for surface phosphorus with binding energies of $133.4 \mathrm{eV}$ (P1) and $131.4 \mathrm{eV}(\mathrm{P} 2)$. The former value indicates a phosphate state, while the latter value falls between that of $\mathrm{FeP}(129.5 \mathrm{eV})$ and the reported value for oxidized 
phosphorus in a phosphide $(132.7 \mathrm{eV})$. Phosphorous oxidation may have resulted from exposure of the sample to air after testing [105] .Preservation of the lower electron state for phosphorus in the sample exposed to $20 \mathrm{ppm}-\mathrm{PH}_{3}$ may have resulted from enhanced reaction with the perovskite anode due to higher $\mathrm{PH}_{3}$ concentration. Additionally, exposure of the 20-ppm sample to hydrogen during the attempt to recover cell performance likely contributed to the formation of low-valence phosphorus in the sample. The $\mathrm{Sr} 3 \mathrm{~d}_{5 / 2}$ peak in the spectrum of the $5 \mathrm{ppm} \mathrm{PH}_{3}$-poisoned anode was located at 133.0 $\mathrm{eV}$, close to the reported value of the $\mathrm{Sr}$ cation in perovskite oxides [106]. This peak shifted to a lower binding energy of $132.1 \mathrm{eV}$ in the spectrum for the anode exposed to 20ppm $\mathrm{PH}_{3}$, in agreement with $\mathrm{Sr}$ found in $\mathrm{SrO}_{1-\mathrm{x}}(132.2 \mathrm{eV})$ [107]. A similar valence state change for the Fe cation was observed in Figure 5.2.13, where the binding energies corresponding to the $\mathrm{Fe} 2 \mathrm{p}_{3 / 2}$ and $2 \mathrm{p}_{1 / 2}$ electrons also became smaller for the $20 \mathrm{ppm} \mathrm{PH}_{3}$ poisoned anode compared to the $5 \mathrm{ppm}$ case. In general, for higher $\mathrm{PH}_{3}$ concentration, the valence state change of $\mathrm{Sr}$ and $\mathrm{Fe}$ cations may be related to the increased reaction of metal components in the perovskite structure with higher concentration of phosphorus at the anode surface, as electron binding energy tends to decrease when such metal ions bond with $\mathrm{P}$, with lower electronegativity than oxygen. 


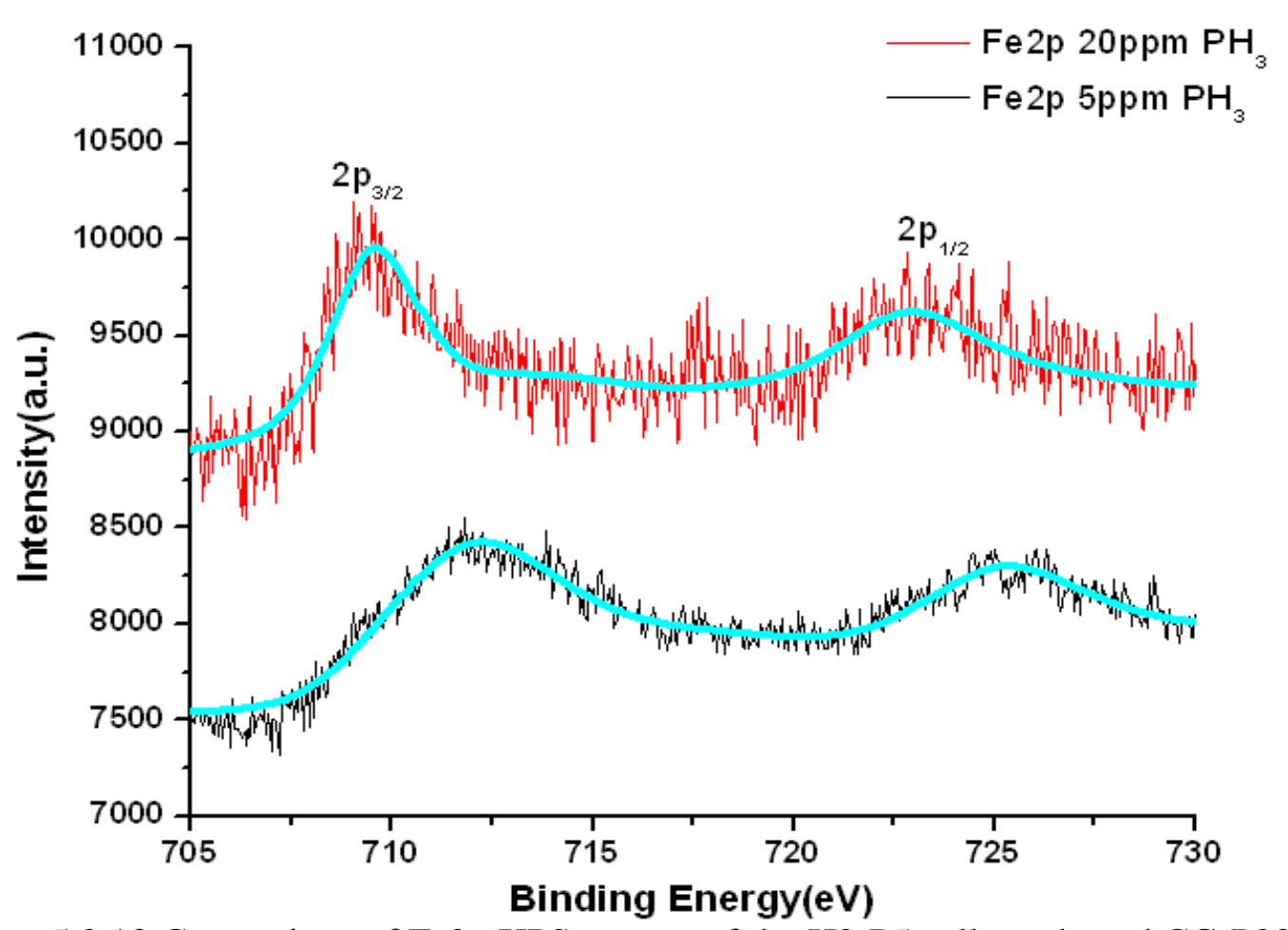

Figure 5.2.13 Comparison of Fe2p XPS spectra of the H2-P5 cell anode and CG-P20 cell anode after $\mathrm{PH}_{3}$ testing in $97 \% \mathrm{H}_{2} / 3 \% \mathrm{H}_{2} \mathrm{O}$

\subsubsection{Discussion}

The results presented above indicated that $\mathrm{PH}_{3}$ impurity at ppm levels severely degrades the performance of LSFeCr SOFC anodes. Structural/chemical analysis in section 5.2.3 indicated the formation of new phosphide and phosphate phases and decomposition of the perovskite phase accompanied by a densification of the anode. The structural/chemical measurements were all taken after cell tests in which the anode was exposed to $\mathrm{PH}_{3}$ until the cell voltage dropped to zero. This suggests that the degradation was nearly complete, i.e., that the anode was approaching its equilibrium composition and phase distribution. Thus, it should be reasonable to compare the experimental results with thermodynamic predictions, at least qualitatively. In the following, a thermodynamic analysis of the stable phases expected in $\mathrm{PH}_{3}$ is described (section 5.2.4.1). The 
degradation mechanisms are then discussed in light of the thermodynamic results (section 5.2.4.2), and compared with $\mathrm{Ni}$-YSZ (section 5.2.4.3).

\subsubsection{Thermodynamic Calculations}

The thermodynamic calculation aimed to determine the conditions under which different phases were expected to form. Given the above XPS and XRD results, where the new phases identified included Fe phosphides and phosphates, the calculations focused on determining the Fe phases expected at varying $\mathrm{PH}_{3}$ concentrations and fuel oxygen partial pressure. The possible phosphide formation reactions between $\mathrm{Fe}$ and $\mathrm{PH}_{3}$ are:

$$
\begin{array}{rr}
2 \mathrm{Fe}+2 \mathrm{PH}_{3}<->2 \mathrm{FeP}+3 \mathrm{H}_{2} & \left(\Delta \mathrm{G}_{0,1073 \mathrm{~K}}=-339.8 \mathrm{~kJ}\right) \\
\mathrm{Fe}_{2} \mathrm{O}_{3}+2 \mathrm{PH}_{3}<->2 \mathrm{FeP}+3 \mathrm{H}_{2} \mathrm{O} \quad\left(\Delta \mathrm{G}_{0,1073 \mathrm{~K}}=-325.6 \mathrm{~kJ}\right)
\end{array}
$$

The Gibbs free energy changes were calculated by FACTSAGE. Figure 5.2.14 and 5.2.15 shows the $\mathrm{Fe}-\mathrm{PH}_{3}-\mathrm{O}_{2}$ predominance phase diagrams that were calculated using the FACTSAGE Software for the surrogate syngas and wet $\mathrm{H}_{2}$ respectively. For the conditions of the present $\mathrm{H}_{2} / \mathrm{H}_{2} \mathrm{O}$ experiments (Fig.5.2.15) - $\mathrm{PH}_{3}$ pressure of $5 \times 10^{-6}$ or $2 \times 10^{-5} \mathrm{~atm}, T=1073 \mathrm{~K}$, and an effective oxygen partial pressure of $10^{-21.38} \mathrm{~atm}$ (humidified $\mathrm{H}_{2}$ ) - the predicted phosphide phase was $\mathrm{FeP}$ for $5 \mathrm{ppm} \mathrm{PH}_{3}$ test and $\mathrm{FeP}_{2}$ for $20 \mathrm{ppm} \mathrm{PH}_{3}$, although the experimental conditions were close to the $\mathrm{FeP} / \mathrm{FeP}_{2}$ phase boundary. In contrast, only FeP was observed experimentally by XRD; this discrepancy may be due to the approximate nature of the calculation results, where Fe was assumed to be present as pure $\mathrm{Fe}$ or $\mathrm{Fe}_{2} \mathrm{O}_{3}$, rather than in the perovskite phase. In the syngas 
atmosphere, the oxygen pressure was higher, $\mathrm{p}_{\mathrm{O} 2}=10^{-19} \sim 10^{-18}$ atm as labeled in Fig.5.2.14, such that $\mathrm{FePO}_{4}$ (s) could form.

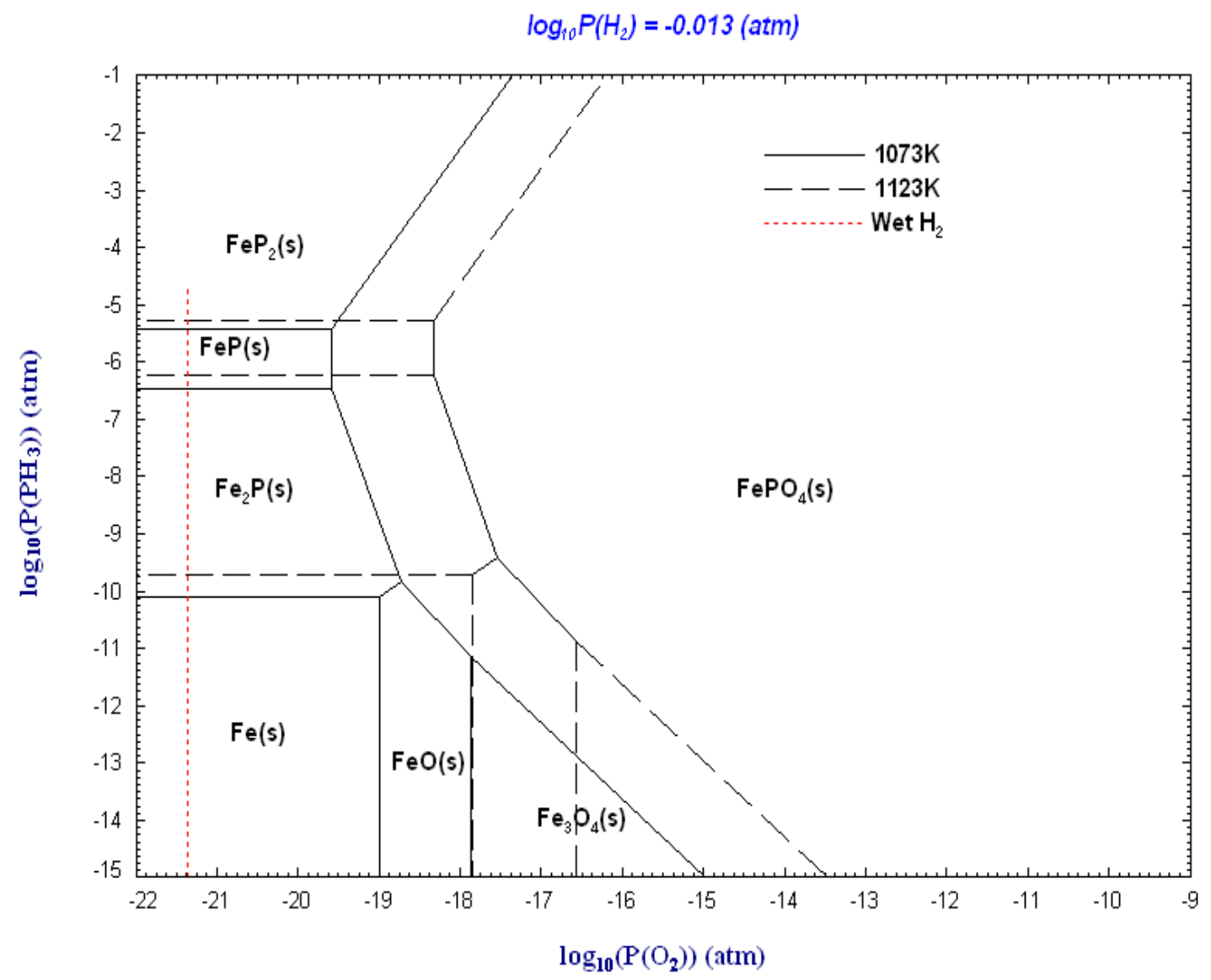

Figure 5.2.14 Predominant phase diagrams of Fe-P-O-H system at $800^{\circ} \mathrm{C}$ and $850^{\circ} \mathrm{C}$, assuming $\mathrm{PH}_{3}$ as reactant and $\mathrm{pH}_{2}=0.97$ bar 


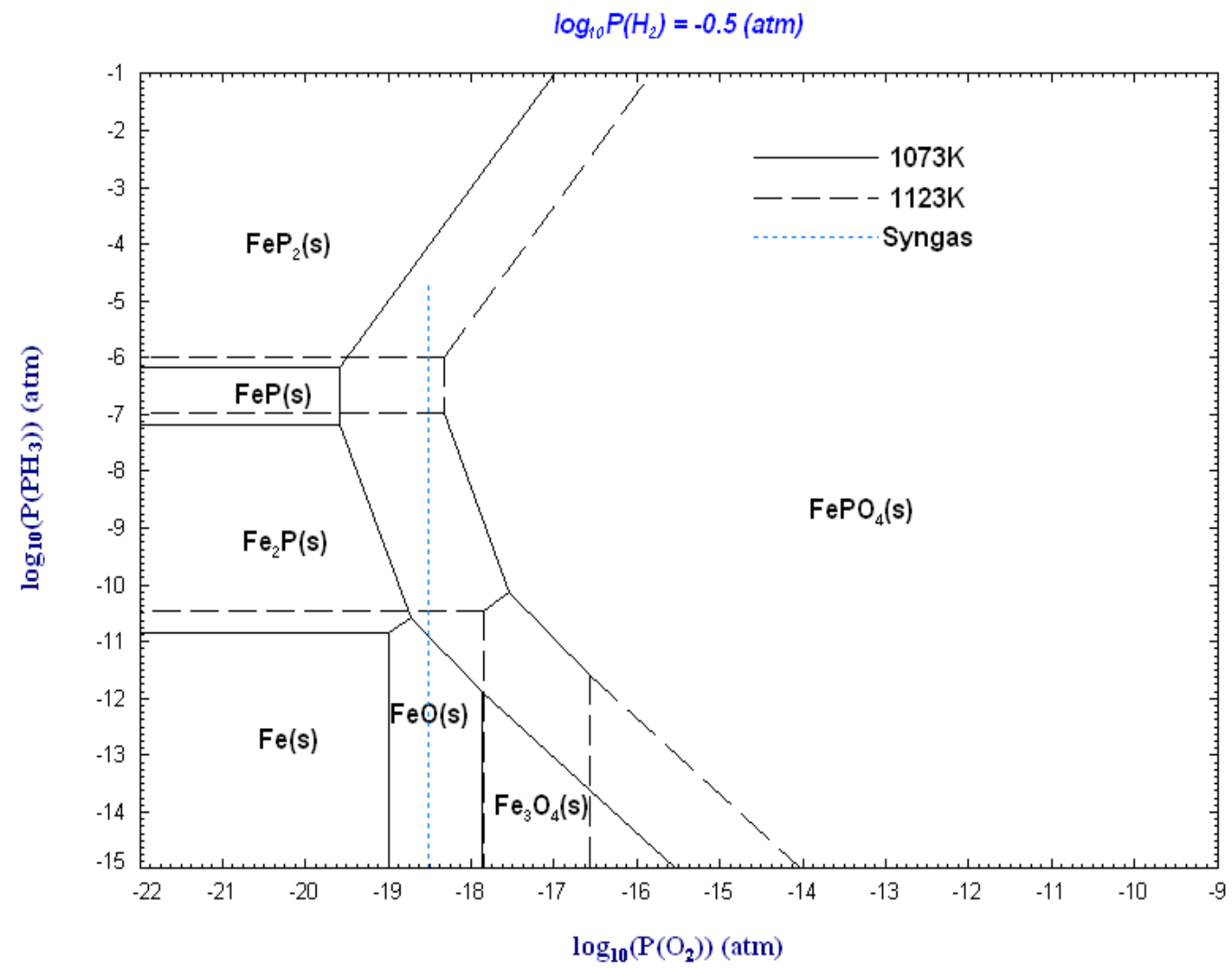

Figure 5.2.15 Predominant phase diagrams of Fe-P-O-H system at $800^{\circ} \mathrm{C}$ and $850^{\circ} \mathrm{C}$, assuming $\mathrm{PH}_{3}$ as reactant and $\mathrm{pH}_{2}=0.31$ bar

Fig. 5.2.14 predicts that increasing the $\mathrm{PH}_{3}$ concentration above $\sim 100 \mathrm{ppm}$ will favor the existence of $\mathrm{FeP}_{2}$ over $\mathrm{FeP}$ and $\mathrm{FePO}_{4}$. The results also indicate that the $\mathrm{PH}_{3}$ concentration would have to be reduced to quite low values, $<1 \mathrm{ppb}$, in order to avoid the formation of phosphate or phosphide phases. The calculated results for $1123 \mathrm{~K}$, also shown in Fig. 5.2.14, indicated that the phosphide region extends to higher $\mathrm{P}_{\mathrm{O} 2}$ at higher temperature. Given that the local cell temperature would increase due to current passage and so might phosphorus concentration due to surface accumulation, phosphide could form consequently. Also the exposure of the sample to hydrogen after $\mathrm{PH}_{3}$ poisoning test in syngas to achieve cell recovery may promote formation of phosphide at high temperature. However, the phosphide is less stable at lower temperatures. Thus, the post- 
test XRD results may reflect the tendency for phosphide to become oxidized while the cell was cooled from operating temperature at the end of the cell tests. Anode reactions may also have occurred after steady-state cell testing, during cool-down of the cell. Note that the cells were cooled from $800^{\circ} \mathrm{C}$ to room temperature in $\mathrm{N}_{2}$ within $2-3$ hours. This may explain the presence of $\mathrm{Fe}_{2} \mathrm{O}_{3}$ with $\mathrm{FeP}$ in the XRD data. Under this more oxidizing condition and with $\mathrm{PH}_{3}$ no longer present, it is reasonable to expect partial oxidation of the FeP. This was previously observed under similar conditions for the case of Nickel phosphide formation [99].

$\mathrm{LaPO}_{4}$ was also identified in the present XRD scans. This is similar to a prior report where the conversion of a $\mathrm{LaCoO}_{3}$ perovskite catalyst to $\mathrm{LaPO}_{4}$ and $\mathrm{La}_{4}\left(\mathrm{P}_{2} \mathrm{O}_{7}\right)_{3}$ secondary phases was observed as a result of organophosphorus exposure in $\mathrm{Ar}$ atmosphere [108]. The lack of thermodynamic data in the FACTSAGE database prevented calculation of the predominant phase diagram for the $\mathrm{La}_{2} \mathrm{O}_{3}-\mathrm{PH}_{3}$ system as a function of oxygen partial pressure and $\mathrm{PH}_{3}$ concentration. Thermodynamic data for possible $\mathrm{LaPO}_{4}$ formation reactions $[109,110]$ was thus used to calculate the Gibbs free energy change $\Delta \mathrm{G}$ of the reaction using

$$
\Delta \mathrm{G}=\Delta \mathrm{G}_{0, \mathrm{~T}}+\mathrm{RT} \ln \mathrm{K}
$$

where $\mathrm{T}$ is temperature. $\mathrm{R}$ is the gas constant, and $\mathrm{K}$ the equilibrium constant. The standard Gibbs free energy change $\Delta \mathrm{G}_{0, \mathrm{~T}}$ was calculated from the formation enthalpy and entropy of each compound involved in the reaction, and then substituted stoichiometrically into Equation 5.2.3 to calculate K to get the overall Gibbs free energy change. The resulting values with $2 \times 10^{-5}$ atm $\mathrm{PH}_{3}$ are: 


$$
\begin{gathered}
\mathrm{PH}_{3}+\frac{5}{2} \mathrm{H}_{2} \mathrm{O}+\frac{1}{2} \mathrm{La}_{2} \mathrm{O}_{3} \rightarrow \mathrm{LaPO}_{4}+4 \mathrm{H}_{2}\left(\Delta \mathrm{G}_{1073 \mathrm{~K}, \text { wet } \mathrm{H} 2}=-260.4 \mathrm{~kJ} ; \Delta \mathrm{G}_{1073 \mathrm{~K}, \text { syngas }}=-\right. \\
\frac{1}{2} \mathrm{P}_{2} \mathrm{O}_{5}+\frac{1}{2} \mathrm{La}_{2} \mathrm{O}_{3} \rightarrow \mathrm{LaPO}_{4}\left(\Delta \mathrm{G}_{298 \mathrm{~K}}=-316.5 \mathrm{~kJ}\right)
\end{gathered}
$$

The calculation is based upon the assumption which views the perovskite structure as a solution composed of simple oxides, which has been adopted in other research on stability of the perovskite anode [49]. The results showed the formation of the $\mathrm{LaPO}_{4}$ phase at $800^{\circ} \mathrm{C}$ is quite energetically favorable, and $\mathrm{LaPO}_{4}$ is a thermodynamically stable phase at cell testing condition. Additionally, the formation of $\mathrm{LaPO}_{4}$ is expected to become more favorable in the syngas atmosphere than in wet $\mathrm{H}_{2}$. The sample exposed to 20ppm $\mathrm{PH}_{3}$ in syngas did appear to degrade faster than the one tested in wet $\mathrm{H}_{2}$ with same $\mathrm{PH}_{3}$ concentration. In addition, Equation 5.2.5 indicates that $\mathrm{LaPO}_{4}$ can be also produced at room temperature as result of $\mathrm{P}_{2} \mathrm{O}_{5}$ and $\mathrm{La}_{2} \mathrm{O}_{3}$ reaction, thus more detailed study are required to identify the real reaction mechanism of $\mathrm{La}_{2} \mathrm{O}_{3}$ in perovskite with $\mathrm{PH}_{3}$.

An important question is whether $\mathrm{LaPO}_{4}$ forms because the perovskite phase is first de-stabilized by the loss of Fe to FeP, or whether it would form from a stable perovskite. Thus additional calculations were completed to estimate the stability of the present perovskite structure under presence of $\mathrm{PH}_{3}$ at cell operation conditions. The characteristic thermodynamic data of LSFeCr perovskite is unknown at this point, hence stability of the anode is estimated by using thermodynamic data recently reported for the simple perovskite systems as $\mathrm{LaCrO}_{3}$ and $\mathrm{LaFeO}_{3}$ [111,112].The Gibbs free energy change for dissociation reactions of above perovskites are calculated as follows: 


$$
\begin{aligned}
& \mathrm{LaCrO}_{3} \rightarrow \frac{1}{2} \mathrm{Cr}_{2} \mathrm{O}_{3}+\frac{1}{2} \mathrm{La}_{2} \mathrm{O}_{3}\left(\Delta \mathrm{G}_{1073 \mathrm{~K}}=+76.05 \mathrm{~kJ}\right) \\
& \mathrm{LaFeO}_{3} \rightarrow \frac{1}{2} \mathrm{Fe}_{2} \mathrm{O}_{3}+\frac{1}{2} \mathrm{La}_{2} \mathrm{O}_{3}\left(\Delta \mathrm{G}_{1073 \mathrm{~K}}=+60.97 \mathrm{~kJ}\right)
\end{aligned}
$$

The combined Gibbs free energy change for reaction (5.2.6) and (5.2.7) together to form $\mathrm{LaPO}_{4}$ would be $-184.35 \mathrm{~kJ}$ and $-274.35 \mathrm{~kJ}$ respectively for wet $\mathrm{H}_{2}$ and syngas atmosphere. The values for $\mathrm{LaFeO}_{3}$ system would be more negative considering further reaction of $\mathrm{Fe}_{2} \mathrm{O}_{3}$ with $\mathrm{PH}_{3}$. Therefore above calculation shows it is energetically favorable for the $\mathrm{La}$ and $\mathrm{Fe}$ containing perovskite systems to decompose under $\mathrm{PH}_{3}$ attack and form $\mathrm{LaPO}_{4}$. Experiments with ( $\left.\mathrm{La}, \mathrm{Sr}\right) \mathrm{CrO}_{3}$ anodes would be useful to further identify the reactions between $\mathrm{La}$ and $\mathrm{PH}_{3}$.

Finally, a thermodynamic analysis similar to that outlined above was performed to examine possible reactions between $\mathrm{Cr}_{2} \mathrm{O}_{3}$ and $\mathrm{PH}_{3}$. It was found that no reaction was expected for the present test conditions. This agrees with the present XRD results that showed no $\mathrm{Cr}$ phosphides or phosphates. Although a new $\mathrm{Sr}_{2} \mathrm{CrO}_{4}$ phase was observed, this may have formed as a result of the loss of $\mathrm{La}$ and $\mathrm{Fe}$ from the original LSFeCr perovskite phase.

\subsubsection{Anode Reaction and Degradation Mechanisms}

While the above thermodynamic predictions provided good agreement with the XRD results, they provided little information about the reaction sequence. It seems reasonable to suggest that $\mathrm{La}$ and $\mathrm{Fe}$ reacted with $\mathrm{PH}_{3}$, with the result that the perovskite phase decomposed. The electrical testing results showed that the rapid cell degradation occurred only after 4-7 h of $\mathrm{PH}_{3}$ exposure. EIS data (Fig. 5.2.6) taken during the initial period of stable performance showed only a slight increase in the first real-axis intercept, which 
was mainly due to the LSGM electrolyte. However, slight variations in the cell performance with time were observed also for cells tested without $\mathrm{PH}_{3}$, so this change was not necessarily associated with anode poisoning. The cell polarization resistance did not change, indicating that the active anode surfaces or three-phase boundaries were not poisoned by $\mathrm{PH}_{3}$.

The delay prior to the rapid degradation could have a few explanations. First, there may have been an incubation time prior to nucleation of the new phosphide or phosphate phases. Second, the growth of the new phases may have been relatively slow, such that it took some time before sufficient LSFeCr was consumed to deleteriously affect electrochemical processes. Prior studies have shown that the out-diffusion of cation species from chromite anode particles, i.e., Ru out of LSCrRu,[113] occurred over several hours at SOFC operating conditions. This process could have limited the phosphide/phosphate growth rate. Another possibility is that the reaction occurred first at the outer surfaces of the anode, having little impact on anode function until the reaction front approached the electrolyte. Finally, the reaction may have been limited by the supply of $\mathrm{PH}_{3}$. Given that the anode was $20 \mu \mathrm{m}$ thick, $0.5 \mathrm{~cm}^{2}$ in area, $~ 33 \% \mathrm{LSFeCr}$ by volume, and the density of LSFeCr is $\approx 6 \mathrm{~g} \mathrm{~cm}^{-3}$, there was $2.0 \mathrm{mg}$ of $\mathrm{LSFeCr}(0.36 \mathrm{mg}$ $\mathrm{Fe}, 0.45 \mathrm{mg} \mathrm{La}$ ) in the anode. Thus, $\approx 0.8 \mathrm{mg}$ of $\mathrm{P}$ was needed to react with these species according to the above phosphide or phosphate formation reactions. At a flow rate of 200 sccm with 5 ppm $\mathrm{PH}_{3}$, the molar $\mathrm{PH}_{3}$ flow rate is $4.16 \times 10^{-8}$ moles $\min ^{-1}$ or $1.3 \mu \mathrm{g} \mathrm{P}$ per minute. At this rate, it would take 620 min to fully react the $\mathrm{La}$ and $\mathrm{Fe}$ in the anode, in a good agreement with the time required for complete anode failure. For the $20 \mathrm{ppm} \mathrm{PH}_{3}$ case, the predicted time is reduced to $155 \mathrm{~min}$, again in reasonable agreement with the 
observed degradation time. These estimates suggest that $\mathrm{PH}_{3}$ is extremely reactive with LSFeCr, such that the reaction is limited mainly by the supply of $\mathrm{PH}_{3}$.

During the rapid degradation stage, both the ohmic and polarization resistance portions of the EIS increased rapidly. This is readily explained by the consumption of LSFeCr, which eliminated surfaces and three-phase boundaries that contributed to electrochemical reactions, reduction of anode current-carrying capability, and the disruption and densification of the anode structure due to volume changes upon phosphide/phosphate formation.

\subsubsection{Comparison with Ni-YSZ Anodes}

The present results can be compared directly with a recent report on the operation of Ni-YSZ anode-supported SOFCs on syngas containing 10 ppm $\mathrm{PH}_{3}$ [99]. A striking difference is the much slower degradation of the Ni-YSZ anodes $\left(\approx 0.5 \mathrm{mV} \mathrm{h}^{-1}\right)$ compared to the present anodes $\left(\approx 100 \mathrm{mVh}^{-1}\right)$. This is despite the higher reactivity of $\mathrm{Ni}$ with $\mathrm{PH}_{3}$; thermodynamic predictions suggested that Nickel phosphides form at $\mathrm{PH}_{3}$ partial pressures down to $10^{-13} \mathrm{~atm}$ compared to $10^{-11} \mathrm{~atm}$ for the $\mathrm{LSFeCr}$ anodes. A likely explanation for the much slower Ni-YSZ anode degradation rate was the much larger amount of $\mathrm{Ni}, \sim 330 \mathrm{mg}$ or $\sim 400$ times the amount of $\mathrm{La}$ and $\mathrm{Ni}$ in the present anodes. The calculation in the prior section indicated that the rate of anode phosphidization was limited by the supply of $\mathrm{PH}_{3}$. Thus, the larger amount of $\mathrm{Ni}$ resulted in a much slower degradation rate.

One might also suggest that $\mathrm{Fe}$ being in the stable perovskite oxide might lend it greater stability against $\mathrm{PH}_{3}$ attack compared to a metallic phase such as Ni. However, it 
has been noted previously that $\mathrm{Fe}$ in $\mathrm{LSFeCr}$ is barely stable under SOFC anode conditions compared to metallic $\mathrm{Fe}$. Thus, the activities of $\mathrm{Fe}$ in the metallic and perovskite phases must be similar, and hence they should have similar reactivities with $\mathrm{PH}_{3}$.

\subsubsection{Summary and Conclusions}

Generally, the above thermodynamic analysis confirmed the assumption made that the PH3 poisoning of LaSrFeCr-GDC anode occurred by decomposition of perovskite structure and formation of corresponding secondary phases of phosphide and phosphate. The performance and stability of LSGM-electrolyte supported SOFCs with LSFeCr-GDC composite anodes were studied in coal syngas and wet $\mathrm{H}_{2}$ fuels containing phosphine impurity. Several conclusions can be drawn and future work is suggested:

1. Introduction of 5 to $20 \mathrm{ppm} \mathrm{PH}_{3}$ into the fuels caused complete cell performance degradation within 11 to 24 hrs, with no recovery after removing $\mathrm{PH}_{3}$ impurity from the fuels.

2. There was an initial period of $4-7 \mathrm{~h}$ where there was little change in cell electrochemical performance, followed by a very rapid decline in cell voltage at constant current. This suggests that impurity-related chemisorbed species did not interfere with electrochemical reactions.

3. Rather, the degradation was associated with a decomposition of the LSFeCr perovskite structure, with the formation of new phases including $\mathrm{FeP}, \mathrm{FePO}_{4}, \mathrm{LaPO}_{4}$, and $\mathrm{Sr}_{2} \mathrm{CrO}_{4}$. It seems likely that the perovskite phase was de-stabilized by the removal of $\mathrm{Fe}$ to form $\mathrm{FeP}$ and/or $\mathrm{FePO}_{4}$. It is not clear whether $\mathrm{LaPO}_{4}$ would form from an otherwise stable perovskite, such as $(\mathrm{La}, \mathrm{Sr}) \mathrm{CrO}_{3}$. This is an important 
question to be answered in future work, as it will establish whether La-based anodes can be useful P-tolerant anodes.

4. The present results, combined with prior work on Ni-YSZ, suggest that anodes containing transition metals that are highly reactive with $\mathrm{P}$ will not be stable in ppm levels of $\mathrm{PH}_{3}$.. Thus materials such as $(\mathrm{La}, \mathrm{Sr})(\mathrm{Cr}, \mathrm{Mn}) \mathrm{O}_{3}$ and $\mathrm{Sr}(\mathrm{Mn}, \mathrm{Mo}, \mathrm{Mg}) \mathrm{O}_{3}$ should probably be tested with PH3-containing fuels.

5. Thermodynamic calculations were in reasonable agreement with the experimental observations, predicting $\mathrm{FeP}, \mathrm{FeP}_{2}, \mathrm{FePO}_{4}$, and $\mathrm{LaPO}_{4}$ as stable reaction products under the SOFC anode test conditions. The calculations also indicated that phosphide/phosphate formation was expected even for $1 \mathrm{ppb} \mathrm{PH}_{3}$ concentrations. Thus, it seems likely that similar degradation will occur at the $\mathrm{PH}_{3}$ concentrations expected in coal syngas (1-2 ppm), that are slightly lower than in the present experiments.

6. The time to anode failure, which increased for lower $\mathrm{PH}_{3}$ concentration, agreed well with the time required to supply sufficient $\mathrm{PH}_{3}$ to fully react with the $\mathrm{La}$ and $\mathrm{Fe}$ in the anode. This shows that the $\mathrm{LSFeCr}$ was extremely reactive with $\mathrm{PH}_{3}$. 


\section{Chapter 6 Fundamental Modeling of SOFC Cathode Kinetics}

\subsection{Introduction}

For decade, solid oxide fuel cells (SOFCs) have been widely investigated as a promising power generation technology with high conversion efficiency, fuel flexibility and emission controls [114,115]. Usually yittria-stablized-zirconia (YSZ) is applied as the electrolyte material due to its superior stability and low cost $[116,117]$. On the other hand, various perovskite oxides with mixed ionic and electronic conductivity (MIECs) are developed into SOFC cathode materials, among which strontium-doped lanthanum manganite (LSM) becomes a choice of interest as far as high electrical conductivity, competitive activity for oxygen reduction, compatibility with YSZ electrolyte and performance reliability are concerned[118]. For cost-reduction it is desirable for the SOFC to operate at an intermediate temperature (IT) typically of $700 \sim 850^{\circ} \mathrm{C}$, in order to use metallic interconnects. But IT-SOFCs would have higher internal resistances with major fraction of polarization loss from relatively sluggish oxygen reduction on SOFC cathodes $[119,120]$. Intensive research efforts have been put into investigation and improvement of SOFC cathodes kinetics, however due to randomness of electrode microstructure, sensitivity of material properties to manufacturing history and uncertainty within the testing configurations for conventional electrochemical analysis techniques, questions remain about the assignment of rate-limiting steps (RLSs) to the specific electrode processes and the mechanism of electrode activation during cathodic polarization [121,122]. Particularly for the LSM-based cathode, it is well known that the low intrinsic ionic conductivity of the material would lead to poor oxygen transport through the reaction interfaces originally. The proposed RLSs include charge-transfer to 
the oxygen adsorbate, surface oxygen diffusion, and incorporation of oxygen adsorbate at the triple-phase-boundary (TPB) according to AC impedance and DC polarization study results $[123,124,125,126]$. When subjected to cathodic current conditioning, partial reduction of Mn cations and subsequent oxygen vacancy formation in LSM are generally accepted as the activation mechanism [127,128,129], although removal of surface passive species and microstructure changes are also considered responsible for performance improvement $[130,131,132]$. Nevertheless, the dispute over chemical and electrochemical nature of the gas-electrode reactions further complicates identification of RLSs and interpretation of activation behaviors for porous cathodes $[133,134]$. To avoid such disagreement and ambiguity, more mechanistic approaches are being sought in kinetic studies of SOFC cathodes. Micro-electrodes with geometrically well-defined architecture have been used to enable direct observation of RLSs by quantifying electrode electrochemical response as function of parameters like film diameter and thickness[135,136,137]. In addition, physical simulations of electrode reaction have been also preferred by researchers through parametric study of the MIEC materials to obtain a fundamental understanding of the oxygen reduction pathways to facilitate experimental design.

Theoretically there are two pathways recognized for oxygen reduction on MIEC cathode [138], the surface pathway and the bulk pathway, with the consecutive mass and charge transfer as: (i) Gaseous diffusion; (ii) Surface oxygen exchange; (iii) Surface/bulk solid-state diffusion of oxygen adsorbates; (iv) Charge-transfer at the triple-phaseboundary (TPB) or the buried two-phase boundary (2PB) between cathode and electrolyte. From a physical point of view, models on the MIEC cathode concerning with 
two pathways categorily emphasize mass-transport and/or interfacial charge-transfer kinetical contributions. An ALS continuum model was proposed by Alder to analyze oxygen reduction on porous MIEC electrode based upon the 2PB pathway [133]. The model predicted well impedances for highly ionic conductive MIEC with chemical kinetics dominance, but generally did not hold for poorly ionic conductive materials on which reaction through the 3PB-pathway may dominate. Søgaard further modeled the 2PB-pathway polarization resistance of a composite MIEC cathode from surface exchange and diffusion parameters by using 2-D methodology [139]. Mebane, on the other hand, created a 2-D model from first principle analysis. The model examines the dependence of electrochemical and chemical driving forces for MIEC electrode reaction on material properties, although surface mass and charge transfer is not distinguished from bulk path [140]. Tanner and Virkar developed both 1-D and 2-D models to quantify micro-structural effects on the total cell resistance with an intrinsic 3PB charge-transfer polarization resistance $[141,142]$. The results together formed a solid basis for SOFC cathode design. However cares must be taken for the simulation to assume that kinetics of one pathway would totally dominate over the other pathway. In fact, the two pathways for oxygen reduction might co-exist competitively on the MIEC cathode, which can be especially the case for LSM with initial poor ionic conductivity. Based on impedance and polarization study of SOFC cathodes, Takeda and Siebert first came up with semiempirical models addressing kinetics influences from the bulk reaction path $[127,129]$. Liu then summarized both $2 \mathrm{~PB}$ and $3 \mathrm{~PB}$ pathways kinetics in a comprehensive MIEC model $[143,144]$. Svensson brought forth a continuum model simulating the masstransfer and charge-transfer processes in MIEC cathode controlled by both 3PB and 2PB 
electrochemical pathways $[145,146]$. The model was further improved by Coffey and coworkers to establish the transition between $3 \mathrm{~PB}$ and $2 \mathrm{~PB}$ kinetics by relating the overpotentials of the two pathways to each other [147]. These models enable direct comparison between two kinetic pathways from diverse material property parameters, and are thus useful as guide for experimental development. However, there are two challenges for the above models when applied especially to MIECs with low ionic conductivity. First, the models considered the chemical nature for oxygen-MIEC surface reactions and a simple charge-transfer mode for $3 \mathrm{~PB}$ and $2 \mathrm{~PB}$ reactions. Instead, examination of oxygen reduction on LSM cathode by Van Heuvlen and subsequent researchers indicated that charge-transfer through 3PB pathway could be break down into multiple steps $[123,124,125]$. A first-principle study by quantum chemistry on oxygen reduction also supported the electrochemical nature of the surface exchange reactions [148], which was also systemically modeled by Fleig [149]. Second, as stated by Adler [118], simulation of non-linear steady-state behavior of the electrode cannot be used to predict impedance and other physical processes with time resolution.

Inspired by the previous works of Svensson and Coffey, a one-dimensional diffusion model is thus developed in this study to simulate the bi-pathway controlled oxygen reduction on an MIEC electrode by incorporation of multi-step charge-transfer into the electrode kinetics. The main difference made is that, in addition to the charge-transfer at $2 \mathrm{~PB}$ and $3 \mathrm{~PB}$, surface reaction rates for oxygen adsorbate on MIEC are also treated with Butler-Volmer type expressions based upon multi-step charge-transfer assumption. This approach enables examination of the kinetic pathway transition for oxygen reduction on SOFC cathode from a more realistic scenario. A different computational method of finite 
volume control analysis is also applied in this model to visualize the transient profile of defects inside electrode as a result of overpotentials and various material physical parameters. On the other hand, as the current model does assume a uniform Fermi-level and perfect current collection throughout the SOFC cathode, which has been pointed out to frequently become problematic for the systems with high oxygen vacancy concentration and thin-film structure $[149,150]$, the simulation is designed and performed primarily for a LSM-type MIEC. Furthermore, as the model mainly contributes to a comparison of oxygen reduction pathways under charge-transfer RLSs control, microstructure-related diffusion effects are less addressed. The modeling results reveal that the nature of the 3PB-to-2PB electrode kinetics transition involves oxygen vacancy evolution and eventually suppression of surface oxygen diffusion. The present findings serve as basis of future model refinement to apply to other MIEC material systems.

\subsection{Physical model}

\subsubsection{General schemes for oxygen reduction}

In Fig.6.1 the oxygen reduction on SOFC cathode is divided into three mechanisms.

In mechanism I, where materials with poor ionic conductivity are operated under low overpotential, the electrode is essentially an electronic conductor (EC) like a "metal". Only surface pathway is active with charge-transfer restricted to the TPB. In mechanism III for MIEC with good ionic conductivity, adsorbed oxygen is taken into the MIEC bulk and diffused through the $2 \mathrm{~PB}$ overwhelmingly. Mechanism II is the interest for this study. For a material like LSM, the initial poor ionic conductivity can increase over time with the applied voltage, activating the near-TPB bulk region for oxygen reduction in addition to surface pathway. The electrode kinetics then become bi-pathway controlled. 

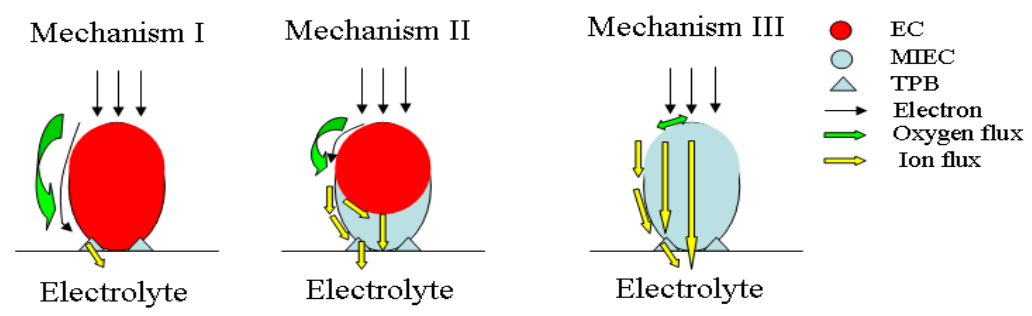

Figure 6.1 Three mechanisms for oxygen reduction on SOFC cathode

\subsubsection{Multi-step charge transfer model}

Oxygen transport on a SOFC cathode in contact with electrolyte (yttria-stablizedzirconia, YSZ) is described in a 1-D physical model shown in Fig. 6.2. The electrode consists of two layers: an MIEC layer extended from the $2 \mathrm{~PB}$ interface with sufficient ionic conductivity for bulk oxygen reduction, and an electronic conductive (EC) catalytic layer for oxygen adsorption. The boundary separating the MIEC and EC layer is determined by the bulk flux $\left(\mathrm{J}_{\mathrm{diff}, \mathrm{V}}\right)$ of oxygen vacancy in the MIEC $\left(V_{o, \text { MIEC }}^{\cdot \bullet}\right)$ generated by electrochemical exchange at the 2PB. Geometrical factors are not considered except for the volume specific surface area of particles. The surface pathway consists of four elementary steps referred to serially as S1-S4, and the corresponding physical processes are listed in Table 6.1.

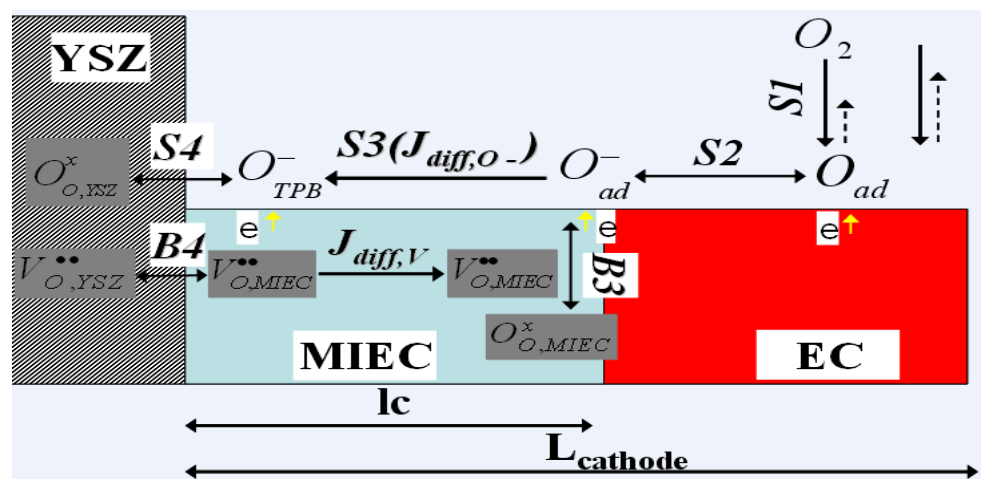

Figure 6.2 Schematic description of the bi-pathway dominated oxygen reduction on MIEC cathode (LSM) 
Table 6.1 Electrode processes assigned to each elementary steps in surface and bulk pathways

\begin{tabular}{|c|c|c|c|}
\hline Pathway & & Reaction steps & Process description \\
\hline \multirow{4}{*}{ Surface } & S1 & $1 / 2 O_{2}+S \underset{k_{S 1}^{-}}{\stackrel{k_{S 1}}{\longrightarrow}} O_{a d}$ & $\begin{array}{c}\text { Dissociate oxygen adsorption ( } S \text { :surface } \\
\text { adsorption site) }\end{array}$ \\
\hline & S2 & $O_{a d}+e^{-} \underset{k_{S 2}^{-}}{\stackrel{k_{S 2}}{\longleftrightarrow}} O_{a d}^{-}$ & $\begin{array}{c}\text { Oxygen intermediate formation }\left(1^{\text {st }} \text { step }\right. \\
\text { charge-transfer })\end{array}$ \\
\hline & S3 & $O_{a d}^{-} \stackrel{k_{S 3}}{\stackrel{k_{S 3}^{-}}{\longrightarrow}} \longrightarrow O_{T P B}^{-}$ & Surface diffusion towards TPB \\
\hline & S4 & $O_{T P B}^{-}+e+V_{O, Y S Z}^{\bullet \bullet} \stackrel{k_{S 4}}{\underset{k_{S 4}^{-}}{\longrightarrow}} O_{O}^{x}$ & $\begin{array}{l}\text { TPB incorporation of oxygen intermediates } \\
\left(2^{\text {nd }} \text { step charge-transfer }\right)\end{array}$ \\
\hline \multirow{2}{*}{ Bulk } & B3 & $O_{a d}^{-}+V_{O, M I E C}^{\bullet \bullet}+e^{-} \stackrel{k_{B 3}}{\underset{k_{B 3}^{-}}{\longrightarrow}} O_{O, M I E C}^{x}+\mathrm{S}$ & $\begin{array}{c}\text { Reaction of vacancy from MIEC bulk with } \\
\text { surface oxygen intermediates }\end{array}$ \\
\hline & B4 & $O_{O, M I E C}^{x}+V_{O, Y S Z}^{\cdot \bullet} \stackrel{k_{B 4}}{\stackrel{k_{B}}{\longrightarrow}} O_{O, Y S Z}^{x}+V_{O, M I E C}^{\cdot \bullet}$ & 2PB exchange between YSZ and MIEC \\
\hline
\end{tabular}

The bulk pathway shares the first two reaction steps with the surface pathway, but oxygen intermediates can be also consumed by a vacancy from MIEC to form lattice oxygen. Oxide ion vacancies are transferred through the bulk from $2 \mathrm{~PB}$ interface. The two additional steps are denoted as B3 and B4 in Table 6.1. According to the multi-step electron transfer theory on a charged electrode [151,152], rates of the consecutive reaction steps for surface and bulk pathways can be expressed as:

$$
\begin{aligned}
r_{S 1} & =k_{S 1} p_{O_{2}}^{1 / 2} \Gamma(1-\theta)-k_{S 1}^{-} \Gamma \theta \\
r_{S 2} & =k_{S 2} \Gamma \theta \exp \left(-\alpha_{3 P B} f E_{s}\right)-k_{S 2}^{-} C_{O^{-}} \exp \left[\left(1-\alpha_{3 P B}\right) f E_{s}\right] \\
r_{S 3} & =k_{S 3} C_{O_{a d}^{-}}-k_{S 3}^{-} C_{O_{T P B}^{-}} \\
r_{S 4} & =k_{S 4} C_{O_{T P B}^{-}} C_{V, Y S Z} \exp \left(-\alpha_{3 P B} f E_{s}\right)-k_{S 4}^{-} \Gamma(1-\theta) \exp \left[\left(1-\alpha_{3 P B}\right) f E_{s}\right] \\
r_{B 3} & =k_{B 3} C_{O_{a d}^{-}} C_{V, M I E C} \exp \left(\alpha_{2 P B} f E_{B}\right)-k_{B 3}^{-} \Gamma(1-\theta) \exp \left[-\left(1-\alpha_{2 P B}\right) f E_{B}\right] \\
r_{B 4} & =k_{B 4} C_{V, Y S Z} \exp \left(-2 \alpha_{2 P B} f E_{B}\right)-k_{B 4}^{-} C_{V, M I E C} \exp \left[2\left(1-\alpha_{2 P B}\right) f E_{B}\right]
\end{aligned}
$$

Where $k_{S}$ and $k_{S}^{-}$are the forward and backward rate constants in the surface pathway; $k_{B}$ and $k_{B}^{-}$are rate constants for the bulk pathway; $C_{O_{a d}^{-}}, C_{V, M I E C}$ and $C_{V, Y S Z}$ are the concentrations of oxygen intermediates on the electrode surface, vacancies inside MIEC produced by $2 \mathrm{~PB}$ exchange and vacancies of electrolyte, respectively; $\Gamma$ is the surface adsorption site density, and $\theta$ is the oxygen surface coverage. Equations (6.2), (6.4), (6.5) 
and (6.6) are expressed in electrochemical form for simple charge-transfer. The symmetry factors, $\alpha_{3 P B}$ and $\alpha_{2 P B}$ are taken as 0.5 , and $f=\mathrm{F} / \mathrm{RT}$ with usual definition of symbols $F, R$ and $T$. $E_{S}$ is the surface electrode potential and $E_{B}$ is the bulk electrode potential. Electron transport is not considered to cause additional overpotential here, based on the loose assumptions of high electronic conductivity and approximately uniform Fermi level throughout the MIEC electrode, as used by other models. $\mathrm{E}_{\mathrm{S}}$ can then be regarded to be equal to $\mathrm{E}_{\mathrm{B}}$. The derivation, however, becomes questionable if considering the electrochemical nature for gas-MIEC surface reactions. This point will be further discussed in section 6.4 .

\subsubsection{Thermal equilibrium and electrode activation}

The potential and overpotential of the MIEC electrode is considered in an electrochemical cell of 3-electrode configuration with the MIEC cathode as working electrode (WE), a Pt counter electrode (CE) and a Pt reference electrode (RE). At open circuit, the net reaction rate is zero for the WE. The forward and backward elementary reaction rates, $r_{f, i}$ and $r_{b, i}$, are thus equal to the exchange reaction rates $r_{0, i}$. This condition yields the Nernst relationship between equilibrium potential of WE and oxygen partial pressure no matter which step is presumably the RLS [123]:

$$
E_{e q}^{W E}=\text { constant }+\frac{R T}{4 F} \ln p_{O_{2}}^{W E}
$$

The open circuit potential of the cell $\left(\mathrm{E}_{\mathrm{OCV}}\right)$ is the potential difference between the WE and RE. With oxygen thermal equilibrium at both the WE and the RE, E $\mathrm{OCV}_{\text {will }}$ only depend on the oxygen activity difference according to Nernst equation [147]:

$$
E_{O C V}=E_{e q}^{W E}-E^{R E}=-\frac{R T}{4 F} \ln p_{O_{2}}^{R E}+\frac{R T}{4 F} \ln p_{O_{2}}^{W E}
$$


For an ideal RE, any measured overpotential against the RE is due to the WE potential change:

$$
\eta=E-E_{O C V}=E^{W E}-E_{e q}^{W E}
$$

Since $E_{S}=E_{B}=E^{W E}$ for a uniform Fermi level, equations (2),(4),(5) and (6) then can be transformed into Butler-Volmer type expressions [152]:

$$
\begin{aligned}
r_{S 2} & =r_{S, 0}\left\{\exp \left(-\alpha_{3 P B} f \eta_{s}\right)-\frac{C_{O^{-}, a d}}{C_{O^{-}, a d, e q}} \exp \left[\left(1-\alpha_{3 P B}\right) f \eta_{s}\right]\right\} \\
r_{S 4} & =r_{S 4,0}\left\{\frac{C_{O_{a d}^{-}}}{C_{O_{a d}^{-}, e q}} \exp \left(-\alpha_{3 P B} f \eta_{s}\right)-\exp \left[\left(1-\alpha_{3 P B}\right) f \eta_{s}\right]\right\} \\
r_{B 3} & =r_{B 3,0}\left\{\frac{C_{O_{a d}^{-}} C_{V, M I E C}}{C_{O_{a d}^{-}, e q} C_{V, M I E C, e q}} \exp \left(\alpha_{2 P B} f \eta_{B}\right)-\exp \left[-\left(1-\alpha_{2 P B}\right) f \eta_{B}\right]\right\}(6.12) \\
r_{B 4} & =r_{B 4,0}\left[\exp \left(-2 \alpha_{2 P B} f \eta_{B}\right)-\frac{C_{V, M I E C}}{C_{V, M I E C, e q}} \exp \left[2\left(1-\alpha_{2 P B}\right) f \eta_{B}\right]\right]
\end{aligned}
$$

Where $C_{O_{a d}^{-}, e q}$ and $C_{V, M I E C, e q}$ are the concentrations of surface oxygen intermediates and vacancies from the MIEC bulk at $\mathrm{OCV} ; \eta_{s}$ and $\eta_{B}$ are overpotentials for the 3PB and 2PB pathways, respectively, and $\eta_{s}=\eta_{B}$ if the electrode is equi-potential. The exchange reaction rates $r_{S 2,0}, r_{S 4,0}, r_{B 3,0}$ and $r_{B 4,0}$ are derived from $k_{S}, k_{S}^{-}, k_{B}, k_{B}^{-}, C_{O_{a d}^{-}, e q}$ and $C_{V, M I E C, e q}$. Detailed deduction of the interrelationships between parameters is given in Section 6.4.

\subsection{Formulation of the 1-D model}

\subsubsection{Governing equations and boundary conditions}

The model considers $C_{O_{a d}^{-}}$and $C_{V, M I E C}$ as two variables for simulation. Concentrations of other species are taken as either constant or as a function of the variables. This condition requires specific RLSs to be screened out to simplify calculation routes and make the results relevant to measurable oxygen reduction kinetics. For this reason, steps S2, B3 
and B4 are set as RLSs, and the other reaction steps remain at quasi-equilibrium, which implies $r_{S 1}=r_{S 4} \equiv 0$. Such scenario is made to highlight contribution from surface oxygen ion and surface-bulk exchanges on the transition of bi-pathway controlled electrode kinetics, which is the main difference between this work and previous models $[145,146,147]$. Then the coupled mass-transport equations can be built for the two variable species with Fick's $2^{\text {nd }}$ law:

$$
\begin{aligned}
& \frac{\partial C_{o-, x}}{\partial t}=D_{s, \text { chem }}\left(\frac{\partial^{2} C_{o-, x}}{\partial x^{2}}\right)+\left(r_{S 2}-r_{B 3}\right) \\
& =D_{s, \text { chem }}\left(\frac{\partial^{2} C_{o-, x}}{\partial x^{2}}\right)+r_{s 2,0}\left(\exp \left(-\alpha_{3 P B} f \eta_{s}\right)-\frac{C_{O^{-}, a d}}{C_{0^{-}, a d, e q}} \exp \left[\left(1-\alpha_{3 P B}\right) f \eta_{s}\right]\right\} \\
& -r_{B, 0,0}\left\{\frac{C_{O_{a d}^{-a}} C_{V, M I E C}}{C_{O_{a d, e q}} C_{V, M I E C, e q}} \exp \left(\alpha_{2 P B} f \eta_{B}\right)-\exp \left[-\left(1-\alpha_{2 P B}\right) f \eta_{B}\right]\right\} \\
& \frac{\partial C_{V, M I E C}}{\partial t}=D_{b, \text { chem }}\left(\frac{\partial^{2} C_{V, M I E C}}{\partial x^{2}}\right)-\frac{\Delta S}{\Delta V} r_{B 3} \\
& =D_{b, \text { chem }}\left(\frac{\partial^{2} C_{V, M I E C}}{\partial x^{2}}\right)-\frac{\Delta S}{\Delta V} r_{B, 0,0}\left\{\frac{C_{\sigma^{-, a d}} C_{V, M I E C}}{C_{\sigma^{-, a d, e q}} C_{V, M I E C, e q}} \exp \left(\alpha_{2 P B} f \eta_{B}\right)-\exp \left[-\left(1-\alpha_{2 P B}\right) f \eta_{B}\right]\right\}
\end{aligned}
$$

Where $D_{s, \text { chem }}$ and $D_{b, \text { chem }}$ are the surface and bulk chemical diffusivities respectively; $\Delta S / \Delta V$ is the volume-specific surface area of the electrode. Equation (14) and (15) indicate that the diffusion fluxes are controlled by corresponding RLSs for the two pathways. At the end of MIEC layer ( $\mathrm{x}=\mathrm{lc}$ as drawn in Fig.6.2), a balance between surface oxygen ion flux and local reaction rates is considered for surface pathway, while for bulk pathway a blocking boundary condition is used, implying with Eq.6.17 that the vacancy concentration at cathode outside-layer should be the same as that at equilibrium $(\eta=0)$ : 


$$
\left\{\begin{aligned}
\frac{\Delta S}{\Delta V} D_{s, c h e m}\left(\frac{\partial C_{O-, x=l c}}{\partial x}\right) & =r_{S 2}-r_{B 3} \\
& =r_{S 2,0}\left\{\exp \left(-\alpha_{3 P B} f \eta_{s}\right)-\frac{C_{{O^{-}}^{a d}}}{C_{{O^{-}}{ }_{a d, e q}}} \exp \left[\left(1-\alpha_{3 P B}\right) f \eta_{s}\right]\right\}+D_{b, \text { chem }}\left(\frac{\partial C_{V, x=l c}}{\partial x}\right)(6 . \\
C_{V, M I E C, x=l c} & =C_{V, M I E C, e q}
\end{aligned}\right.
$$

At the MIEC/electrolyte interface where $\mathrm{x}=0$, with $r_{B 4}$ as RLS and $r_{S 4}=0$, it can be shown that

$$
\left\{\begin{aligned}
C_{O_{a d}^{-}} & =C_{O_{a d}^{-}, e q} \exp \left(f \eta_{s}\right) \\
D_{b, c h e m}\left(\frac{\partial C_{V, M I E C, x=0}}{\partial x}\right) & =-r_{B 4} \\
& =r_{B 4,0}\left[\frac{C_{V, M I E C}}{C_{V, M I E C, e q}} \exp \left[2\left(1-\alpha_{2 P B}\right) f \eta_{B}\right]-\exp \left(-2 \alpha_{2 P B} f \eta_{B}\right)\right](6
\end{aligned}\right.
$$

Hence, we have a blocking boundary condition for surface oxygen ions and a flux boundary condition for vacancies from the MIEC bulk.

\subsubsection{Numerical method}

Governing equations (6.14) and (6.15) with boundary conditions (16)-(19) have to be solved numerically with selected values for the multiple parameters involved. Instead of direct evaluation of the steady-state solutions, a finite volume control analysis was adopted to obtain the time-transient solution of the variables, which allows elucidation of non-stationary electrode kinetics. The modeled distance $(10 \mu \mathrm{m})$ between the MIEC/electrolyte interface $(\mathrm{x}=0)$ to the end of the MIEC layer $(\mathrm{x}=\mathrm{lc})$ is divided into 40 flux nodes with equal spacing between each other. The $1^{\text {st }}$ flux node is placed right at the electrolyte/MIEC interface. As a convergence routine, the locations for node properties (e.g., specie concentration and pressure) are offset by $1 / 2$ grid spacing away from the flux 
nodes following Patankar's method [153]. The computation code is generated and implemented with Visual $\mathrm{C}++6.0$ software. Overpotentials of $+0.1 \mathrm{~V}$ to $-0.45 \mathrm{~V}$ are given as the external input with $50 \mathrm{mV}$ intervals between data points. Initial $(\mathrm{t}=0)$ computation starts with calculation of boundary conditions with the inputs, and automatically attains steady-state after 240 nominal time-steps (the real duration depends on input values and material parameters). Calculation of the model requires a large number of physical parameters, which are roughly classified into type I and II. Type I parameters are material constants directly used in governing equations and boundary conditions to obtain simulation results. Type II parameters include material constants like forward/backward rate constants defined in the model but not directly used in numerical solution, together with other thermal and electrochemical constants for the simulated condition. Values of type I parameters and type II parameters actually used in each simulation case are listed in Table 6.2. Values for type I parameters has been given previously in similar models except for $C_{O_{a d}^{-}, e q}[145,147]$, but the values cannot be directly adopted in this model designed for a poor MIEC operated at a lower temperature. Re-estimation of the type I parameters is thus made from reported properties of LSM established mainly by means of isotopic oxygen exchange (IOE) and electrical conductivity relaxation (ECR) measurements $[154,155,156,157,158]$. Despite this difficulty, parameter values in Table 6.2 are believed to be within order of magnitude accuracy at best due to the lack of experimental data for typical SOFC operation conditions. Details on parameter selection are separately discussed in the Appendix. 
Table 6.2 Values of Type I and II parameters used in the simulation cases

\begin{tabular}{|c|c|c|c|c|c|}
\hline \multicolumn{2}{|c|}{ Parameter } & Case 1 & Case 2 & Case 3 & Description \\
\hline \multirow{8}{*}{ I } & $D_{b, \text { chem }}$ & $1 \times 10^{-6} \mathrm{~cm}^{2} \mathrm{~s}^{-1}$ & same (as case 1 ) & same & $\begin{array}{c}\text { Surface oxygen } \\
\text { diffusivity }\end{array}$ \\
\hline & $D_{s, \text { chem }}$ & $1 \times 10^{-6} \mathrm{~cm}^{2} \mathrm{~s}^{-1}$ & same & same & $\begin{array}{c}\text { Bulk vacancy } \\
\text { diffusivity }\end{array}$ \\
\hline & $C_{V, M I E C, e q}$ & $1 \times 10^{-8} \mathrm{~mol} \mathrm{~cm}^{-3}$ & $1 \times 10^{-8} \mathrm{~mol} \mathrm{~cm}^{-3}$ & $1 \times 10^{-7} \mathrm{~mol} \mathrm{~cm}^{-3}$ & $\begin{array}{l}\text { Equilibrium vacancy } \\
\text { conc. in MIEC }\end{array}$ \\
\hline & $C_{O_{a d}^{-}, e q}$ & $1 \times 10^{-11} \mathrm{~mol} \mathrm{~cm}^{-2}$ & $1 \times 10^{-10} \mathrm{~mol} \mathrm{~cm}^{-2}$ & $1 \times 10^{-10} \mathrm{~mol} \mathrm{~cm}^{-2}$ & $\begin{array}{c}\text { Equilibrium surface } \\
\text { oxygen conc. }\end{array}$ \\
\hline & $r_{S 2,0}$ & $1 \times 10^{-7} \mathrm{~mol} \mathrm{~cm}^{-2} \mathrm{~s}^{-1}$ & same & same & $\begin{array}{l}\text { Exchange rate } \\
\text { constant for } \mathrm{S} 2\end{array}$ \\
\hline & $r_{B 3,0}$ & $1 \times 10^{-7} \mathrm{~mol} \mathrm{~cm}^{-2} \mathrm{~s}^{-1}$ & same & same & $\begin{array}{l}\text { Exchange rate } \\
\text { constant for B3 }\end{array}$ \\
\hline & $r_{B 4,0}$ & $1 \times 10^{-6} \mathrm{~mol} \mathrm{~cm}^{-2} \mathrm{~s}^{-1}$ & same & same & $\begin{array}{l}\text { Exchange rate } \\
\text { constant for B4 }\end{array}$ \\
\hline & $\Delta S(\Delta V)^{-1}$ & $1 \times 10^{5} \mathrm{~cm}^{-1}$ & same & same & $\begin{array}{l}\text { Volume-specific } \\
\text { surface area }\end{array}$ \\
\hline \multirow{5}{*}{ II } & $\alpha_{3 P B}, \alpha_{2 P B}$ & 0.5 & same & same & Symmetry factor \\
\hline & $\Gamma$ & $10^{-9} \mathrm{~mol} \mathrm{~cm}^{-2}$ & $5 \times 10^{-9} \mathrm{~mol} \mathrm{~cm}^{-2}$ & $5 \times 10^{-9} \mathrm{~mol} \mathrm{~cm}^{-2}$ & $\begin{array}{c}\text { Surface adsorption } \\
\text { site density }\end{array}$ \\
\hline & $\theta_{e q}$ & 0.01 & 0.02 & 0.02 & $\begin{array}{l}\text { Equilibrium oxygen } \\
\text { coverage }\end{array}$ \\
\hline & $\mathrm{T}$ & $1073 \mathrm{~K}$ & same & same & Temperature \\
\hline & $\mathrm{p} \mathrm{O}_{2}$ & $0.21 \mathrm{~atm}$ & same & same & $\begin{array}{c}\text { Oxygen partial } \\
\text { pressure }\end{array}$ \\
\hline
\end{tabular}

\subsection{Model Validation with oxygen partial pressure dependence}

The model assumes multiple elementary reaction steps for specific electrode processes. To verify the kinetic assumptions before numerical simulations with overpotential, the model is first analytically validated by derivation of relationships between equation parameters and the oxygen partial pressure $\left(p\left(O_{2}\right)\right)$ at the OCV condition.

\subsubsection{Analysis of $C_{O_{a d}^{-a}, e q}$ and $C_{V, M I E C, e q}$}

Firstly, for the 3PB pathway reaction equations (6.1)-(6.4), assume that the rates of non-charge-transfer steps $\left(r_{S 1}\right.$ and $\left.r_{S 3}\right)$ are zero and that there is a low oxygen surface coverage rate $(\theta<<1)$ at thermal equilibrium, then equation (6.2) and (6.4) can be rewritten as: 


$$
\begin{gathered}
r_{S 2}=\frac{k_{S 2} k_{S 1} \Gamma}{k_{S 1}^{-}} p\left(O_{2}\right)^{1 / 2} \exp \left(-\alpha_{3 P B} f E_{e q}^{W E}\right)-k_{S 2}^{-} C_{O_{a d}^{-}} \exp \left[\left(1-\alpha_{3 P B}\right) f E_{e q}^{W E}\right] \\
r_{S 4}=k_{S 4} \frac{k_{S 3}}{k_{S 3}^{-}} C_{O_{T P B}^{-}} C_{V, Y S Z} \exp \left(-\alpha_{3 P B} f E_{e q}^{W E}\right)-k_{S 4}^{-} \Gamma \exp \left[\left(1-\alpha_{3 P B}\right) f E_{e q}^{W E}\right]
\end{gathered}
$$

As the net current approaches zero for the working electrode at equilibrium potential, it follows that $r_{S 2}=r_{S 4}=0$ and $C_{O_{\alpha 4}^{-a}}=C_{O_{T s}^{-r}}=C_{O_{\alpha u}^{-}, e q}$. Then equations (6.20) and (6.21) convert to:

$$
\begin{array}{r}
C_{O^{-} a d, e q}=\frac{k_{S 2} k_{S 1} \Gamma}{k_{S 2}^{-} k_{S 1}^{-}} p\left(O_{2}\right)^{1 / 2} \exp \left(-f E_{e q}^{W E}\right) \\
C_{O^{-} a d, e q}=\frac{k_{S 4}^{-} k_{S 3}^{-} \Gamma}{k_{S 4} k_{S 3} C_{V, Y S Z}} \exp \left(f E_{e q}^{W E}\right)
\end{array}
$$

So it can be further derived that

$$
\exp \left(f E_{e q}^{W E}\right)=\left(\frac{k_{S 2} k_{S 1}}{k_{S 2}^{-} k_{S 1}^{-}}\right)^{1 / 2}\left(\frac{k_{S 4}^{-} k_{S 3}^{-}}{k_{S 4} k_{S 3}}\right)^{1 / 2} p\left(O_{2}\right)^{1 / 4}
$$

Which reflects the Nernst relationship between the electrode equilibrium potential and the oxygen partial pressure. Equation (6.24) also demonstrates that $C_{\sigma_{\alpha u}, e q} \propto p\left(O_{2}\right)^{1 / 4}$ and that the generation of surface oxygen ion (reaction Step S2) is electrochemical in nature. For the 2PB pathway, the value of $C_{V, M I E C, e q}$ is obtained when $r_{S 1}=r_{S 2}=r_{B 3}=r_{B 4}=0$ at electrode equilibrium potential $E_{e q}^{W E}$. From $r_{B 4}=0$ it can be derived that

$$
C_{V, M I E C, e q}=\frac{k_{B 4}}{k_{B 4}^{-}} C_{V, Y S Z} \exp \left(-2 f E_{e q}^{W E}\right)
$$

Which yields $C_{V, M I E C, e q} \propto p\left(O_{2}\right)^{-1 / 2}$ at the 2PB according to equation (6.24). After substitution of equation (6.22) for $C_{\sigma_{\alpha \mu}^{-} \text {eq }}$ into equation (6.12), it follows from $r_{B 3}=0$ that

$$
C_{V, M I E C, e q}=\frac{k_{B 3}^{-}}{k_{B 3}}\left(\frac{k_{S 2} k_{S 1} \Gamma}{k_{S 2}^{-} k_{S 1}^{-}}\right)^{-1} p\left(O_{2}\right)^{-1 / 2}
$$


Hence equation (6.25) and (6.26) indicate that, at the OCV condition, the vacancy concentrations at both MIEC/YSZ and MIEC/EC interfaces will assume an equilibrium value of $C_{V, M I E C, \text { eq }}$ with the same $p\left(O_{2}\right)^{-1 / 2}$ dependence, which confirms the basic assumption made in this model.

\subsubsection{Analysis on exchange current densities}

Comparing equations (2), (4), (5) and (6) to equations (10)-(13) gives rise to the expressions for exchange rates $r_{S 2,0}, r_{S 4,0}, r_{B 3,0}$ and $r_{B 4,0}$ as

$$
\begin{gathered}
r_{S 2,0}=k_{S 2}^{-}\left[\frac{k_{S 2} k_{S 1} \Gamma}{k_{S 2}^{-} k_{S 1}^{-}} p\left(O_{2}\right)^{1 / 2}\right]^{\left(1-\alpha_{3 P B}\right)}\left(C_{O^{-}}\right)^{\alpha_{3 P}, e q} \\
r_{S 4,0}=k_{S 4} \frac{k_{S 3}}{k_{S 3}^{-}} \frac{\left(k_{S 4}\right)^{1-\alpha_{3 P B}}}{\left(k_{S 4}^{-} C_{V, Y S Z} \Gamma\right)^{\left(-\alpha_{3 P B}\right)}}\left(C_{O_{a d}^{-}, e q}\right)^{1-\alpha_{3 P B}} \\
r_{B 3,0}=\left(k_{B 3}^{-}\right)^{\alpha_{2 P B}}\left(k_{B 3}\right)^{1-\alpha_{2 P B}}(\Gamma)^{\alpha_{2 P B}}\left(C_{O_{a d}^{-}, e q} C_{V, M I E C, e q}\right)^{1-\alpha_{2 P B}} \\
r_{B 4,0}=\left(k_{B 4} C_{V, Y S Z}\right)^{1-\alpha_{2 P B}}\left(k_{B 4}^{-} C_{V, M I E C, e q}\right)^{\alpha_{2 P B}}
\end{gathered}
$$

From the dependences of $C_{O_{a d}^{-}, e q}$ and $C_{V, M I E C, \text { eq }}$ on $p\left(O_{2}\right)$, the relationships between exchange current densities for corresponding elementary reaction steps and oxygen partial pressure can be determined accordingly as

$$
\begin{aligned}
& i_{S 2,0} \propto p\left(O_{2}\right)^{3 / 8} \\
& i_{S 4,0} \propto p\left(O_{2}\right)^{1 / 8} \\
& i_{B 3,0} \propto p\left(O_{2}\right)^{-1 / 4} \\
& i_{B 4,0} \propto p\left(O_{2}\right)^{-1 / 4}
\end{aligned}
$$

Where the exponents for the $p\left(O_{2}\right)$ dependence of surface and bulk exchange current densities are in good agreement with the reported values for specific oxygen reduction 
processes on LSM-based cathode $[123,125]$. Such an analysis of electrode kinetics in a manner of multi-step charge-transfer enables explicit examination of effects of $p\left(O_{2}\right)$ on the RLSs, which is useful to predict the kinetic transition trend during electrode activation.

\subsection{Results and discussion}

The simulation results are obtained computationally with governing equations 6.146.15, boundary condition equations 6.16-6.19 and parameters in Table 6.2. Steady-state calculation results are discussed in detail in section 6.5.2 to investigate kinetic transition of the MIEC cathode from case to case. Meanwhile the transient concentration and vacancy profiles for active electrode species are also given in section 6.5.1 to monitor the convergence and efficiency of the mode during simulation.

\subsubsection{Transient distribution of the active electrode species}

Fig. 6.3 shows the transient diffusion profiles for concentrations of surface oxygen ion $\left(\mathrm{C}_{\mathrm{o}}\right)$ and bulk vacancy $\left(\mathrm{C}_{\mathrm{v}}\right)$ under moderate overpotential $(-0.2 \mathrm{~V})$. This condition is selected to represent typical transient profile data obtained with overpotential and material property parameters listed in Table 6.2. Values of $C_{O_{\overline{a u}, e q}^{-e q}}$ and $C_{V, M I E C, e q}$ used to obtain data in Fig. 6.3 and 6.4 are believed to be similar as those reported for LSM material (as is discussed in Appendix). And calculation with a cathodic overpotential value of $-0.2 \mathrm{~V}$ is chosen to represent typical operation condition for SOFC during output of power (usually overall cell voltage is kept between $0.7 \mathrm{Vto} 0.8 \mathrm{~V}$ ). Although this study mainly focuses on analysis of the electrode kinetic transition from steady-state results, transient-state profiles of species concentration and flux matter in two aspects. First, the capability of the calculation of transient-state data separates this model from previous 
similar ones [145,146,147], in which only a steady-state calculation could be performed. The transient-steady data can be used to further derive electrode impedance and associated physical processes, which are directly correlated to practical experimental measurements. In this sense the current stage of work may provide a foundation for future model verification via an AC impedance study on MIEC electrode. Second, the calculated transient-state data can also be used to assess simulation efficiency and determine factors influencing simulation duration.

The details about calculation of concentration and flux values for each node are given in 6.3.2. It should be pointed out here that the 240 time-steps artificially set for every simulation run are nominal, and the value for each nominal time-step represents equal division of the actual simulation duration to reach steady-state normalized by actual timestep required for simulation converge. As mentioned in 6.3.2, the actual simulation duration can take from a few tens of minutes to several days, while the actual time-step varies from $10^{-10} \mathrm{~s}$ to $10^{-9} \mathrm{~s}$ depending on simulation parameters. For the case used in Fig.6.3 and 6.4, the value of the actual time-step is about $3 \times 10^{-9}$ s. For the following discussions, each nominal time-step is referred sequentially as "series" in the figure legends to represent the elapse of a certain fraction of actual simulation duration before reaching steady-state. 


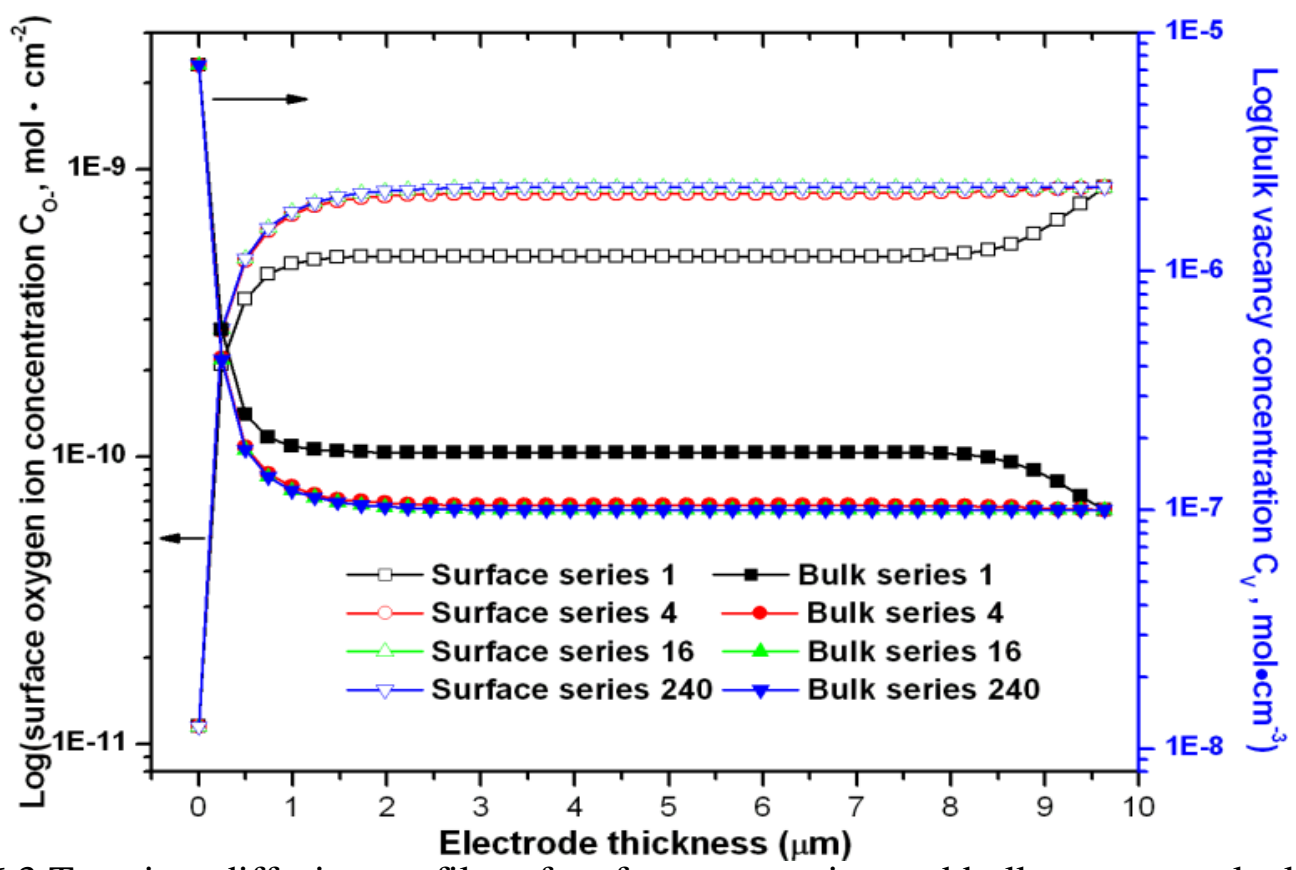

Figure 6.3 Transient diffusion profiles of surface oxygen ion and bulk vacancy calculated with $\mathrm{C}_{\mathrm{v}, \mathrm{eq}}=1 \times 10^{-7} \mathrm{~mol} \mathrm{~cm} \mathrm{~cm}^{-3}$ and $\mathrm{C}_{\mathrm{o}-\mathrm{eq}}=1 \times 10^{-10} \mathrm{~mol} \mathrm{~cm}^{-2}$ at $-0.2 \mathrm{~V}$ overpotential (open symbol: $\mathrm{C}_{\mathrm{o}-}$; filled symbol: $\mathrm{C}_{\mathrm{v}}$; value of actual time-step: $3.08 \times 10-{ }^{9} \mathrm{~s}$ )

It can be seen in Fig.6.3 that initially the concentration of surface oxygen ion is lowest at the cathode/electrolyte interface and highest at the end of electrode surface, while the bulk vacancy distributes in an almost symmetric manner opposite to $\mathrm{C}_{\mathrm{o}}$, with maximum value of $\mathrm{C}_{\mathrm{v}}$ at $\mathrm{x}=0$ and equilibrium concentration attained at $\mathrm{x}=\mathrm{lc}$. This pattern demonstrated that concentrations of the two electrode species are closely regulated by boundary conditions at the two electrochemical interfaces, with highest reaction rates anticipated for both pathways at the cathode/electrolyte contact and low activity for the bulk pathway at the end surface, confirming the physical model scheme. From series 1 to series 240, there is almost no change for species concentrations at the electrode boundaries, while in the rest region of electrode between these two boundaries concentrations are rather adjusted to match the boundary conditions. This behavior results 
in a decrease of bulk vacancies and an increase of surface oxygen ion concentration within the first 4 time-steps, which indicates that local electrode reactions $\left(r_{S 2}\right.$ and $\left.r_{B 3}\right)$ are dominant over the diffusion processes during the simulation run. Although in Fig.6.3 the convergence of species concentrations is very fast, it actually takes a longer time for the model to reach steady-state. Therefore further analysis is made on the diffusion flux.

Fig. 6.4 shows the transient profile for the bulk vacancy flux from time-step 1 to 240 . Shape of the flux plot at initial state (series 1) represents accordingly the characteristics of vacancy concentration profile in Fig.6.3 then, with high gradients at both of the simulation boundaries and minimum flux in the center of electrode. As time-step increases, the conical-shaped bottom gradually disappears as a more uniform gradient is obtained in the middle of MIEC electrode. Meanwhile further adjustment on the vacancy flux near the MIEC/EC interface continues until simulation ends, although $C_{V, M I E C, e q}$ is achieved earlier during the run. This late convergence of diffusion flux causes simulation span up to tens of hours. From Fig.6.3, it can be also learned that the electrode is further activated at region adjacent to $\mathrm{x}=0$ during simulation process, and less activated near MIEC/EC interface which is electrochemically "inert". Judging from the magnitude of vacancy flux, extension of $2 \mathrm{~PB}$ current density would be limited within 2-3 $\mu \mathrm{m}$ away from MIEC/electrolyte interface. Detailed analysis on steady-state distribution of species and active electrochemical reaction zone along as function of overpotential and material properties will be provided in section 6.5.3. 


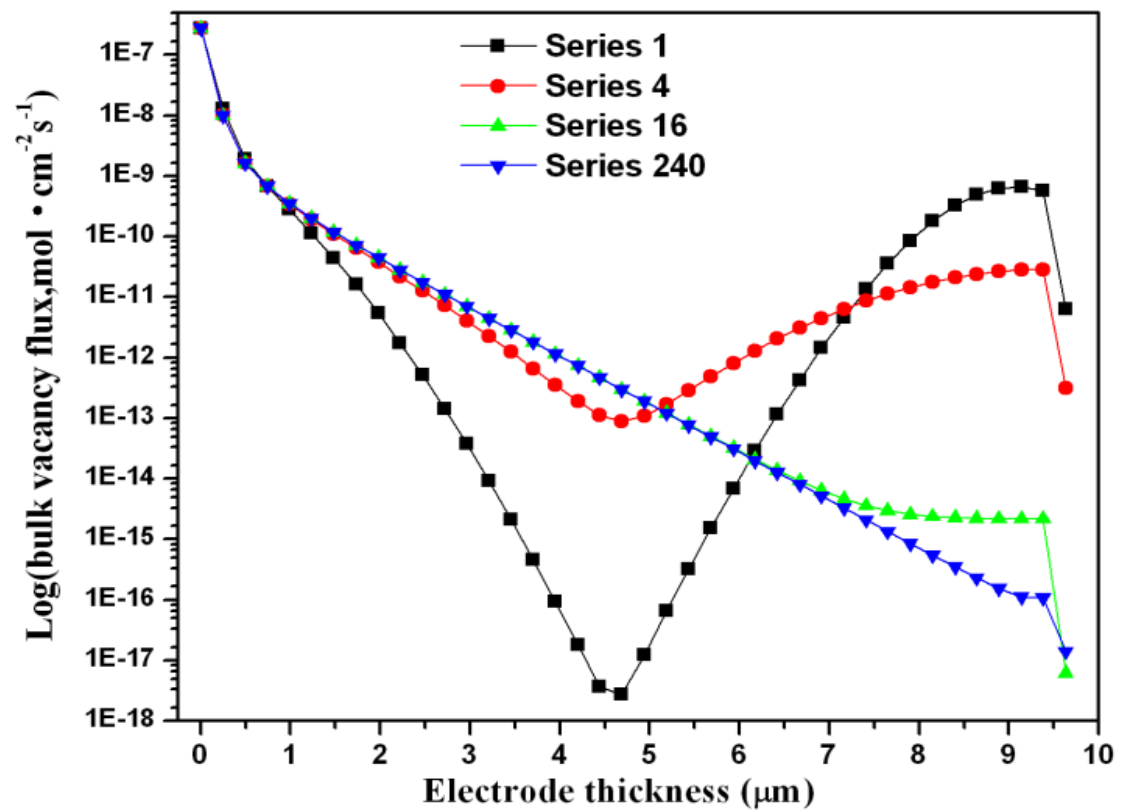

Figure 6.4 Transient profiles of the bulk vacancy flux calculated with $\mathrm{C}_{\mathrm{v}, \mathrm{eq}}=1 \times 10^{-7} \mathrm{~mol}$ $\mathrm{cm}^{-3}$ and $\mathrm{C}_{\mathrm{o}-\mathrm{eq}}=1 \times 10^{-10} \mathrm{~mol} \mathrm{~cm}^{-2}$ at $-0.2 \mathrm{~V}$ overpotential

\subsubsection{Transition of the dominant pathway for cathode kinetics}

In this section the main focus is to study the relative dominance of the $3 \mathrm{~PB}$ and $2 \mathrm{~PB}$ pathways on cathode kinetics at different overpotential regime, how the pathway transition is favored by material parameters selection and the consequent influences on electrode performances. Generally the simulation is performed between overpotentials of $-0.4 \mathrm{~V}$ to $+0.1 \mathrm{~V}$ with $50-100 \mathrm{mV}$ interval for each data point, and the equilibrium concentrations of surface oxygen ion $\left(\mathrm{C}_{\mathrm{o}, \mathrm{eq}}\right)$ and bulk vacancy $\left(\mathrm{C}_{\mathrm{v}, \mathrm{eq}}\right)$ are varied among the three cases listed in Table 6.2 for a parametric study on electrode kinetics:

(1) $\mathrm{C}_{\mathrm{o}-\mathrm{eq}}=1.0 \times 10^{-11} \mathrm{~mol} / \mathrm{cm}^{2} \& \mathrm{C}_{\mathrm{v}, \mathrm{eq}}=1.0 \times 10^{-8} \mathrm{~mol} / \mathrm{cm}^{3}$ for Case 1

(2) $\mathrm{C}_{\mathrm{o}-\mathrm{eq}}=1.0 \times 10^{-10} \mathrm{~mol} / \mathrm{cm}^{2} \& \mathrm{C}_{\mathrm{v}, \mathrm{eq}}=1.0 \times 10^{-8} \mathrm{~mol} / \mathrm{cm}^{3}$ for Case 2 


\section{(3) $\mathrm{C}_{\mathrm{o}-\mathrm{eq}}=1.0 \times 10^{-10} \mathrm{~mol} / \mathrm{cm}^{2} \& \mathrm{C}_{\mathrm{v}, \mathrm{eq}}=1.0 \times 10^{-7} \mathrm{~mol} / \mathrm{cm}^{3}$ for Case 3}

The 3PB current density and 2PB current density are given by the diffusion fluxes of surface oxygen ions and bulk vacancies at $\mathrm{x}=0$ respectively as:

$$
\begin{aligned}
& i_{3 P B}=-2 F \frac{\Delta S}{\Delta V} D_{s, \text { chem }}\left(\frac{\partial C_{O-, x=0}}{\partial x}\right) \\
& i_{2 P B}=2 F D_{b, \text { chem }}\left(\frac{\partial C_{V, M I E C, x=0}}{\partial x}\right)
\end{aligned}
$$

Shown in Fig.6.5, Fig.6.7 and Fig.6.8 are the simulated logarithmic current-overpotential (I-V) curves of the two kinetic pathways within the overall electrode kinetics from different values of $\mathrm{C}_{\mathrm{o}-\text { eq }}$ and $\mathrm{C}_{\mathrm{v}, \text { eq }}$ for Case 1,2 and 3 respectively. On the figures lines are drawn to display the Tafel estimation of the exchange current densities for the 3PB path, the $2 \mathrm{~PB}$ path and the overall electrode. The exchange current densities, kinetic transition voltage and overall current densities at $-0.3 \mathrm{~V}$ identified for each case from Fig.6.5, Fig.6.7 and Fig.6.8 are listed in Table 6.3.

\begin{tabular}{|c|c|c|c|c|c|c|c|c|c|c|}
\hline Case & $\begin{array}{c}\mathrm{C}_{\mathrm{v}, \mathrm{eq}} \\
\left(\mathrm{mol} / \mathrm{cm}^{3}\right)\end{array}$ & $\begin{array}{c}\mathrm{C}_{\mathrm{O}-\mathrm{eq}} \\
\left(\mathrm{mol} / \mathrm{cm}^{2}\right)\end{array}$ & $\begin{array}{l}\text { Transitior } \\
\text { Voltage } \\
\text { (V) }\end{array}$ & $\begin{array}{c}\text { n Set-up of } \\
\mathrm{i}_{0,3 \mathrm{~PB}} \\
\left(\mathrm{~mA} / \mathrm{cm}^{2}\right)\end{array}$ & $\begin{array}{c}\text { Extracted } \\
\mathrm{i}_{0,3 \mathrm{~PB}} \\
\left(\mathrm{~mA} / \mathrm{cm}^{2}\right)\end{array}$ & $\begin{array}{l}\text { Set-up of } \\
\mathrm{i}_{0,2 \mathrm{~PB}} \\
\left(\mathrm{~mA} / \mathrm{cm}^{2}\right)\end{array}$ & $\begin{array}{c}\text { Extracted } \\
\mathrm{i}_{0,2 \mathrm{~PB}} \\
\left(\mathrm{~mA} / \mathrm{cm}^{2}\right.\end{array}$ & $\begin{array}{l}\text { Extracted } \\
\mathrm{i}_{0, \mathrm{TOT}} \\
\left(\mathrm{mA} / \mathrm{cm}^{2}\right)\end{array}$ & $\begin{array}{c}\mathrm{i}_{\text {тот }} \\
\text { at }-0.3 \mathrm{~V} \\
(\mathrm{~mA} / \mathrm{cm} 2))\end{array}$ & $\begin{array}{l}\text { Electrode } \\
\text { activation }\end{array}$ \\
\hline 1 & $1 \times 10^{-8}$ & $1 \times 10^{-11}$ & -0.33 & 10 & 10 & 100 & $7 \times 10^{-5}$ & 7 & 163 & $\begin{array}{c}3 \mathrm{~PB} \& 2 \mathrm{~PB} \\
\text { reactions }\end{array}$ \\
\hline 2 & $1 \times 10^{-8}$ & $1 \times 10^{-10}$ & -0.45 & 10 & 49 & 100 & $8 \times 10^{-5}$ & 45 & 598 & Diffusion \\
\hline 3 & $1 \times 10^{-7}$ & $1 \times 10^{-10}$ & -0.26 & 10 & 45 & 100 & $7 \times 10^{-4}$ & 45 & 719 & Diffusion \\
\hline
\end{tabular}

Table 6.3 Summary of V-I curve simulaiton and tafel analysis results for case 1 to 3 . 


\subsubsection{Overpotential effects and the mechanism of pathway transition}

One of the major research interests for this study is to investigate how the surface reaction pathway and bulk reaction pathway evolve as cathode overpotential changes, and their contribution to the overall electrode kinetic characteristics. In this section the MIEC cathode kinetics are examined with Case 1 parameters. Simulation results from I-V profiles and corresponding exchange current densities are used to analyze overpotential effects on the kinetic pathway transition. Additionally the constitution of 3PB reaction current is further studied in terms of diffusion current and local reaction current to unveil the mechanistic physical processes potentially involved in the pathway transition.

Analysis on I-V profiles----With low concentration values of both $\mathrm{C}_{\mathrm{o}-\mathrm{eq}}$ and $\mathrm{C}_{\mathrm{v}, \mathrm{eq}}$ in Case 1, Fig.6.5 demonstrated that the 3PB pathway dominates at relatively low cathodic and anodic overpotentials, while contributions from the 2PB pathway current become increasingly important at higher cathodic overpotentials. A change of electrode kinetics from 3PB-dominance to $2 \mathrm{~PB}$-dominance is observed at around $-0.33 \mathrm{~V}$, resulting in a deviation of the total current density from the 3PB current profile and an improved electrode performance. Since this transition of electrode kinetics at negative overpotential is the main interest here for SOFC research, no further simulations in the anodic polarization region $(>0.1 \mathrm{~V})$ were made. 


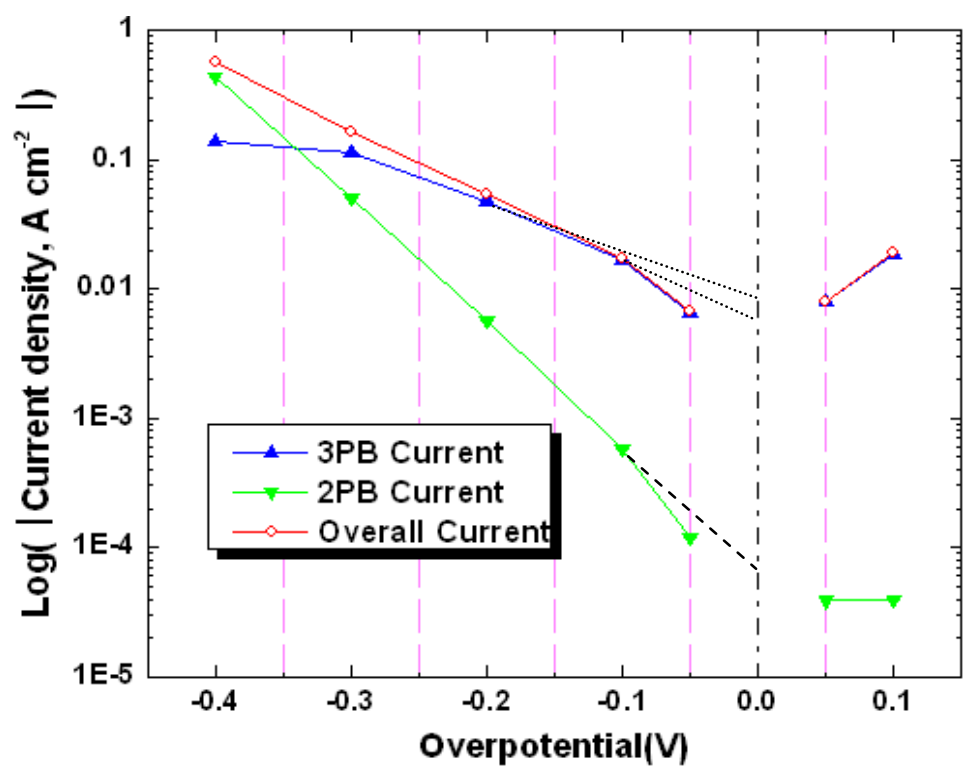

Figure 6.5 Logarithmic current versus overpotential profiles for bi-pathway constituted overall electrode kinetics with the parameters in Case 1 as $\mathrm{C}_{\mathrm{o}-\mathrm{eq}}=1 \times 10^{-11} \mathrm{~mol} \mathrm{~cm}^{-2}$ and $\mathrm{C}_{\mathrm{v}, \mathrm{eq}}=1 \times 10^{-8} \mathrm{~mol} \mathrm{~cm}^{-3}$

Examinations on exchange current----The logarithmic relationship between current density and overpotential as plotted in Fig.6.5 enables a Tafel analysis on the 3PB and 2PB pathway kinetics during electrode activation. It can be seen that both the 3PB and $2 \mathrm{~PB}$ currents enter into the Tafel zone at overpotential negative to $-0.1 \mathrm{~V}$, close to value given by high-field approximation of the $\mathrm{B}-\mathrm{V}$ equation at $800^{\circ} \mathrm{C}(-\eta>>\mathrm{RT} / \mathrm{F} \approx 0.09 \mathrm{~V})$ $[123,159]$. However, the dashed tangent lines extracted from the current plots yield rather different intercepts of exchange current densities $\left(i_{0}\right)$ for each pathway as well as for the total current. For the 3PB pathway, the $i_{0,3 P B}$ intercept is about $10^{-2.05} \mathrm{~A} / \mathrm{cm}^{2}$, matching well with the exchange current density $i_{s 2,0}$ for the generation of surface oxygen ion (reaction step S2) calculated from parameter $r_{S 2,0}$. Despite the fact that the exchange 
reaction rate $r_{B 4,0}$ used for $2 \mathrm{~PB}$ pathway is about 2 orders of magnitude higher than that for the 3PB pathway, the Tafel analysis in Fig.6.5 results in a much smaller 2PB exchange current density $i_{0,2 P B}$ of $10^{-4.17} \mathrm{~A} / \mathrm{cm}^{2}$. The overall exchange current density is close to $i_{0,3 P B}$ with a value around $6 \sim 7 \mathrm{~mA} / \mathrm{cm}^{2}$. These results indicate that the electrode activation in case 1 is mainly controlled by the surface reaction to form the oxygen intermediate $\mathrm{O}^{-}$, while the significant deviation of $2 \mathrm{~PB}$ exchange current density away from the intrinsic value implies a suppression of $2 \mathrm{~PB}$ kinetics by the $3 \mathrm{~PB}$ reaction, which results in the $2 \mathrm{~PB}$ current development delayed to more negative overpotentials. As is shown by equation (6.5) for reaction step $\mathrm{B} 3$, the generation of $\mathrm{O}^{-}$by step $\mathrm{S} 2$ would favor the surface/bulk exchange reaction between $\mathrm{O}^{-}$and oxygen vacancy, and diminish the vacancy concentration generated from cathode/electrolyte exchange reaction at $2 \mathrm{~PB}$. Therefore, 2PB kinetics appear to "submerge" into the 3PB kinetics at low overpotential. However, as a larger driving force for vacancy generation is created at more negative overpotentials, the $2 \mathrm{~PB}$ reaction eventually outweighs the incorporation of surface oxygen ion into the bulk, and dominates over the 3PB pathway kinetics. And, as a consequence of the kinetic transition to slower 2PB kinetics, the total exchange current density exhibits a rather lower value than the $3 \mathrm{~PB}$ exchange current density in this case.

Analysis on composition of $3 P B$ current----To further understand the interaction between $3 \mathrm{~PB}$ and $2 \mathrm{~PB}$ pathways during electrode activation process, a detailed analysis is made in Fig.6.6 and Fig.6.9 for each simulation case to examine the relationship between overpotential and proportion of local current density $i_{l o c}$ in the total 3PB current density $i_{t o t}$. $i_{t o t}$ can be viewed as the sum of diffusion current density $i_{\text {diff }}$ cause by the 
accumulative flux of $\mathrm{O}^{-}$just outside TPB and local current density $i_{l o c}$ caused by surface reactions $r_{S 2}$ and $r_{B 3}$ at $\mathrm{x}=0$ :

$$
i_{\text {tot }}=i_{\text {diff }}+i_{l o c}
$$

With both reaction steps S2 and B3 as RLSs, $i_{l o c}$ can be given as $[123,160]$

$$
\begin{aligned}
& i_{\text {loc }}=i_{\text {anodic }, \text { loc }}-i_{\text {cathodic, loc }} \\
& =\frac{i_{B 3,0}^{2} \frac{C_{V, M I E C, x=0}}{C_{V, M I E C, e q}} \exp \left[\left(2 \alpha_{2 P B}\right) f \eta_{B}\right] \bullet i_{S 2,0}\left\{\exp \left[\left(2-\alpha_{3 P B}\right) f \eta_{s}\right]-\exp \left(-\alpha_{3 P B} f \eta_{s}\right)\right\}}{\left\{i_{S 2,0} \exp \left[\left(2-\alpha_{3 P B}\right) f \eta_{s}\right]+i_{B 3,0} \frac{C_{V, M I E C, x=0}}{C_{V, M I E C, e q}} \exp \left[\left(1+\alpha_{3 P B}\right) f \eta_{B}\right]\right\} \bullet\left\{i_{S 2,0} \exp \left(-\alpha_{3 P B} f \eta_{s}\right)+i_{B 3,0} \exp \left[-\left(1-\alpha_{2 P B}\right) f \eta_{B}\right]\right\}} \\
& +\frac{i_{S 2,0}^{2} \bullet i_{B 3,0} \exp \left[2\left(1-\alpha_{3 P B}\right) f \eta_{s}\right]\left\{\frac{C_{V, M I E C, x=0}}{C_{V, M I E C, e q}} \exp \left[\left(1+\alpha_{3 P B}\right) f \eta_{B}\right]-\exp \left[-\left(1-\alpha_{2 P B}\right) f \eta_{B}\right]\right\}}{\left\{i_{S 2,0} \exp \left[\left(2-\alpha_{3 P B}\right) f \eta_{s}\right]+i_{B 3,0} \frac{C_{V, M I E C, x=0}}{C_{V, M I E C, e q}} \exp \left[\left(1+\alpha_{3 P B}\right) f \eta_{B}\right]\right\} \bullet\left\{i_{S 2,0} \exp \left(-\alpha_{3 P B} f \eta_{s}\right)+i_{B 3,0} \exp \left[-\left(1-\alpha_{2 P B}\right) f \eta_{B}\right]\right\}}
\end{aligned}
$$

with the boundary condition of $C_{O_{a d}^{-}, x=0}=C_{O_{a d}^{-}, e q} \exp \left(f \eta_{s}\right)$ in equation (6.18). For Case 1 it can be learned from Fig.6.6 that at lower overpotential of $-0.1 \sim-0.2 \mathrm{~V}$ most of the 3PB current density comes from the local current density of the oxygen intermediate formation, so it is confirmed that electrode activation is mainly controlled by surface electrochemical reactions of $r_{S 2}$ and $r_{B 3}$ for Case1. The ratio between $i_{l o c}$ and $i_{\text {diff }}$ decreases as cathodic overpotential increases, and reaches a minimum just before occurrence of 3PB-to-2PB transition at $-0.3 \sim-0.4 \mathrm{~V}$. The increasing contribution from diffusion current at overpotential of $-0.1 \sim-0.3 \mathrm{~V}$ indicates that surface electrode region outside of TPB becomes more active for oxygen reduction during the moderate polarization, and accordingly the effective reaction zone is expected to extend over the TPB sites towards the MIEC/EC boundary. This phenomenon will be discussed later on with diffusion profiles under different overpotential in 6.5.3. 


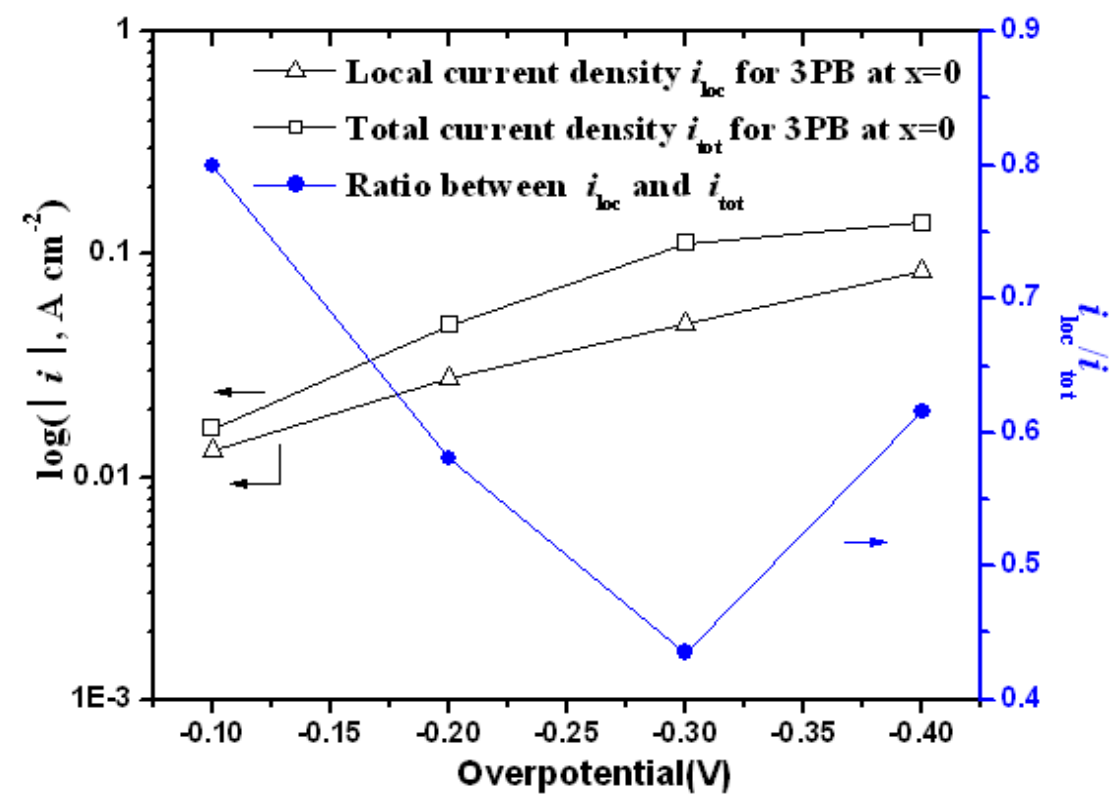

Figure 6.6 Evolution of the local reaction current $\left(i_{\text {loc }}\right)$ in the total 3PB current $\left(i_{\text {tot }}\right)$ as function of overpotential in Case 1 with $\mathrm{C}_{\mathrm{o}-\mathrm{eq}}=1 \times 10^{-11} \mathrm{~mol} \mathrm{~cm}^{-2}$ and $\mathrm{C}_{\mathrm{v}, \mathrm{eq}}=1 \times 10^{-8} \mathrm{~mol}$ $\mathrm{cm}^{-3}$

Mechanism for pathway transition----More importantly, Fig.6.5 and Fig.6.6 also suggest by what mechanism the electrode kinetics switch from one dominant pathway to the other. It can be clearly seen that the total 3PB current encounters a diffusion limit associated with surface oxygen ion flux at overpotential above $-0.3 \mathrm{~V}$, which is associated with the increase of $i_{l o c} / i_{t o t}$ ratio. The coincidence of the diffusion limit for 3PB current with the dominance of $2 \mathrm{~PB}$ kinetics at overpotential above $-0.3 \mathrm{~V}$ implies then that the bulk vacancy concentration increases faster than the production of $\mathrm{O}^{-}$at outside the TPB area. Consequently, additional surface diffusion flux towards TPB is prevented by local consumption of the newly created surface oxygen ions from $r_{S 2}$, e.g., a surface diffusion limit occurs. On the other hand, the 3PB current from local surface reactions (triangle symbol in Fig.6.6) at TPB is less restricted by this negative effect, as can be seen from its linear dependence on overpotential. This behavior is because the concentration of O- is directly defined by the boundary condition at $\mathrm{x}=0$, and consequently the driving forces 
for reactions S2 and B3 would be almost certain. In general the analysis on 3PB current composition in this model suggests suppression of surface oxygen ion diffusion as a potential mechanistic process accounting for 3PB-to-2PB kinetic pathway transition. This transition mechanism, however, has seldom been reported in the literature. Van Heuveln found no diffusion-limiting current when cathode kinetics was governed by surface pathway within $-0.3 \mathrm{~V}$ overpotential [123], while at more negative overpotential range Siebert found that impedances typical of limited mass transport process appeared during transition of cathode kinetics to bulk pathway dominance [129]. In addition, Coffey's simulation results also showed that a diffusion-limit occurred for 3PB current after the pathway transition, although no specific process was identified [147]. Comparing with the last results, it is clarified in this model that blocking of surface diffusion of oxygen intermediate is the physical process behind surface-to-bulk pathway transition.

\subsubsection{Effect of material property on pathway transition and electrode performance}

Fig. 6.7 and Fig.6.8 show the effects of change of material property parameters $\mathrm{C}_{\mathrm{o}, \mathrm{eq}}$ and $\mathrm{C}_{\mathrm{v}, \text { eq }}$ on the transition of dominant pathway for electrode kinetics. In Case 2, where a higher value of $\mathrm{C}_{\mathrm{o}-\mathrm{eq}}$ is used while the other parameters remain the same as in Case 1, Tafel analysis on the logarithmic profile of current density versus overpotential in Fig. 6.7 yields exchange current densities of $10^{-1.42} \mathrm{~A} / \mathrm{cm}^{2}$ and $10^{-4.09} \mathrm{~A} / \mathrm{cm}^{2}$ for the 3PB pathway and $2 \mathrm{~PB}$ pathway, respectively. The overall exchange current density is very close to $i_{0,3 P B}$, and the previously found reduction of its value due to sluggish activation of $2 \mathrm{~PB}$ kinetics is absent in this case. In addition, $i_{0,3 P B}$ obtained from Fig. 6.7 is considerably higher than the exchange current densities associated with surface reaction 
step S2 and B3 used in the simulation. This result may suggest a physical process other than surface reactions of O-contributes more in the 3PB pathway kinetics. In Fig.6.9 an estimation with equation (6.37) and (6.38) showed that the local current density accounts for less than $20 \%$ of the total current density at $-0.1 \sim 0.4 \mathrm{~V}$ in Case 2 , verifying surface diffusion of oxygen ion outside of $3 \mathrm{~PB}$ interface as the dominant reaction step with higher $\mathrm{C}_{\mathrm{o}, \mathrm{eq}}$ value. The change of electrode activation from surface reaction to diffusion control improves the 3PB kinetics as well as the overall electrode performance compared to Case 1 as shown in Fig. 6.7 and Fig. 6.8. According to equation (6.18) and the set-up of reaction S4 as a Non-RLS, the absolute concentration of O- is increased though the ratio of $\mathrm{C}_{0} / \mathrm{C}_{\mathrm{o}-\mathrm{eq}}$ unchanged at the higher $\mathrm{C}_{\mathrm{o}-\mathrm{eq}}$ value. However, Fig. 6.9 reveals that reaction $\mathrm{S} 4$ equilibrates at a rather higher level of diffusion flux at $\mathrm{x}=0$, which gives rise to a larger overall 3PB current. To overcome the suppression effects from the larger 3PB current associated with a high $\mathrm{C}_{\mathrm{o}, \mathrm{eq}}$ value, the interfacial bulk vacancy concentration has to rise to a correspondingly higher level so that $2 \mathrm{~PB}$ kinetics become dominant. This is the reason why the 3PB-to-2PB kinetic transition in Fig. 6.7 is postponed to a higher overpotential around $-0.45 \mathrm{~V}$ and a higher current density above $1 \mathrm{~A} / \mathrm{cm}^{2}$. On the other hand, Fig. 6.8 shows the transition of dominant pathway for electrode kinetics occurs at much lower overpotential of around $-0.26 \mathrm{~V}$ as a result of the increase of $\mathrm{C}_{\mathrm{v}, \mathrm{eq}}$ by 10 times in Case 3 relative to the value in Case 2. Basically, this change reflects increasing contribution from $2 \mathrm{~PB}$ kinetics with the higher value of $\mathrm{C}_{\mathrm{v}, \mathrm{eq}}$, as both concentration and flux of bulk vacancies at the $2 \mathrm{~PB}$ would increase accordingly. It can be also seen that for Case 3 the exchange current density identified for the 2PB pathway increases in Fig. 6.8 
due to the higher vacancy concentration, resulting in a slightly decrease of overall exchange current densities as compared to that for the 3PB pathway.

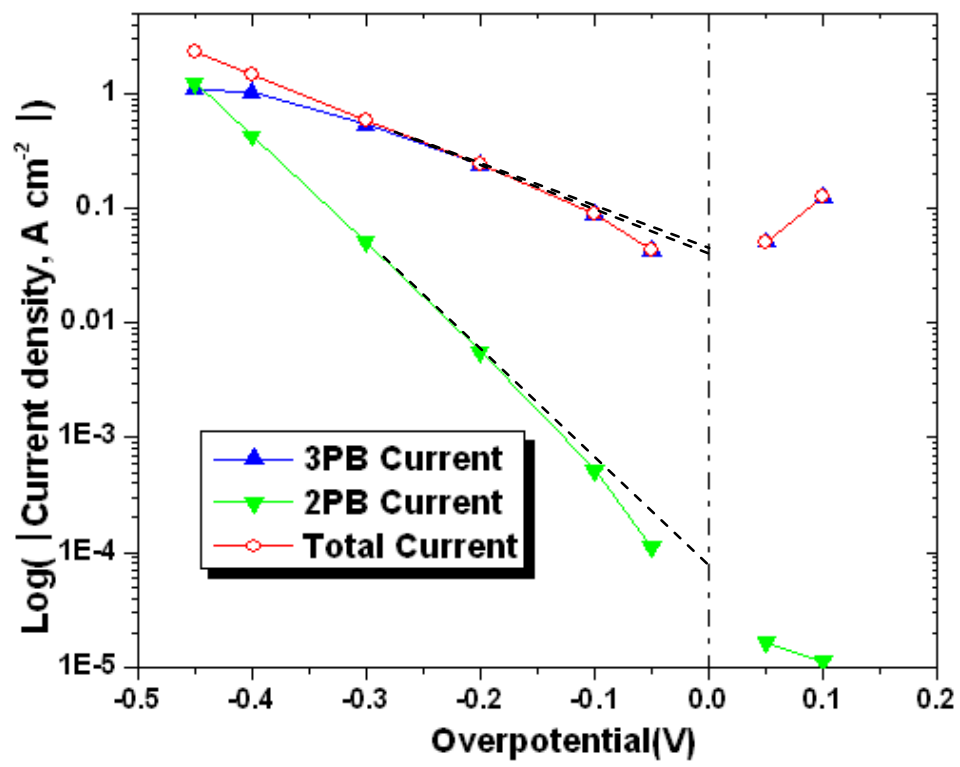

Figure 6.7 Logarithmic current versus overpotential profiles with parameters in Case 2 as $\mathrm{C}_{\mathrm{o}-\mathrm{eq}}=1 \times 10^{-10} \mathrm{~mol} \mathrm{~cm}^{-2}$ and $\mathrm{C}_{\mathrm{v}, \mathrm{eq}}=1 \times 10^{-8} \mathrm{~mol} \mathrm{~cm}^{-3}$

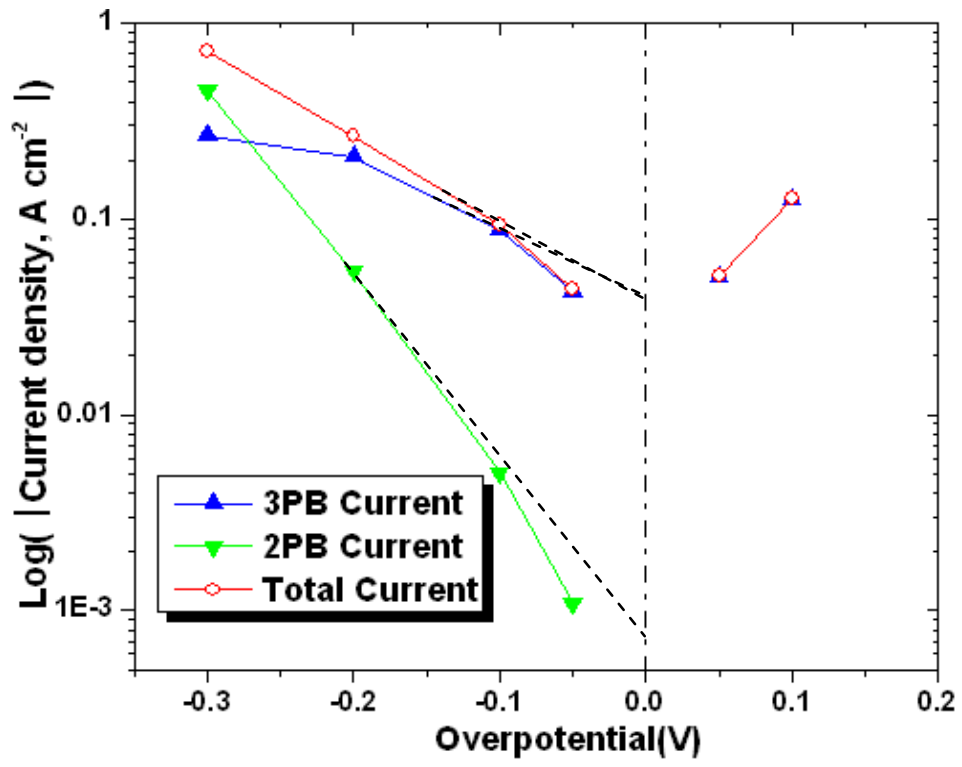

Figure 6.8 Logarithmic current versus overpotential profiles with parameters in Case 3 as $\mathrm{C}_{\mathrm{o}-\mathrm{eq}}=1 \times 10^{-10} \mathrm{~mol} \mathrm{~cm}{ }^{-2}$ and $\mathrm{C}_{\mathrm{v}, \mathrm{eq}}=1 \times 10^{-7} \mathrm{~mol} \mathrm{~cm}^{-3}$

The influence of material parameter change on electrode kinetic characteristic is further studied in Fig.6.9 by examining the total 3PB currents and relative significance of 
local reaction currents in 3PB pathway kinetics for these two cases. The higher value of $\mathrm{C}_{\mathrm{v}, \mathrm{eq}}$ used in Case 3 brings about a reduction of the total $3 \mathrm{~PB}$ current and concomitant rise of $i_{\text {loc }} / i_{\text {tot }}$ ratio, although surface diffusion dominates 3PB kinetics throughout the overpotential regime for both of the cases. Notably the above observation reveals that a change of surface and bulk parameters really affects electrode kinetics in a different manner. An increase of oxygen vacancy equilibrium concentration promotes an early transition to bulk pathway and actually block some of the oxygen surface diffusion, while large equilibrium coverage of surface oxygen ion improves 3PB kinetics by enhancing oxygen transport on the surface. Despite the differences of electrode kinetics and performance between Cases 1-3, Fig.6.6 and Fig.6.9 did show that the response of $i_{\text {loc }} / i_{\text {tot }}$ ratio to overpotential follows a similar trend for all the cases studied, confirming the suppression of surface diffusion of oxygen ion as the physical mechanism for 3PB-to2PB pathway transition.

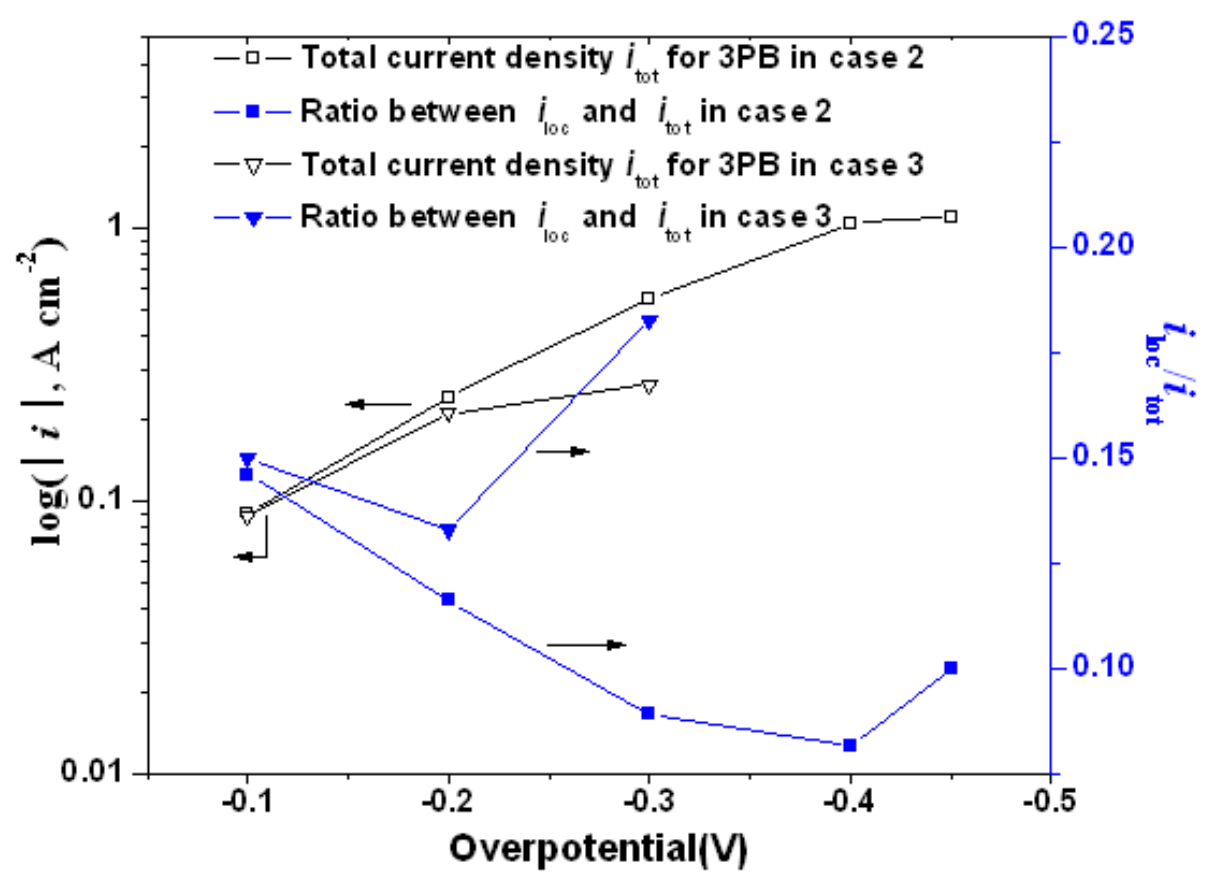

Figure 6.9 Comparison of the relationship between local reaction currents and total 3PB currents in Case 2 and Case 3 (Case 2: $\mathrm{C}_{\mathrm{o}-\mathrm{eq}}=1 \times 10^{-10} \mathrm{~mol} \mathrm{~cm}^{-2}$ and $\mathrm{C}_{\mathrm{v}, \mathrm{eq}}=1 \times 10^{-8} \mathrm{~mol} \mathrm{~cm}$ ${ }^{3}$; Case 3: $\mathrm{C}_{\mathrm{o}-\mathrm{eq}}=1 \times 10^{-10} \mathrm{~mol} \mathrm{~cm}^{-2}$ and $\mathrm{C}_{\mathrm{v}, \mathrm{eq}}=1 \times 10^{-7} \mathrm{~mol} \mathrm{~cm}^{-3}$ ) 
Combined simulation results from Case 1-3 indicates that the transition of the dominant pathway greatly depends upon material properties, with earlier transition in terms of cathodic overpotential promoted by lower values of $\mathrm{C}_{\mathrm{o}-\mathrm{eq}}$ and higher values of $\mathrm{C}_{\mathrm{v}, \mathrm{eq}}$. Change of $\mathrm{C}_{\mathrm{o}-\mathrm{eq}}$ and $\mathrm{C}_{\mathrm{v}, \mathrm{eq}}$ also determines the RLS for electrode kinetics, and accordingly the electrode performance. The exchange current densities, kinetic transition voltage and overall current densities at $-0.3 \mathrm{~V}$ identified for each case is listed in Table 6.3. From the practical viewpoint of electrode operation, occurrence of 3PB-to-2PB transition at lower overpotential is preferred, as the total electrode kinetics would benefit from higher 2PB exchange current density. However from data in Table 6.3 it can be learned that earlier 3PB-to-2PB transition does not necessarily lead to higher electrochemical performance of electrode. Case 3 has the highest current density at $-0.3 \mathrm{~V}$ among the three cases, due to the increased contribution from $2 \mathrm{~PB}$ kinetics at a relatively smaller overpotential. However the dominance of $3 \mathrm{~PB}$ kinetics in Case 2 are most of the simulated overpotential range results in even greater performance improvement compared to Case 1, though with a late kinetic transition. So, this model shows that modification of material property parameters can really promote electrode performance through different mechanisms. Generally, the value of $\mathrm{C}_{\mathrm{o}-\text { eq }}$ can be viewed to associate with electrocatalytic activity of the cathode material, while a higher $\mathrm{C}_{\mathrm{v}, \mathrm{eq}}$ may relate to higher ionic conductivity for the MIEC. With respect to practical development of high performance SOFC cathode, usually poor MIEC like LSM is either directly mixed with a good ionic conductor like YSZ or impregnated with materials of both high ionic conductivity and catalytic activity for oxygen exchange/reduction, such as doped ceria, to achieve the purpose. It is hereby implied by the simulation scenario in this study that 
improving surface catalytic activity for a poor MIEC with certain ionic conductivity can be more efficient in terms of electrode performance promotion at a defined electrode configuration (fixed TPB and 2PB contact area).

In comparison to the simulation results in this model, it is well known during experimental and theoretical studies on SOFC cathode that electrode kinetics can improve at high cathodic overpotential due to promotion of oxygen reduction through bulk pathway. However, the reported overpotential when $2 \mathrm{~PB}$ contribution becomes apparent as well as identified RLS for the dominant kinetic pathway tends to vary from case to case. Siebiert noticed considerable current increase for LSM cathodes around overpotential of $-0.4 \mathrm{~V}$ [129]. Kim reported the resistance of LSM-YSZ electrode was greatly reduced after current treatment at $-0.5 \mathrm{~V}$ [125]. At higher temperature of $950^{\circ} \mathrm{C}$, Van Heuveln found significant relaxation of LSM cathode resistance shortly after passage of DC current with overpotential equivalent to about $-0.3 \mathrm{~V}[123]$. More recently, studies from Fleig's group and Shao-Horn's group on dense LSM microelectrodes at 700$800^{\circ} \mathrm{C}$ both indicated that the bulk path of oxygen reduction increased dramatically at DC bias of $-300 \mathrm{mV}[135,137]$. In this work, the simulated overpotential for the transition into $2 \mathrm{~PB}$ pathway dominance is around $-0.26 \mathrm{~V}$ to $-0.45 \mathrm{~V}$, which lies within the reported data range. The discrepancy of different research results rather reflects that the kinetic transition between surface and bulk path for oxygen reduction is sensitive to electrode operation conditions and material properties, which closely depend on the manufacturing, composition, geometry and structure of the electrode. 


\subsubsection{Dependence of active reaction zone and surface reaction rates on overpotential and material parameters}

In section 6.5.1 and 6.5.2, the pathway transition of MIEC cathode kinetics is studied with the $3 \mathrm{~PB}$ currents and $2 \mathrm{~PB}$ currents at cathode/electrolyte interface $(\mathrm{x}=0)$. However the previous analysis has shown that the $3 \mathrm{~PB}$ currents and $2 \mathrm{~PB}$ currents not only depend on local concentrations and reaction rates of electrode species at $\mathrm{x}=0$, but also fluxes of surface oxygen ion and bulk oxygen vacancies outside of the $2 \mathrm{~PB} / 3 \mathrm{~PB}$ electrochemical boundary. In this section contributions from electrode proportions outside of the cathode/electrolyte interface to the overall electrode reaction kinetics are characterized in two aspects.

First, in the physical scenario of oxygen reduction (Fig. 6.2), it is assumed that there will be a "critical" boundary lc on the electrode beyond which bulk pathway reactions would cease to modify the local vacancy concentration from its intrinsic value $\left(\mathrm{C}_{\mathrm{v}, \mathrm{eq}}\right)$. The thickness of this active reaction zone represents the electrode area actually participating in oxygen reduction reaction, and is important to cathode performance improvement through microstructure design. A detailed analysis is thus performed in section 6.5.3.1 to derive the thickness for this active reaction zone from concentration profiles of electrode species along the modeled distance. Second, as the surface reaction rates $r_{S 2}$ and $r_{B 3}$ determine local diffusion fluxes along the MIEC electrode according to Eq. 6.14 and 6.15, it is of research interest for this study in section 6.5.3.2 to investigate how the surface reaction rates change as kinetic pathway transition occurs in order to further understand the mechanism accounting for 3PB-to-2PB pathway transition.

Overall the main purpose of analysis in the section 6.5 .3 is to identify effects from both applied overpotential and material property parameters on the thickness of active 
reaction zone and corresponding surface reaction rates $r_{S 2}$ and $r_{B 3}$. The results are used to reveal potential implication of current simulation findings on the practical routes adopted for cathode performance improvement.

\subsubsection{Effects of overpotential and material property on active reaction zone}

Fig.6.10 and Fig.6.11 show the overpotential-driven distribution profiles of oxygen vacancy concentration (normalized by $\mathrm{C}_{\mathrm{v}} / \mathrm{C}_{\mathrm{v}, \text { eq }}$ ) along the electrode thickness in case 1 and case 2 respectively. The electrode is electrochemically activated at regions near $2 \mathrm{~PB} / 3 \mathrm{~PB}$ interfaces as indicated by increased local vacancy concentrations at larger cathodic overpotential. The consequences of a more negative overpotential increases the penetration distance of oxygen vacancy concentration deviating from the equilibrium value. When comparing the magnified views of vacancy concentrations outside $2 \mathrm{~PB} / 3 \mathrm{~PB}$ interfaces in Fig.6.10 and Fig.6.11, it can be identified that the thickness of active reaction zone extends from $\sim 1 \mu \mathrm{m}$ in case 1 to $\sim 4 \mu \mathrm{m}$ in case 2 with higher value of $\mathrm{C}_{\mathrm{o} \text {,eq }}$ used, and, accordingly, local vacancy concentrations outside of $2 \mathrm{~PB}$ also rise since same value of $\mathrm{C}_{\mathrm{v}, \mathrm{eq}}$ is used in both cases. This suggested change of surface material properties not only affects 3PB pathway transport as discussed in section 6.5 .2 but also the distribution of bulk pathway kinetics via a vacancy concentration adjustment. This phenomenon will be addressed during later discussion on methodology for cathode performance improvement. However Fig. 6.10 and Fig. 6.11 do not provide any explanation for why the active reaction zone is extended. Another fact observed for Fig; 6.10 and Fig. 6.11 is that there are large concentration gradient between the first node and second node calculated with overpotentials more negative than $-0.1 \mathrm{~V}$ at the cathode/electrolyte interface. This result is associated with higher electrochemical 
reaction rate at more negative overpotentials, which may introduce non-linear behavior at region close to electrochemical boundary. To resolve this issue, future calculation with more nodes or non-uniform node mesh will be necessary.

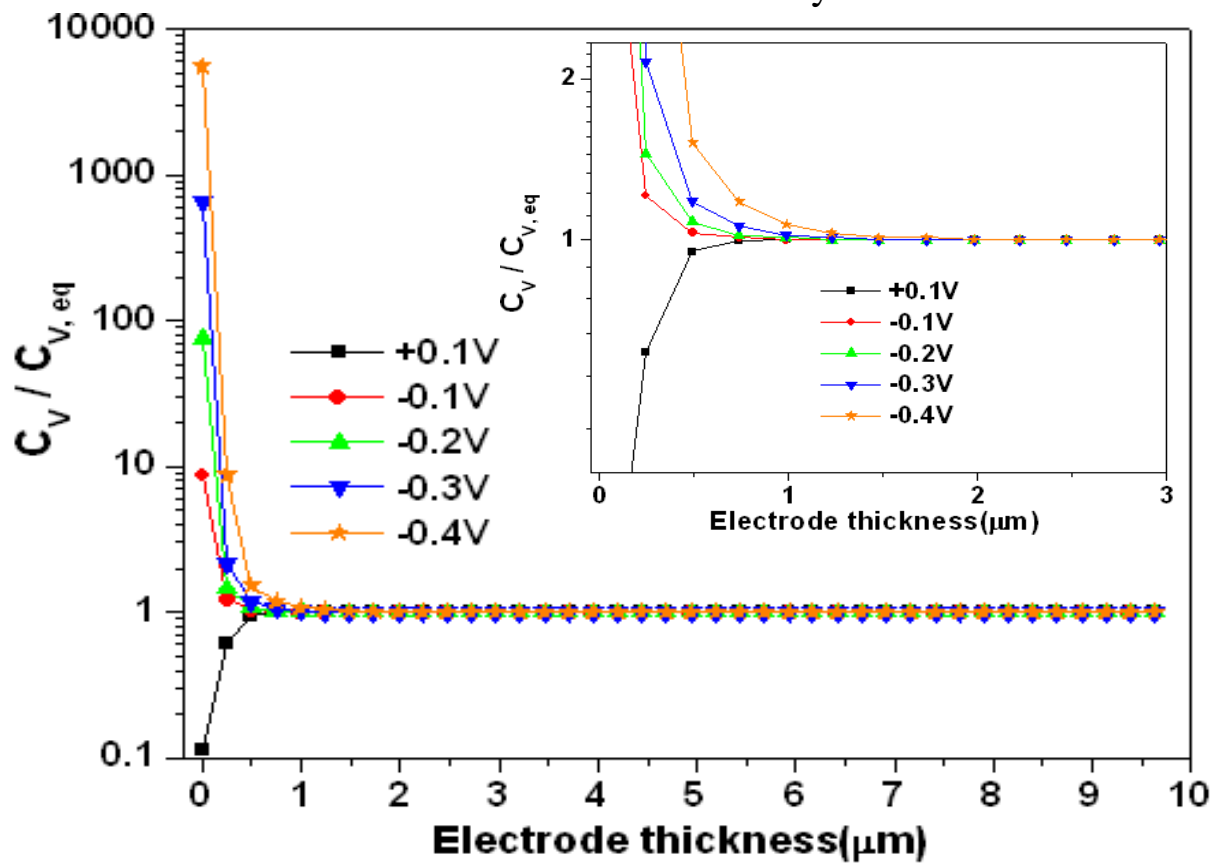

Figure 6.10 Distribution profiles of oxygen vacancy concentrations under different overpotential in Case 1 as $\mathrm{C}_{\mathrm{o}-\mathrm{eq}}=1 \times 10^{-11} \mathrm{~mol} \mathrm{~cm}^{-2}$ and $\mathrm{C}_{\mathrm{v}, \mathrm{eq}}=1 \times 10^{-8} \mathrm{~mol} \mathrm{~cm}^{-3}$

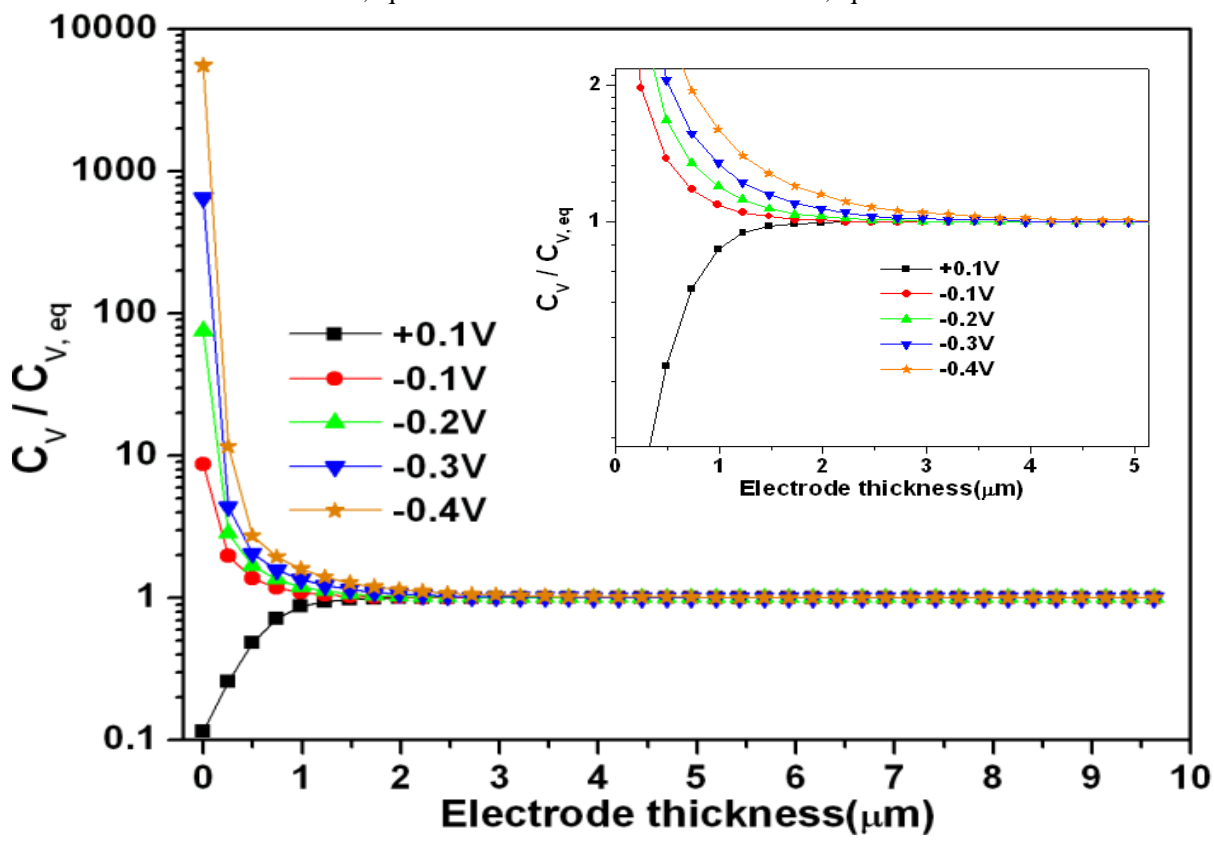

Figure 6.11 Distribution profiles of oxygen vacancy concentrations under different overpotential in Case 2 as $\mathrm{C}_{\mathrm{o}-\mathrm{eq}}=1 \times 10^{-10} \mathrm{~mol} \mathrm{~cm}^{-2}$ and $\mathrm{C}_{\mathrm{v}, \mathrm{eq}}=1 \times 10^{-8} \mathrm{~mol} \mathrm{~cm}^{-3}$ 
The reason for extension of active reaction zone is discussed with results of Fig. 6.12, which shows the distribution profile of surface oxygen concentrations and step B3 reaction rates for case 1 and case 2 at $-0.2 \mathrm{~V}$ overpotential. Fig 6.12.indicates that an increase of $\mathrm{C}_{\mathrm{o}-\text { eq }}$ by 10 times in case 2 relative to case 1 reduces the local ratio of $\mathrm{C}_{\mathrm{o}-} / \mathrm{C}_{\mathrm{o}-\text {,eq }}$ while increasing the reaction rates $r_{B 3}$ between bulk oxygen vacancy and surface oxygen ion. It is noteworthy that such changes of surface concentration ratio $\mathrm{C}_{\mathrm{o}-\mathrm{I}} / \mathrm{C}_{\mathrm{o}-\mathrm{eq}}$ and reaction rate $r_{B 3}$ are more pronounced at a certain distance away from $3 \mathrm{~PB}$, while at $3 \mathrm{~PB}$ (virtually within one-node distance to it) there is almost no difference of $r_{B 3}$ rates between the two cases. This result implies step B3 reaction near $\mathrm{x}=0$ is strongly controlled by electrochemical boundary condition and relatively independent of material property effects. At a distance of around 2 4 $\mu \mathrm{m}$ away from 3PB/2PB interfaces $r_{B 3}$ rates decay to a equilibrium plateau or very small values (corresponding to current density well below $0.01 \mathrm{~mA} / \mathrm{cm}^{2}$ ), as surface oxygen ion concentrations stabilize.

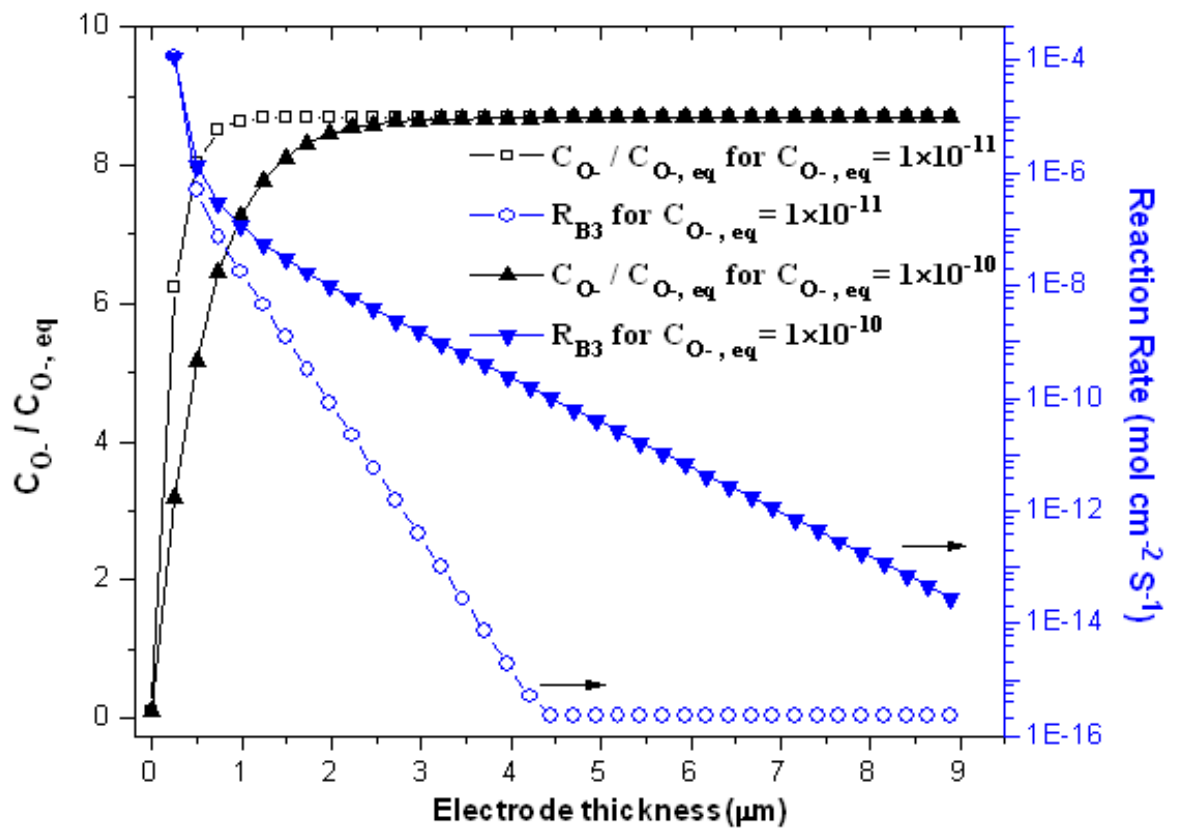

Figure 6.12 Distribution profiles of surface oxygen concentrations and step-B3 reaction rates at $-0.2 \mathrm{~V}$ overpotential in Case 1 and Case 2 as $C_{\mathrm{v}, \text { eq }}=1 \times 10^{-8} \mathrm{~mol} \mathrm{~cm}^{-3}$ 
The results from Fig. 6.12 indicate that increase of $\mathrm{C}_{\mathrm{o}-\text { eq }}$ can decrease $\mathrm{C}_{\mathrm{o}-} / \mathrm{C}_{\mathrm{o}-\text { eq }}$ while increase $r_{B 3}$. According to equation (6.12), a reduced value of $\mathrm{C}_{\mathrm{o}-} / \mathrm{C}_{\mathrm{o}-\text { eq }}$ and increased value of $r_{B 3}$ yield larger value of $\mathrm{C}_{\mathrm{v}} / \mathrm{C}_{\mathrm{v}, \text { eq }}$ (e.g. absolute $\mathrm{C}_{\mathrm{v}}$ ) if overpotential is constant. Thus the observed increase of $\mathrm{C}_{\mathrm{v}} / \mathrm{C}_{\mathrm{v}, \text { eq }}$ at higher value of $\mathrm{C}_{\mathrm{o}-\text { eq }}$ together with consequent extension $r_{B 3}$ of active reaction zone in Fig. 6.11 can be explained by relative change of $\mathrm{C}_{\mathrm{o}-} / \mathrm{C}_{\mathrm{o}-\mathrm{eq}}$ and $r_{B 3}$ in Fig. 6.12.

The increasing of $\mathrm{C}_{\mathrm{v}} / \mathrm{C}_{\mathrm{v} \text {,eq }}$ as $\mathrm{C}_{\mathrm{o}-\text { eq }}$ increases implies additional vacancy can be transferred from 2PB interface to MIEC cathode due to change of surface material property. An increase of $\mathrm{C}_{\mathrm{o}-\text { eq }}$ leads to a higher background chemical potential on the electrode, and, in this case, the model predicts that, even though absolute concentration of surface oxygen ion rises, the local chemical potential determined by $\mathrm{C}_{\mathrm{o}-} / \mathrm{C}_{\mathrm{o}-\text { eq }}$ virtually drops (which is also confirmed under cathodic overpotentials other than $-0.2 \mathrm{~V}$; results not shown here for discussion convenience). This condition can be expected to slow down reaction $\mathrm{B} 3$ according to equation (6.12) initially, and hence promote an increase of local vacancy concentration. Consequently additional vacancy formed via $2 \mathrm{~PB}$ exchange reaction $\mathrm{B} 4$ could be transported to regions away from $2 \mathrm{~PB}$ until new steady-state level of $r_{B 3}$ is achieved. In this way the active reaction zone expands, and electrode kinetics is also improves as $\mathrm{C}_{\mathrm{o}-\mathrm{eq}}$ increases. 


\subsubsection{Change of surface reaction rates $r_{S 2}$ and $r_{B 3}$ as functions of electrode position, overpotential and material property}

Analysis of section 6.5 .2 has demonstrated suppression of surface diffusion as a mechanistic process for 3PB-to-2PB pathway transition. As mentioned at the beginning of section 6.5.3, surface reaction rates $r_{S 2}$ and $r_{B 3}$ determine local diffusion fluxes of surface oxygen ion and bulk oxygen vacancies. Therefore it is of research interest for this study to characterize evolution of the surface reaction rates $r_{S 2}$ and $r_{B 3}$ during this kinetic transition as function of overpotential and $\mathrm{C}_{\mathrm{o}-\mathrm{eq}}$, and the change of their values are used to identify reason for occurrence of surface diffusion limit during kinetic transition. On the other hand, results of section 6.5.3.1 indicate change of material property $\left(\mathrm{C}_{\mathrm{o}-\mathrm{eq}}\right)$ modifies surface reaction rates outside of $2 \mathrm{~PB} / 3 \mathrm{~PB}$ interface, but has little effect on surface reaction rates at $2 \mathrm{~PB} / 3 \mathrm{~PB}$ interface. So, the analysis on $r_{S 2}$ and $r_{B 3}$ is separately performed at electrochemical boundary $(\mathrm{x}=0)$ and outside of electrochemical boundary to further investigate different driving forces for surface reaction S2 and B3 along electrode.

Analysis on surface reaction rates $r_{S 2}$ and $r_{B 3}$ at electrochemical boundary---- Fig. 6.13 shows the numerical results of surface reaction rates at TPB $(x=0)$. It can be seen from Fig. 6.13 that reaction rates $r_{S 2}$ and $r_{B 3}$ are independent of $\mathrm{C}_{\mathrm{o}-\mathrm{eq}}$ change, indicating at $\mathrm{TPB} / 2 \mathrm{~PB}$ interfaces the surface reactions are strictly controlled by electrochemical boundary conditions. As a result cathodic overpotential would drive reaction S2 forward and reaction $\mathrm{B} 3$ backward, while the case is reverse for anodic overpotential just as described in the B-V equation (6.10) and (6.12). 


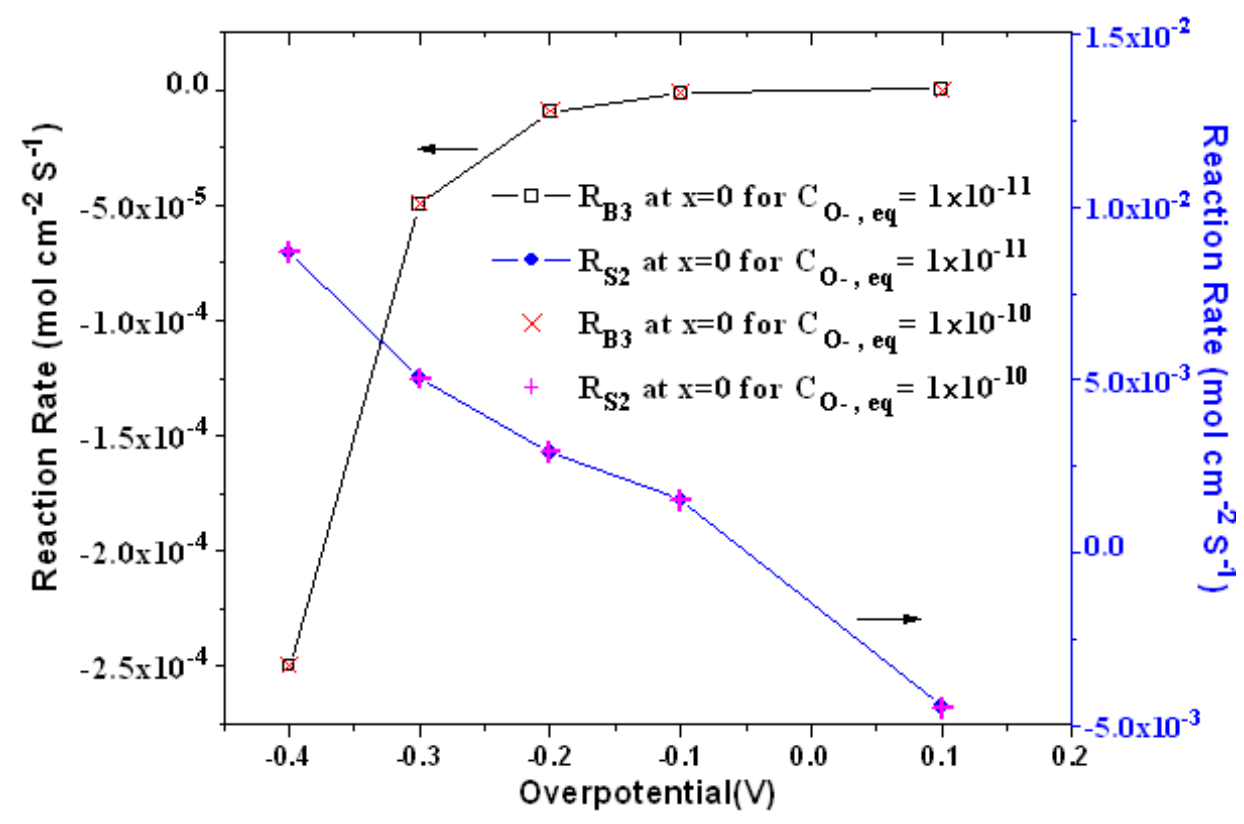

Figure 6.13 Dependence of rates of step $\mathrm{S} 2$ and $\mathrm{B} 3$ reactions at $3 \mathrm{~PB}(\mathrm{x}=0)$ on overpotential in Case 1 and 2 as $C_{\mathrm{v}, \mathrm{eq}}=1 \times 10^{-8} \mathrm{~mol} \mathrm{~cm}^{-3}$

It should be noticed in Fig. 6.13 that $r_{B 3}$ has negative values under cathodic overpotentials, which imply at TPB the process of incorporation of surface oxygen ion into MIEC is rather reversed. According to equation (6.12), a negative overpotential tends to drive the reaction $\mathrm{B} 3$ reversely, e.g., towards direction of the left side. This phenomenon reflects that at electrochemical boundary $(x=0)$ reaction $B 3$ is strongly controlled by overpotential driving force as defined by equation (6.12), and effects from local concentrations of surface oxygen ion and bulk oxygen vacancies are not decisive. This finding, however, is restricted to cathode/electrolyte interface $(\mathrm{x}=0)$ only. As will be discussed later in analysis of $r_{S 2}$ and $r_{B 3}$ outside TPB, $r_{B 3}$ has positive values at electrode position other than $\mathrm{x}=0$, indicating that the model assumption on bulk pathway oxygen reduction scenario is valid outside TPB.

On the other hand, an important question raised by results of Fig. 6.13 is whether a 
reversed step B3 reaction at TPB challenges the physical validity of this model. This question will be discussed as follows. First, this model assumes for oxygen reduction through bulk pathway (the $2 \mathrm{~PB}$ pathway), surface oxygen ion has to be incorporated into MIEC bulk before it is taken into electrolyte. This assumption is found valid at all of the electrode surface except at TPB. However, for the TPB point $(x=0)$, surface oxygen ion can directly react with oxygen vacancies from electrolyte through step S4 reaction. This direct reduction of surface oxygen ion at TPB makes reduction of oxygen through MIEC bulk rather redundant. Because with the presence of oxygen vacancies from electrolyte at TPB, surface oxygen ion needs not to undergo additional incorporation step into cathode bulk to finish reduction, especially when S4 reaction step is fast (step S4 is set as NonRLS in this model). From this analysis positive B3 reaction at TPB is rather not favorable. Second, according to equation (6.12) negative step B3 reaction indicates transfer of lattice oxygen out from cathode bulk towards TPB surface. This phenomenon can be related to an oxygen "spill-over" effect. Recent study on SOFC cathode has found that oxygen spill-over occurred at near TPB region [161]. During this process oxygen ions are transferred from electronic-conductive cathode particles onto the electrolyte surface.

Generally above analysis has shown that at $x=0$ the step $B 3$ reaction is driven by overpotential to have a negative reaction rate, which implies oxygen spill-over from cathode to electrolyte through surface path. This phenomenon is physically sound because TPB reaction S4 is assumed to be fast in this model. In comparison, Wang reported that for LSM cathode supported on YSZ electrolyte, oxygen spill-over occurred when TPB reaction was not rate-limiting for cathode kinetics [126].

Surface reaction rates $r_{S 2}$ and $r_{B 3}$ outside of electrochemical boundary---- Fig. 6.14 
shows the numerical results of surface reaction rates at one electrode point just outside TPB $(\mathrm{x}=0.5 \mu \mathrm{m})$. In Fig. 6.12 and Fig.6.14 $r_{B 3}$ was found to be positive at an electrode surface region other than the TPB, suggesting surface reaction outside of electrochemical boundary was controlled more by the chemical terms $\mathrm{C}_{\mathrm{v}} / \mathrm{C}_{\mathrm{v}, \text { eq }}$ and $\mathrm{C}_{\mathrm{o}-\text { - }} / \mathrm{C}_{\mathrm{o}, \text { eq }}$ in equation (6.12) than by overpotential. Fig. 6.14 also suggests that both $r_{B 3}$ and $r_{S 2}$ increases as overpotential becomes more negative. According to equation (6.12), the backward rate for $r_{B 3}$ increases at more negative overpotential. So, this means that for $r_{B 3}$ to become more positive, $\mathrm{C}_{\mathrm{v}} / \mathrm{C}_{\mathrm{v} \text {,eq }}$ and $\mathrm{C}_{\mathrm{o}-} / \mathrm{C}_{\mathrm{o}-\text { eq }}$ have to increase accordingly to offset the larger backward rate. To verify whether this is the case for $r_{B 3}$ at $\mathrm{x}=0.5 \mu \mathrm{m}$, the forward reaction rates of $r_{B 3}$ calculated from the simulated values of $\mathrm{C}_{\mathrm{v}} / \mathrm{C}_{\mathrm{v}, \text { eq }}$ and $\mathrm{C}_{\mathrm{o}-} / \mathrm{C}_{\mathrm{o}-\mathrm{eq}}$ are compared with the backward reaction rates of $r_{B 3}$ calculated from applied overpotentials in Fig. 6.15. From the magnified views of reaction rates at $-0.1 \mathrm{~V}$ and $-0.4 \mathrm{~V}$ in Fig. 6.15 , it can be seen that forward reaction rates of $r_{B 3}$ are larger than backward reaction rates for the given overpotential range. Therefore, it is confirmed here that step B3 reaction is more driven by local chemical concentrations of surface oxygen ion and bulk vacancies outside of TPB/2PB interface.

However, this simulation result does not necessarily means that the surface reactions are chemical in nature. Instead it can be learned from Fig.6.14 that $r_{s 2}$ remains $2 \sim 3$ orders of magnitude higher than $r_{B 3}$ for each overpotential. According to equation (6.10) and (6.12), combination of reaction S2 and B3 would yield zero charge transfer. Therefore, from formulism point of view, the overall oxygen exchange reaction on MIEC is a chemical process. But the simulation results show rate of step S2 reaction is much 
larger than that of step B3 reaction. This rate difference makes oxygen intermediates $\left(\mathrm{O}^{-}\right)$ appear as a stable phase during reduction, and hence both of surface reactions S2 and B3 become electrochemically controlled [150].

Fig. 6.14 shows that at higher value of $\mathrm{C}_{\mathrm{o}, \mathrm{eq}}, r_{S 2}$ increases faster than $r_{B 3}$, while results in a larger rate difference between $r_{S 2}$ and $r_{B 3}$ for case 2 with $\mathrm{C}_{\mathrm{o}, \mathrm{eq}}=1 \times 10^{-10} \mathrm{~mol} / \mathrm{cm}^{2}$. According to equation (6.14), increasing of surface diffusion flux can be expected from a larger rate difference between $r_{S 2}$ and $r_{B 3}$. This explains change of 3PB pathway kinetics from local reaction control for case 1 to surface diffusion control for case 2 , as shown by Fig. 6.6 and Fig. 6.9. It can be also noticed in Fig. 6.14 that there is abrupt increase of $r_{B 3}$ above the overpotentials for 3PB-to-2PB transition, as is shown by slope change of the $\mathrm{R}_{\mathrm{B} 3}$ plots in the figure. This indicates that abrupt increase of $r_{B 3}$ causes the suppression of surface diffusion (according to equation (6.14)) and eventually the 3PB-to-2PB transition.

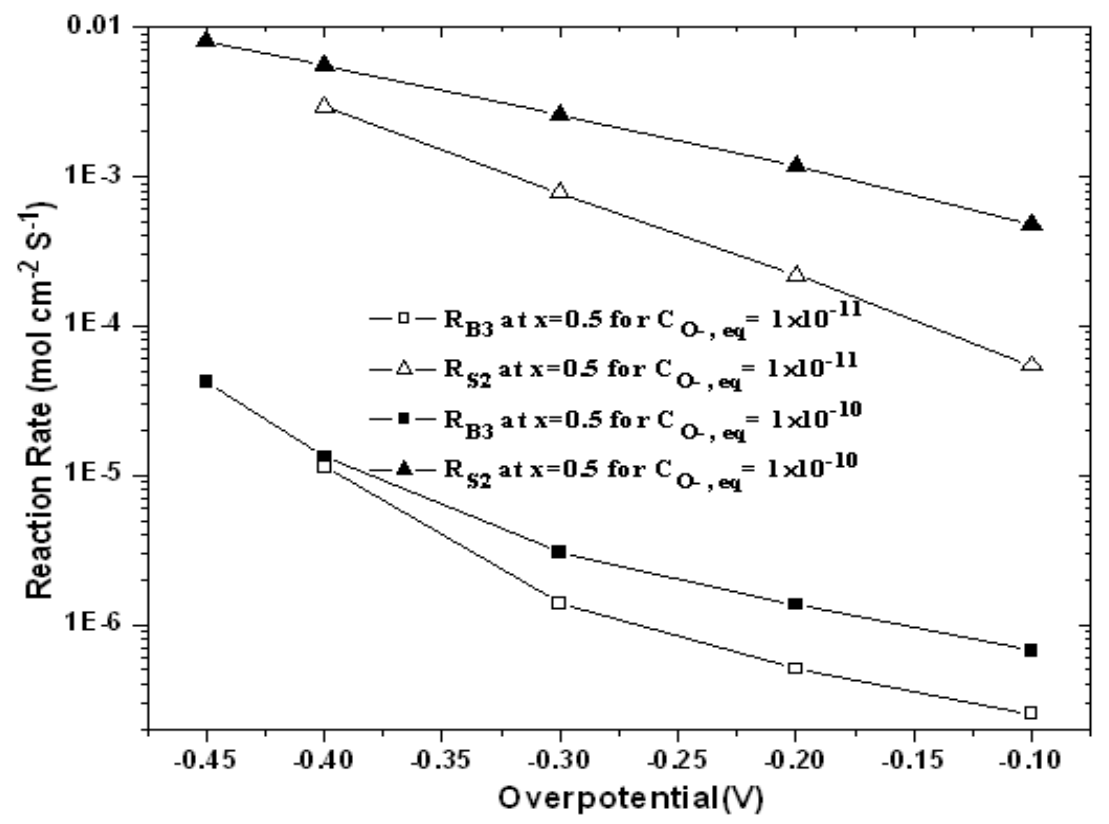

Figure 6.14 Dependence of rates of step S2 and B3 reactions at $0.5 \mu \mathrm{m}$ away from 3PB on overpotential in case 1 (open symbol) and case 2 (filled symbol) as $C_{\mathrm{v}, \mathrm{eq}}=1 \times 10^{-8} \mathrm{~mol} \mathrm{~cm}^{-3}$ 


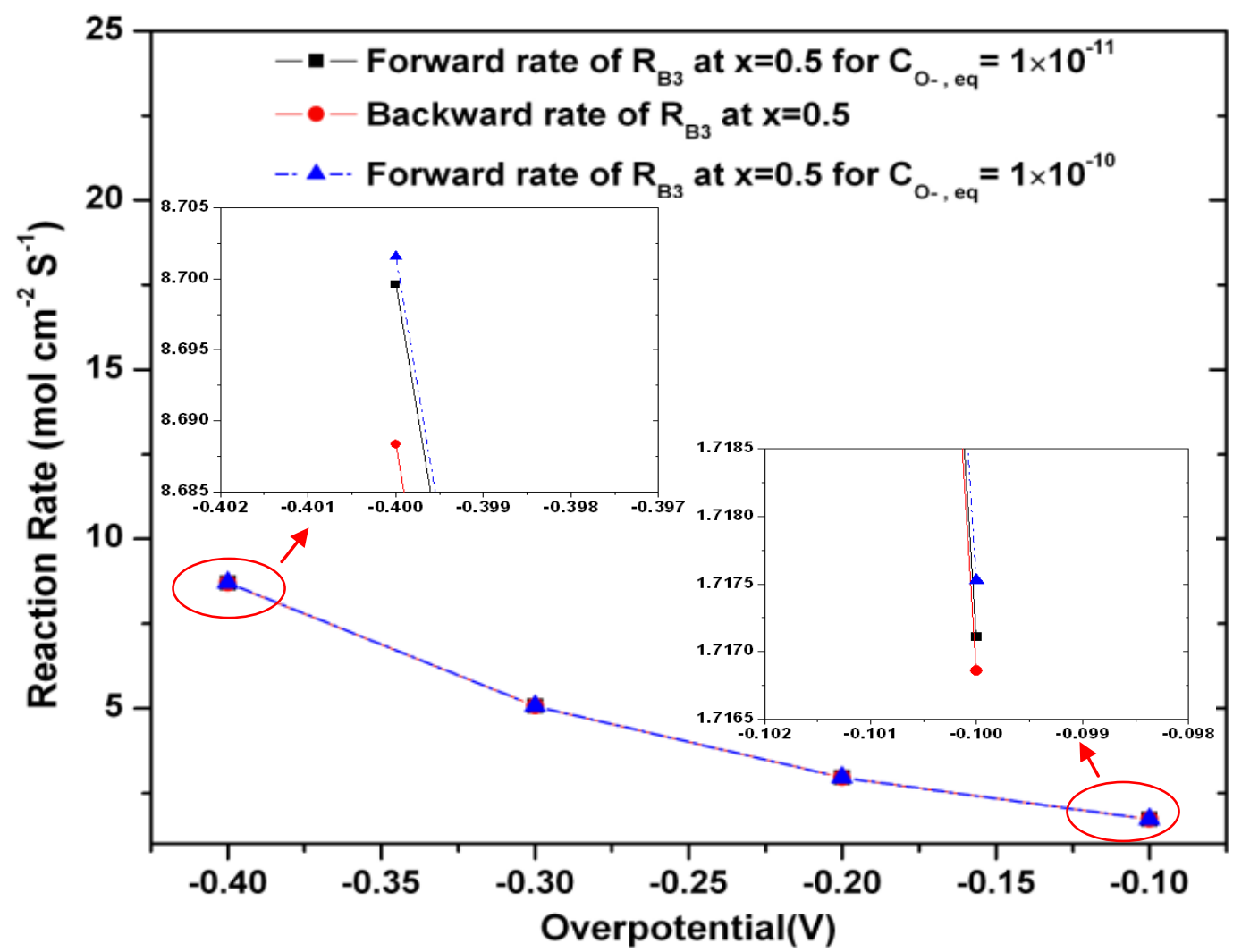

Figure 6.15 Dependence of backward reaction rates and forward reaction rates of step B3 reactions at $0.5 \mu \mathrm{m}$ away from $3 \mathrm{~PB}$ on overpotential in Case 1 and Case 2 as $\mathrm{C}_{\mathrm{v}, \mathrm{eq}}=1 \times 10^{-8}$ $\mathrm{mol} \mathrm{cm} \mathrm{cm}^{-3}$

Association with cathode performance improvement---- Together, the above results and discussions confirms the existence of an active reaction zone in the MIEC electrode with micron-level thickness determined by surface reaction S2 and B3. A change of surface material properties influences the 3PB-to-2PB pathway transition by modifying the distribution of surface oxygen ion and bulk vacancy and corresponding local reaction rates outside of the $2 \mathrm{~PB} / 3 \mathrm{~PB}$ interfaces. The oxygen/MIEC surface reactions along the electrode remain electrochemical in nature despite of increasing contribution from local concentration changes away from the electrochemical interfaces. As a comparison, Kuznecov observed that the diffusion length of oxygen vacancies from the YSZ electrolyte into the LSM cathode was about $2 \mu \mathrm{m}$ at $950^{\circ} \mathrm{C}[162]$, while the effective 
thickness for oxygen bulk diffusion in LSM derived from oxygen chemical diffusivity $\left(D_{\text {chem }}\right)$ and surface exchange coefficient $(K)$ previously reported in literature ranges from a few $\mu \mathrm{m}$ to $\mathrm{cm}$-level $[154,155,156]$. This large discrepancy may reflect sophisticated control over data acquisition and processing required for measurement of MIEC thermodynamic properties. Simulation in this model does predict discernible extension of oxygen vacancy diffusion thickness for improved material surface catalytic properties as a higher $\mathrm{C}_{\mathrm{o}, \mathrm{eq}}$ value provides more surface sites available for oxygen adsorption and potentially higher oxygen surface equilibrium coverage. Consequently, this finding may offer some guidance on the practical methodology for cathode performance improvement. It has become a conventional route to improve kinetics of a poor MIEC cathode through infiltration of second-phase particles with high ionic conductivity such as doped ceria. However the confined active reaction zone near the electrochemical interfaces in case 1 implies that impregnated particles need to be in good contact with the TPB or extended electrolyte network out from the $2 \mathrm{~PB}$ to effectively affect reaction rates magnificently. Thus, control over processing parameters such as precursor, material loading and sintering temperature would be important to optimize the final particle size and distribution. In contrast, the case 2 study indicates that impregnation with a highly catalytic material could improve surface reaction kinetics and extend the active reaction zone at moderate overpotentials. Thus, less restriction on secondary particle size and distribution can be expected in this case to achieve similar performance improvement, since contribution from surface diffusion and reactions outside TPB to the total performance becomes more dominant. Hence potentially the second methodology may benefit from enhanced processing efficiency. 


\subsubsection{Assumption of oxygen reduction scenario}

To investigate effects from multi-step charge transfer on the 3PB-to-2PB pathway transition at a MIEC cathode, we breaks down the oxygen reduction process into six elementary steps (S1-B4), and tentatively propose step S2, B3 and B4 as RLSs based on literature survey and boundary conditions required for numerical solution. Although there are fair assumptions that at the given system conditions according to experimental results, we can not rule out other possible reaction scenario with different RLSs and elementary steps from this model. A recent study on LSM microelectrodes by the research group from MIT has confirmed that charge transfer at $2 \mathrm{~PB} / 3 \mathrm{~PB}$ interfaces is the RLS below $700^{\circ} \mathrm{C}$ and electrode surface reactions are the RLS above $700^{\circ} \mathrm{C}[137]$. This finding suggests that there is room for adjustment of the RLS and correspondingly the boundary conditions within current scenario at temperatures of interest. Lately, it has been shown by quantum chemistry and first principle analysis that oxygen adsorption is accompanied by formation of molecular oxygen ions at the electrode surface $\left(\mathrm{O}_{2}^{-}\right.$and $\left.\mathrm{O}_{2}^{2-}\right)$, which can be subsequently converted into $\mathrm{O}^{-}[140,148]$. This prediction would complicate RLS assignments and governing equations derivation by introducing additional elementary steps. However, with necessary assumptions on transition states and diffusibility for the ion species, this scenario can still be simplified to select one type of surface ion for the final governing equations. Another important factor that needs to be taken into consideration for future simulation work is, as pointed out by Fleig and Mebane $[140,149]$, that the change of surface potential for a MIEC electrode across the air/cathode interface may in general deviate from the nominal bulk overpotential across 
cathode/electrolyte interface. Thus, it would be necessary to separate overpotentials driving surface reactions from that driving bulk vacancy exchange. Studies from Fleig also showed that surface overpotential would either linearly depend on the bulk overpotential or remain constant through out the cathodic overpotential regime [149], with values between $0 \sim 2 \eta$ ( $\eta$ :bulk overpotential). In the current model set-up, surface overpotential is assumed to be equal to bulk overpotential for computational simplification. To overcome this insufficiency, a detailed relationship between surface/bulk overpotentials has to be derived with corresponding RLS assumptions of surface reactions.

\subsection{Conclusion and future work}

In this study multi-step charge transfer is incorporated into a 1-D physical model designed for the oxygen reduction scenario to examine the competitve behaviors between the paralleled 3PB and 2PB kinetic pathway during MIEC electrode activation. Analysis by V-I polarization curve, Tafel estimation and local 3PB current constitution has identified the suppression of surface oxygen ion diffusion as the mechanism for 3PB-to2PB kinetic transition. The transition voltage between $-0.2 \sim-0.4 \mathrm{~V}$ depends on both material surface and bulk parameters. The transition voltage becomes more negative at higher $\mathrm{C}_{\mathrm{o}, \mathrm{eq}}$ and less negative at higher $\mathrm{C}_{\mathrm{v}, \mathrm{eq}}$. The model also demonstrated surface reactions are driven predominantly by electrochemical forces at the TPB, while they are controlled by oxygen vacancy concentration variation at regions away from TPB. Consequently, improving of material surface catalytic activity can effectively promote electrode performance by extending the active reaction zone outside of the TPB/2PB interface, and may be more efficient than addition of a separate ionic conductor into the 
electrode in terms of less restriction on processing control. As discussed before the complex nature of oxygen/MIEC reactions needs the model to focus on the following aspects to become more applicable in the future: (1) Adopt a physically more plausible oxygen adsorption scenario into 1-D model involving peroxide and superoxide ions; (2) Choose the RLS and boundary conditions for simulation with changed system properties of material, temperature and oxygen partial pressure; (3) Incorporate into governing reaction mechanisms the interrelationship between surface potential change and bulk overpotential derived from specific assumptions on the surface charging layer configuration. 


\section{Appendix}

This section provides efforts and arguments to predict various physical variables needed for the model calculation from existing reports. Oxygen vacancy diffusivity $D_{v}$, which is $D_{b, c h e m}$ in this model, is reported by Mizusaki to be almost independent of perovskite compositions and vacancy concentrations at $700 \sim 1000^{\circ} \mathrm{C}[163]$. Yasuda found that $\mathrm{D}_{\mathrm{v}}$ for $\mathrm{La}_{0.8} \mathrm{Sr}_{0.2} \mathrm{MnO}_{3}(\mathrm{LSM} 20)$ with values of $10^{-6} \sim 10^{-5} \mathrm{~cm}^{2} / \mathrm{s}$ at $850^{\circ} \mathrm{C}$ varied little with oxygen partial pressure $\left(\mathrm{pO}_{2}\right)[156]$. Thus $D_{b, \text { chem }}$ in Table 2 is determined to be $1 \times 10^{-6} \mathrm{~cm}^{2} / \mathrm{s}$ for LSM at $800^{\circ} \mathrm{C}$. Diffusivity of surface oxygen ion $D_{s, \text { chem }}$ is kept the same as $D_{b, c h e m}$ as assumed in Svensson and Coffey's models[145,147]. Oxygen vacancy concentration, which is sensitive to material composition, $\mathrm{pO}_{2}$ and temperature, is estimated by oxygen tracer diffusivity $D_{\mathrm{O}}^{*}$ via the following equation $[154,158]$ :

$$
D_{\mathrm{O}}^{*}=f D_{V}\left[V_{O}^{\bullet \bullet}\right]
$$

Where the correlation factor $f$ is usually taken as 0.69 for perovskite-type crystal structure. Values of $D_{\mathrm{O}}^{*}$ reported for LSM20 at $800^{\circ} \mathrm{C}$ ranges from $4 \times 10^{-15} \sim 1 \times 10^{-13}$ for oxygen partial pressure between 0.13 to $1 \mathrm{~atm}[154,155,156,157]$. Substitution of $D_{V}$ and $D_{\mathrm{O}}^{*}$ into equation (A1) gives vacancy concentration values of $5.8 \times 10^{-9} \sim 1.4 \times 10^{-7}$. Thus $C_{V, M I E C, \text { eq }}$ is chose as $1 \times 10^{-8} \sim 1 \times 10^{-7} \mathrm{~mol} / \mathrm{cm}^{3}$. In comparison, oxygen vacancy concentration of $2 \times 10^{-7} \mathrm{~mol} / \mathrm{cm}^{3}$ is reported by Yasuda for LSM20 at $900^{\circ} \mathrm{C}$ [157]. Despite the fact that no literature data is available for the equilibrium concentration of surface oxygen ion $C_{O_{\alpha \Delta, e q}^{-e q}}$, this value can be estimated with the equilibrium concentration of atomic oxygen adsorbates, which is given by the equilibrium coverage of adsorbed oxygen and surface adsorption site density as $\Gamma \theta_{e q}$. In the literature, $\Gamma$ is reported to be $10^{-8} \sim 10^{-9} \mathrm{~mol} / \mathrm{cm}^{2}$ for oxygen adsorption on LSM and $\theta_{e q}$ is usually assumed to be $0.01 \sim 0.1[146,162]$. So $C_{O_{\text {ad }}^{-, e q}}$ is set as $1 \times 10^{-10} \sim 1 \times 10^{-11} \mathrm{~mol} / \mathrm{cm}^{2}$. Volume-specific surface area $\frac{\Delta S}{\Delta V}$ depends on average particle size of the electrode according to close-packaging model [164]: 


$$
\frac{\Delta S}{\Delta V}=\frac{6}{d_{\text {avg }}}(1-\varepsilon)
$$

Where $d_{\text {avg }}$ is the average particle size, and $\varepsilon$ is 0.26 for face-centered cubic lattice. Then $\frac{\Delta S}{\Delta V}=8.9 \times 10^{6} \mathrm{~m}^{-1}$ if $d_{\text {avg }}=0.5 \mu \mathrm{m}$. So the value of $\frac{\Delta S}{\Delta V}$ is set as $1 \times 10^{5} \mathrm{~cm}^{-1}$ in the model for submicron-sized MIEC particles.

The exchange reaction rates $r_{S 2,0}, r_{B 3,0}$ and $r_{B 4,0}$ directly relate to the exchange current densities $i_{S 2,0}, i_{B 3,0}$ and $i_{B 4,0}$. AC impedance and DC polarization techniques are frequently used to determine $i_{0}$ for the specific RLS, however the reported values in literature tend to vary over a large range due to different testing conditions and disagreement on interpretation of electrode kinetics. Van Heuveln obtained $i_{0}$ of $20 \sim 110 \mathrm{~mA} / \mathrm{cm}^{2}$ at $950^{\circ} \mathrm{C}$ for a LSM electrode with surface electron donation and diffusion of surface oxygen ion as RLSs [123]. While the same RLSs was also identified in S.Wang's work on LSM supported by YSZ and LSGM electrolytes, $i_{0}$ was measured to be around 10 $\mathrm{mA} / \mathrm{cm}^{2}$ at $900^{\circ} \mathrm{C}$ [126]. In contrast, Chen reported diffusion and TPB incorporation of surface oxygen ion as RLSs for LSM under much lower oxygen partial pressure at $800^{\circ} \mathrm{C}$, and a fitting of $i_{0}$ yielded $1 \sim 10 \mathrm{~mA} / \mathrm{cm}^{2}[160]$. At a much lower temperature of $700^{\circ} \mathrm{C}$ Horita still obtained an $i_{0}$ of $2 \mathrm{~mA} / \mathrm{cm}^{2}$ from polarization of a LSM mesh electrode on YSZ with $<0.1 \mathrm{~V}$ overpotential [136]. The value of $r_{S 2,0}$ selected in this model gives $i_{0}$ equal to about $10 \mathrm{~mA} / \mathrm{cm}^{2}$, which generally lies within the reported data range. On the other hand, estimation of kinetic parameters $r_{B 3,0}$ and $r_{B 4,0}$ eludes us due to lack of experimental data for a LSM electrode. The rates adopted in Svensson and Coffey's models for surface oxygen exchange and bulk vacancy exchange in MIEC electrode convert to $i_{0}$ well below $1 \mathrm{~mA} / \mathrm{cm}^{2}[146,147]$. Compared with the reported exchange current densities for 3PB reactions, such a low value means that the enhancement of electrode kinetics given by $2 \mathrm{~PB}$ pathway contribution may be rather limited. However, if LSM does become a good MIEC like LSF and LSC as expected at higher overpotential, it 
should exhibit similar kinetic properties for bulk oxygen reduction as these materials. The 2PB exchange current densities described for LSC and LSCF are generally between $330 \sim 1100 \mathrm{~mA} / \mathrm{cm}^{2}$ at $800^{\circ} \mathrm{C}$ in the literature $[165,166]$. Since the surface exchange process is believed to limit the electrode kinetics for materials with high ionic conductivity, $i_{0}$ for vacancy exchange at the $2 \mathrm{~PB}$ interface would be even higher than the reported values. With this in mind, $r_{B 3,0}$ is set equal to $r_{S 2,0}$, resulting in $i_{B 3,0}$ equivalent to about $10 \mathrm{~mA} / \mathrm{cm}^{2}$. This choice is made out of considerations that surface exchange coefficiency of LSM is about 1 2 orders of magnitude lower than other good MIECs, and essentially $3 \mathrm{~PB}$ and $2 \mathrm{~PB}$ pathway kinetics would be competitive on surface electrode reactions. The value of $r_{B 4,0}$ is chosen so that $i_{B 4,0}$ equal to $193 \mathrm{~mA} / \mathrm{cm}^{2}$, which indicates $2 \mathrm{~PB}$ interfacial reactions can become RLS at negative polarization. 


\section{Overall Summary}

The main focus of current research is to investigate the degradation mechanism of SOFC anode poisoned by fuel impurities such as sulfur and phosphorus in coal derived syngas and development of corresponding impurity-tolerant anode materials as remedy approach. In addition, the research study also involves the build-up of a 1-D continuum physical model to analyze the oxygen reduction kinetics on MIEC SOFC cathode materials in order to understand the governing factors for the reaction mechanism, which is key to future development of high performance SOFC for direct coal syngas application. A thorough review was firstly provided to weigh the existing works on this topic in terms of sulfur tolerance efficiency and anode performance. Based on understand of poisoning mechanism at this ground, lanthanum doped ceria (LDC) oxide was introduced into the Ni-YSZ anode through a wet nitrates impregnation process. Electrochemical cell test in coal syngas with $20 \mathrm{ppm} \mathrm{H} 2 \mathrm{~S}$ indicated the impregnated LDC coating improved sulfur tolerance of the electrolyte-supported SOFCs with Ni-YSZ/SSZ anode by inhibiting on-set of sulfur poisoning for over $10 \mathrm{hrs}$ and reducing poisoning extent compared to baseline cells. The tolerance mechanism was further analyzed through X-ray photon spectroscopy (XPS), X-ray diffraction (XRD) and AC impedance spectroscopy, which revealed LDC coating reacted with H2S via chemisorptions, resulting in less sulfur blocking triple--phase-boundary and minimized performance loss. In addition thermodynamic calculation performed by Factsage has also confirmed ceria oxides as superior sulfur adsorbent in reducing atmosphere due to tendency to form oxysulfide with $\mathrm{H}_{2} \mathrm{~S}$.

Other impurities such as $\mathrm{PH}_{3}$ commonly present in coal syngas may potentially interact with SOFC electrode components and degrade cell performance. Test with conventional Ni-YSZ anode supported cell indicates irreversible reaction between $\mathrm{Ni}$ and $\mathrm{PH}_{3}$ in coal syngas to form low melting point species, which prohibits both TPB kinetics and fuel diffusion. The predominant phase diagram constructed for Ni-P-O-H system clarified phase formation during cell testing as function of temperature and impurity concentration. In the joint work with research group in Northwestern University, stability of SOFCs with $\mathrm{LaSr}_{2} \mathrm{Fe}_{2} \mathrm{CrO}_{9-\delta}$ ( $\mathrm{LSFeCr}$ )- $\mathrm{Gd}_{0.1} \mathrm{Ce}_{0.9} \mathrm{O}_{2}$ (GDC) composite anodes are evaluated in simulated coal syngas and humidified $\mathrm{H}_{2}$ containing 5-20ppm $\mathrm{PH}_{3}$. 
Combined analysis with AC impedance spectroscopy, XRD, EDX and XPS suggested that $\mathrm{LSFeCr}$ decomposed to form simple oxides, phosphides and phosphates, resulting in conductivity and catalytic activity loss. It is further confirmed by thermodynamic estimation that stable phosphide and phosphate phases could form at ppm level of $\mathrm{PH}_{3}$ not only from simple oxides but also a complex $\mathrm{ABO}_{3}$ structure. The contribution of this study is for the first time to identify the potential challenge from phosphorus on the application of relatively sulfur-tolerant perovskite anode catalysts in fuels with multiple impurities and open a new question for design of stable MIEC alternative anodes.

To complement with the experimental work, a significant part of current research is concerned with the electrochemical reaction mechanism in SOFC cathode, which plays important role for application of SOFC in alternative fuels other than hydrogen at intermediate temperature. A modified one-dimensional model is developed to predict defect evolution of MIEC cathode under overpotential by incorporating multi-step charge-transfer into the bi-pathway continuum model. Analysis by V-I polarization curve, Tafel estimation and local 3PB current constitution identified suppression of surface oxygen ion diffusion as the mechanism for 3PB-to-2PB kinetic transition. The transition voltage between -0.2 -0.4 $\mathrm{V}$ depends on both material surface and bulk parameters, which delays transition at higher $\mathrm{C}_{\mathrm{o}, \mathrm{eq}}$ and facilitates the process for higher $\mathrm{C}_{\mathrm{v}, \mathrm{eq}}$. The model also found that surface reactions are driven complete by electrochemical forces at TPB, while rather controlled by concentration variations of oxygen vacancy and surface oxygen ion at regions away from TPB, implying change of surface catalytic activity as effective route for cathode performance improvement. 


\section{Reference}

1 Fuel Cell Handbook 7th edition, EG\&G Technical Services, Inc. for NETL of U.S. Dept. of Energy, 2004

2 A.Atkinson, et al. Advanced anode for high temperature fuel cells, Nature, 2004,3 (1) 17-41

3 Chris Yates, Jack Winnick. Anode Materials for a Hydrogen Sulfide Solid Oxide Fuel Cell, J. Electrochem. Soc., 1999, 146 (8): 2841-2844.

4 K. Sasaki, et al. H2S Poisoning of Solid Oxide Fuel Cells, J. Electrochem. Soci., 2006, 153 (11): A2023-A2029

5 Yoshio Matsuzaki, Isamu Yasuda. The poisoning effect of sulfur-containing impurity gas on a SOFC anode: Part I. Dependence on temperature, time, and impurity concentration, Solid State Ionics, 2000,132: 261-269

6 Jason P. Trembly, David J. Bayless, Randall S. Gemmen, The Effect of a Current Collection Layer Containing a Sulfur Tolerant Material On the Operation of a PSOFC Utilizing Coal Derived Syngas Containing H2S as Fuel, symposium of International Pittsburgh Coal Conference, 2006

7 Nirupama U. Pujare, Krystyna W. Semkow, Anthony F. Sammells. A Direct H2S/Air Solid Oxide Fuel Cell, J. Electrochem. Soc., 1987,134: 2639-2640

8 I. V. Yentekakis, C. G. Vayenas. Chemical Cogeneration in Solid Electrolyte Cells: The Oxidation of H2S to S02, J. Electrochem. Soc., 1989,136 (4): 996-1002

9 Dan Weaver, Jack Winnick. Sulfidation of the Molten Carbonate Fuel Cell Anode, J. Electrochem. Soc., 1989,136 (6): 1679-1686

10 Jason P. Trembly,et al. Effects of coal syngas and H2S on the performance of solid oxide fuel cells: Single-cell tests, Journal of Power Sources, 2006,158: 263-273

11 Sossina M. Haile. Fuel cell materials and components, Acta Materialia, 2003, 51: 5981-6000

12 Bernard A. Boukamp. The amazing perovskite anode, Nature Material, 2003, 2: 294-295

13 Jeffrey W. Fergus. Oxide anode materials for solid oxide fuel cells, Solid State Ionics, 2006, in press

14 David R. Peterson, Jack Winnick. Utilization of Hydrogen Sulfide in an IntermediateTemperature Ceria-Based Solid Oxide Fuel Cell, J. Electrochem. Soc., 1998, 145(5): 1449_ 1454

15 Uribe A Francisco.; Rockward Tommy Q.T. Cleaning (de-poisoning) PEMFC electrodes from strongly adsorbed species on the catalyst surface. U S patent 328898, 2006.

16 Carrette L. P. L, et al. Improvement of CO tolerance of proton exchange membrane (PEM) fuel cells by a pulsing technique. Phys. Chem. Chem. Phys., 2001, 3: 320-324.

17 Y.M.Choi, et al. A mechanistic study of $\mathrm{H} 2 \mathrm{~S}$ decomposition on Ni- and Cu-based anode surface in a solid oxide fuel cell. Chemical Physics letters, 2006(421):179-183.

18 Shaowu Zha, Zhe Cheng, Meilin Liu. Sulfur Poisoning and Regeneration of Ni-Based Anodes in Solid Oxide Fuel Cells. J. Electrochem. Soc., 2007,154(2): B201-B206.

19 C.H. Bartholomew, P.K. Agrawal, J.R. Katzer. Sulfur Poisoning of Metals. Adv. Catal. 1982,31: 135-242.

20 C.H. Bartholomew. Mechanisms of catalyst deactivation, Applied Catalysis A: General, 2001, $212: 17-60$

21 Scott A. Barnett, Jiang Liu, Yuanbo Lin. Operation of Solid Oxide Fuel Cell Anodes with Practical Hydrocarbon Fuels. Final report submitted to DOE, DE-FC26-02NT41577:37

22 Andres I. Marquez, Yolanda D. Abreu, Gerardine G. Botte. Theoretical investigation of NiYSZ in the presence of H2S. Electrochemical and Solid-State Letters, 2006, 9 (3):A163-A166.

23 Jian Dong, et al. Identification of nickel sulfides on Ni-YSZ cermet exposed to $\mathrm{H}_{2}$ fuel containing H2S using Raman spectroscopy, Journal of Power Sources, 2006,156: 4613-465

$24 \mathrm{SH}$. Zha, et al. Electrical properties and sulfur tolerance of La0.75Sr0.25Cr1_xMnxO3 under 
anodic conditions, Journal of Solid State Chemistry 2005,178: 1844-1850

25 P. He,et al. Stabilization of Platinum Anode Catalyst in a H2S-O2 Solid Oxide Fuel Cell with an Intermediate TiO2 Layer, J. Electrochem. Soc., 2002, 149 (7): A808-A814

26 Shizhong Wang, Meilin Liu, Jack Winnick. Stabilities and electrical conductivities of electrode materials for use in H2S-containing gases, Journal of Solid State Chemistry 2001,5: $188-195$

27 Nirupama U. Pujare, Kan J. Tsai, Anthony F. Sammells. An Electrochemical Claus Process for Sulfur Recovery. J. Electrochem. Soc., 1989,136(12): 3362-3378

28 Man Liu, et al. Use of Metal Sulfides as Anode Catalysts in H2S-Air SOFCs. J. Electrochem. Soc., 2003, 150 (8): A1025-A1029

29 G.L. Wei, J. Luo, A.R. Sanger, K.T. Chuang, High-Performance Anode for H2S-Air SOFCs. J. Electrochem. Soc. 2004,151(2): A232-A237

30 T.H.Etsell, S.N.Flengas. Electrical properties of solid oxide electrolytes. Chem. Rew, 1970, 70(3): 339-376.

31 Maria Flytzani-Stephanopoulos, Mann Sakbodin, Zheng Wang. Regenerative Adsorption and Removal of H2S from Hot Fuel Gas Streams by Rare Earth Oxides. Science, 312: 1508-1510.

$32 \mathrm{H}$. Devianto, et al .The effect of a ceria coating on the H2S tolerance of a molten carbonate fuel cell. J Power Sources, 2006,159 (2): 1147-1152

33 Park S.; Vohs J.M.; Gorte R.J. Direct oxidation of hydrocarbons in a solid-oxide fuel cell,2000,404(6775): 265-267.

34 M. Boder, R. Dittmeyer. Catalytic modification of conventional SOFC anodes with a view to reducing their activity for direct internal reforming of natural gas. J Power Sources, 2006,155 (1): 13-22

35 Gorte R.J, Kim.H, Vohs J.M. Novel SOFC Anodes for the Direct Electrochemical Oxidation of Hydrocarbon. J Power Sources, 2002,106 (1-2): 10-15.

36 Z. F. Zhou, et al. Direct oxidation of jet fuels and Pennsylvania crude oil in a solid oxide fuel cell. J Power Sources, 2004,133 (2): 181-187.

37 H.He, Gorte R.J, Vohs J.M. Highly sulfur tolerant cu-ceria anode. Electrochem. Solid State Lett.2005,8(6):A279-A280.

38 Inaba H, Tagawa H. Ceria-based solid electrolytes - Review. Solid State Ionics, 1996, 83(1-2) : $1-16$.

39 P.V. Aravind, et al. Impact of biosyngas and its components on SOFC anodes. In Proceedings of the 9th International Symposium on Solid Oxide Fuel Cells, 2005: 15-20.

40 Atsuko Tomita, et al. Chemical and redox stabilities of a solid oxide fuel cell with $\mathrm{BaCe} 0.8 \mathrm{Y} 0.2 \mathrm{O} 3-\alpha$ functioning as an electrolyte and as an anode. Solid State Ionics, 2006, 177: 2951-2956.

41 Tatsumi Ishihara, et al. Nickel-Gd-doped $\mathrm{CeO} 2$ cermet anode for intermediate temperature operating solid oxide fuel cells using $\mathrm{LaGaO} 3$-based perovskite electrolyte. Solid State Ionics, 2000, 132(3-4):209-216.

42 S. P. Jiang, et al. Performance of GDC-Impregnated Ni Anodes of SOFCs. Electrochemical and Solid-State Letters, 2004, 7 (9): A282-A285.

43 Yoon S.P, et al. Improvement of anode performance by surface modification for solid oxide fuel cell running on hydrocarbon fuel. J Power Sources, 2004,136 (1): 30-36

44 Xinge Zhang, et al. Ni-SDC cermet anode for medium-temperature solid oxide fuel cell with lanthanum gallate electrolyte. J Power Sources, 1999, 83(1-2):170-177.

45 Jiang Liu, et al. A Fuel-Flexible Ceramic-Based Anode for Solid Oxide Fuel Cells. Electrochemical and Solid-State Letters, 2002, 5 (6):A122-A124.

46 R.Munkundan, E.L.Brosha, F.H.Garzon. Sulfur tolerant anodes for SOFCs. Electrochemical and Solid-State Letters, 2004, 7 (1):A5-A7.

47 Luis Aguilar, et al. A solid oxide fuel cell operating on hydrogen sulfide (H2S) and sulfur- 
containing fuels. J Power Sources, 2004, 135 (1): 17-24

48 O.A.Marina. Development of advanced SOFC anodes. SECA Core Technology Program Peer Review. Boston, MA, 2004.

49 Zhe Cheng, et al. Chemical, electrical, and thermal properties of strontium doped lanthanum vanadate. Solid State Ionics 2005, 176:1921 - 1928.

50 Yun-Hui Huang, Ronald I. Dass, Zheng-Liang Xing, John B. Goodenough. Double Perovskites as Anode Materials for Solid-Oxide Fuel Cells. Science, 2006, 312:254-257.

51 Yun-Hui Huang, Ronald I. Dass, Jonathan C. Denyszyn, John B. Goodenough. Synthesis and Characterization of $\mathrm{Sr} 2 \mathrm{MgMoO} 6-\delta$ An Anode Material for the Solid Oxide Fuel Cell. Journal of the Electrochemical Society, 2006, 153 (7) A1266-A1272.

52 S. Primdahl, et al. Sr-Doped LaCrO3 Anode for Solid Oxide Fuel Cells, Journal of the Electrochemical Society, 2001, 148 (1): A74-A81.

53 S. P. Simner, et al. Sintering of lanthanum chromite using strontium vanadate. Solid State Ionics, 2000,128(1-4):53-63.

54 B. D. Madsen, S. A. Barnett. Effect of fuel composition on the performance of ceramic-based solid oxide fuel cell anodes. Solid State Ionics, 2005, 176: 2545 - 2553.

55 Shanwen Tao, John T. S. Irvine. Synthesis and Characterization of La0.75Sr0.25Cr0.5Mn0.5O 3 , a Redox-Stable, Efficient Perovskite Anode for SOFCs. Journal of the Electrochemical Society, 2004,151 (2): A252-A259.

56 J. Sfeir, et al. Lanthanum Chromite Based Catalysts for Oxidation of Methane Directly on SOFC Anodes. Journal of Catalysis, 2001, 202: 229-244.

57 Olga A. Marina, N. L. Canfield, Jeff W. Stevenson. Thermal, electrical, and electrocatalytical properties of lanthanum-doped strontium titanate. Solid State Ionics 2002, 149(1): 21- 28

58 Q. X. Fu, F. Tietz.z, D. Stöver. La0.4Sr0.6Ti1-xMnxO3- $\delta$ Perovskites as Anode Materials for Solid Oxide Fuel Cells. Journal of the Electrochemical Society, 2006,153 (4): D74-D83.

59 Juan Carlos Ruiz-Morales, et al. Disruption of extended defects in solid oxide fuel cell anodes for methane oxidation. Nature, 439(2): 568-571.

60 O. A. Marina, L. R. Pederson. in Proceedings of the 5th European Solid Oxide Fuel Cell Forum, J. Huijsmans, Editor, European SOFC Forum, Lucerne, Switzerland 2002: 481.

61 Shiqiang Hui, Anthony Petric. Conductivity and stability of SrVO3 and mixed perovskites at low oxygen partial pressures. Solid State Ionics, 2001,143(2): 275-283

62 Zhe Cheng, et al. A Solid Oxide Fuel Cell Running on $\mathrm{H}_{2} \mathrm{~S} / \mathrm{CH}_{4}$ Fuel Mixtures. Electrochemical and Solid-State Letters, 9(1):A31-A33.

63 Zhe Cheng, Shaowu Zha, Meilin Liu. Stability of Materials as Candidates for Sulfur-Resistant Anodes of Solid Oxide Fuel Cells. Journal of The Electrochemical Society, 153 2006(7): A1302-A1309.

64 J. Androulakis,et al. LaSrMnCoO6: a new cubic double perovskite oxide. Journal of Solid State Chemistry. 2003, 173: 350-354.

65 Shaowu Zha, Zhe Cheng, Meilin Liu. A Sulfur-Tolerant Anode Material for SOFCs. Gd2Ti1.4Mo0.6O7. Electrochemical and Solid-State Letters, 2005, 8 (8):A406-A408.

66 O. Porat, C. Heremans, H.L. Tuller. Stability and mixed ionic electronic conduction in Gd2(Ti 1-xMox)2O7 under anodic conditions. Solid State Ionics, 1997, 94 (1): 75-83.

67 J.P. Trembly, R.S. Gemmen, D.J. Bayless, Journal of Power Sources 163(2007):986-996

68 L. R. Pederson, O. A. Marina, X.D. Zhou, Y.S. Chou, G. W.Coffey. SECA Coal-Based Systems Core Research. Advanced Research. DOE FY 2007 Annual Report

69 Mingjia Zhi, Xinqi Chen, Harry Finklea, Ismail Celik, Nianqiang Q.Wu, Journal of Power Sources 183 (2008) 485-490.

70 O. A. Marina, L. R. Pederson, C.A Coyle, E.C. Thomsen, D.J. Edwards, G.W. Coffey, C.N. Cramer, B.W. Arey, Y.S. Chou. Proceedings of $10^{\text {th }}$ SECA Annual Workshop, Pittsburgh, PA, June, 2009 
71 P. V. Aravind, J. P. Ouweltjes,N. Woudstra, G. Rietveld. Electrochemical and Solid-State Letters, 11(2)(2008):B24-B28

72 E. Brightman, D. Ivey. D. Brett, N. Brandon, J. Power Sources (2010), doi:10.1016/j.jpows our.2010.09.089

73 V. Gil , et al. Solid State Ionics 180 (2009): 784-787

74 Taro Shimonosono, et al. Solid State Ionics 174 (2004): 27-33.

75 Z.Cheng, S. Zha, M. Liu, Journal of Power Sources 172 (2007): 688-693

76 C. Xu, J. Zondlo, M. Gong, F.Blancas, X. Liu, I. Celik. Journal of Power Sources 195(310): 4583-4592

77 Y Lin and S.A.Barnett. Electrochemical and Solid-State Letters 9 (6)(2006):A406-A408

78 P. Lohsoontorn, D. Brett, N. Brandon, Journal of Power Sources 183 (2008): 232-239

79 Z. Cheng, M. Liu, Solid State Ionics, 178(2007): 925-935

80 L. Tang, C.Wu, Y. Huang, Z. Liu, M. Guire, the Proceedings of 209 MS\&T conference, Pittsburgh, PA,USA,2009

81 R.M. Ferrizz, R.J. Gorte, J.M. Vohs, Catalysis Letters, 82(1-2)(2009): 123-129

82 R.J. Fruchan, Metal Trans. B, 10B(1979): 143-148

83 Fatma Nihan Cayan, Mingjia Zhi, Suryanarayana Raju Pakalapati, Ismail Celik, Nianqiang Wu and Randall Gemmen, Journal of Power Sources 185 (2008) 595-602.

84 J.P. Trembly, PhD. Dissertation, Ohio University, 2007

85 Feng Zhao, Anil V. Virkar Journal of Power Sources 141 (2005) 79-95

86 Olga A. Marina, Larry R Petterson, Danny J Edwards, et al. Proceedings of the 8th SECA Workshop. San Antonio, TX, Aug, 2007.

87 Masatomo Yashima, Satoshi Sasaki and Masato Kakihana, Acta Cryst. Sec. B 50(1994):663

88 G.S.Saini, L.D. Calvert and J.B. Taylor, Canadian Journal of Chemistry 42(7)(1964)

89 M. Yousuf, P. CH.Sahu, H. K.Jajoo, S. Rajagopalan and K. Govinda Rajan, Journal of Physics, F 16F, 373-378, (1986)

90 Taylor. D, Trans. J. Br. Ceramic Society 83( 5)(1984)

91 J. D Hanawalt, H. W Rinn, L. K Frevel, Industrial \& engineering chemistry. Analytical edition, 10(457) (1938)

92 Wagner C.D., Riggs W.M., Davis L.E., Moulder J.F., Muilenberg G.E. Handbook of X-Ray Photoelectron Spectroscopy, Perkin-Elmer Corporation, Physical Electronics Division, Eden Prairie, Minn. 55344 (1979)

93 Kim K.S., Winograd N. Surface Science. 43(2) (1974):625-643

94 Konstantinov and Lee et al. Landolt-Bornstein, New Series IV/5,Ni-P, pp.1

95 Subhash C Singhal and Kevin Kendall ISSN 14710846 "High Temperature Solid Oxide Fuel Cells Fundamentals, Design and Applications" Elsevier Ltd. pp. 280

96 R.E. Dietz, G.I. Parisot, A.E. Meixner, Phys. Rev. B4, (7)(1971)

97 M.C. Williams, J. Strakey, W. Surdoval, J. Power Sources 159 (2006): 1241-1247.

98 R.S. Gemmen, J.P. Trembly. J. Power Sources 161(2) (2006): 1084-1095.

99 C. Xu , et al. J. Power Sources 193(2)(2009):739-746

100 S. W. Tao and J. T. S. Irvine, Chem. Mater., 16(21)(2004):4116-4121_.

101 S.W.Tao, and J T S Irvine, Nature Materials. 2(2003):320-323.

102 J. M. Haag, et al. Electrochemical and Solid-State Letters, 11(4) (2008):B51-B53

103 J.F. Moulder, et al, Handbook of X-ray Photoelectron Spectroscopy, Physical Electronics, Eden Prairie, MN, 1995.

104 National Institute of Standard and Technology (NIST) X-ray Photoelectron Spectroscopy Database, http://srdata.nist.gov/xps/

105 Guzelian AA , et al. J. Phys. Chem. 100(1996):7212-7219

106 H. Falcon, et al. Chem. Mater. 14(2002): 2325-2333 
107 K. Tabata, S. Kohiki, J. Mater. Sci. Lett. 6 (1987) 1030

108 R.Tan and Y. Zhu. Applied Catalysis B: Environmental, 58 (2005): 61-68

109 C. Thiriet, et al. J. Chem. Thermodynamics 37 (2005): 131-139

110 K. Popa, et al. J. Chem. Thermodynamics 38 (2006): 825-829

111 E.Povoden, et al. Journal of Phase Equilibria and Diffusion, 30(2009):12-27

112 E.Povoden, et al. Journal of Phase Equilibria and Diffusion, 30(2009):351-366

113 B.D. Madsen, et al. J Power Sources 166(1)(2007): 64-67.

114 N.Q.Minh, T.Takahashi. Science and Technology of Ceramic Fuel Cells. Elsevier, Amsterdam, 1995

115 M.C.Williams, J..P.Strakey and W.A.Surdoval. Int. J. Appl. Ceram. Technol., 2 (4) (2005): 295-300

116 S.P.S. Badwal, Solid State Ionics.,143 (2001): 39-46.

117 K.C. Wincewicz, J.S. Cooper. Journal of Power Sources, 140 (2005): 280-296.

118 S.B.Adler. Chem. Rev., 104(2004): 4791-4843

119 E. Ivers-Tiffée, A. Weber, D. Herbstritt. Journal of the European Ceramic Society, 21(1011)(2001): 1805-1811

120 Y. Jiang, A.V.Virkar, F. Zhang. Journal of The Electrochemical Society, 148 (10)(2001): A1091-A1099.

121 J.Fleg. Annu. Rev. Mater. Res., 33(2003):361-382.

122 S. B. Adler. Journal of the Electrochemical Society, 149(2002): E166-E172.

123 F.H. van Heuveln, H.J.M. Bouwmeester, J. Electrochem.Soc. 144(1997):134-140

124 X.J. Chen, K.A. Khor, S.H. Chan, J. Power Sources, 123 (2003): 17-25.

125 J-D. Kim, G-D. Kim, J-W. Moon, Y-I. Park, W-H. Lee, K. Kobayashi, M. Nagai, C-E. Kim. Solid State Ionics 143(2001):379-389

126 S. Wang, X. Lu, M. Liu, J. Solid State Electrochem., 6(2002):384-390

127 Y. Takeda, R. Kanno, M. Noda, Y. Tomida, O. Yamamoto, J. Electrochem. Soc., 134(11)(1987):2656-2661

128 Y. Jiang, S. Wang, Y. Zhang, J. Yan, W. Li. J. Electrochem. Soc. 145(1998):373-378

129 E. Siebert, A. Hammouche, M. Kleitz, Elecrrochimica Acta. 40(11)(1995):1741-1753

130 S.P.Jiang, J.G. Love, Solid State Ionics 138 (2001): 183

131 X.J. Chen, K.A. Khor, S.H. Chan, Solid State Ionics 167 (2004): 379-387

132 M. Kuznecov, P. Otschik, P. Obenaus, K. Eichler, W. Schaffrath, Solid State Ionics, 157(2003):371-378

133 S.B. Adler, J. A. Lane, B.C.H. Steele, J. Electrochem. Soc., 143(11)(1996):3554-3564

134 M. Liu, J. Winnick, Solid State Ionics, 118 (1999): 11-21

135 V. Brichzin, J. Fleig , H.-U. Habermeier, G. Cristiani, J. Maier, Solid State Ionics,152153(2002):499- 507

136 T. Horita, K. Yamaji, N. Sakai, Y. Xiong, T. Kato, H. Yokokawa, T. Kawada, J. Power Sources, 106(2002): 224-230

137 G. J. la O', B. Yildiz, S. McEuen, Y. Shao-Horn, J. Electrochem. Soc., 154 (4)(2007): B427B438

138 J. Fleig, J. Power Sources, 105(2002):228-238

139 M. Søgaard, P.V. Hendriksen, T. Jacobsen, M. Mogensen, Proceedings of the 7th European SOFC Forum, European Fuel Cells Group, Lucerne, Switzerland, July 2006

140 D.S. Mebane, M. Liu, J. Solid State Electrochem., 10 (2006): 575-580

141 C.W. Tanner, K-Z. Fung, A.V. Virkar, J. Electrochem. Soc. 144(1997):21-30

142 A.V. Virkar, J. Chen, C.W. Tanner, J.W. Kim, Solid State Ionics, 131(2000):189

143 M. Liu, J. Winnick, J. Electrochem. Soc., 144(1997):1881-1884

144 M. Liu, J. Electrochem. Soc., 145(1) (1998): 142-154 
145 A. M. Svensson, S. Sunde, K. Nisancioglu, J. Electrochem. Soc., 144(1997):2719-2732

146 A. M. Svensson, S. Sunde, K. Nisancioglu, J. Electrochem. Soc., 145(1998):1390-1400

147 G.W. Coffey, L.R. Pederson, P.C. Rieke, J. Electrochem. Soc., 150(8)(2003):A1139-A1151

148 Y.M. Choi, D.S. Mebane, J.-H. Wang, M. Liu, Top Catal (2007) 46:386-401

149 J. Fleig, Phys. Chem. Chem. Phys., 7(2005):2027-2037

150 D.S. Mebane, Y. Liu, M. Liu, J. Electrochem. Soc., 154(2007):A421-A426

151 J. O'M. Bockris, A.K.N. Reddy, Modern Electrochemistry, Vol. 2, Plenum Press, New York , 1977

152 H.R.Thirsk, J.A. Harrison, A Guide to the Study of Electrode Kinetics, Academic Press, London and New York, 1972

153 S.V. Patankar, in: W.J. Winkowycz, E.M. Sparrow (Eds.), Numerical Heat Transfer and Fluid Flow, Series in Computational Methods in Mechanics and Thermal Sciences, McGraw-Hill Book Company, New York, 1980

154 R.A. De Souza, J.A. Kilner, J.F. Walker, Materials Letters, 43(2000):43-52

155 L. Mikkelsen, E. Skou, J. Therm. Anal. Cal., (64)2001:873-878

156 I. Yasuda, M. Hishinuma, J. Solid Sate Chem., 123(1996):382-390

157 I. Yasuda, K. Ogasawaraa, M. Hishinuma, T. Kawada, M. Dokiya, Solid State Ionics, 143(2001):39-46

158 T. Horita, K. Yamaji, N. Sakai, H. Yokokawa,T. Kato, J. Electrochem. Soc., 148(5)(2001):J25-J30

159 A.C. Co, X.J. Xia, V.I. Birss, J. Electrochem. Soc., 152(3)(2005):A570-A576

160 X.J. Chen, K.A. Khor, S.H. Chan, Electrochimica Acta 49 (2004):1851-1861

161 B.C.H. Steele, K.M. Hori, S. Uchino, Solid State Ionics 135 (1-4)(2000): 445-450

162 M. Kuznecov, P. Otschik, N. Trofimenko, K. Eichler, Russian Journal of Electrochemistry, 40(11)(2004):1355-1363

163 J. Mizusaki, I. Yasuda, J-i. Shimoyama, S. Yamauchi, K. Fueki, J. Electrochem. Soc., 140(2)(1993):467-471

164 J. Deseure, Y. Bultel, L. Dessemond, E. Siebert, P. Ozil, J. Appl. Electrochem., 37(2007):129-136

165 T. Horita, K. Yamaji, N. Sakai, H. Yokokawa, A. Weber, E. Ivers-Tiffee, J.Electrochem. Soc., 148(2001):A456

166 A. Esquirol, N. P. Brandon, J. A. Kilner, M. Mogensen, J.Electrochem. Soc., 151(11) (2004):A1847-A1855 


\section{Curriculum Vitae}

Mingyang Gong, Address: 22 Copper Creek Ct, Morgantown, WV, 26505 Tel: (304)

906-9591 Email: mingyang.gong@ gmail.com

\section{QUALIFICATIONS}

- Fabrication of Solid Oxide Fuel Cells (SOFC) as high temperature electrochemical device for energy conversion (ceramics processing by tape cast, co-sintering, screen-printing and spin-coating)

- High-temperature investigation of SOFC electrochemical properties ( electrode activation, degradation mechanism in impurity-containing coal derived syngas, DC polarization and $\mathrm{AC}$ impedance analysis)

- Optimization of SOFC tolerance against fuel impurity by impregnation of nanosized ceramic oxides with mixed ionic and electronic conductivity (MIEC)

- Morphological and structural characterization of electrical ceramic materials by SEM, XRD and XPS

- Fundamental modeling of SOFC electrode reaction kinetics ( multi-step chargetransfer theoretical analysis, finite element numerical analysis)

- Synthesis, processing and electrochemical evaluation of nano-sized noble metal oxides as dimensionally stable anode (DSA) for alkaline electrolysis and wastewater treatment

\section{EDUCATION}

Ph.D., Mechanical Engineering, West Virginia University, Morgantown, WV, USA 2006-2010

Dissertation: "Sulfur tolerant solid oxide fuel cell for coal syngas application: experimental study on diverse impurity effects and fundamental modeling of electrode kinetics"

Advisor: Professor Xingbo Liu

M.S., Materials Science, University of Science Technology Beijing, Beijing, China 2004-2006

Thesis: "Attrition mechanism study of fluidic catalytic cracking catalyst"

Advisor: Professor Xiaogang Li

B.S., Materials Science \& Engineering, University of Science Technology Beijing, Beijing, China

Graduate Project: "Preparation and characterization of nano-crystalline noble metal oxide anode for industrial wastewater treatment"

Advisor: Professor Huimin Meng 


\section{RESEARCH EXPERIENCE}

Research Assistant, West Virginia University, Morgantown, WV, 2006-2010

- Developed and prepared doped ceria as conductive sulfur-tolerant coating for Ni-YSZ SOFC anode via wet impregnation, and improved sulfur tolerance in coal syngas by delaying the on-set of poisoning

- Deigned and built lab-scale SOFC electrochemical testing system

- Set-up SOFC manufacturing labs from scratch

- Collaborate with Northwestern University on investigating degradation of $\mathrm{La}-\mathrm{Sr}-\mathrm{Fe}-\mathrm{Cr}-\mathrm{O}$ perovskite $\mathrm{SOFC}$ anode in $\mathrm{PH}_{3^{-}}$ containing syngas by electrochemical testing, XRD, SEM and XPS, and for the first time thermodynamically determined stability of perovskite structure in phosphine atmosphere

- Studied effects of $\mathrm{PH}_{3}$ and $\mathrm{HCl}$ on the performance of Ni-YSZ anode supported SOFC, and provided understanding of degradation mechanism by supplying Ni-P-O-H and Ni-Cl-O-H predominant phase diagram

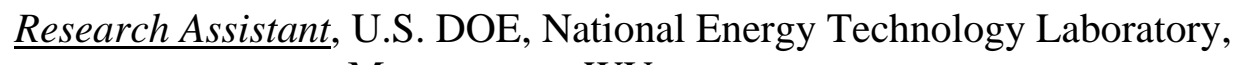
Morgantown, WV,

2007-2010

- Prepared electrolyte-supported and anode-supported SOFC cells by tape casting, screen printing and co-sintering processes

- Collaborated with NETL Fuel Cell Research Group to develop a 1-D physical model on bi-pathway dominated oxygen reduction kinetics on SOFC cathode based on multi-step charge-transfer theory and finite element analysis to identify rate-determining steps

- Electrochemical test of anode-supported cell performance degradation in $\mathrm{H}_{2} \mathrm{~S}$-containing coal syngas via DC polarization, $\mathrm{V}$-I curve and AC impedance measurement

Research Assistant, University of Science \& Technology Beijing, Beijing, China,

2004-2006

- Designed and built a lab-scale attrition testing system to measure attrition resistances of FCC (Fluidic Catalytic Cracking) catalyst particles and developed a theoretical model which quantified effects of particle properties and hydrodynamic characteristics in attrition process for performance prediction under practical conditions

- Studied failure mechanism of 304L stainless steel used in the Benzaldehyde production plant through metallographic analysis, SEM, $\mathrm{XRD}$ and electrochemical corrosion tests.

- Investigated effects of Sn addition and processing parameters on oxygen evolution efficiency of $\mathrm{IrO}_{2}-\mathrm{Ta}_{2} \mathrm{O}_{5}$ oxide anode used for industrial wastewater treatment by XRD, SEM and Electrochemical Polarization techniques 


\section{REVIEW EXPERIENCE}

- Journal of Power Sources

- International Journal of Hydrogen Energy

- International Journal of Applied Ceramic Technology

- CIMAT(Cl) Research Pre-proposals

\section{AFFILIATIONS AND AWARDS}

Member of the American Ceramic Society

Member of Association for Iron and Steel Technology

Member of American Society for Metals

Member of the Minerals Metals and Materials Society

Member of the Electrochemical Society

2009

Outstanding Graduate Student, University of Science \& Technology Beijing,

People's Scholarship ( $2^{\text {nd }}$ Class), University of Science \& Technology

Beijing,

2005

Outstanding Undergraduate Student, University of Science \& Technology

Beijing,

\section{FUNDINGS}

- "Experimental Program for Stimulating Competitive Research", grant \# DE-FG02-06ER46299, U. S. Department of Energy (Collaboration with NETL and Northwestern University)

- “MSE-SOFC”, RDS contract \# DE-AC26-04NT41817,National Energy Technology Laboratory, U.S. Department of Energy

- "PetroChina Advanced Universal Research Project", grant \#W050508-0301, PetroChina Co. Ltd

\section{PUBLICATIONS}

\section{Journal Papers}

1. Gong, M.; Bierschenk, D.; Haag, J.; Poeppelmeier, K. R.; Barnett, S. A.; $\mathrm{Xu}, \mathrm{C}$; Zondlod J. W.; Liu, X. "Degradation of $\mathrm{LaSr}_{2} \mathrm{Fe}_{2} \mathrm{CrO}_{9-\delta}$ solid oxide fuel cell anodes in phosphine-containing fuels" Journal of Power Sources, 2010, 195:4013-4021

2. Xu, C.; Gong, M.; Zondlo, J. W.; Finklea, H. O.; Liu, X. "The effect of $\mathrm{HCl}$ in syngas on Ni-YSZ anode-supported solid oxide fuel cells" Journal of Power Sources, 2010, 195: 2149-5158

3. Xu, C.; Zondlo, J. W.; Gong, M.; Elizalde-Blancas, F.; Liu, X.; Celik, I. B. "Tolerance Tests of $\mathrm{H}_{2} \mathrm{~S}$-laden Biogas Fuel on Solid Oxide Fuel Cells" Journal of Power Sources 2010, 195: 4583-4592 
4. Ding, D.; Liu, B.; Gong, M.; Liu, X.; Xia, C. "Electrical properties of samaria-doped ceria electrolytes" Electrochimica Acta, 2010, 55: 45294535

5. Wu, J.; Li, X; Gong M.; Zhang, Z.; Guo, J. "Kinetics and Mechanism of Attrition of Several FCC Catalysts" Journal of Chinese Society for Corrosion and protection, 2010, 30(2): 135-140

6. Xu, C.; Zondlo, J. W.; Finklea, H. O.; Demircan, O.; Gong, M.; Liu, X. "The Effect of Phosphine in Syngas on Ni-YSZ Anode-Supported Solid Oxide Fuel Cells" Journal of Power Sources, 2009, 193(2): 739-746

7. Gong, M.; Trembly, J. P.; Johnson, C.; Liu, X. "Sulfur Tolerant Anode for SOFC Application" Journal of Power Sources, 2007, 168(2): 289-298

8. Gong, M.; Li, X.; Du, W.; Wu, J.; Dong C. "Research Progress on Fluid Catalyst Attrition" Mocaxuebo/Tribology (Chinese), 2007, 27(1): 91-96

9. Gong, M. "Study on Nano-crystal $\mathrm{IrO}_{2}-\mathrm{Ta}_{2} \mathrm{O}_{5}$ Oxide Coat Anode on Titanium Substrate" China Paint (Chinese), 2005, 20(11): 21-25

\section{Conference Presentations}

1. Gong, M.; Gemmen, R. S.; Liu, X.; "Modeling of Oxygen Reduction Mechanism for 3PB and 2PB pathways at Solid Oxide Fuel Cell Cathode from Multi-step Charge transfer", 34th International Conference \& Exposition on Advanced Ceramics and Composites, Daytona Beach , FL, 2010

2. Gong, M.; Bierschenk, D.; Barnett, S. A.; Xu, C.; Zondlo, J. W.; Liu, X. "Degradation of Perovskite-Based SOFC Anode by Phosphine as Fuel Impurity" MS\&T Conference, Pittsburgh, PA, 2009

3. Xu, C.; Gong, M.; Liu, X.; Zondlo, J. W. " Solid oxide fuel cell impurity tolerance tests by using synthetic biogas" 238th ACS National Meeting, Washington, DC, August, 2009

4. Gong, M.; Liu, X.; Gemmen, R. S. "Improving Sulfur Tolerance of NiYSZ Anode in SOFC by Impregnation of Doped Ceria" 213th ECS meeting, Phoenix, AZ, 2008

5. Gong, M.; Liu, X.; Jiang, Y.; Xu, C.; Zondlo, J. W. ; Johnson, C.; Gemmen, R. S. "Anode Supported SOFC Fabricated by Tape-casting and co-sintering of anode and electrolyte" MS\&T Conference, Pittsburgh, PA, 2008 